John Harry Forero Gaona

\title{
Modelos constitutivos elastoplásticos aplicados à rocha carbonática travertino
}

Tese apresentada como requisito parcial para obtenção do grau de Doutor pelo Programa de Pós-Graduação em Engenharia Civil da PUC-Rio.

Orientador: Prof. Eurípedes do Amaral Vargas Junior Coorientadora: Profa ${ }^{\text {a }}$ Flávia de Oliveira Lima Falcão 
John Harry Forero Gaona

\title{
Modelos constitutivos elastoplásticos aplicados à rocha carbonática travertino
}

\begin{abstract}
Tese apresentada como requisito parcial para obtenção do grau de Doutor pelo Programa de Pós-Graduação em Engenharia Civil da PUC-Rio. Aprovada pela Comissão Examinadora abaixo.
\end{abstract}

Prof. Eurípedes do Amaral Vargas Junior

Orientador

Departamento de Engenharia Civil e Ambiental - PUC-Rio

Profa. . Raquel Quadros Velloso

Departamento de Engenharia Civil e Ambiental - PUC-Rio

Prof. Antonio Claudio Soares Cenpes/PETROBRAS

Prof. Manoel Porfírio Cordão Neto Universidade de Brasília-UnB

Prof. Erick Slis Raggio Santos Cenpes/PETROBRAS

Prof. Guilherme José Cunha Gomes Universidade Federal de Ouro Preto-UFO

Rio de Janeiro, 23 de Agosto de 2019 
Todos os direitos reservados. É proibida a reprodução total ou parcial do trabalho sem autorização da universidade, do autor e do orientador.

\section{John Harry Forero Gaona}

Graduou-se em Engenharia Civil na Universidade Industrial de Santander-UIS de Colômbia em 2011, Mestrado em Geotecnia na Universidade Industrial de Santander-UIS em 2014. Participou de diversos congressos Geocarioca 2015, Cobramseg 2016 e 2018. Possui experiência nas áreas experimental e numérica da mecânica das rochas de reservatório.

Ficha Catalográfica

Forero Gaona, John Harry

Modelos constitutivos elastoplásticos aplicados à rocha carbonática travertino/ John Harry Forero Gaona; orientador: Eurípides do Amaral Vargas Junior; coorientadora: Flávia de Oliveira Lima Falcão - 2019.

201 f. : il. color. ; $30 \mathrm{~cm}$

Tese (doutorado)-Pontifícia Universidade Católica do Rio de Janeiro, Departamento de Engenharia Civil e Ambiental, 2019.

Inclui bibliografia

1. Engenharia Civil e Ambiental - Teses. 2. Modelos constitutivos. 3. Rocha carbonática travertino. 4. Análise inversa. 5. Anisotropia. I. Vargas Júnior, Eurípedes do Amaral. II. Falcão, Flávia de Oliveira Lima. III. Pontifícia Universidade Católica do Rio de Janeiro. Departamento de Engenharia Civil e Ambiental. IV. Grau. 
A meus pais e minha irmã pelo apoio e confiança 


\section{Agradecimentos}

A Deus por ser minha fortaleza e acompanhar-me em cada instante da minha vida.

Aos meus pais e minha irmã, por seu imenso apoio em todas as etapas da minha vida, e por que sempre me fizeram acreditar que tudo é possível.

À minha namorada Monica Velandia pelo apoio, amor e compreensão ao longo da tese que hoje culmina com grande satisfação.

Ao meu orientador professor Eurípedes do Amaral Vargas Junior pelo conhecimento transmitido, contribuição e especialmente por ter me incentivado nesta importante linha de pesquisa.

A minha co-orientadora Dra. Flávia de Oliveira Lima Falcão a quem expresso imensa gratidão pelas sugestões, conhecimento, acompanhamento e disposição para realizar este trabalho junto com as publicações feitas.

A professora Raquel pela disposição, contribuição e os conceitos transmitidos para o desenvolvimento da tese e dos artigos técnicos.

A Jose Silvestre e Luis Fernando, pelos conceitos transmitidos, indispensáveis para conseguir alguns resultados importantes. 
A Guilherme José Cunha Gomes pelo conhecimento fornecido no análise inversa e manejo do algoritmo DREAM.

Aos técnicos do laboratório da engenharia civil da PUC-Rio e ao Mauro, pela parceria em todos os procedimentos de laboratório.

Ao Eduardo pelo conserto e instalação de todos os programas fundamentais para desenvolvimento da parte numérica da tese.

Aos meus parceiros da Colômbia, Peru, Bolívia e Brasil que tive a grande oportunidade de conhecer no Rio de Janeiro e compartilhar momentos inesquecíveis.

Ao CNPq e à PUC-Rio, pelos auxílios concedidos, sem os quais este trabalho não poderia ter sido realizado.

Ao Brasil, o pais que me acolheu e me deu a oportunidade de formar-me como doutor na PUC-Rio. 


\section{Resumo}

Forero Gaona, John Harry; Vargas Junior, Eurípides do Amaral; Lima Falcão, Flávia de Oliveira. Modelos constitutivos elastoplásticos aplicados à rocha carbonática travertino. Rio de Janeiro, 2019. 201p. Tese de Doutorado - Departamento de Engenharia Civil e Ambiental, Pontifícia Universidade Católica do Rio de Janeiro.

Para uma melhor previsibilidade e gerenciamento de reservatórios de hidrocarbonetos é necessário estabelecer modelos constitutivos adequados para representar o comportamento mecânico e hidráulico desses materiais. Durante a produção de hidrocarbonetos, ocorre um aumento das tensões efetivas devido à redução de pressão de poros. Isto pode levar à redução do espaço poroso do reservatório, podendo chegar ao colapso de poros. A compactação dos reservatórios é consequência da alteração do estado de tensões, que produzem deformações elásticas e plásticas, levando eventualmente à ruptura da rocha. Sabe-se que a resistência dos carbonatos está relacionada à porosidade, mineralogia e arranjo dos grãos. Sendo que este tipo de rocha, geralmente, tem um comportamento elastoplástico com características anisotrópicas. O uso de modelos constitutivos avançados é necessário para reproduzir o complexo comportamento de tensão-deformação-permeabilidade das rochas carbonáticas. Os modelos elastoplásticos isotrópicos Lade-Kim e Cam Clay Modificado com Coesão (CCMC), são usados neste trabalho para tentar representar o comportamento geomecânico do travertino; rocha análoga a uma das fácies do Pré-Sal brasileiro. Parâmetros destes modelos para este tipo de rochas dificilmente são encontrados na literatura, sendo sua determinação dependente de ensaios de laboratório cuidadosamente realizados. O presente trabalho tem como objetivo contribuir com o estabelecimento de modelos adequados para representar o comportamento geomecânico da rocha carbonática travertino em função da porosidade. Como parte do presente trabalho foi desenvolvido um modelo anisótropico denominado CALK, baseado no modelo isotrópico de Lade-Kim. Além disso ensaios triaxiais a compressão, hidrostáticos e compressão uniaxial foram realizados em amostras da rocha carbonática travertino com diferentes orientações das camadas em relação ao eixo axial das amostras (paralelo, $\beta=90^{\circ}$; ortogonal, $\beta=0^{\circ}$; e inclinado, $\beta=45^{\circ}$ ). Os resultados dos ensaios foram usados para estabelecer parâmetros dos modelos constitutivos Lade-Kim e CCMC. O processo de retroanálise foi utilizado, incorporando o algoritmo Lade-Kim, desenvolvido em MATLAB $2017 \AA$ e FORTRAN $90 \AA$ nos algoritmos DREAM e MINPACK, respectivamente. Os resultados obtidos indicam que a metodologia proposta e o modelo CALK é capaz de representar adequadamente, o comportamento mecânico do travertino observado em laboratório.

\section{Palavras-chave}

Modelos constitutivos; rocha carbonática travertino; análise inversa; anisotropia. 


\section{Abstract}

Forero Gaona, John Harry; Vargas Junior, Eurípides do Amaral (Advisor); Lima Falcão, Flávia de Oliveira (Coadvisor). Elastoplastic constitutive models applied to travertine carbonate rock. Rio de Janeiro, 2019. 201p. Tese de Doutorado - Departamento de Engenharia Civil e Ambiental, Pontifícia Universidade Católica do Rio de Janeiro.

For better predictability and management of hydrocarbon reservoirs it is necessary to establish adequate constitutive models to represent the mechanical and hydraulic behavior of these materials. During the production of hydrocarbons, an increase in effective stresses occur due to the reduction of pore pressure. This can lead to a reduction in the pore space of the reservoir and may lead to pore collapse. The compaction of the reservoirs is a consequence of the alteration of the state of stress, which produce elastic and plastic deformations, eventually leading to failure of the rock. It is known that the resistance of the carbonates is related to the porosity, mineralogy and arrangement of the grains. Since this type of rock usually has an elastoplastic behavior with anisotropic characteristics. The use of advanced constitutive models is necessary to reproduce the complex stress-strainpermeability behavior of sedimentary rocks. The Lade-Kim and Modified Cam Clay with Cohesion (CCMC) isotropic models are used in this work to try to represent the geomechanical behavior of travertine; a rock analogous to one of the Brazilian Pre-Salt facies. Parameters of these models for these type of rocks are seldom found in the literature, and their determination depends on carefully performed laboratory tests. The present work aims to contribute with the establishment of adequate models to represent the geomechanical behavior of travertine carbonate as a function of porosity. As a part of the present work an anisotropic model called CALK was developed, based on the isotropic model of Lade-Kim. In addition, triaxial compression, hydrostatic and uniaxial compression tests were performed on travertine carbonate samples with different orientations of the layers in relation to the axial axis of the samples ( parallel, $\beta=90^{\circ}$, orthogonal, $\beta=0^{\circ}$ and inclined, $\beta=45^{\circ}$ ) The results of the tests were used to establish parameters of the constitutive models Lade-Kim and CCMC. The retro-analysis process was used, incorporating the Lade-Kim algorithm, developed in MATLAB 2017 ® and FORTRAN 90 $\AA$, to the DREAM and MINPACK algorithms, respectively. The results indicate that the proposed methodology and the CALK model are able to adequately represent the mechanical behavior of the travertine observed in the laboratory.

\section{Keywords}

Constitutive models; travertine carbonate rock; inverse analysis; anisotropy. 


\section{Sumário}

1 INTRODUÇÃO

1.1. Justificativa 32

1.2. Objetivos 32

1.3. Organização 34

2 REVISÃO BIBLIOGRÁFICA

2.1. Rocha carbonática Travertino 35

$\begin{array}{ll}\text { 2.1.1. Modelos isotrópicos em rochas sedimentares } & 37\end{array}$

2.1.2. Modelos anisotrópicos em rochas sedimentares 40

2.2. Fundamentos da plasticidade 46

2.2.1. Função de escoamento 46

$\begin{array}{ll}\text { 2.2.2. Lei de endurecimento e amolecimento } & 47\end{array}$

2.2.3. Função potencial plástico e regra de fluxo 49

2.2.4. Formulação modelo elastoplástico isotrópico 50

2.3. Modelo elastoplástico isotrópico Lade-Kim 52

2.3.1. Lei elástica

2.3.2. Critério de ruptura 53

2.3.3. Função potencial plástica 56

$\begin{array}{ll}\text { 2.3.4. Função de escoamento } & 58\end{array}$

2.4. Modelo Cam Clay Modificado com Coesão (CCMC) 62

2.4.1. Parâmetros elásticos 62

2.4.2. Superfície de escoamento CCM 63 
2.4.4. Superfície de escoamento CCMC 65

$\begin{array}{ll}\text { 2.4.5. Regra de fluxo } & 66\end{array}$

2.4.6. Determinação de Parâmetros do modelo CCM e CCMC 67

2.5. Análise inversa 69

2.5.1. Análise inversa usando o DREAM 69

2.5.2. Análise inversa usando o MINPACK 74

3 METODOLOGIA $\quad 81$

3.1. Procedimentos laboratoriais 82

3.1.1. Material usado na pesquisa $\quad 82$

3.1.2. Determinação da porosidade da rocha carbonática travertino 83

$\begin{array}{ll}\text { 3.1.3. Classificação dos corpos de prova } & 87\end{array}$

3.1.4. Ensaios triaxiais à compressão do travertino 88

3.1.5. Ensaios hidrostáticos com amostras de rocha travertino 90

3.2. Implementação dos modelos constitutivos 91

3.2.1. Algoritmo Lade-Kim isotrópico 92

$\begin{array}{ll}\text { 3.2.2. Algoritmo do modelo CALK } & 94\end{array}$

3.2.3. Algoritmo Cam Clay Modificado com Coesão (CCMC) 97

3.3. Análise inversa 99

3.3.1. Implementação do modelo de Lade-Kim no MINPACK 99

3.3.2. Implementação do modelo de Lade-Kim isotrópico no DREAM 101

4 RESULTADOS E DISCUSSÃO 104

$\begin{array}{ll}\text { 4.1. Resultados dos ensaios triaxiais de compressão } & 104\end{array}$ 
4.1.1. CPV com porosidade $<8.5 \%\left(\beta=0^{\circ}\right) \quad 105$

$\begin{array}{ll}\text { 4.1.2. CPV com porosidade }>8.5 \%\left(\beta=0^{\circ}\right) & 107\end{array}$

4.1.3. $\mathrm{CPH}$ com porosidade $<8.5 \%\left(\beta=90^{\circ}\right) \quad 110$

4.1.4. $\mathrm{CPH}$ com porosidade $>8.5 \%\left(\beta=90^{\circ}\right) \quad 112$

4.1.5. CPI com porosidade $>8.5 \%\left(\beta=45^{\circ}\right) \quad 114$

4.2. Análise Comparativa da resistência entre CPV, CPI e CPH 116

$\begin{array}{lr}\text { 4.2.1. Imagens de o microtomógafo } & 118\end{array}$

$\begin{array}{ll}\text { 4.3. Resultados dos ensaios hidrostáticos } & 121\end{array}$

4.4. Calibração analítica do modelo Lade-Kim 123

$\begin{array}{lr}\text { 4.4.1. Parâmetros elásticos } & 123\end{array}$

$\begin{array}{lr}\text { 4.4.2. Parâmetros de ruptura } & 126\end{array}$

$\begin{array}{ll}\text { 4.4.3. Parâmetros da função potencial plástico } & 128\end{array}$

4.4.4. Parâmetros de endurecimento e amolecimento 131

$\begin{array}{ll}\text { 4.4.5. Parâmetros da função de escoamento } & 133\end{array}$

4.4.6. Resultados dos parâmetros para o modelo Lade-Kim isotrópico 135

4.5. Validação do modelo isotrópico Lade-Kim 136

4.5.1. CPV com porosidade $<8.5 \%\left(\beta=0^{\circ}\right) \quad 136$

4.5.2. $\mathrm{CPV}$ com porosidade $>8.5 \%\left(\beta=0^{\circ}\right) \quad 138$

4.5.3. $\mathrm{CPH}$ com porosidade $<8.5 \%\left(\beta=90^{\circ}\right) \quad 139$

4.5.4. $\mathrm{CPH}$ com porosidade $>8.5 \%\left(\beta=90^{\circ}\right) \quad 141$

4.6. Calibração analítica do modelo CCMC 142

4.6.1. Parâmetros $\lambda$ e $k^{\prime} \quad 142$

4.6.2. Parâmetros coesão $C^{*}$ e ângulo de atrito $\Phi$ 
4.6.3. Resultados dos parâmetros do modelo CCMC

4.7. Validação do modelo CCMC

4.8. Comparação entre os modelos constitutivos Lade-Kim e CCMC

4.9. Análise inversa usando MINPACK

4.9.1. CPV com porosidade $<8.5 \%$

4.9.2. CPV com porosidade $>8.5 \%$

4.10. Análise inversa usando DREAM

4.10.1. Rocha travertino para CPV com porosidade $>8.5 \%$

4.10.2. Rocha travertino CPV com porosidade $<8.5 \%$ 158

4.10.3. Rocha sedimentar Tournemire shale

4.11. Comparação entre calibração analítica, DREAM e MINPACK

4.12. Anisotropia em rochas sedimentares

4.12.1. Validação do modelo CALK na rocha carbonática travertino

4.12.2. Validação do modelo CALK para a rocha Tournemire shale

5 CONCLUSÕES E SUGESTÕES

5.1. Conclusões

5.2. Sugestões 


\section{Lista de figuras}

Figura 2 Plano transversalmente isotrópico das rochas sedimentares

Figura 3 Ensaios triaxiais com amostra de rocha sedimentar

Tournemire shale (Pietruszczak, 2010). (a) Variação da tensão

desviadora com diferentes tensões de confinamento e

orientação das camadas; (b) corpo de prova com orientação das

camadas em relação ao eixo axial, ângulo $\beta$.

Figura 4 Mecanismos de rupturas típicos com variação do acamamento e tensão de confinamento (Pietruszczak, 2010).

Figura 5 Anisotropia transversal para areia Santa Monica no plano desviador (Abelev A e Lade P, 2004).

Figura 6 Orientação das camadas com relação aos eixos globais (X$\mathrm{Y}-\mathrm{Z})$ e os eixos locais ( $\left.\mathrm{X}^{\prime}-\mathrm{Y}^{\prime}-\mathrm{Z}^{\prime}\right)$.

Figura 7 Escalonamento da superfície de escoamento do modelo constitutivo Mohr-Coulomb (Mánica et al., 2016).

Figura 8 Superfície de escoamento, estado de tensões elástico e elastoplástico.

Figura 9 Endurecimento perfeitamente plástico. (a) plano tensão vs. deformação e (b) plano desviador.

Figura 10 Endurecimento isotrópico, superfície de escoamento varia uniformente, (a) plano tensão vs. deformação e (b) no plano desviador.

Figura 11 Endurecimento cinemático, superfície de escoamento não varia, mas é trasladada com a rotação, no plano desviador.

Figura 13 Critério de ruptura (a) plano octaédrico (b) plano triaxial.(Lade 2005).

Figura 14 Translação das tensões principais ao comprimento do eixo hidrostático (Lade 2014). 
Figura 15 Superfície potencial plástica e incrementos de deformação plástica (Kim e Lade, 1988).

Figura 16 Modelo de endurecimento e de amolecimento (Kim e Lade, 1988).

Figura 17 (a) Superfície de escoamento, (b) Índice de vazios vs. Ln P do modelo Cam Clay (Helwany, 2007).

Figura 18 (a) função de escoamento do Cam Clay Modificado com coesão, no plano octaédrico (Ya et al., 2014); (b) superfície de escoamento com coesão no espaço de tensões p-q (Uchida et al., 2012).

Figura 19 Diferença entre dados experimentais e dados numéricos (Cekerevac et al., 2006).

Figura 20 Esquema do DREAM : (1) parâmetros do modelo, (2) dados de entrada, (3) distribuição prévia, (4) estrutura do modelo, (5) saída de dados, (6) dados observados (Vrugt et al., 2016).

Figura 21. Principais componentes de um problema de análise inversa (Velloso 2000).

Figura 22 Algoritmo geral de otimização (Velloso 2000).

Figura 23 Esquema da metodologia desenvolvida na pesquisa.

Figura 24 (a) Dimensões e cortes do bloco 1 da rocha travertino romano. (b) Dimensões do bloco 2 da rocha travertino romano.

Figura 25 Determinação do Gs da rocha carbonática travertino.

Figura 26 Variação da porosidade total $\mathrm{CPH}$, retirados do Bloco 1.

Figura 27 Variação da porosidade total CPV, retirados do Bloco 1.

Figura 28 Variação da porosidade total CPI, retirados do Bloco 2.

Figura 29 Equipamento triaxial usado nos ensaios do travertino, PUC-Rio. 
Figura 30 Esquema de ensaio triaxial à compressão (Davis \&

Selvadurai, 2002).

Figura 31 Esquemas de representação dos algoritmos

implementados (a) esquema do ensaio triaxial drenado. (b)

modelo conceitual das variveis de entrada e saida dos

algortimos.

Figura 32. Incorporação de Lade-Kim no MINPACK.

Figura 33 Esquema geral do modelo isotrópico Lade-Kim no DREAM.

Figura 34 Esquema dos dados numéricos de saída do Lade-Kim no DREAM.

Figura 35 Esquema dos dados experimentais de entrada no DREAM. 102

Figura 36 Esquema da sequência na obtenção de parâmetros ótimos.

Figura 37 Resultados dos ensaios triaxiais do travertino com CPV e porosidades $<8.5 \%$. (a) curva tensão desviadora vs deformação axial, (b) curva deformação volumétrica vs deformação axial.

Figura 38 Ensaios triaxiais à compressão do travertino com porosidade $<8.5 \%$ e orientação das camadas ortogonal ao eixo axial.

Figura 39 Resultados dos ensaios triaxiais do travertino CPV e porosidades $>8.5 \%$. (a) Curva tensão desviadora vs deformação axial, (b) Curva deformação volumétrica vs deformação axial.

Figura 40 Ensaios triaxiais à compressão do travertino com porosidade $>8.5 \%$ e orientação das camadas ortogonal ao eixo axial.

Figura 41 Resultados dos ensaios triaxiais do travertino $\mathrm{CPH}$ e porosidades < 8.5\%.(a) Curva tensão desviadora vs deformação axial (b) Curva deformação volumétrica vs deformação axial. 
Figura 42 Ensaios triaxiais à compressão do travertino com porosidade $<8.5 \%$ e orientação das camadas paralelo ao eixo axial.

Figura 43 Resultados dos ensaios triaxiais do travertino $\mathrm{CPH}$ e porosidades $>8.5 \%$. (a) Curva tensão desviadora vs deformação axial, (b) curva deformação volumétrica vs deformação axial.

Figura 44 Ensaios triaxiais à compressão do travertino com porosidade $>8.5 \%$ e orientação das camadas paralelo ao eixo axial.

Figura 45 Corpos de prova inclinados $(\mathrm{CPI})$ com porosidades $>8.5 \%$.

Figura 46 Resultados dos ensaios triaxiais do travertino CPI e porosidades $>8.5 \%$. (a) Curva tensão desviadora vs deformação axial, (b) Curva deformação volumétrica vs deformação axial.

Figura 47 Resultados ensaios triaxiais na curva tensão desviadora vs deformação axial (a) com porosidades $>8.5 \%$ (b) com porosidades $<8.5 \%$.

Figura 48 Imagem com microtomógafo para o CPV 30.

Figura 49 Imagem microtomógafo do CPH 22.

Figura 50 Amostras da rocha carbonática travertino utilizadas em ensaios hidrostáticos.

Figura 51 Ensaio hidrostático CPV22

Figura 52 Parâmetros $K$ e $n$ do modelo Lade-Kim da rocha carbonática travertino, CPV. $\left(\beta=0^{\circ}\right)$. (a) Porosidade $>8.5 \%$, (b) porosidade $<8.5 \%$.

Figura 53 Parâmetros $k$ e $n$ do modelo Lade-Kim da rocha travertino, $\mathrm{CPH} .\left(\beta=90^{\circ}\right)$ (a) porosidade $>8.5 \%(\mathrm{~b})$ porosidade $<8.5 \%$. 
Figura 54 Parâmetros $\eta_{1}$ e $m$ do modelo Lade-Kim da rocha travertino, CPV. $\left(\beta=0^{\circ}\right)$ (a) porosidade $>8.5 \%$ (b) porosidade $<8.5 \%$.

Figura 55 Parâmetros $\eta_{1}$ e $m$ do modelo Lade-Kim da rocha travertino $\mathrm{CPH} .\left(\beta=90^{\circ}\right)$. (a) Porosidade $>8.5 \%$, (b) porosidade $<8.5 \%$.

Figura 56 Parâmetros $\psi_{2}$ e $\mu$ do modelo Lade-Kim da rocha travertino $\operatorname{CPV}\left(\beta=0^{\circ}\right)$. (a) Porosidade $>8.5 \%$, (b) porosidade $<8.5 \%$.

Figura 57 Parâmetros $\psi_{2}$ e $\mu$ do modelo Lade-Kim da rocha travertino, $\mathrm{CPH}$. $\left(\beta=90^{\circ}\right)$. (a) Porosidade $>8.5 \%$, (b) porosidade $<8.5 \%$.

Figura 58 Determinação dos parâmetros $C$ e $P$ do travertino.

Figura 59 Parâmetro $\alpha$ do modelo Lade-Kim da rocha travertino, CPV $\left(\beta=0^{\circ}\right)$. (a) Porosidade $>8.5 \%$, (b) porosidade $<8.5 \%$.

Figura 60 Parâmetro $\alpha$ do modelo Lade-Kim da rocha travertino, $\mathrm{CPH}\left(\beta=90^{\circ}\right)$. (a) Porosidade $>8.5 \%$, (b) porosidade $>8.5 \%$.

Figura 61 Comparação entre ensaio laboratorial e modelagem numérica com o modelo de Lade-Kim para CPV com porosidade $<8.5 \%$. (a) Curva tensão vs deformação axial, (b) deformação volumétrica vs deformação axial.

Figura 62 Comparação entre ensaio laboratorial e modelagem numérica com o modelo de Lade-Kim para CPV com porosidade $>$ 8.5\%. (a) Curva tensão vs deformação axial, (b) deformação volumétrica vs deformação axial.

Figura 63 Comparação entre ensaio laboratorial e modelagem numérica com o modelo de Lade-Kim para $\mathrm{CPH}$ com porosidade $<8.5 \%$. (a) Curva tensão vs deformação axial, (b) deformação volumétrica vs deformação axial. 
Figura 64 Comparação entre ensaio laboratorial e modelagem numérica com o modelo de Lade-Kim para $\mathrm{CPH}$ com porosidade $>$ 8.5\%. (a) Curva tensão vs deformação axial, (b) deformação volumétrica vs deformação axial.

Figura 65 Gráfico $e$ vs. Log $\bar{P}$ da rocha carbonática travertino para CPV com porosidades $>8.5 \%$.

Figura 66 Parâmetros $C^{*}$ e $\phi$-círculo de Mohr para CPV $>8.5 \%$.

Figura 67 Comparação entre ensaio laboratorial e modelagem numérica com o modelo de CCMC para CPV com porosidade > $8.5 \%$. (a) curva tensão vs deformação axial (b) deformação volumétrica vs deformação axial.

Figura 69 Comparação entre ensaios triaxiais, modelo Lade-Kim e MINPACK, da rocha carbonática travertino, CPV com porosidade < 8.5\%. (a) Curva tensão vs deformação axial, (b) deformação volumétrica vs deformação axial.

Figura 71 Convergência com DREAM com 12 parâmetros do modelo Lade-Kim para CPV $>8.5 \%$.

Figura 72 Distribuição utilizada no DREAM para 12 parâmetros CPV $>8.5 \%$.

Figura 73 Incerteza de parâmetros usando o algoritmo DREAM Curvas tensão desviadora vs deformação axial para CPV $>8.5 \%$.

Figura 74 Comparação entre dados experimentais de ensaios triaxiais da rocha carbonática travertino com o modelo LadeKim, obtidos de forma analítica e através do DREAM, CPV com porosidades $>8.5 \%$. (a) curva tensão vs deformação axial (b) deformação volumétrica vs deformação axial.

Figura 75 Incerteza de parâmetros usando o algoritmo DREAM Curvas tensão desviadora vs deformação axial para CPV $<8.5 \%$. 
Figura 76 Comparação entre ensaios triaxiais da rocha carbonática travertino com o modelo Lade-Kim e DREAM, CPV com porosidades < 8.5\%.(a) Curva tensão vs deformação axial, (b) deformação volumétrica vs deformação axial.

Figura 77 Convergência de parâmetros da rocha Tournemire shale

Figura 78 Distribuição de parâmetros com o DREAM para a rocha Tournemire shale

Figura 79 Comparação entre ensaios triaxiais da rocha sedimentaria Tournemire shale com o modelo Lade-Kim e DREAM. (a) Curva tensão vs deformação axial, (b) deformação volumétrica vs deformação axial.

Figura 80 Comparação entre calibração analítica, MINPACK e DREAM para CPV com porosidade $>8.5 \%$ com tensão de confinamento de $10 \mathrm{MPa}$. (a) Curva tensão vs deformação axial (b) deformação volumétrica vs deformação axial.

Figura 81 Comparação entre calibração analítica, MINPACK e DREAM para CPV com porosidade $8.5 \%$ com tensão de confinamento de $20 \mathrm{MPa}$. (a) Curva tensão vs deformação axial, (b) deformação volumétrica vs deformação axial.

Figura 82 Comparação entre calibração analítica, MINPACK e DREAM para CPV com porosidade $>8.5 \%$ com tensão de confinamento de $30 \mathrm{MPa}$. (a) Curva tensão vs deformação axial, (b) deformação volumétrica vs deformação axial.

Figura 83 Comparação entre curvas laboratoriais de ensaios triaxiais CPV > $8.5 \% \beta=0^{\circ}$ e a retroanálise usando o DREAM com o modelo numérico CALK CN=1.0 e CS=1.0 (caso isotrópico). (a) Curva tensão vs deformação axial, (b) deformação volumétrica vs deformação axial.

Figura 84 Distribuição posterior dos parâmetros anistrópicos $C N, C S$ e $\eta_{1}$ da rocha carbonática travertino, usando o algoritmo DREAM. 
Figura 85 Orientação das camadas vs tensão desviadora (MPa) da rocha carbonática travertino, usando calibração analítica e o algoritmo anisotrópico de Lade-Kim, com porosidades $>8.5 \%$.

(a) Ensaios laboratoriais vs modelo numérico CALK, (b) analíse de sensibilidade do modelo CALK.

Figura 86 Comparação entre o modelo anisótropico Lade-Kim e ensaios triaxiais com tensões de confinamento de 10, 20 e 30 MPa na rocha carbonática travertino com porosidades $>8.5 \%$. (a) Curva tensão desviadora vs deformação axial, (b) curva deformação volumétrica vs deformação axial para $\beta=0^{\circ}$; (c) Curva tensão desviadora vs deformação axial, (d) curva deformação volumétrica vs deformação axial para $\beta=45^{\circ} ;(\mathrm{e})$ Curva tensão desviadora vs deformação axial, (f) curva deformação volumétrica vs deformação axial para $\beta=90^{\circ}$.

Figura 87 Distribuição posterior dos parâmetros anistrópicos CN, CS e $\eta_{1}$ para a rocha Tournemire shale, usando o algoritmo DREAM.

Figura 88 Orientação das camadas vs tensão desviadora (MPa) da rocha Tournemire shale, usando a retroanálise com o DREAM e o modelo CALK.

Figura 89 Comparação entre o modelo anisótropico Lade-Kim e ensaios triaxiais com tensões de confinamento de 30, 40 e 50 MPa para amostras de rocha Tournemire shale. (a) Curva tensão desviadora vs deformação axial, (b) curva deformação volumétrica vs deformação axial para $\beta=0^{\circ}$; (c) Curva tensão desviadora vs deformação axial, (d) curva deformação volumétrica vs deformação axial para $\beta=45^{\circ}$; (e) Curva tensão desviadora vs deformação axial, (f) curva deformação volumétrica vs deformação axial para $\beta=90^{\circ}$. 


\section{Lista de tabelas}

Tabela 1 Classificação da porosidade total (Rodríguez, 2006) com mudanças na porosidade baixa e média com valor intermediário de $8.5 \%$.

Tabela 2 Valores de parâmetros $T_{o}$ e $t_{i}$ para vários tipos de materiais com atrito (Kim e Lade 1984)

Tabela 3 Parâmetros do modelo Lade-Kim.

Tabela 4 Parâmetros do modelo CCMC.

68

Tabela 5 Cálculo da densidade relativa dos grãos Gs.

Tabela 6 Classificação dos corpos de prova da rocha travertino, pela porosidade e orientação das camadas.

Tabela 7: Ensaios triaxiais em corpos de prova do travertino verticais.

Tabela 8 Ensaios triaxiais em corpos de prova do travertino inclinados.

Tabela 9 Ensaios triaxiais em corpos de prova do travertino horizontais.

Tabela 10 Amostras de rocha carbonática travertino para ensaios hidrostáticos.

Tabela 11 Resultados dos ensaios triaxiais à compressão com corpos de prova verticais com porosidade $<8.5 \%$.

Tabela 12 Resultados dos ensaios triaxiais a compressão com corpos de prova verticais com porosidades $>8.5 \%$.

Tabela 13 Resultados dos ensaios triaxiais à compressão com corpos de prova horizontais com porosidade $<8.5 \%$.

Tabela 14 Resultados dos ensaios triaxiais a compressão com corpos de prova horizontais com porosidade $>8.5 \%$. 
Tabela 15 Resultados dos ensaios triaxiais à compressão com corpos de prova inclinados com porosidade $>8.5 \%$.

Tabela 17 Resultados dos ensaios hidrostáticos com CP horizontais e verticais.

Tabela 18 Variação de parâmetros elásticos $k$ e $n$ do travertino com o modelo Lade-Kim.

Tabela 19 Variação de parâmetros de ruptura do travertino no modelo Lade-Kim.

Tabela 20 Coesão da rocha carbonática travertino do modelo LadeKim

Tabela 21 Variação de parâmetros da função potencial plástico do travertino para o modelo Lade-Kim.

Tabela 22 Variação de parâmetros de endurecimento do travertino com o modelo Lade-Kim.

Tabela 24 Parâmetros da rocha carbonática travertino com o modelo Lade-Kim.

Tabela 25 Parâmetros do modelo CCMC para CPV com porosidade $>8.5 \%$

Tabela 26 Parâmetros ótimos do travertino vertical com porosidade $<8.5 \%$, usando MINPACK

Tabela 27 Parâmetros ótimos do travertino vertical com porosidade $>8.5 \%$, usando MINPACK

Tabela 28 Parâmetros de entrada no DREAM para o travertino com porosidades $>8.5 \%$

Tabela 30 Parâmetros da rocha carbonática travertino para o modelo Lade-Kim, determinados analiticamente e através do DREAM. Com 12 parâmetros, para CPV >8.5\%. 
Tabela 31 Parâmetros da rocha carbonática travertino usando o modelo Lade-Kim e o DREAM. Com 9 parâmetros, para CPV $<8.5 \%$.

Tabela 32 parâmetros de entrada DREAMpar da rocha Tournemire shale

Tabela 33 Limites de parâmetros do DREAM da rocha Tournemire shale

Tabela 35 Parâmetros do modelo Lade-Kim, calibração analítica, MINPACK e DREAM para CPV com porosidade $>8.5 \%$

Tabela 36 Parâmetros da rocha carbonática travertino para o modelo Lade-Kim, determinados analiticamente e através do DREAM com CALK.

Tabela 37 Limite de parâmetros e valores ótimos dos parâmetros anisotrópicos $\mathrm{CN}$, CS e $\eta_{1}$ da rocha carbonática travertino.

Tabela 38 Tensões máximas desviadoras experimentais e numéricas para amostras de travertino com porosidade maior que $8.5 \%$.

Tabela 39 Parâmetros da rocha Tournemire shale para o modelo Lade-Kim, determinados analiticamente e através do DREAM com CALK.

Tabela 40 Limite de parâmetros e valores ótimos dos parâmetros anisotrópicos $\mathrm{CN}$, CS e $\eta_{1}$ para a rocha Tournemire shale.

Tabela 41 Tensões máximas desviadoras experimentais e numéricas para amostras de Tournemire shale.

Tabela A1 Porosidade total dos corpos de prova horizontais $\mathrm{CPH}$. 


\section{Lista de símbolos}

a Parâmetro da coesão do modelo Lade-Kim

CN Fator de escala das tensões normais

CS Fator de escala das tensões cisalhantes

$C_{C} \quad$ Índice de compressão do modelo CCMC

$C_{S L} \quad$ Índice de expansão do modelo CCMC

C Parâmetro de endurecimento do modelo Lade-Kim

$C^{*} \quad$ Coesão do modelo CCMC

$C_{P o}^{-1} \quad$ Matriz de covariância dos parâmetros iniciais

$C_{y} \quad$ Matriz de covariância dos valores medidos

$C_{y}^{-1} \quad$ Inversa da matriz de covariância dos valores medidos

$D^{e} \quad$ Matriz constitutiva elástica

$D^{e p} \quad$ Matriz constitutiva elastoplástica

de Incremento de Índice de vazios

$d e^{e} \quad$ Incremento de Índice de vazios elástico

$d e^{p} \quad$ Incremento de Índice de vazios plástico

$d \varepsilon \quad$ Incremento de deformação total

$d \varepsilon^{e} \quad$ Incremento de deformação elástica

$d \varepsilon^{P} \quad$ Incremento de deformação plástica

$d \varepsilon_{v}^{P} \quad$ Incremento de deformação plástica volumétrica

$d \varepsilon_{s}^{P} \quad$ Incremento de deformação plástica desviadora

$d \sigma \quad$ Incremento de tensões

$d W_{p} \quad$ Incremento do trabalho plástico

$d^{k} \quad$ Direção de busca 


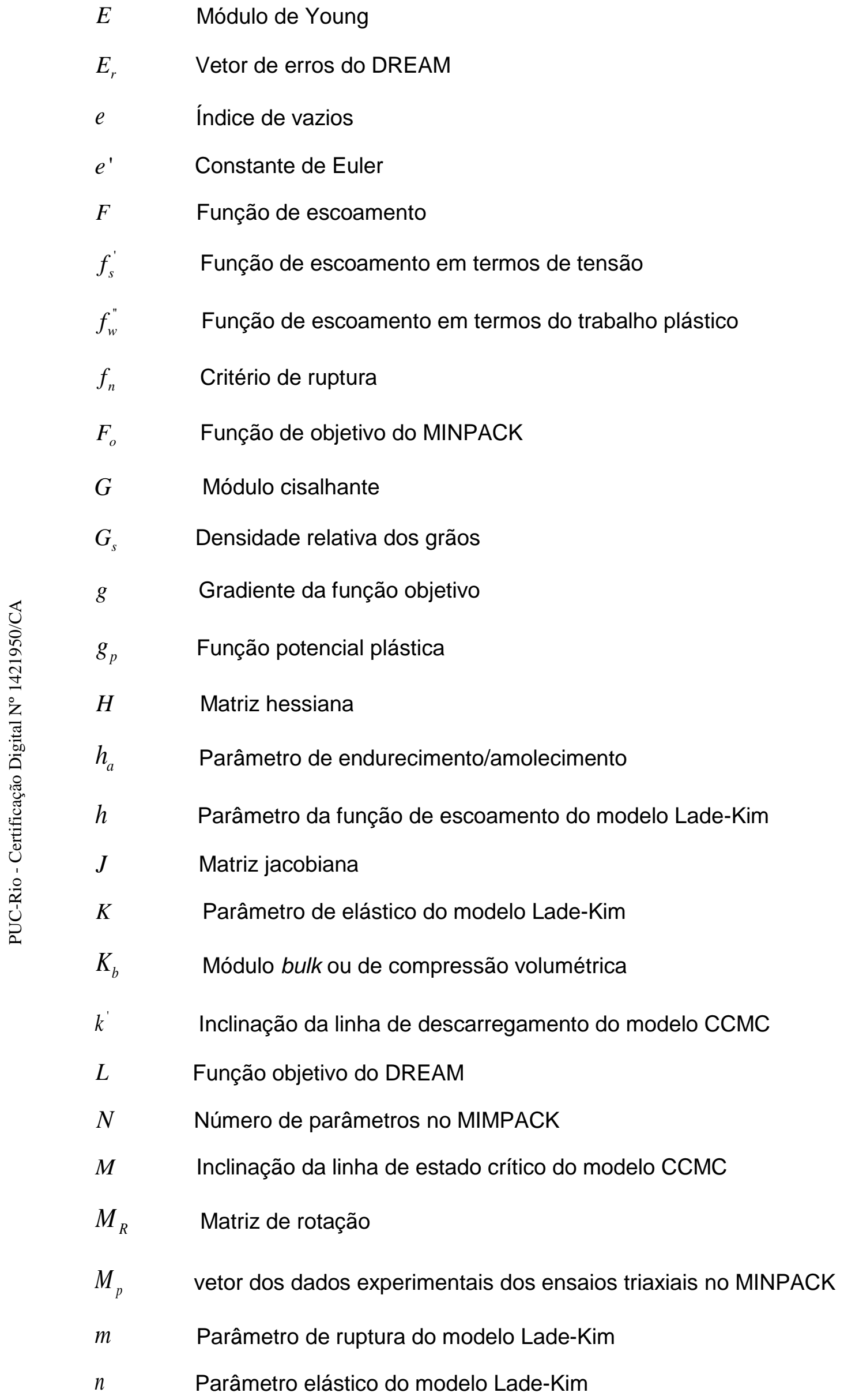




\begin{tabular}{|c|c|}
\hline$n_{e}$ & Número de ensaios triaxiais \\
\hline$n_{p}$ & Número de registros realizados nos ensaios triaxiais \\
\hline $\bar{P}$ & Tensão hidrostática \\
\hline$P_{C}$ & Tensão de endurecimento do modelo CCMC \\
\hline$P_{c n}$ & Parâmetro de endurecimento do modelo CCMC do passo anterior \\
\hline$P_{c i}$ & Tensão de pré-adensamento inicial \\
\hline$P$ & Parâmetro de endurecimento do modelo Lade-Kim \\
\hline$P_{a}$ & Pressão atmosférica \\
\hline$p\left(\mathrm{x}_{i} / \tilde{Y}\right)$ & Distribuição de parâmetros posterior do DREAM \\
\hline$p\left(\mathrm{x}_{i}\right)$ & Distribuição de parâmetros anterior do DREAM \\
\hline$p\left(\tilde{Y} / \mathrm{x}_{i}\right)$ & . Função objetivo do DREAM \\
\hline$p(\tilde{Y})$ & Dados experimentais do DREAM \\
\hline$P_{a c c}$ & Probabilidade que aceita a proposta posterior do DREAM \\
\hline$P_{0}$ & Parâmetros iniciais no MINPACK \\
\hline$p_{i}$ & Parâmetros a retroanalisar do MINPACK \\
\hline$p^{*}$ & Parâmetros retroanalisados do MINPACK \\
\hline$q$ & Parâmetro da função de escoamento do Modelo Lade-Kim \\
\hline $\bar{q}$ & Tensão cisalhante do modelo CCMC \\
\hline$q(\cdot)$ & Distribuição proposta do DREAM \\
\hline$S$ & Nível de tensão do modelo Lade-Kim \\
\hline$S_{c}$ & Tensor desviador \\
\hline$t$ & Tempo \\
\hline$t_{i}$ & Valores de materiais com atrito do modelo Lade-Kim \\
\hline$T_{o}$ & Valores de materiais com atrito do modelo Lade-Kim \\
\hline$W_{p}$ & Trabalho plástico total \\
\hline
\end{tabular}




$\begin{array}{ll}W & \text { Matriz diagonal de pesos } \\ X & \text { Parâmetro do modelo CCMC } \\ X_{i} & \text { Parâmetros à retroanalisar do DREAM } \\ X_{p} & \text { Proposta posterior aceita do DREAM } \\ X_{t-1} & \text { Proposta posterior não aceita do DREAM } \\ x_{(n)} & \text { Número os parâmetros calibrados } \\ \tilde{Y} & \text { Vetor de dados experimentais do DREAM e MINPACK } \\ Y & \text { Vetor de dados numéricos do DREAM e MINPACK } \\ \text { X-Y-Z } & \text { Eixos globais } \\ X^{\prime}-Y^{\prime}-Z^{\prime} & \text { Eixos Locais }\end{array}$

\section{Símbolos gregos}

$\alpha \quad$ Parâmetro de escoamento do modelo Lade-Kim

$\alpha_{S} \quad$ Parâmetro do modelo CCMC

$\alpha_{r} \quad$ Ângulo de rotação com relação ao eixo $\mathrm{Y}$

$\alpha^{k} \quad$ Tamanho do passo

$\beta \quad$ Ângulo de rotação com relação ao eixo $Z$

$\gamma \quad$ Variáveis internas da função de escoamento

$\varepsilon \quad$ Tensor de deformações

$\varepsilon^{P} \quad$ Deformação plástica

$\varepsilon^{\exp } \quad$ Vetor de deformações experimentais

$\varepsilon^{\text {num }} \quad$ Vetor de deformações numéricas

$\varepsilon_{v}^{\exp } \quad$ Vetor de deformações volumétricas experimentais

$\varepsilon_{v}^{n u m} \quad$ Vetor de deformações volumétricas numéricas

$\eta_{1} \quad$ Parâmetro de ruptura do modelo Lade-Kim 


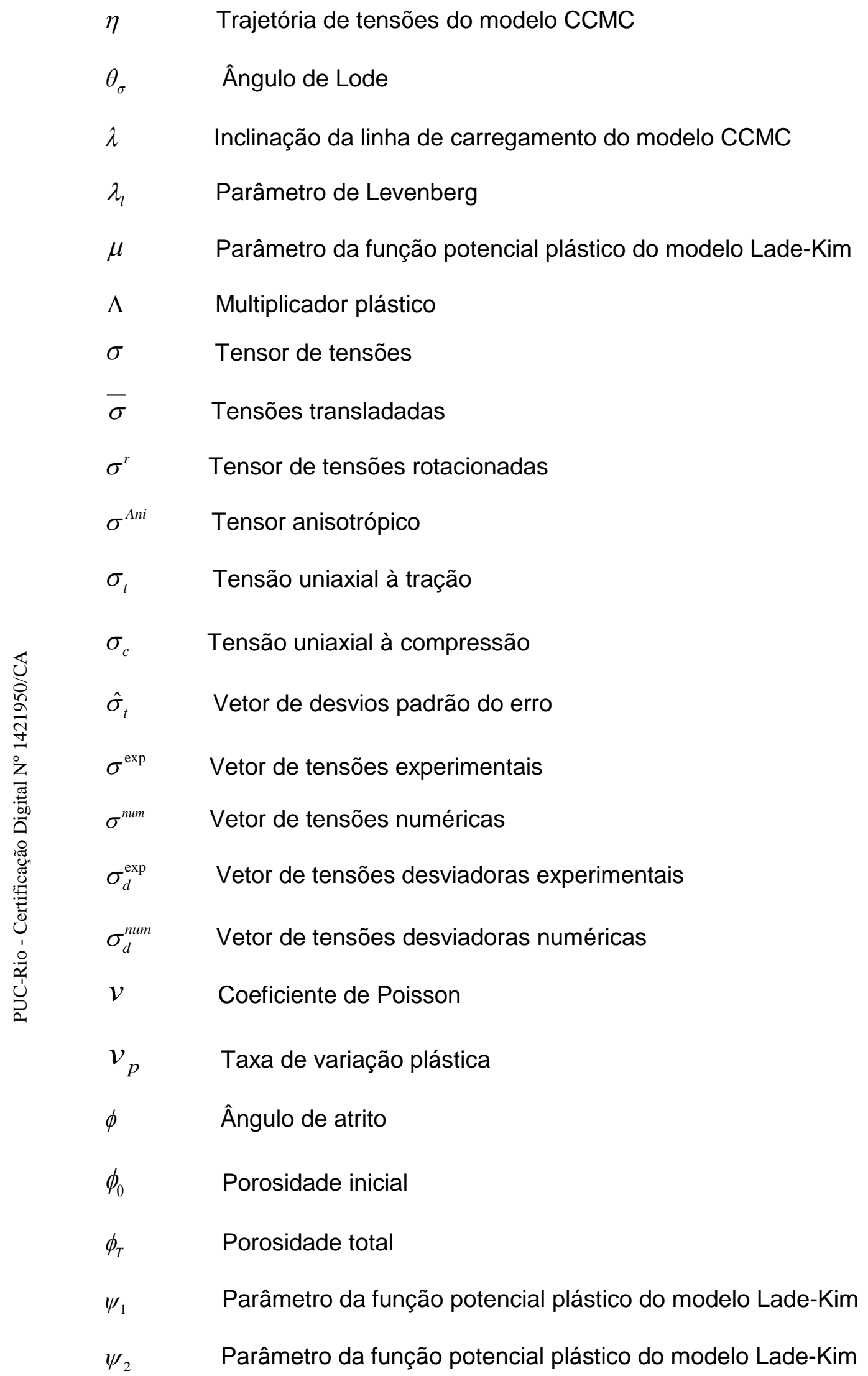




\section{1 \\ INTRODUÇÃO}

Reservatórios petrolíferos constituídos por rochas carbonáticas "sempre exerceram um papel relevante na indústria do petróleo por conterem elevados volumes de óleo e gás natural em muitas bacias sedimentares ao redor do mundo" (Alves 2007), correspondendo a mais de 60\% das reservas de petróleo e $40 \%$ das reservas de gás no mundo. No Brasil, esses reservatórios são característicos do Pré-Sal. Nesse contexto, para a indústria do petróleo é importante conhecer o comportamento geomecânico das rochas, estudando as propriedades mecânicas da rocha-reservatório a fim de mitigar os riscos decorrentes de tensões aplicadas, que podem gerar deformações e variações de volumes porosos. De acordo com (Yu et al., 2014) os carbonatos são altamente heterogêneos, o que torna essencial compreender os mecanismos que controlam a evolução de propriedades como porosidade e permeabilidade.

Durante a produção, a extração de hidrocarbonetos reduz a pressão de poros, o que causa aumento das tensões efetivas e a compactação mecânica do reservatório, podendo causar problemas como colapso de revestimento de poços, subsidência, produção de areia, redução da permeabilidade, entre outros problemas na produção. A previsão das deformações decorrentes das tensões depende de ensaios de laboratório e suas respectivas representações através de modelos constitutivos elastoplásticos (Alves, 2007).

Devido a sua formação e consolidação durante a digênese, as rochas sedimentares apresentam, geralmente, um comportamento anisotrópico conhecido como transversalmente isotrópico. Neste caso, a rocha exibe um comportamento isotropico no plano de orientação das camadas e um eixo perpendicular com características anisotrópicas. Existe grande quantidade de autores que publicaram modelos constitutivos isotrópicos com extensão anisotrópica, sendo alguns deles Pietruszczak et al., 2002; Wheeler et al., 2003; Abelev et al., 2007; Pei, 2008; Mortara, 2010; François et al., 2011b; Mánica et al., 2016. No entanto, os modelos avançados isotrópicos e anisotrópicos como LadeKim e Cam Clay Modificado com Coesão ainda não foram validados na rocha carbonática travertino, considerada análoga a uma das fácies dos reservatórios 
carbonáticos do Pré-Sal brasileiro. Nesse caso é importante testar modelos constitutivos que representam adequadamente a evolução do endurecimento na zona plástica deste material, como observado durante ensaios laboratoriais de mecânica de rochas. Modelos constitutivos elastoplásticos diferem uns dos outros no espaço de tensões, como Lade-Kim e Cam Clay Modificado com Coesão CCMC. A partir desta consideração, o presente trabalho pretende analisar esses modelos através da comparação entre curvas tensão-deformação e concluir qual deles representa melhor o comportamento da rocha travertino em condições de reservatório.

O comportamento mecânico das rochas carbonáticas, medida através de ensaios laboratoriais de mecânica de rochas, depende, entre outros fatores, da pressão de confinamento, porosidade total e da orientação das camadas em relação ao eixo axial das amostras. Assim, o principal objetivo deste trabalho é determinar os comportamentos isotrópico e anisotrópico (transversalmente isotrópico) da rocha carbonática travertino a partir dos fatores acima mencionados. Para isso, serão utilizados modelos elastoplásticos com endurecimento isotrópico. Primeiro o modelo elastoplástico Lade-Kim (Kim e Lade, 1988; Lade e Kim, 1988 a; 1988 b; Lade e Kim, 1995; Lade, 2005), seguido pelo modelo de estado crítico CCMC (Ya et al., 2014), implementados no MATLAB 2017료 ${ }^{\circledR}$ e FORTRAN $90 \AA$, respectivamente. Ambos modelos consideram uma superfície de escoamento tipo CAP, que representa o colapso de poros. O modelo elastoplástico Lade-Kim, formulado no espaço das tensões principais, usa o trabalho plástico como parâmetro de endurecimento. Diferentemente, o modelo elastoplástico CCMC, formulado no espaço de tensões $p$-q, utiliza a pressão de pré-adensamento em função das deformações plásticas volumétricas como parâmetros de endurecimento. Importante ressaltar que ambos modelos contém um parâmetro que representa a coesão da rocha, além de terem a capacidade de representar seu comportamento tensão-deformação seguindo diferentes trajetórias de tensões.

Visando a obtenção dos parâmetros de ambos os modelos, serão utilizados resultados experimentais de ensaios triaxiais de compressão, com diferentes pressões confinantes, hidrostáticos e uniaxiais em amostras de travertino. Um diferencial deste trabalho é a apresentação dos parâmetros dos modelos constitutivos Lade-Kim e CCMC, que estarão em função da porosidade e da orientação das camadas (perpendicular e paralela ao eixo axial das amostras). 
Para conhecer o comportamento anisotrópico das rochas sedimentares é importante estabelecer um modelo constitutivo que represente adequadamente a resistência da rocha considerando a orientação das camadas. No presente trabalho, foi desenvolvido o modelo elastoplástico anisótropico Lade-Kim, denominado CALK, baseado no modelo isotrópico de Lade-Kim e no critério anisótropico proposto por (Mánica et al., 2016). O modelo CALK possui três parâmetros anisotrópicos $C N, C S, \eta_{1}$ e foi implementado no programa MATLAB $2017^{\circledR} \circledast$ e na linguagem FORTRAN $90 \AA$. Devido às características simétricas da isotropia transversal, o critério anisótropico usa dois parâmetros de escalonamento $C N$ e $C S$, que controlam as tensões normal e cisalhante, respectivamente. Além disso o parâmetro do critério de ruptura $\eta_{1}$ é considerado anisotrópico pela capacidade de atingir as tensões de ruptura em todas as orientações. Considerando que esta formulação aplicada ao modelo constitutivo Lade-Kim ainda não está disponível na literatura, este desenvolvimento é uma importante contribuição deste trabalho, que visa a representação do comportamento anisótropico da rocha carbonática travertino.

O modelo CALK será validado para dois tipos de rochas sedimentares: a rocha carbonática travertino, análoga a uma rocha-reservatório, e a rocha Tournemire shale. A utilização desta última se justifica tanto pela característica fortemente anisotrópica do material, quanto pela disponibilidade, na literatura, dos dados necessários para a calibração do modelo (Niandou et al., 1997).

A estimativa de parâmetros pode ser feita de forma direita ou utilizando a metodologia de análise inversa. De acordo com (Cekerevac et al., 2006; Guimarães, 2006) o processo de retroanálise consiste em encontrar um conjunto de parâmetros ótimos do modelo que minimize a diferença entre os dados experimentais e as simulações numéricas, definidos por uma função objetivo. $O$ presente trabalho incorpora o algoritmo isotrópico Lade-Kim em dois diferentes algoritmos de otimização. O primeiro é o Differential Evolution Adaptive Metropolis, DREAM, um algoritmo implementado no MATLAB por (Vrugt Jasper et al., 2008; Vrugt et al., 2009) que usa inferência bayesiana com simulações de Cadeias de Markov Monte Carlo, MCMC, para determinar a probabilidade dos parâmetros ótimos. O segundo é o MINPACK, um algoritmo de uso livre, que resolve problemas não lineares mediante o algoritmo Levenberg-Marquardt. Para obter parâmetros anisotrópicos, o modelo CALK é incorporado no algoritmo DREAM. 


\section{1.}

\section{Justificativa}

Modelos constitutivos elastoplásticos possuem parâmetros que dificilmente podem ser obtidos diretamente em laboratório ou em campo. A determinação dos parâmetros destes modelos é uma etapa fundamental, de forma a obter uma melhor representação numérica do comportamento tensão-deformação observado em laboratório. Uma das principais dificuldades relacionadas à modelagem e simulação de reservatórios reside na ausência de parâmetros de modelos constitutivos capazes de representar o comportamento geomecânico das da rocha-reservatório. Portanto, o maior interesse desta pesquisa é contribuir para o estabelecimento de modelos constitutivos adequados, incluindo a determinação de seus parâmetros. Neste sentido, propõe-se a utilização de metodologias de calibração analítica (direta) (Lade, 2005) e de análise inversa com os algoritmos DREAM e MINPAK.

O travertino romano, usado nesta pesquisa, é uma rocha que apresenta analogia mecânica a uma das fácies da rocha-carbonática existente nos reservatórios do Pré-sal brasileiro. Atualmente, na literatura não consta a aplicabilidade de modelos constitutivos como Lade-Kim e CCMC para representar o comportamento anisótropico da rocha carbonática travertino. Desta forma, a adequação de tais modelos, a determinação dos parâmetros e sua validação trará benefícios no campo da investigação do comportamento mecânico da rochareservatório, mais especificamente ao Pré-sal brasileiro.

\section{2.}

\section{Objetivos}

Esta pesquisa se propõe a estabelecer um modelo constitutivo apropriado que determine o comportamento anisotrópico da rocha carbonática travertino a partir de parâmetros isotrópicos obtidos por retroanálise.

Para atingir o objetivo geral, propõe-se as seguintes etapas:

1. Como uma etapa preliminar à realização de ensaios laboratoriais de mecânica de rochas, classificar corpos de prova de travertino considerando a porosidade total e a orientação das camadas em relação ao eixo axial das amostras (perpendicular, inclinado e paralelo). Segue-se, então, à realização de ensaios de laboratório convencionais triaxiais a compressão (CTC), uniaxiais (UCS) e compressão hidrostática (HC). 
2. A partir de ensaios de laboratório, determinar analiticamente (metodologia direita) parâmetros dos modelos constitutivos isotrópicos Lade-Kim e Cam Clay modificado com Coesão (CCMC).

3. Implementar modelos constitutivos isotrópicos Lade-Kim e CCMC e o modelo anisotrópico CALK, usando o critério anisotrópico desenvolvido por (Mánica et al., 2016), nos programas FORTRAN 90® e MATLAB 2017a®.

4. Usar retroanálise (metodologia inversa) para determinar os parâmetros do modelo elastoplástico Lade-Kim, usando os algoritmos MINPACK e DREAM.

5. Validar os modelos isotrópicos Lade-Kim e CCMC e o modelo anisotrópico CALK comparando os resultados numéricos e experimentais para as curvas tensão desviadora vs. deformação axial e deformação volumétrica vs deformação axial.

As contribuições do presente trabalho são: Estabelecimento do modelo constitutivo anisotrópico CALK, baseado no modelo isotrópico Lade-Kim e no critério anisotrópico desenvolvido por Mánica (2016) para representar anisotropia das rochas sedimentares. Para isso são utilizados resultados de ensaios de laboratório da rocha carbonática travertino a diferentes orientações de acamamento, tensão de confinamento e porosidade. Em seguida, é feita uma comparação dos modelos constitutivos isotrópicos Lade-Kim e CCMC indicando qual modelo representa melhor o comportamento mecânico da Rocha carbonática travertino. Além disso, são determinados parâmetros isotrópicos dos modelos elastoplásticos já mencionados, e parâmetros anisotrópicos do modelo CALK determinados analiticamente e pela metodologia inversa usando o código DREAM. Tais desenvolvimentos permitirão que os referidos modelos e seus parâmetros reproduzam o comportamento mecânico dos materiais estudados, incluindo o comportamento análogo ao de compactação da rocha-reservatório. 


\section{3. \\ Organização}

Esta dissertação está dividida em seis capítulos e IV apêndices.

No capítulo 1 é apresentada uma breve introdução ao estudo que será desenvolvido na tese, além dos objetivos e etapas propostas.

O capítulo 2 contém uma descrição do tipo de material usado na tese, o travertino romano, seguido pela revisão dos trabalhos feitos com modelos constitutivos isotrópicos e anisotrópicos em rochas porosas. Segue-se a apresentação dos conceitos básicos de plasticidade, e as equações que descrevem os modelos constitutivos Lade-Kim e CCMC, posteriormente a teoria sobre metodologia inversa com MINPACK e DREAM.

No capítulo 3 são apresentadas as metodologias sobre os procedimentos e ensaios de laboratório, esquemas de implementação dos algoritmos tipo explícito dos modelos constitutivos Lade-Kim, CCMC e CALK, seguido da metodologia da análise inversa.

O capítulo 4 contém os resultados e discussões sobre os ensaios realizados no laboratório de engenharia civil da PUC-Rio, parâmetros obtidos da calibração analítica (direta) e análise inversa, validação dos modelos constitutivos Lade-Kim e CCMC, comparando-os às curvas tensão desviadora vs deformação axial e deformação volumétrica vs deformação axial obtidas experimentalmente. Contém, ainda, a apresentação dos resultados da anisotropia em rochas sedimentares usando o modelo CALK.

No capítulo 5 são apresentadas as conclusões e sugestões para trabalhos futuros.

O capítulo 6 contém as referências bibliográficas utilizadas.

No Apêndice I são apresentados os resultados dos índices físicos obtidos dos corpos de prova horizontais (CPH), Inclinados (CPI) e verticais (CPV) da rocha carbonática travertino.

No Apêndice II são apresentadas as derivadas do modelo constitutivo isotrópico Lade-Kim, e do modelo CALK.

O desenvolvimento do modelo constitutivo CCMC é apresentado no Apêndice III. 


\section{2 \\ REVISÃO BIBLIOGRÁFICA}

Neste capítulo serão apresentados os principais conceitos necessários para o desenvolvimento deste trabalho. Será feita uma breve descrição da rocha carbonática travertino usada na presente pesquisa, seguida por uma revisão dos modelos constitutivos elastoplásticos isotrópicos e anisotrópicos aplicáveis às rochas sedimentares. Posteriormente serão apresentados os fundamentos da plasticidade e uma detalhada descrição dos modelos constitutivos Lade-Kim e Cam Clay Modificado com Coesão (CCMC), escolhidos para representar o comportamento geomecânico da rocha carbonática travertino. Finalmente, serão descritos os conceitos da análise inversa dos algoritmos MINPACK e DREAM.

\section{1. \\ Rocha carbonática Travertino}

A rocha carbonática travertino é considerada como um material análogo a uma das fácies do reservatório do Pré-sal, constituída principalmente por carbonato de cálcio, formada na maior parte em ambientes marítimos por processos químicos ou orgânicos. Neste contexto, as rochas carbonáticas como o travertino são formadas a partir da precipitação química em solução aquosa ou por acúmulo de carapaças de organismos calcários, em águas quentes e ambiente marítimo pouco profundo.

Os blocos do travertino Romano usados nesta pesquisa foram extraídos da pedreira localizada na Itália perto da cidade de Tivoli, aproximadamente $30 \mathrm{Km}$ a Leste de Roma. No presente trabalho foi determinada a porosidade total do travertino Romano no laboratório da Geotecnia da PUC-Rio, obtendo valores entre $4 \%$ e $15 \%$. Estes valores são similares a outros na literatura: de acordo com (Ronchi et al., 2015), a rocha carbonática travertino Saturnia, também análoga a uma das fácies do Pré-Sal, localizado próximo à região da Toscana, na Itália, apresenta valores de porosidade total entre $4 \%$ e $30 \%$.

De acordo com Rodriguez (2006), as rochas podem ser classificadas em função da porosidade total. No presente trabalho se baseia na classificação de Rodrigez (2006), tendo sido feita uma pequena mudança nos valores propostos, 
devido aos resultados obtidos no laboratório com a rocha carbonática travertino, que serão apresentados no capítulo 3. Por enquanto na, Tabela 1 são apresentados os valores para classificar os corpos de prova em função da porosidade total.

Tabela 1 Classificação da porosidade total (Rodríguez, 2006) com mudanças na porosidade baixa e média com valor intermediário de $8.5 \%$.

\begin{tabular}{lc}
\hline \multicolumn{1}{c}{ Classificação } & Porosidade Total \\
\hline Porosidade muito baixa & $\phi_{T}<4 \%$ \\
Porosidade baixa & $4 \% \leq \phi_{T} \leq 8.5 \%$ \\
Porosidade media & $8.5 \% \leq \phi_{T} \leq 16 \%$ \\
Porosidade alta & $16 \% \leq \phi_{p} \leq 32 \%$ \\
Porosidade muito alta & $\phi_{T}>32 \%$ \\
\hline
\end{tabular}

A resistência da rocha carbonática é função da porosidade total, distribuição de poros, tensão de confinamento, orientação das camadas com relação à direção do carregamento, entre outros. Na Figura 1, segundo (Del-Cura et al., 2012), observa-se que a resistência da rocha carbonática travertino depende das fácies predominantes, da quantidade de poros e da orientação das camadas.

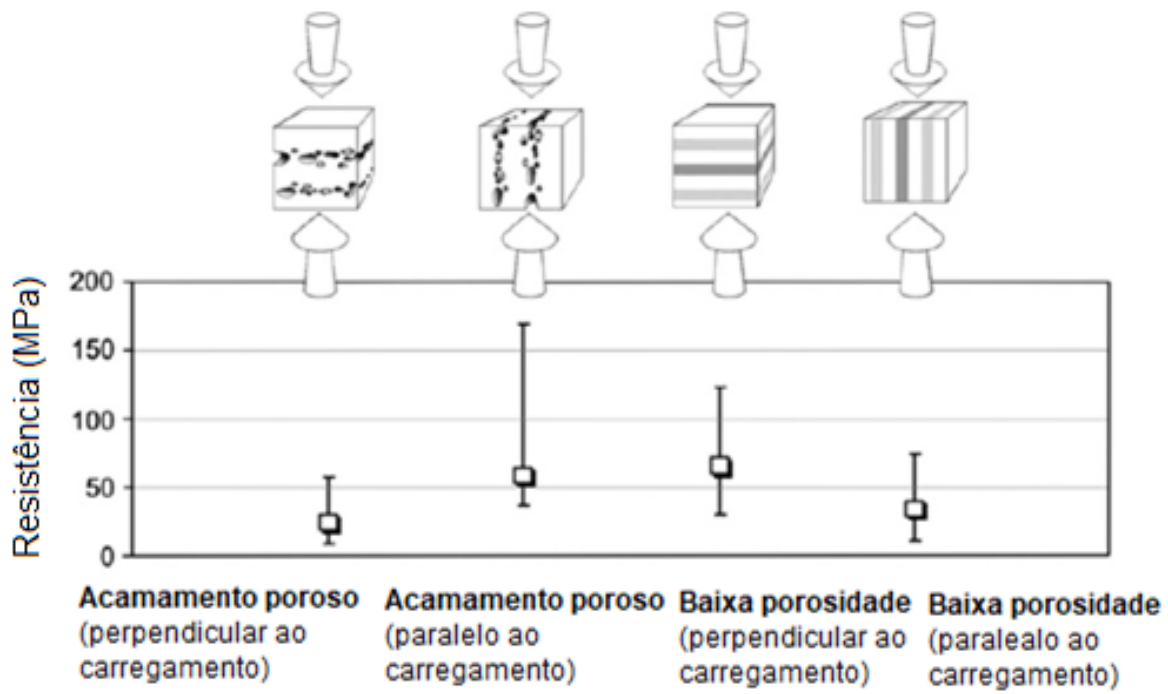

Figura 1 Resistência vs. porosidade travertino (Del-Cura et al., 2012)

Segundo Goodman (1989), o travertino apresenta os valores entre 20 e 100 MPa na transição entre rúptil para dúctil em esaios de compressão simples. De acordo Huillca (2014), resultados de ensaios de laboratório realizados por ele com 
diferentes amostras de travertino Romano, extraídos da mesma pedreira na Itália perto da cidade de Tivoli, apresentaram valores de resistência à compressão simples (UCS), entre 16.23 e $48.04 \mathrm{MPa}$. Ensaios de mecânica de rochas realizados por Kiewiet (2015) com a rocha carbonática travertino, com orientação das camadas vertical e horizontal com relação ao eixo axial das amostras, com diâmetro de $38 \mathrm{~mm}$, no laboratório de mecânica de rochas do Commonwealth Scientific and Industrial Research Organisation, CSIRO, na Austrália, apresentaram valores de UCS entre 12.60 e $24.04 \mathrm{MPa}$, o que seria uma rocha moderadamente resistente à deformação, de acordo com a classificação de (Azevedo 2002).

O presente trabalho pretende dar continuidade à pesquisa feita por Huillca (2014), que utilizou três critérios de ruptura clássicos, Mohr-Coulomb, Hoek-Brown e Lade-Kim, para representar a superfície de ruptura a partir de ensaios de mecânica de rochas utilizando amostras de travertino da mesma pedreira, perto da cidade de Tivoli. Neste caso, a pesquisa será feita aprofundando na utilização de modelos constitutivos elastoplásticos avançados, para determinar a variação da resistência em função da porosidade, tensão de confinamento e orientação das camadas em relação ao eixo axial das amostras.

\subsection{1. Modelos isotrópicos em rochas sedimentares}

Os modelos constitutivos como Von Mises e Tresca foram desenvolvidos visando o comportamento mecânico de metais. Estes modelos só têm variação nas tensões cisalhantes, desprezando a variação das tensões hidrostáticas. No entanto, o comportamento mecânico das rochas depende da variação das tensões cisalhantes e volumétricas. Modelos elastoplásticos baseados na teoria de estado crítico com elvoltoria de fechamento tipo CAP, podem determinar a ruptura pelo cisalhamento e determinar o colapso de poros.

Visando representar o comportamento de carbonatos com porosidades entre $10 \%$ e $38 \%$, Alves (2007) utilizou o modelo tipo CAP, mostrando que as tensões de escoamento dependem do parâmetro de endurecimento durante o incremento das deformações plásticas volumétricas. Soares (2000) executou numerosos ensaios de laboratório para determinar a resistência ao colapso de poros de amostras de rochas carbonáticas com porosidades entre $20 \%$ a $36 \%$ amostradas de testemunhos de um campo da Bacia de Campos. De acordo com Shen e Shao (2017), atualmente os modelos constitutivos incorporam parâmetros 
que incluem a variação do sistema poroso e podem representar o comportamento de diferentes tipos de rochas, como clayey (rocha de baixa porosidade e alta resistência, ideal para armazenamento de sustâncias químicas e resíduos nucleares), chalks e arenitos.

Trabalhos recentes, que utilizam modelos elastoplásticos baseados em ensaios laboratoriais hidrostáticos, triaxiais a compressão e uniaxiais, apresentam o comportamento mecânico de rochas sedimentares porosas como o chalk, cuja porosidade média de $43 \%$ é superior às rochas como arenitos e folhelhos (Xie e Shao, 2015). As rochas chalk são comumente observadas em explorações da indústria petrolífera, principalmente no Mar do Norte. Como resultado da alta porosidade e do seu comportamento mecânico, as rochas chalk podem atingir a ruptura pelo cisalhamento o sofrer colapso de poros. Alguns modelos elastoplásticos desenvolvidos para representar este tipo de comportamento são os modelos de Mohr-Coulomb e Druker-Prager com fechamento tipo Cap, além do Cam Clay Modificado (Zhang et al., 2017). No caso de rochas areníticas, com porosidade média de $17 \%$, diversos modelos foram desenvolvidos modificando a superfície de escoamento do modelo Drucker-Prager (Zhang et al., 2013; Xie e Shao, 2015; Zhang et al., 2015; Wang et al., 2017). Estes modelos incluem o parâmetro que representa a coesão da rocha. Com base nos resultados dos ensaios, os autores concluem que o comportamento mecânico das rochas porosas depende fortemente da pressão de confinamento e porosidade total, entre outros.

De acordo com Shen e Shao (2017) o comportamento macroscópico das rochas sedimentares, como deformações plásticas, compressibilidade volumétrica e dilatância, depende fortemente da evolução de sua microestrutura, que inclui poros, microfissuras e inclusões de minerais. Nesse sentido, Pietruszczak et al., (2002); Shen e Shao, (2015) desenvolveram modelos constitutivos elastoplásticos, considerando o comportamento macroscópico, para a rocha Tournemire shale com porosidade de $15 \%$. No caso da rocha lixhe chalk, uma rocha sedimentar composta por carbonato de cálcio, comum nos reservatórios do mar no norte e com porosidade até $43 \%$, os autores Shen e Shao (2016) desenvolveram um modelo elastoplástico com regra de fluxo não associado, baseado na superfície de Drucker-Prager, incorporando macro e micro porosidades. No caso da rocha sedimentar carbonática Haubourdin chalk, com porosidade de 45\%, os autores Zhang et al., (2017) usaram o modelo Breakage, acoplando o colapso de poro à superfície de cisalhamento com o objetivo de 
capturar a degradação da microestrutura induzida pelo macro comportamento. Outros autores como (Shen et al., 2013) desenvolveram um modelo elastoplástico para as rochas clayey, com porosidade entre $11 \%$ e $13.84 \%$, considerando a macroporosidade. Neste caso eles afirmam que o modelo com fluxo associado não representa corretamente as deformações plásticas volumétricas e a dilatância da rocha, já que o material apresentou novas fissuras com o incremento do carregamento. Neste caso, o dano é um importante parâmetro que deve ser relacionado ao acréscimo das microfissuras das rochas. O autor Zhu (2017) desenvolveu um modelo de dano baseado na micromecânica e termodinâmica para representar o comportamento de rochas porosas. Este modelo descreve a rocha como sendo um material constituído por três fases: o esqueleto da rocha, onde não há porosidade, os poros iniciais e as novas fissuras. Os resultados indicam que o incremento da porosidade gera um decréscimo da resistência, enquanto as inclusões de minerais geram um ganho desta.

Buscando uma melhor representação do comportamento mecânico de rochas sedimentares, alguns modelos de estado crítico incluem modificações na função de escoamento e nas variáveis internas. Assim, os modelos desenvolvidos por Mohamadi et al., (2017) incorporam parâmetros como o ângulo de atrito e de dano, para modelar a desestruturação do meio poroso, cujo objetivo é prever melhor os efeitos de compressão e dilatância do material. Além disso, outros autores, como Ma (2016), incluem parâmetros como tensões efetivas e sucção para representar a resposta elastoplástica de rochas porosas chalk com porosidade total de $34 \%$.

Além das tensões, a resistência da rocha depende de outros fatores, como a temperatura. Uma variação da temperatura pode aumentar ou diminuir a resistência da rocha. De acordo com Zhang et al., (2012), que formulou um modelo termo-elastoplástico para representar o comportamento termo-mecânico de rochas com resistência à compressão simples menor a $20 \mathrm{MPa}$, conclui que a tensão máxima desviadora diminui com o incremento da temperatura. Okada (2005) desenvolveu um estudo experimental para rochas sedimentares (siltito, arenito e mudstone) com pouca resistência à compressão, com temperaturas entre $24^{\circ} \mathrm{C}$ e $60^{\circ} \mathrm{C}$. Os resultados indicaram que a resistência das rochas decresce aos $60 \stackrel{\circ}{ } \mathrm{C}$, tendo sido observado um pequeno aumento da rigidez para o siltito e mudstone. Geralmente, esses modelos são complexos pela formulação termodinâmica acoplada ao meio contínuo. Modelos de estado crítico, como Cam Clay Modificado, possuem extensões à formulação termodinâmica e aplicações 
para rochas sedimentares (Zhang e Zhang, 2009; He et al., 2017). Para determinar os parâmetros dos modelos termo-elastoplásticos, pode-se empregar os ensaios convencionais triaxiais à compressão a diferentes temperaturas. Neste trabalho não se considera a variação da temperatura na determinação da resistência da rocha carbonática travertino, mas pode ser válido para trabalhos futuros.

\subsection{2.}

\section{Modelos anisotrópicos em rochas sedimentares}

A rocha carbonática travertino, devido ao seu processo de deposição, apresenta um comportamento transversalmente isotrópico. Neste caso, o material exibe propriedades simétricas em um plano isotrópico perpendicular ao eixo com propriedades anisotrópicas. Na Figura 2 pode ser observado o plano isotrópico no plano $\mathrm{X}$-Z e o eixo $\mathrm{Y}$ ortogonal ao plano isotrópico com propriedades anisotrópicas.

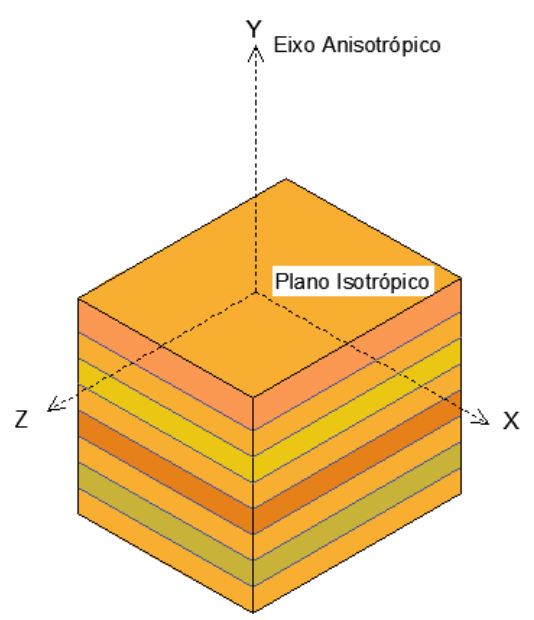

Figura 2 Plano transversalmente isotrópico das rochas sedimentares

Segundo (Fjar et al., 2008) existem dois tipos de anisotropia: intrínseca, que está relacionada à microestrutura e deposição das camadas da rocha; e anisotropia induzida, causada pelas forças externas como microfissuras geradas por tensões desviadoras. De acordo com François et al., (2011a) a maioria das rochas sedimentares mostra um comportamento anisotrópico intrínseco ou inerente, relacionado com o plano de deposição das camadas. Nesse caso, as deformações dependem da orientação das tensões aplicadas com relação ao acamamento. Karakul et al., (2010) executou numerosos ensaios de laboratório em rochas sedimentares como limestone, arenito, folhelho e travertino, variando o ângulo entre a direção de carregamento e a orientação das camadas. O estudo concluiu que os valores mais baixos de resistência à compressão simples (UCS) ocorrem para os casos em que o ângulo entre a direção de acamamento em 
relação ao eixo de carregamento aplicado é $\beta=30^{\circ}$. Niandou et al., (1997) realizou numerosos ensaios triaxiais de compressão com amostras de rocha sedimentar Tournemire shale a diferentes pressões de confinamento variando a orientação das camadas em relação ao eixo de carregamento, $\beta$ entre $0^{\circ}$ até $90^{\circ}$. O estudou mostrou que a resistência é maior quando o carregamento é aplicado a ângulos $\beta=0^{\circ}$ e $\beta=90^{\circ}$, enquanto a mínima resistência é usualmente obtida entre $\beta=30^{\circ}$ e $\beta=60^{\circ}$. Pietruszczak (2010) chegou à mesma conclusão, no entanto, ele concluiu que a resistência depende também da tensão de confinamento, microestrutura e do plano de ruptura. Na Figura 3 é apresentado o esquema de variação da resistência com relação ao acamamento realizado por (Pietruszczak, 2010) baseado nos resultados experimentais de (Niandou et al., 1997).

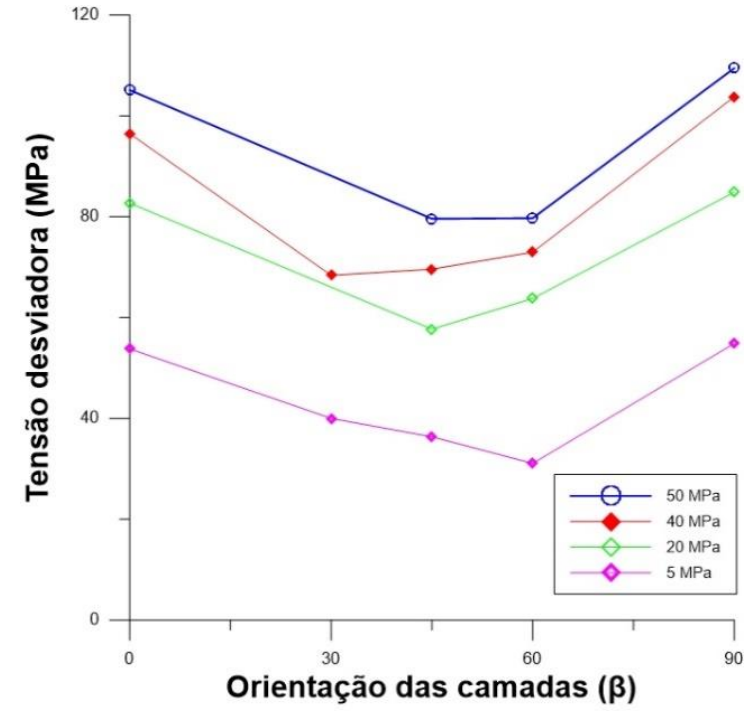

(a)

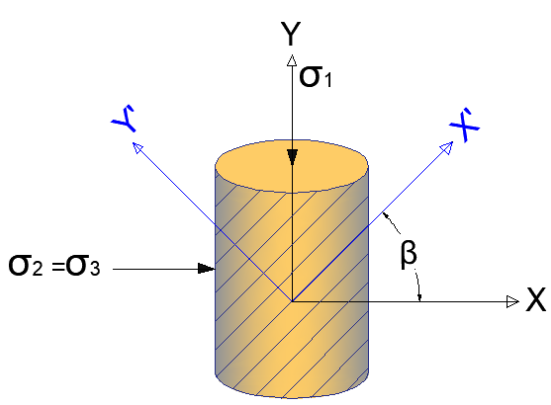

(b)

Figura 3 Ensaios triaxiais com amostra de rocha sedimentar Tournemire shale (Pietruszczak, 2010). (a) Variação da tensão desviadora com diferentes tensões de confinamento e orientação das camadas; (b) corpo de prova com orientação das camadas em relação ao eixo axial, ângulo $\beta$.

A Figura 4 ilustra, esquematicamente, os corpos de provas ensaiados, indicando o ângulo entre o eixo axial e o plano de acamamento, além da condição de confinamento e do mecanismo de ruptura. Os ensaios indicaram que, para $15^{\circ} \leq \beta \leq 65^{\circ}$, as amostram apresentaram menores resistências porque, 
geralmente, a ruptura cisalhante coincide com o plano de inclinação das camadas, o que é comum quando submetidos a baixas pressões de confinamento. No entanto, com o aumento da pressão de confinamento, o ângulo de inclinação do plano de ruptura é alterado. Ainda assim, estes ângulos $15^{\circ} \leq \beta \leq 65^{\circ}$ continuam apresentando menor resistência. Por outro lado, na Figura 4 pode-se observar que, para ângulos entre $65^{\circ} \leq \beta \leq 90^{\circ}$, o plano de ruptura depende fortemente da pressão de confinamento. Para altas tensões de confinamento, geralmente a rocha apresenta uma ruptura cisalhante que não coincide com a orientação do acamamento, gerando um aumento da resistência da rocha. No caso contrário, a baixas tensões de confinamento, onde o plano de ruptura é paralelo ao acamamento, $\beta=90^{\circ}$, observa-se menor resistência na rocha. De acordo com Pietruszczak (2010), quando o carregamento aplicado é paralelo ao acamamento, a ruptura é associada a uma diminuição da coesão das camadas no caso de baixas tensões confinantes. Mas, para altas tensões de confinamento, a coesão aumenta e ocorre ruptura cisalhante, como pode-se evidenciar na Figura 4 para $65^{\circ} \leq \beta \leq 90^{\circ}$. Sendo $\beta$ variação das camadas com respeito ao eixo axial e varia entre eixos globais $X-Y-Z$ e locais $X^{\prime}-Y^{\prime}-Z^{\prime}$.

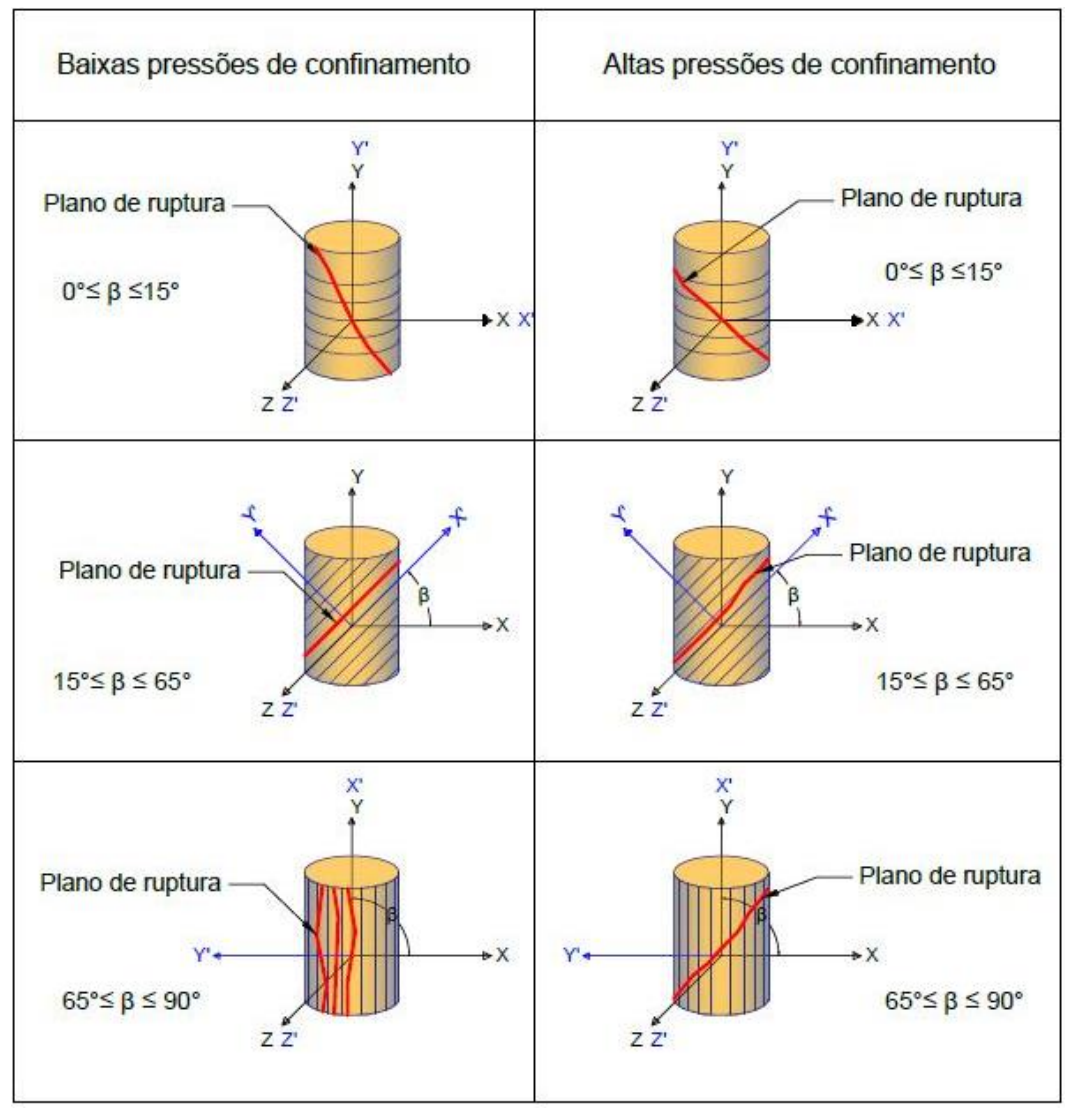

Figura 4 Mecanismos de rupturas típicos com variação do acamamento e tensão de confinamento (Pietruszczak, 2010). 
O comportamento anisótropico intrínseco das rochas sedimentares está relacionado ao comportamento microestrutural que pode ser representado por um tensor de segunda ordem. De acordo com (Pietruszczak et al., 2002), que desenvolveram uma formulação anisotrópica para a rocha Tournemire shale, este tensor de segunda ordem é constituído pelo tensor das tensões e um parâmetro escalar anisótropico. Este parâmetro escalar anisotrópico, inicialmente incorporado em critérios de ruptura por Pietruszczak e Mroz (2000), relaciona a direção de carregamento com a direção da anisotropia. Além disso, o comportamento geomecânico transversalmente isotrópico das rochas sedimentares pode ser representado por rotação de tensões no plano triaxial. Neste caso, o Modelo constitutivo transversalmente isotrópico de Lade-Kim (Abelev e Lade, 2003; Abelev e Lade P, 2004; Abelev et al., 2007; Lade, 2007; Lade, 2008), baseado no modelo isotrópico e formulado no espaço das tensões, usa a rotação do sistema de coordenadas dos eixos principais. Assim, quando o carregamento é aplicado, as superfícies de escoamento e potencial plástico crescem e rotacionam, semelhante ao endurecimento cinemático (Lade et al., 2009; Wei e Zhu, 2013). Neste caso, o comportamento anisotrópico pode ser observado no plano desviador na Figura 5 mediante a variação do Ângulo de Lode $\theta$. De acordo com (Abelev et al., 2007), geomateriais mostram maior comportamento anisotrópico para valores no setor II, $60^{\circ} \leq \theta \leq 120^{\circ}$, e no setor III, $120^{\circ} \leq \theta \leq 180^{\circ}$. Mortara (2010) modificou a superfície de escoamento de modelos constitutivos como Matsuoka-Nakai e Lade-Duncan através do ângulo de Lode, representando o comportamento isotrópico e transversalmente isotrópico no plano desviador de materiais rochosos.

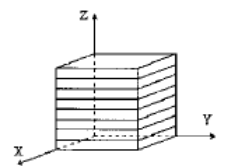

(a)

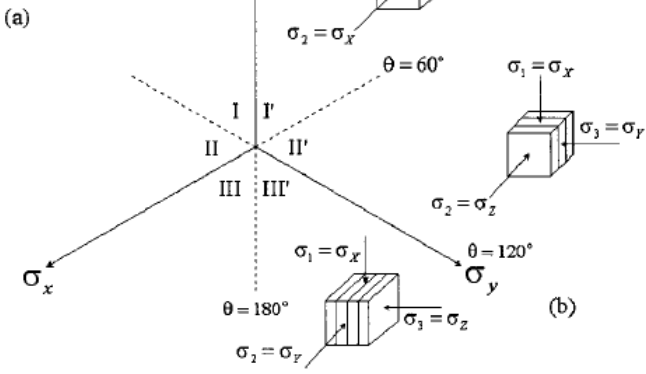

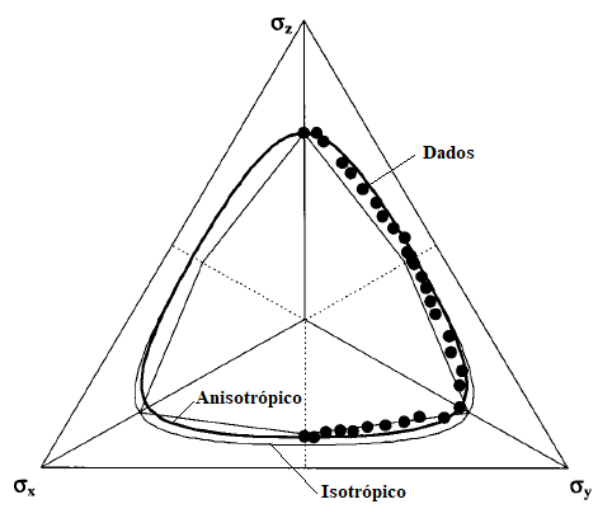

Figura 5 Anisotropia transversal para areia Santa Monica no plano desviador (Abelev A e Lade P, 2004). 
Neste trabalho, a incorporação da anisotropia no modelo Lade-Kim é baseada no critério anisótropico desenvolvido por (Mánica et al., 2016). Neste caso, ocorre uma transformação do tensor de tensões de eixos globais (X-Y-Z) à eixos locais ( $\left.X^{\prime}-Y^{\prime}-Z^{\prime}\right)$, através da matriz de rotação apresentada a seguir.

$$
\begin{gathered}
{\left[\sigma^{r}\right]=\left[M_{R}\right][\sigma]\left[M_{R}\right]^{T}} \\
{\left[M_{R}\right]=\left[\begin{array}{ccc}
\cos \beta \cos \alpha_{r} & \sin \beta & -\cos \beta \sin \alpha_{r} \\
-\cos \alpha_{r} \sin \beta & \cos \beta & \sin \beta \sin \alpha_{r} \\
\sin \alpha_{r} & 0 & \cos \alpha_{r}
\end{array}\right]}
\end{gathered}
$$

Sendo $\sigma^{r}$ o tensor de tensões rotacionadas, $\sigma$ é o tensor de tensões, $M_{R}$ é a matriz de rotação, $\beta$ e $\alpha_{r}$ ângulos responsáveis pela rotação dos eixos $\mathrm{Z}$ e $\mathrm{Y}$, respectivamente. No presente trabalho, $\alpha_{r}=0$, o qual indica que a rotação ocorre só no ângulo $\beta$ do eixo Z. Na Figura 6 é apresentada a variação do ângulo $\beta$ com respeito aos eixos globais $X-Y-Z$ e locais $X^{\prime}-Y^{\prime}-Z^{\prime}$, usados na rotação de tensões.
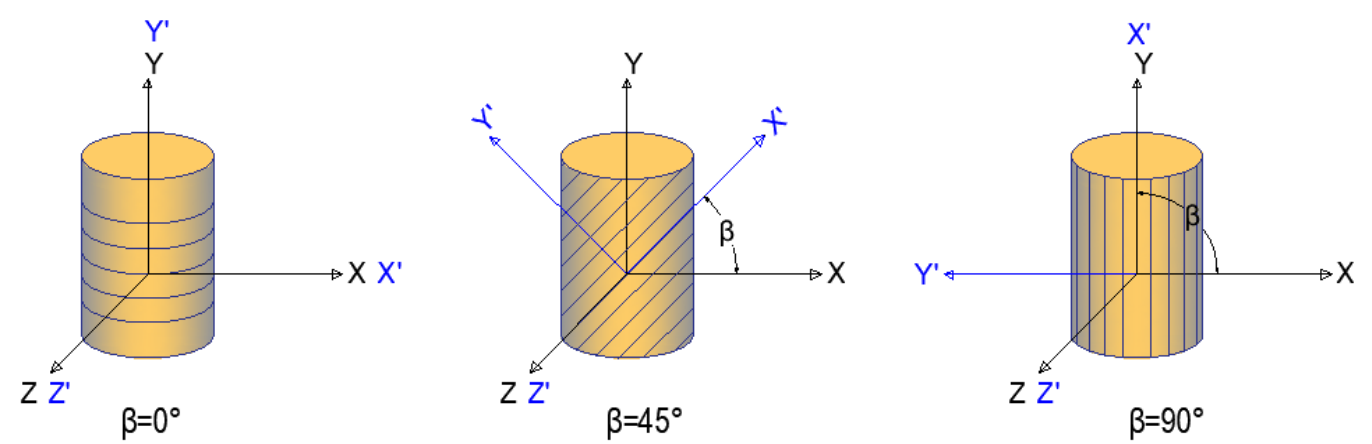

Figura 6 Orientação das camadas com relação aos eixos globais (X-Y-Z) e os eixos locais $\left(X^{\prime}-Y^{\prime}-Z^{\prime}\right)$.

De acordo com (Mánica et al., 2016) o tensor anisotrópico é formado pelo tensor de tensões rotacionado e por dois fatores de escala não uniforme, $C N$ e $C S$, onde o primeiro é o fator de escala das tensões normais, e o segundo é o fator de escala das tensões cisalhantes. Pode-se observar na Figura 7 os efeitos do escalonamento com o modelo constitutivo perfeitamente plástico MohrCoulomb no espaço das tensões principais. Assim, quando as direções globais e locais coincidem e os componentes das tensões normais são as tensões principais, observa-se que uma redução de $C N$ gera um acréscimo da resistência 
na direção do eixo anisótropico Y e vice-versa. Na equação (2.3) é apresentada o tensor anisótropico $\sigma^{A n i}$.

$$
\left[\sigma^{A n i}\right]=\left[\begin{array}{ccc}
\frac{\sigma_{11}^{r}}{C N} & C S \sigma_{12}^{r} & \sigma_{13}^{r} \\
C S \sigma_{12}^{r} & C N \sigma_{22}^{r} & C S \sigma_{23}^{r} \\
\sigma_{13}^{r} & C S \sigma_{23}^{r} & \frac{\sigma_{33}^{r}}{C N}
\end{array}\right]
$$

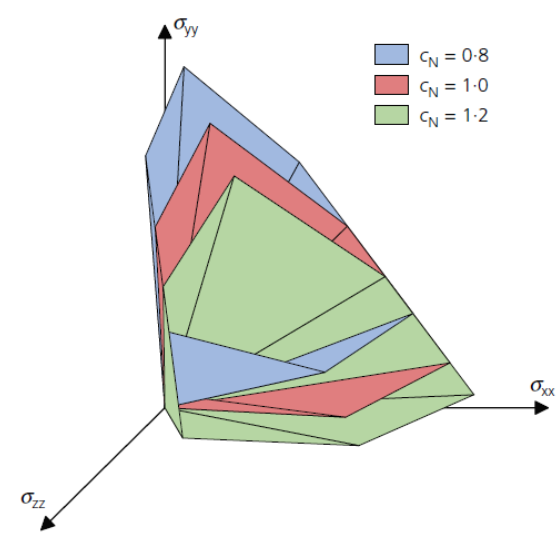

Figura 7 Escalonamento da superfície de escoamento do modelo constitutivo MohrCoulomb (Mánica et al., 2016).

O tensor anisotrópico é responsável pela variação da resistência. Assim, usando os dois fatores de escala $C N$ e $C S$, que controlam as tensões normais e cisalhantes, respectivamente, o modelo anisótropico tem a capacidade de determinar a resistência com a variação do ângulo $\beta$, o qual correspondente à inclinação do plano das camadas com relação ao eixo anisotrópico. Neste caso, quando $\beta=0^{\circ}$ o plano das camadas isotrópico é perpendicular à direção do carregamento, e quando $\beta=90^{\circ}$ o plano das camadas isotrópico é paralelo ao carregamento. Quando os valores dos parâmetros de escala $C N$ e $C S$ são iguais à unidade, independente da variação do ângulo $\beta$, o modelo sempre é Isotrópico.

O tensor anisótropico atua mudando o critério de escoamento e os gradientes das funções potencial plástica e de escoamento, sem mudanças no critério elástico do modelo. O critério anisótropico pode ser aplicado a qualquer modelo constitutivo elastoplástico com endurecimento isotrópico. No capítulo 3, será aprofundada a incorporação da anisotropia dos gradientes potencial plástico e de escoamento do modelo constitutivo elastoplástico isotrópico Lade-Kim. 


\section{2.}

\section{Fundamentos da plasticidade}

Nesta seção serão definidos os conceitos básicos fundamentais da plasticidade para o desenvolvimento dos modelos constitutivos. Serão brevemente abordados temas como função de escoamento, lei de endurecimento, regra de fluxo e função potencial plástica.

\subsection{1.}

\section{Função de escoamento}

Define o limite entre o comportamento elástico e plástico de um material. A função de escoamento está relacionada ao estado de tensões e seu tamanho pode variar quando os parâmetros de endurecimento e amolecimento estão presentes.

$$
F=f(\{\sigma\})=0
$$

Admitindo-se que um material seja isotrópico e homogêneo, a função de escoamento $F$ pode ser simplificada em termos das tensões principais ou em termos dos invariantes das tensões.

$$
\begin{aligned}
& F=f\left(\sigma_{1}, \sigma_{2}, \sigma_{3}\right)=0 \\
& F=f\left(\mathrm{I}_{1}, \mathrm{I}_{2}, \mathrm{I}_{3}\right)=0
\end{aligned}
$$

Quando $F<0$, o comportamento é elástico, quando $F=0$ ocorre comportamento elástico ou elastoplástico. Para $F>0$ o estado de tensões é inadmissível e deve ser retornado à superfície de escoamento. A Figura 8 ilustra esses cenários.

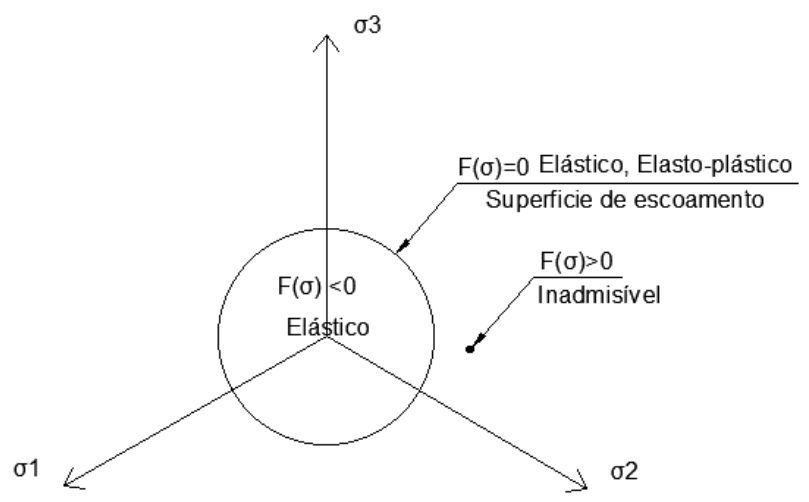

Figura 8 Superfície de escoamento, estado de tensões elástico e elastoplástico. 


\subsection{2.}

\section{Lei de endurecimento e amolecimento}

O parâmetro de endurecimento/amolecimento $h_{a}$ representa a variação da magnitude do estado de tensões da superfície de escoamento, que passa a ser expressa não somente em função das tensões. Abaixo apresenta-se a formulação matemática da superfície de escoamento.

$$
F=f(\{\sigma\})-f\left(h_{a}\right)=0
$$

De acordo com (Pietruszczak, 2010), um material tem endurecimento perfeitamente plástico quando o parâmetro $h_{a}$ é constante. Nesse caso, quando o estado de tensões atinge a superfície de escoamento, as deformações plásticas continuam crescendo, enquanto as tensões permanecem constantes. Critérios clássicos de ruptura como Mohr-Coulomb, Druker-Prager, Tresca e Von Mises estão nesta categoria "perfeitamente plásticos", onde a forma, tamanho e rotação da superfície de escoamento permanecem sem variações durante a deformação plástica. A Figura 9 representa este comportamento.

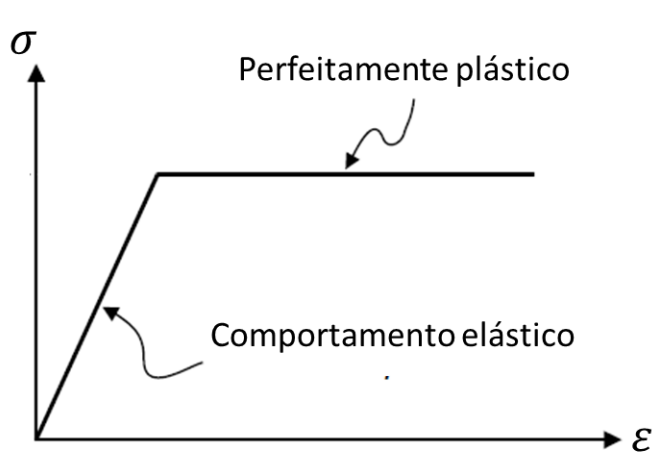

(a)

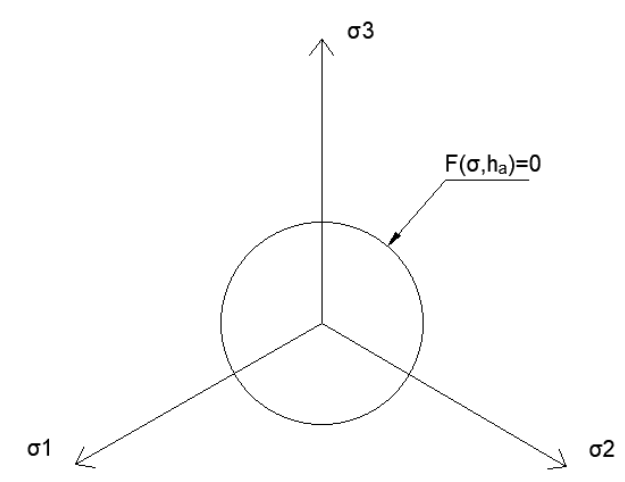

(b)

Figura 9 Endurecimento perfeitamente plástico. (a) plano tensão vs. deformação e (b) plano desviador.

O endurecimento isotrópico ocorre quando existe um incremento acumulado de deformações plásticas $\varepsilon^{p}$ ou trabalho plástico $W_{p}$. O tamanho da superfície se expande ou contrai no espaço de tensões com o carregamento, mas a superfície conserva sua forma, e sua posição no centro não muda, como ilustrado na Figura 10.

Em termos de deformação plástica: 


$$
F=f(\{\sigma\})-f\left(\varepsilon^{p}\right)=0
$$

Em termos de trabalho plástico:

$$
F=f(\{\sigma\})-f\left(W_{p}\right)=0
$$

O Modelo elastoplástico CCMC usa os incrementos de deformação plástica como parâmetro de endurecimento, enquanto, o modelo elastoplástico Lade-Kim usa o incremento de trabalho plástico total.

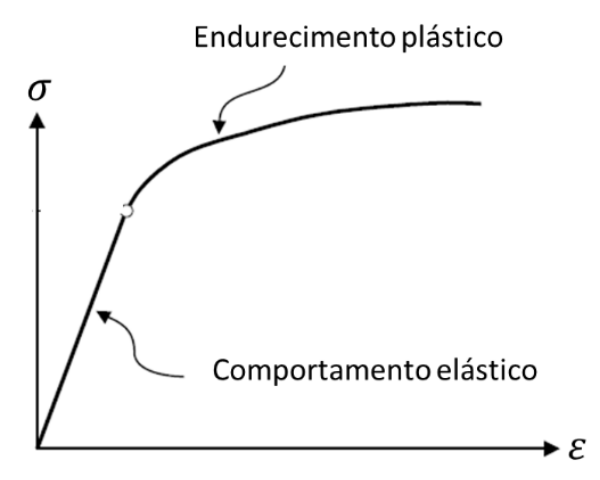

(a)

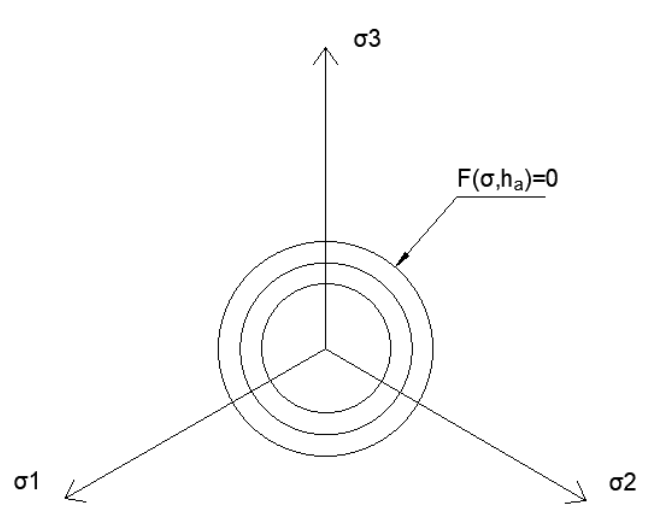

(b)

Figura 10 Endurecimento isotrópico, superfície de escoamento varia uniformente, (a) plano tensão vs. deformação e (b) no plano desviador.

O Endurecimento cinemático ocorre quando existe rotação da superfície de escoamento na direção do tensor de deformação plástica, sendo que a superfície conserva sua forma e o tamanho. O endurecimento cinemático é ilustrado na Figura 11.

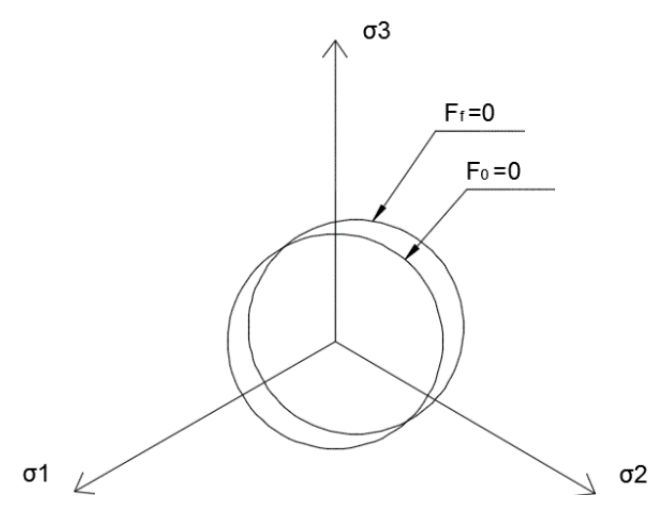

Figura 11 Endurecimento cinemático, superfície de escoamento não varia, mas é trasladada com a rotação, no plano desviador. 


\subsection{3.}

\section{Função potencial plástico e regra de fluxo}

O fluxo plástico ocorre quando um estado de tensões atinge a superfície potencial plástica. Nesse caso, os incrementos de deformação plástica, que são sempre perpendiculares à função potencial plástica, estão em função do multiplicador plástico e das derivadas da função de escoamento com respeito às tensões. Porém, é importante que, para que ocorra fluxo plástico, o multiplicador plástico seja sempre positivo.

$$
\left\{d \varepsilon^{p}\right\}=\Lambda\left\{\frac{\partial g_{p}}{\partial \sigma}\right\}
$$

Sendo $g_{p}$ a função potencial plástica, $d \varepsilon^{p}$ incrementos de deformação plástica e $\Lambda$ multiplicador plástico que controla a magnitude das deformações plásticas e está diretamente relacionado com as leis de endurecimento/amolecimento. A relação $\left\{\partial g_{p} / \partial \sigma\right\}$ controla a direção das deformações plásticas e os $d \varepsilon^{p}$ são normais à superfície de potencial plástico. A Figura 12 ilustra esses conceitos.

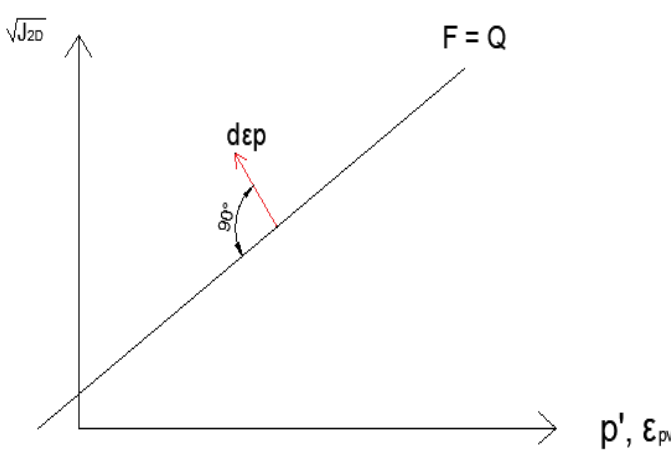

(a)

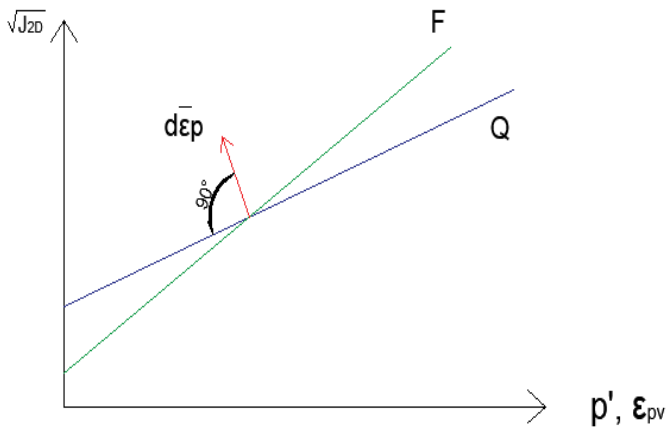

(b)

Figura 12 Fluxo associado (a), e fluxo não associado (b).

Caso a função de escoamento seja igual à função potencial plástica, o fluxo é dito associado, caso contrário, não associado. Neste último caso, fluxo de 
escoamento é controlado pelo ângulo de dilatância, sempre menor que o ângulo de atrito. Esta característica pode ser considerada como uma vantagem, já que permite que o modelo constitutivo represente melhor a transição do comportamento compressivo para dilatante das deformações volumétricas observadas em laboratório.

\subsection{4.}

\section{Formulação modelo elastoplástico isotrópico}

Os incrementos de deformações totais são compostos por duas parcelas, uma elástica e outra plástica.

$$
\{d \varepsilon\}=\left\{d \varepsilon^{e}\right\}+\left\{d \varepsilon^{p}\right\}
$$

Os incrementos de deformação elástica são determinados pela lei de Hooke. Incorporando a equação (2.10) na relação tensão-deformação pode-se obter

$$
\{d \sigma\}=\left[D^{e}\right]\left(\{d \varepsilon\}-\left\{d \varepsilon^{p}\right\}\right)
$$

onde $D^{e}$ é a matriz constitutiva elástica.

Os incrementos de deformação plástica são determinados pela regra de fluxo. A equação (2.12) é aplicada para o caso de regra de fluxo associado, enquanto a equação (2.13) aplica-se ao caso não-associado.

$$
\begin{aligned}
& \left\{d \varepsilon^{p}\right\}=\Lambda\left\{\frac{\partial F}{\partial \sigma}\right\} \\
& \left\{d \varepsilon^{p}\right\}=\Lambda\left\{\frac{\partial g_{p}}{\partial \sigma}\right\}
\end{aligned}
$$

onde $F$ é a função de escoamento e $g_{p}$ é a função potencial plástica. $\Lambda$ representa a magnitude do fluxo plástico. Quando o estado de tensões atinge a superfície de escoamento, deformações plásticas podem ocorrer:

$$
F(\sigma, \gamma)=0
$$


A função de escoamento $F$ pode ser expressa em termos das tensões ou invariantes das tensões e das variáveis internas $\gamma$. Deve-se cumprir a condição de irreversibilidade de fluxo plástico de Kuhn-Tuker, apresentada como:

$$
\Lambda \geq 0, F \leq 0, \Lambda F=0
$$

Quando ocorre deformações plásticas pela condição de consistência tem-se que $d F=0$, em termos de trabalho plástico e do tensor de tensões.

$$
d F=\left\{\frac{\partial f_{s}^{\prime}}{\partial \sigma}\right\}^{T}\{d \sigma\}+\frac{\partial f_{w}^{\prime \prime}}{\partial W_{p}} d W_{p}=0
$$

onde o incremento de trabalho plástico é dado em termos das tensões e dos incrementos de deformação plástica

$$
d W_{p}=\{\sigma\}^{T}\left\{d \varepsilon^{p}\right\}
$$

Substituindo (2.11), (2.13) e (2.17) em (2.16), temos

$$
d F=\left\{\frac{\partial f_{s}^{\prime}}{\partial \sigma}\right\}^{T}\left[D^{e}\right]\left(\{d \varepsilon\}-\Lambda\left\{\frac{\partial g_{p}}{\partial \sigma}\right\}\right)+\frac{\partial f_{w}^{\prime \prime}}{\partial W_{p}}\{\sigma\}^{T} \Lambda\left\{\frac{\partial g_{p}}{\partial \sigma}\right\}=0
$$

A partir da manipulação da equação (2.18), o multiplicador plástico pode ser obtido através de

$$
\Lambda=\frac{\left\{\frac{\partial f_{s}^{\prime}}{\partial \sigma}\right\}^{T}\left[D^{e}\right]\{d \varepsilon\}}{\left\{\frac{\partial f_{s}^{\prime}}{\partial \sigma}\right\}^{T}\left[D^{e}\right]\left\{\frac{\partial g_{p}}{\partial \sigma}\right\}-\frac{\partial f_{w}^{\prime \prime}}{\partial W_{p}}\{\sigma\}^{T}\left\{\frac{\partial g_{p}}{\partial \sigma}\right\}}
$$

Usando a equação (2.19) e a partir das equações (2.11) e (2.13), os incrementos de tensões podem ser atualizados através de:

$$
\{d \sigma\}=\left[D^{e}\right]\left(\{d \varepsilon\}-\Lambda\left\{\frac{\partial g_{p}}{\partial \sigma}\right\}\right)
$$

A partir da equação (2.20), sem os incremento de deformação, obtemos a matriz constitutiva elastoplástica $D^{e p}$, reponsável pela relação das tensões e deformações na parte plástica. 


$$
\left[D^{e p}\right]=\left[D^{e}\right]-\frac{\left[D^{e}\right]\left\{\frac{\partial g_{p}}{\partial \sigma}\right\}\left\{\frac{\partial f_{s}^{\prime}}{\partial \sigma}\right\}^{T}\left[D^{e}\right]}{\left\{\frac{\partial f_{s}^{\prime}}{\partial \sigma}\right\}^{T}\left[D^{e}\right]\left\{\frac{\partial g_{p}}{\partial \sigma}\right\}-\frac{\partial f_{w}^{\prime \prime}}{\partial W_{p}}\{\sigma\}^{T}\left\{\frac{\partial g_{p}}{\partial \sigma}\right\}}
$$

No final podemos usar a matriz constitutiva elastoplástica para atualizar os incrementos das tensões

$$
\{d \sigma\}=\left[D^{e p}\right]\{d \varepsilon\}
$$

Esta formulação isotrópica explícita é aplicada para desenvolvimento do modelo constitutivo Lade-Kim e, de forma similar, para o modelo CCMC (como será descrito nos itens 3.2.1 e 3.2.3).

\section{3.}

\section{Modelo elastoplástico isotrópico Lade-Kim}

O modelo constitutivo elastoplástico com uma única superfície de escoamento permite boa representação do comportamento de materiais com atrito, tais como areia, concreto e rocha (Kim e Lade, 1988; Lade e Kim, 1988 a; 1988 b). A superfície de escoamento é expressa em termos dos invariantes das tensões. O comportamento elástico é descrito através da lei de Hooke, enquanto uma lei de fluxo não associado determina o comportamento das deformações plásticas. O trabalho total plástico serve como parâmetro de endurecimento, usado para definir a localização e forma da superfície de escoamento. Uma função de escoamento descreve contornos de igual trabalho plástico (Lade, 2005).

\subsection{1.}

\section{Lei elástica}

Os incrementos de deformação elástica são calculados através da Lei de Hooke. Usando o módulo de Young a partir de cenários de carregamento e descarregamento, definido por Janbu (1963):

$$
E=K P_{a}\left(\frac{\sigma_{3}}{P_{a}}\right)^{n}
$$

onde $K$ e $n$ são parâmetros determinados a partir de um ensaio convencional triaxial de compressão, realizado com várias pressões de confinamento $\sigma_{3}$. O 
parâmetro $P_{a}$ é a pressão atmosférica expressa nas mesmas unidades de $E$ e $\sigma_{3}$ (Lade e Kim, 1988 b). Na literatura existe outra formulação (Lade e Kim, 1995; Lade, 2005) para expressar a variação não linear do módulo de Young com o estado de tensões:

$$
E=M_{e} P_{a}\left[\left(\frac{I_{1}}{P_{a}}\right)^{2}+6 \frac{1+v}{1-2 v}\left(\frac{J_{2}}{P_{a}^{2}}\right)\right]^{\lambda}
$$

onde $I_{1}$ é o primeiro invariante do tensor de tensões Equação (2.25) e $J_{2}$ é o segundo invariante do tensor de tensões desviadoras Equação (2.26), $M_{e}$ e $\lambda$ são parâmetros adimensionais, obtidos de ciclos de carregamento e descarregamento de um ensaio de compressão triaxial.

$$
I_{1}=\sigma_{x}+\sigma_{y}+\sigma_{z}
$$

$$
J_{2}=\frac{1}{6}\left(\sigma_{x}-\sigma_{y}\right)^{2}+\left(\sigma_{y}-\sigma_{z}\right)^{2}+\left(\sigma_{z}-\sigma_{x}\right)^{2}+\tau_{x y}{ }^{2}+\tau_{y z}{ }^{2}+\tau_{z x}{ }^{2}
$$

\subsection{2.}

\section{Critério de ruptura}

O critério de ruptura é expresso em termos de primeiro e terceiro invariantes do tensor de tensões.

$$
f_{n}=\left(\frac{I_{1}^{3}}{I_{3}}-27\right)\left(\frac{I_{1}}{P_{a}}\right)^{m}
$$

Na ruptura:

$$
f_{n}=\eta_{1}
$$

O parâmetro $m$ e $\eta_{1}$ são constantes adimensionais. $m$ varia com a curvatura da envoltória de ruptura, se $m>1.979$ ela será convexa em relação ao eixo hidrostático (Kim e Lade, 1984) o que tornaria ao modelo inconsistente. Numerosos ensaios utilizando amostras de concreto e de rocha indicam que $m$, normalmente, é menor que 1.5. O parâmetro $\eta_{1}$ controla a forma da superfície de 
ruptura. Assim, mantendo $m=$ cte e incrementando os valores de $\eta_{1}$, a forma da superfície de ruptura muda de circular para triangular. Para $m=0$ a forma da superfície de ruptura não muda com o valor de $I_{1}$. No caso que $m>0$, a superfície de ruptura passa de triangular para circular com incremento de valores de $I_{1}$ (Lade e Kim, 1988 b; Lade e Kim, 1995; Lade, 2005). Essas condições são ilustradas na Figura 13.

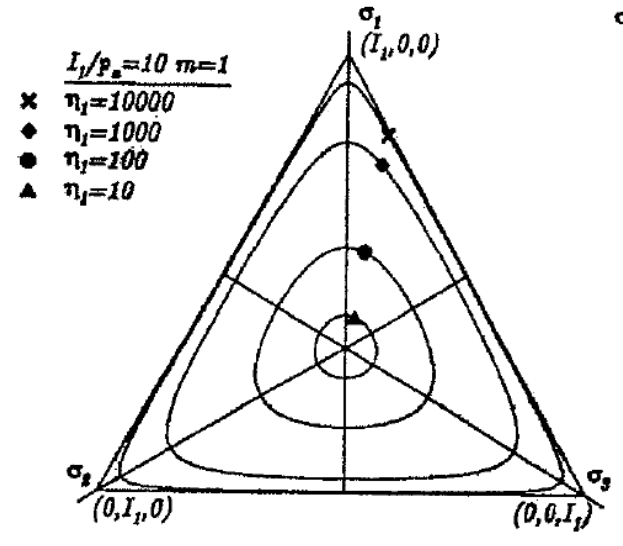

(a)

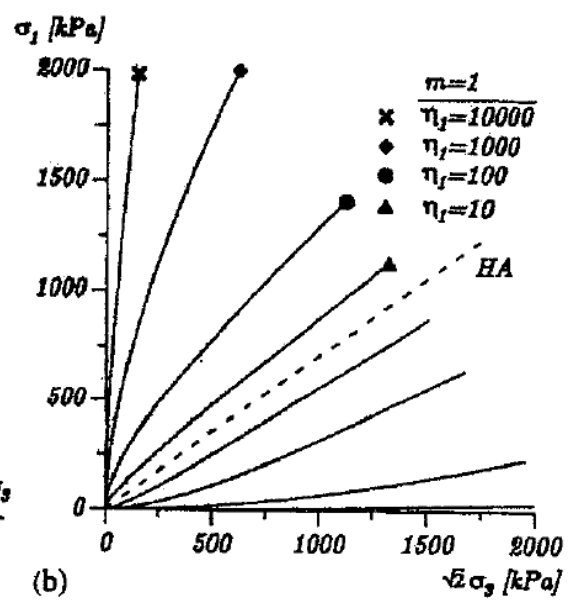

Figura 13 Critério de ruptura (a) plano octaédrico (b) plano triaxial.(Lade 2005).

A fim de incluir a coesão presente no concreto e rochas, autores como Kim e Lade (1984) propuseram a translação dos eixos de tensão principal ao longo do eixo hidrostático através da inclusão da constante $a P_{a}$, adicionada aos tensores de esforços principais:

$$
\{\bar{\sigma}\}=\{\sigma\}+a P_{a}
$$

onde $a$ é um parâmetro adimensional e $P_{a}$ é a pressão atmosférica nas mesmas unidades de $\sigma_{1}, \sigma_{2}$ e $\sigma_{3}$. O valor da constante $a P_{a}$ é aproximadamente o mesmo valor da tensão uniaxial à tração $\sigma_{t}$, frequentemente bem expressa por uma fração da tensão uniaxial à compressão $\sigma_{c}$ (Kim e Lade 1984), mediante a seguinte equação: 


$$
\sigma_{t}=T_{o} P_{a}\left(\frac{\sigma_{c}}{P_{a}}\right)^{t_{i}}
$$

A Figura 14 ilustra a translação dos eixos de tensão principal para consideração da coesão.

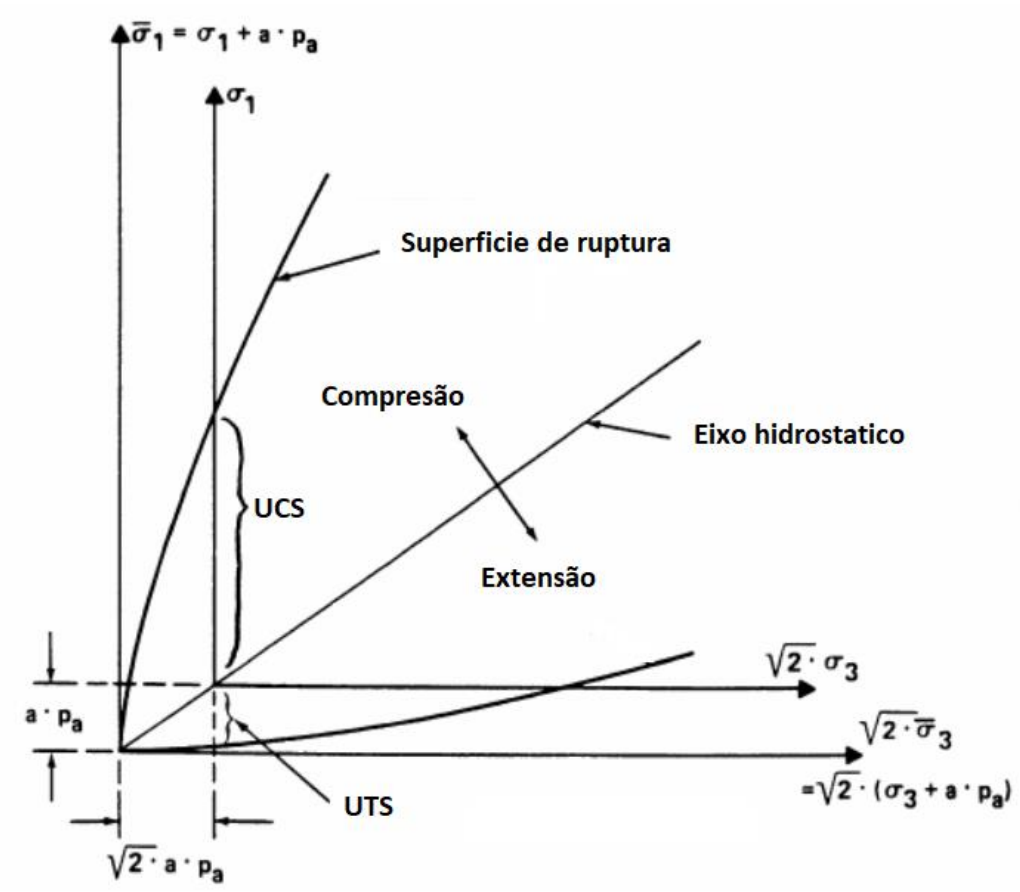

Figura 14 Translação das tensões principais ao comprimento do eixo hidrostático (Lade 2014).

Na Tabela 2 são apresentados os valores dos parâmetros adimensionais $T_{o}$ e $t_{i}$ que representam o melhor ajuste dos dados experimentais de materiais com coesão utilizando a equação (2.30).

Tabela 2 Valores de parâmetros $T_{o}$ e $t_{i}$ para vários tipos de materiais com atrito (Kim e Lade 1984)

\begin{tabular}{lcc}
\hline \multicolumn{1}{c}{ Materiais } & $\boldsymbol{T}_{\boldsymbol{o}}$ & $\boldsymbol{t}_{\boldsymbol{i}}$ \\
\hline Solos Cimentados & -0.37 & 0.88 \\
Concreto & -0.61 & 0.67 \\
Rochas Ígneas & -0.53 & 0.70 \\
Rochas Metamórficas & -0.00082 & 1.6 \\
Rochas Sedimentares & -0.22 & 0.75 \\
Cerâmica & -1.0 & 0.73 \\
\hline
\end{tabular}




\subsection{3.}

\section{Função potencial plástica}

De acordo com o fluxo não associado, a derivada da função potencial plástica é usada para determinar os incrementos de deformação plástica, equação (2.9). A função potencial plástica está em termos dos invariantes das tensões. Para materiais com coesão, deve ser feita a translação das tensões com relação a eixo hidrostático, o que tambiem se aplica ao critério de ruptura e à superfície de escoamento:

$$
g_{p}=\left[\psi_{1} \frac{I_{1}^{3}}{I_{3}}-\frac{I_{1}^{2}}{I_{2}}+\psi_{2}\right]\left(\frac{I_{1}}{P_{a}}\right)^{\mu}
$$

Os parâmetros $\psi_{2}$ e $\mu$ são constantes adimensionais. O parâmetro $\psi_{1}$ é relacionado ao parâmetro de curvatura $m$ do critério de ruptura (Kim e Lade, 1988).

$$
\psi_{1}=0.00155 m^{-1.27}
$$

O parâmetro $\psi_{1}$ define a forma de superfície no plano octaédrico e está relacionado com a curvatura dos meridianos $m$, além de atuar como um valor de ponderação entre a forma triangular e a forma circular, observada no plano octaédrico. O parâmetro $\psi_{2}$ controla a intersecção com o eixo hidrostático e $\mu$ determina a curvatura dos meridianos. $I_{1}$ e $I_{3}$ são o primeiro e terceiro invariantes do tensor de tensões, enquanto $I_{2}$, o segundo invariante de tensões, é dado por:

$$
I_{2}=\tau_{x y} \tau_{y x}+\tau_{y z} \tau_{z y}+\tau_{z x} \tau_{x z}-\left(\sigma_{x} \sigma_{y}+\sigma_{y} \sigma_{z}+\sigma_{z} \sigma_{x}\right)
$$

Observa-se na Figura 15 que a variação de volume para estados de tensão próximos ao eixo hidrostático é acentuadamente compressiva. Próximo à superfície de ruptura, a orientação dos vetores de deformação plástica indica comportamento dilatante. 


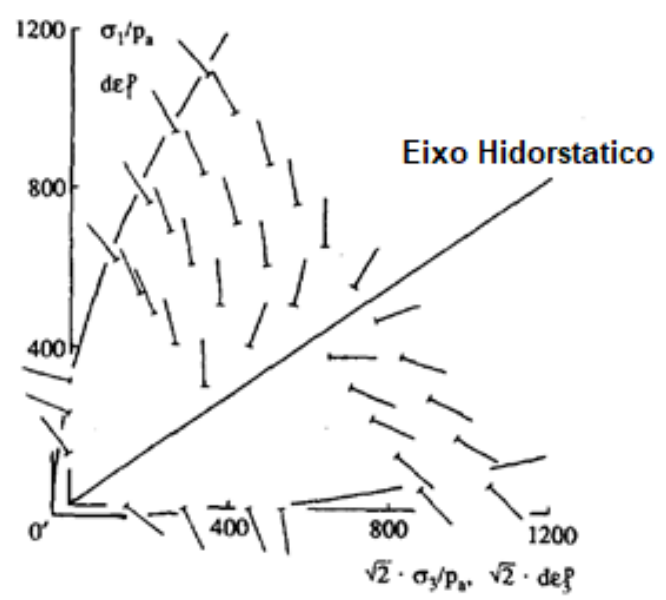

Figura 15 Superfície potencial plástica e incrementos de deformação plástica (Kim e Lade, 1988).

A taxa de variação plástica $v_{p}$ pode ser determinado pelo terceiro $d \varepsilon_{3}^{p} \mathrm{e}$ primeiro $d \varepsilon_{1}^{p}$ incremento de deformação plástica

$$
v_{p}=-\frac{d \varepsilon_{3}^{p}}{d \varepsilon_{1}^{p}}
$$

Os parâmetros $\psi_{2}$ e $\mu$ da função potencial plástico, equação (2.31) podendo ser determinados por regressão linear entre $\xi_{x}$ e $\xi_{y}$ a partir dos resultados dos ensaios triaxiais à compressão. Usando os incrementos de deformação plásticas definidos no Apendice II e a equação da variação plástica (2.34) na condição do ensaio triaxial a compressão $\sigma_{2}=\sigma_{3}$, obtém-se a seguinte relação:

$$
\begin{gathered}
\xi_{y}=\frac{1}{\mu} \xi_{x}-\psi_{2} \\
\xi_{x}=\frac{1}{1+v_{p}}\left[\frac{I_{1}^{3}}{I_{2}^{2}}\left(\sigma_{1}+\sigma_{3}+2 v_{p} \sigma_{3}\right)+\psi_{1} \frac{I_{1}^{4}}{I_{3}^{2}}\left(\sigma_{1} \sigma_{3}+v_{p} \sigma_{3}^{2}\right)\right]-3 \psi_{1} \frac{I_{1}^{3}}{I_{3}}+2 \frac{I_{1}^{2}}{I_{2}} \\
\xi_{y}=\psi_{1} \frac{I_{1}^{3}}{I_{3}}-\frac{I_{1}^{2}}{I_{2}}
\end{gathered}
$$

Os incrementos de deformação plásticos são calculados a partir de resultados de ensaios triaxiais de compressão pela subtração de incrementos de deformação elástica dos incrementos de deformação total. 


\subsection{4.}

\section{Função de escoamento}

A função de escoamento descreve os mesmos contornos do trabalho plástico. O procedimento foi implementado por Lade e Kim (1988 a) mediante a observação de ensaios de laboratório. Eles compararam os contornos de igual trabalho plástico com as curvas experimentais de escoamento. Este procedimento evita trajetórias de tensões complexas. A função de escoamento isotrópica $F$ é descrita por:

$$
F=f_{\mathrm{s}}^{\prime}(\{\sigma\})-f_{\mathrm{w}}^{\prime \prime}\left(W_{p}\right)=0
$$

onde a função de escoamento em termo das tensões é:

$$
f_{\mathrm{s}}^{\prime}=\left[\psi_{1} \frac{I_{1}^{3}}{I_{3}}-\frac{I_{1}^{2}}{I_{2}}\right]\left(\frac{I_{1}}{P_{a}}\right)^{h} e^{\prime q}
$$

Onde $e^{\prime}$ é a constante de Euler. O parâmetro $h$ assume um valor constante e $q$ depende do estado de tensoes. Durante a compressão isotrópica $q=0$, endurecimento $0<q<1$ e amolecimento $q=1$. O parâmetro $h$ pode ser determinado considerando-se dois pontos $A$ e $B$. O ponto $A$ no eixo hidrostático e $B$ na superfície de ruptura. A mesma superfície de escoamento possuem o mesmo valor de trabalho plástico, assim, pode-se determinar o valor de $h$ com as seguintes relações :

$$
\left[\psi_{1} \frac{I_{1 A}^{3}}{I_{3 A}}-\frac{I_{1 A}^{2}}{I_{2 A}}\right]\left(\frac{I_{1 A}}{P_{a}}\right)^{h} e^{q A}=\left[\psi_{1} \frac{I_{1 B}^{3}}{I_{3 B}}-\frac{I_{1 B}^{2}}{I_{2 B}}\right]\left(\frac{I_{1 B}}{P_{a}}\right)^{h} e^{1 q B}
$$

Se o ponto $A$ está no eixo hidrostático $q=0.0$; e para o ponto $B$ na superfície de ruptura $q=1.0$. Então:

$$
\begin{gathered}
\frac{I_{1}^{3}}{I_{3}} \geq 27,\left(-\frac{I_{1}^{2}}{I_{2}}\right) \geq 3 \text { No eixo hidrostático } \\
{\left[\psi_{1} \cdot 27+3\right]\left(\frac{I_{1 A}}{P_{a}}\right)^{h} e^{q A}=\left[\psi_{1} \frac{I_{1 B}^{3}}{I_{3 B}}-\frac{I_{1 B}^{2}}{I_{2 B}}\right]\left(\frac{I_{1 B}}{P_{a}}\right)^{h} e^{\prime}}
\end{gathered}
$$




$$
h=\frac{\log \frac{\left[\psi_{1} \frac{I_{1 B}^{3}}{I_{3 B}}-\frac{I_{1 B}^{2}}{I_{2 B}}\right] e^{\prime}}{\psi_{1} 27+3}}{\log \frac{I_{1 A}}{I_{1 B}}}
$$

O nível de tensões $S$ varia desde zero no eixo hidrostático até a unidade na superfície de ruptura. A relação de variação do parâmetro $q$ com cada nível de tensão $S$ é desenvolvida pelas seguintes expressões:

$$
\begin{gathered}
q=\ln \frac{\left(\frac{1}{D}\right)^{\frac{1}{\rho}}\left(\frac{W_{p}}{P_{a}}\right)^{\frac{1}{\rho}}}{\left[\psi_{1} \frac{I_{1}^{3}}{I_{3}}-\frac{I_{1}^{2}}{I_{2}}\right]\left(\frac{I_{1}}{P_{a}}\right)^{h}} \\
S=\frac{f_{n}}{\eta_{1}}=\frac{1}{\eta_{1}}\left(\frac{I_{1}^{3}}{I_{3}}-27\right)\left(\frac{I_{1}}{P_{a}}\right)^{m} \\
q=\frac{\alpha S}{1-(1-\alpha) S}
\end{gathered}
$$

O parâmetro $\alpha$ é uma constante do modelo. Na fase de endurecimento a superfície de escoamento aumenta isotropicamente com o trabalho plástico (Lade, 2005), de acordo com:

$$
\begin{gathered}
f_{\mathrm{w}}^{\prime \prime}=\left(\frac{1}{D}\right)^{\frac{1}{\rho}}\left(\frac{W_{p}}{P_{a}}\right)^{\frac{1}{\rho}} \\
D=\frac{C}{\left(27 \psi_{1}+3\right)^{\rho}}
\end{gathered}
$$

Onde $\rho=P / h$, os parâmetros $C$ e $P$ constantes do modelo, são usados para modelar o trabalho plástico $W_{p}$ durante a compressão isotrópica que produz deformações elásticas e plásticas. O trabalho plástico cresce monotonicamente com o aumento das tensões aplicadas, podendo ser modelado conforme a seguinte expressão: 


$$
W_{p}=C P_{a}\left(\frac{I_{1}}{P_{a}}\right)^{p}
$$

Outro aspecto importante é a verificação da violação da condição de irreversibilidade. Neste contexto, o trabalho plástico deve ser sempre positivo, caso uma mudança nas deformações plásticas ocorra (Kim e Lade, 1988).

$$
d W_{p}=\{\sigma\}\left\{d \varepsilon^{p}\right\}=\{\sigma\} \Lambda\left\{\frac{\partial g_{p}}{\partial \sigma_{i j}}\right\} \geq 0
$$

Para que isto aconteça é necessário que a superfície potencial plástico seja convexa em relação à origem dos espaços das tensões principais:

$$
\left\{\frac{\partial g_{p}}{\partial \sigma}\right\}\{\sigma\}=\mu g_{p}
$$

A condição de irreversibilidade requer que $\Lambda>0$ e que:

$$
\begin{gathered}
d W_{p}=\Lambda \mu g_{p} \quad \mu g_{p} \geq 0 \\
\frac{I_{1}^{3}}{I_{3}} \geq 27,\left(-\frac{I_{1}^{2}}{I_{2}}\right) \geq 3 \text { eixo hidrostático, } \frac{I_{1}}{P_{a}}>0 \\
\mu>0 \\
\psi_{2}>-\left(27 \psi_{1}+3\right)
\end{gathered}
$$

$\mathrm{Na}$ fase de amolecimento a superfície de escoamento decresce isotrópicamente e pode ser expressa como:

$$
f_{\mathrm{w}}^{\prime \prime}=A e^{-B \frac{W_{p}}{P_{a}}}
$$

No equação acima $A$ e $B$ são constantes positivas. A fase de amolecimento tem início quando $q=1$, ou seja , quando o nível de tensões alcança 
a superfície de ruptura. A Figura 16 apresenta as fases de endurecimento e amolecimento, como proposto por (Kim e Lade, 1988):

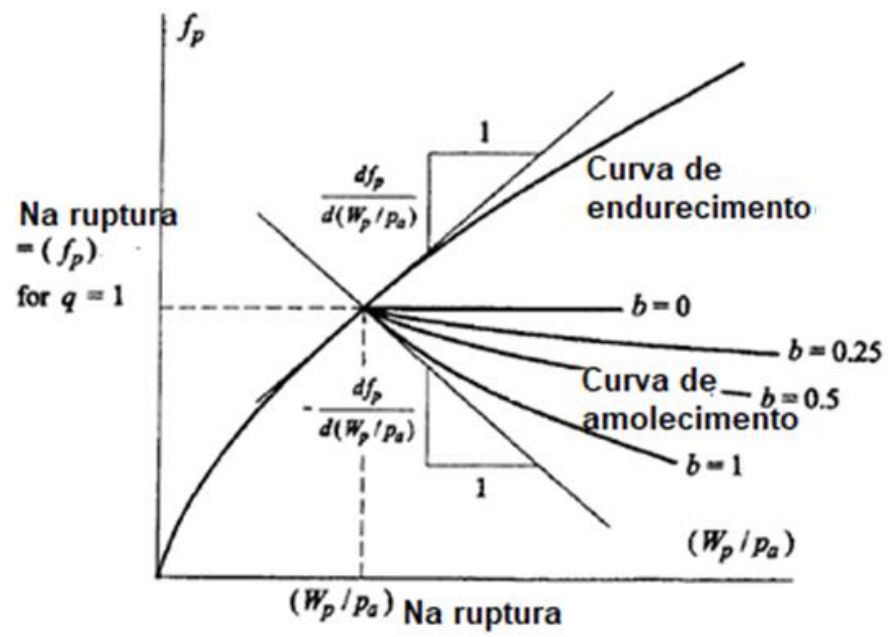

Figura 16 Modelo de endurecimento e de amolecimento (Kim e Lade, 1988).

Considerando que a curva de amolecimento intercepta a curva de endurecimento no ponto de ruptura, pode-se determinar os parâmetros $A$ e $B$.

$$
A=\left[f_{\mathrm{w}}^{\prime \prime} e^{B \frac{W_{p}}{P_{a}}}\right]_{S=1} ; B=\left[b \frac{d f_{\mathrm{w}}^{\prime \prime}}{d\left(\frac{W_{p}}{P_{a}}\right)} \frac{1}{f_{\mathrm{w}}^{\prime \prime}}\right]_{S=1}
$$

Finalmente, na Tabela 3 são apresentados os 12 parâmetros isotrópicos adimensionais utilizados no modelo de Lade-Kim. Tais parâmetros serão melhor discutidos e determinados no capítulo 4.

Tabela 3 Parâmetros do modelo Lade-Kim.

Modelo Elastoplástico Lade-Kim Parâmetros Isotrópicos

\begin{tabular}{|c|c|c|c|c|c|c|c|c|c|c|}
\hline \multicolumn{3}{|c|}{ Critério de Ruptura } & \multicolumn{3}{|c|}{$\begin{array}{c}\text { Comportamento } \\
\text { Elástico }\end{array}$} & \multicolumn{2}{|c|}{$\begin{array}{c}\text { Potencial } \\
\text { Plástico } \\
\text { (gp) }\end{array}$} & \multicolumn{2}{|c|}{$\begin{array}{l}\text { Parâmetro de } \\
\text { Endurecimento }\end{array}$} & $\begin{array}{c}\text { Função de } \\
\text { Escoamento }\end{array}$ \\
\hline$a$ & $m$ & $\eta_{1}$ & $K$ & $n$ & $v$ & $\psi_{2}$ & $\mu$ & $C$ & $P$ & $h$ \\
\hline
\end{tabular}




\section{4. \\ Modelo Cam Clay Modificado com Coesão (CCMC)}

Os modelos Cam Clay (Roscoe et al. 1963; Schofield and Wroth, 1968) e Cam Clay Modificado (Roscoe e Burland, 1968) são baseados na teoria de estado crítico. O modelo Cam Clay modificado (CCM) é um modelo elastoplástico formulado no espaço de tensões $\bar{P}-\bar{q}$, possui endurecimento isotrópico, regra de fluxo associada e duas superfícies de escoamento, sendo uma superfície de ruptura cisalhante e outra fechada que representa o colapso de poros, tipo CAP. Esses modelos representam adequadamente o comportamento geomecânico de materiais tais como argilas. Em seu trabalho (Ya et al., 2014) modificou o modelo CCM para o modelo Cam Clay Modificado com Coesão (CCMC), o qual se ajusta à superfície de escoamento do modelo Mohr-Coulomb mediante a variação do ângulo de Lode no plano desviador, incorporando o parâmetro de coesão, presente em rochas carbonáticas como o travertino. No Apêndice III são apresentadas as derivadas dos modelos CCM e CCMC implementados no programa FORTRAN 90.

\subsection{1.}

\section{Parâmetros elásticos}

Os modelos CCM e CCMC são modelos elásticos não lineares. A partir dos incrementos de deformações totais é possível obter as parcelas de deformações plásticas e elásticas. As deformações elásticas são obtidas pela relação constitutiva de Hooke $\{d \sigma\}=\left[D^{e}\right]\{d \varepsilon\}$. Para determinar o valor da matriz constitutiva elástica $\left[D^{e}\right]$ se deve calcular o módulo cisalhante $G$ e o módulo bulk $K_{b}$ :

$$
\begin{gathered}
G=\frac{3 K_{b}(1-2 v)}{2(1+v)} \\
K_{b}=\frac{(1+e) \bar{P}}{k^{\prime}}
\end{gathered}
$$

Como pode-se observar $G$ depende de $v$ e varia com o valor de $K_{b}$. No caso do parâmetro $K_{b}$, este varia com o estado de tensões hidrostáticas $\bar{P}$. 
Sendo $e$ o índice de vazios e $k^{\prime}$ a linha de descarregamento (LD), como indicado na Figura 17 b.

\subsection{2.}

\section{Superfície de escoamento CCM}

A superfície de escoamento $F$ do modelo CCM, formulada em função dos parâmetros $M$ e $P_{C}$, descreve uma elipse no espaço de tensões $\bar{P}-\bar{q}$. O parâmetro $M$ representa a inclinação da linha de estado crítico (LEC), enquanto a tensão de pré-adensamento $P_{C}$ determina o tamanho da superfície de escoamento no eixo hidrostático, indicado na Figura 17 a .

$$
F=\frac{\bar{q}^{2}}{M_{\theta}^{2}}+\bar{P}\left(\bar{P}-P_{C}\right)
$$

sendo $\bar{P}=\frac{I_{1}}{3}$ o estado de tensões hidrostáticas e $\bar{q}=\sqrt{\frac{3}{2}\left\{S_{c}\right\}^{T}\left\{S_{c}\right\}}$ o estado de tensões cisalhantes, $\left\{S_{c}\right\}=\{\sigma\}-\bar{P}$ o estado de tensões desviadoras e $P_{C}$ parâmetro de endurecimento.

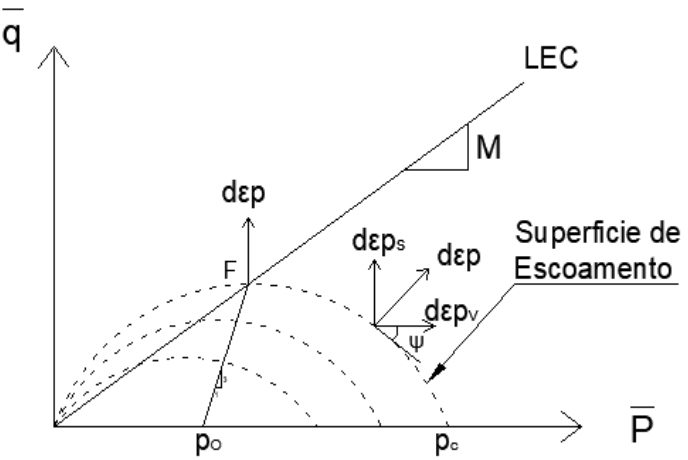

(a)

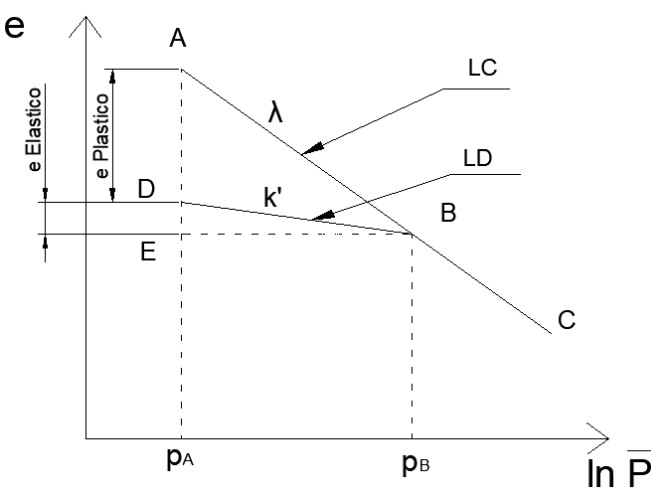

(b)

Figura 17 (a) Superfície de escoamento, (b) Índice de vazios vs. Ln P do modelo Cam Clay (Helwany, 2007).

Na Figura 17 a, observa-se que a trajetória de tensões atravessa várias linhas tracejadas que indicam uma superfície que vai se deslocando até atingir a ruptura, conhecida como estado crítico. Neste ponto o material não muda de 
volume, mas continua com deformação constante. Os materiais mais densos geralmente têm um comportamento inicialmente compressivo e depois tornam-se dilatante. O parâmetro de endurecimento é definido em função dos incrementos de deformação plástica volumétrica, o qual não depende das deformações plásticas desviadoras. Na Figura 17 b, pode-se observar o carregamento isotrópico na linha $A B$, seguido de um descarregamento na linha $B D$. Os índices de vazios elásticos ocorrem na parte do descarregamento $D E$, os quais indicam a variação de volume. Quando o material é novamente carregado, ele segue pelo seguimento $\mathrm{DB}$, continuando para o ponto $\mathrm{C}$.

\subsection{3.}

\section{Parâmetro de endurecimento $P c$}

A seguir são apresentas as formulações para obter o parâmetro de endurecimento $P_{C}$. É importante enfatizar que este parâmetro é considerado tanto para o modelo CCM, quanto para o CCMC.

$$
\begin{gathered}
d e=e-\lambda \ln \left(\frac{\bar{P}}{P_{C}}\right) \\
d e^{e}=e-k^{\prime} \ln \left(\frac{\bar{P}}{P_{C}}\right) \\
d e^{p}=-(1+e)\left\{d \varepsilon_{v}^{p}\right\}
\end{gathered}
$$

Sendo $\lambda$ a inclinação da linha de consolidação (LC), $k^{\prime}$ a inclinação da linha de dilatação (LD) ou descarregamento, observados na Figura 17b. de é o incremento de índice de vazios plástico e $d e^{e}$ é o incremento de índice de vazios elástico. Substituindo as equações (2.59) e (2.60) em (2.61), é obtido o parâmetro de endurecimento $p_{c}$

$$
P_{c}=P_{c n} \exp ^{\left(X\left\{d \varepsilon_{v}^{p}\right\}\right)}
$$

onde $X=\frac{1+e}{\lambda-k^{\prime}}, P_{c n}$ é o parâmetro de endurecimento do passo anterior e $\left\{d \varepsilon_{v}^{p}\right\}$ é o incremento de deformação plástica volumétrica. 


\subsection{4.}

\section{Superfície de escoamento CCMC}

A superfície de escoamento do modelo CCM é a mesma do modelo CCMC, descrito pela equação (2.58). De acordo com (Ya et al., 2014), a superfície do modelo CCMC pode ser ajustada à do modelo de Mohr-Coulomb através das seguintes relações:

$$
\begin{gathered}
\bar{P}=\bar{P}+C^{*} \cot \phi \\
P_{c}=P_{c}+C^{*} \cot \phi \\
M\left(\theta_{\sigma}\right)=\frac{3 \sin \phi}{\sqrt{3} \cos \theta_{\sigma}+\sin \phi \sin \theta_{\sigma}} \\
\theta_{\sigma}=\frac{1}{3} \sin ^{-1}\left(-\frac{3 \sqrt{3}}{2} \frac{J_{3}}{\sqrt{J_{2}^{3}}}\right)
\end{gathered}
$$

onde $C^{*}$ representa a coesão, $\phi$ é ângulo de atrito, $\theta_{\sigma}$ é o Ângulo de Lode, que varia entre $-30^{\circ} \leq \theta_{\sigma} \leq 30^{\circ}, J_{2}$ e $J_{3}$ são o segundo e terceiro invariantes das tensões desviadoras. Na Figura 18 pode-se observar o deslocamento da LEC, sobre o eixo hidrostático, representando a coesão do material.

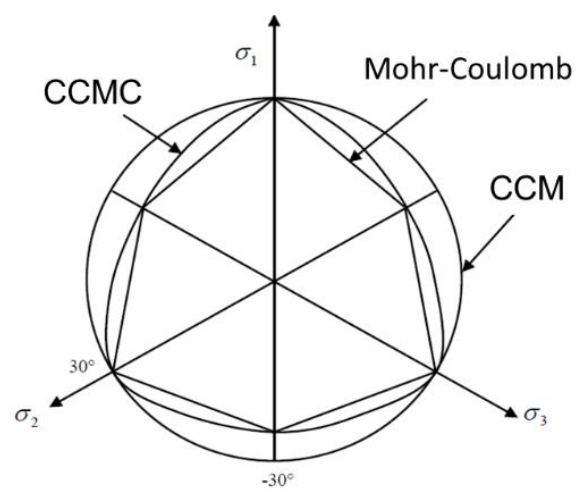

(a)

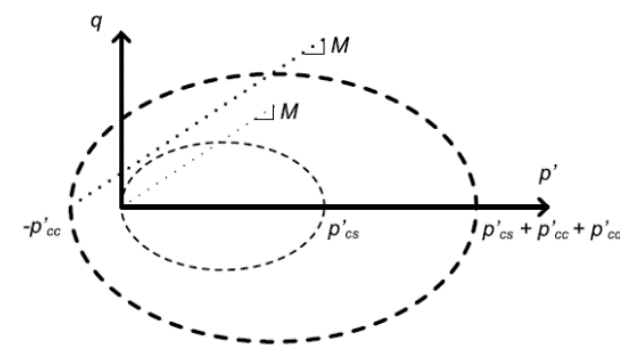

(b)

Figura 18 (a) função de escoamento do Cam Clay Modificado com coesão, no plano octaédrico (Ya et al., 2014); (b) superfície de escoamento com coesão no espaço de tensões p-q (Uchida et al., 2012).

Na função de escoamento, $M$ é definido em função do ângulo de Lode e determina a inclinação da linha de estado crítico. Quando $\theta_{\sigma}=30^{\circ}$ os modelos CCM 
e CCMC convergem. Neste caso, $M\left(\theta_{\sigma}\right)=M$, podendo ser determinado através da equação (2.65) do modelo CCM. Caso contrário, $-30^{\circ}<\theta_{\sigma}<30^{\circ}$, deve usada a equação (2.66), proposta por Sheng e Sloan, (2001) para a convergência do modelo CCMC.

$$
\begin{gathered}
M=\frac{6 \sin \phi}{3-\sin \phi} \\
M\left(\theta_{\sigma}\right)=M\left[\frac{2 \alpha_{s}^{4}}{1+\alpha_{s}{ }^{4}+\left(1-\alpha_{s}{ }^{4}\right) \sin 3 \theta_{\sigma}}\right]^{(1 / 4)} \\
\alpha_{s}=\frac{3-\sin \phi}{3+\sin \phi}
\end{gathered}
$$

\subsection{5.}

\section{Regra de fluxo}

Os modelos Cam Clay Modificado e Cam Clay Modificado com Coesão são baseados na regra de fluxo associada, equação (2.9). Roscoe e Burland (1968) propõem que o incremento de trabalho plástico seja calculado em função dos incrementos de deformação plástica volumétrica e desviadora, equação (2.68). Assim, no estado triaxial, os incrementos de deformação plástica volumétrica estão associados à tensão hidrostática, enquanto os incrementos de deformação plástica desviadora a um estado de tensão cisalhante, equações (2.69) e (2.70).

$$
\begin{gathered}
d W=\bar{P} \sqrt{\left(\left\{d \varepsilon_{v}^{P}\right\}\right)^{2}+M^{2}\left(\left\{d \varepsilon_{s}^{P}\right\}\right)^{2}} \\
\left\{d \varepsilon_{v}^{P}\right\}=\left\{d \varepsilon_{1}^{P}\right\}+2\left\{d \varepsilon_{3}^{P}\right\} \\
\left\{d \varepsilon_{s}^{P}\right\}=\frac{2}{3}\left(\left\{d \varepsilon_{1}^{P}\right\}-\left\{d \varepsilon_{3}^{P}\right\}\right)
\end{gathered}
$$

O vetor de deformação plástica, composto por parcelas plásticas, volumétrica e desviadora, sempre é perpendicular à superfície de potencial plástico, já que considera fluxo associado à superfície de escoamento. A relação 
das componentes deformações plásticas volumétricas e cisalhante indicam a inclinação da superfície de escoamento em qualquer ponto.

$$
\frac{\left\{d \varepsilon_{v}^{P}\right\}}{\left\{d \varepsilon_{s}^{P}\right\}}=\frac{M^{2}-\eta^{2}}{2 \eta}
$$

onde $\eta=\frac{q}{p}$ representa a trajetória de tensões e $M$ a inclinação da linha de estado crítico.

\subsection{6.}

\section{Determinação de Parâmetros do modelo CCM e CCMC}

Os parâmetros do modelo CCMC são determinados a partir de ensaios de laboratório, como os convencionais triaxiais a compressão, hidrostáticos e uniaxiais ou de compressão simples. Os parâmetros $\lambda$ e $k^{\prime}$ representam o estado de carregamento e descarregamento, respectivamente, e podem ser determinados mediante um ensaio hidrostático. Estes valores estão associados aos índices de compressão $\left(C_{C}\right)$ e de expansão $\left(C_{S L}\right)$. Na Figura 17b observase que o índice de compressão $C_{C}$ é a inclinação da linha de carregamento do gráfico e vs Log10P e $C_{S L}$ é o índice de descarregamento representado pela inclinação da linha de descarregamento do gráfico e vs Log10P.

$$
\begin{gathered}
C_{C}=\frac{e_{A}-e_{B}}{\log _{10} P_{B}-\log _{10} P_{A}} \\
C_{S L}=\frac{e_{C}-e_{B}}{\log _{10} P_{B}-\log _{10} P_{C}}
\end{gathered}
$$

O processo de obter os valores de $\lambda, \kappa^{\prime}$ da rocha carbonática travertino difere das argilas, basicamente pela evolução da estrutura porosa quando é submetida ao carregamento. Porém, foi proposto neste trabalho a equação (2.74) , desenvolvida por Wan (2003), que propõe a variação da porosidade total em função da variação volumétrica e da porosidade inicial. 


$$
\phi_{T}=1-\left(1-\phi_{0}\right) e^{i \Delta \varepsilon}
$$

onde $\phi_{0}$ representa a porosidade inicial, $e^{\prime}$ é a constante de Euler e $\Delta \varepsilon=\varepsilon_{v o l}-$ $\varepsilon_{v o l, 0} \circ$ incremento da deformação volumétrica, $\varepsilon_{v o l, 0}=$ deformação volumétrica inicial, usualmente zero. Calculados os valores da equação (2.74), pode-se determinar o índice de vazios $e$ e, posteriormente, gerar as curvas do gráfico $e$ vs $\log \bar{P}$, de forma a obter $\lambda, \kappa^{\prime}$.

$$
\begin{aligned}
\lambda & =\frac{C_{C}}{\ln 10} \\
\boldsymbol{k}^{\prime} & =\frac{C_{S L}}{\ln 10}
\end{aligned}
$$

Outros parâmetros como o coeficiente de Poisson $v$ e o índice de vazios inicial $e$ podem ser determinados a partir dos ensaios triaxiais a compressão e hidrostáticos respectivamente. $O$ parâmetro $P_{c i}$ representa a tensão de préadensamento inicial. Os parâmetros de $C^{*}$ e $\phi$, que representam coesão e ângulo de atrito, respectivamente, são determinados a partir do critério de Mohr-Coulomb. Na Tabela 4 são apresentados os parâmetros do modelo constitutivo CCMC.

Tabela 4 Parâmetros do modelo CCMC.

\begin{tabular}{lc}
\hline Parâmetros do modelo constitutivo elastoplástico CCMC \\
\hline Coeficiente de Poisson & $v$ \\
Índice de vazios & $e$ \\
Tensão de pré-adensamento & $P_{c i}$ \\
Inclinação da Linha de carregamento & $\lambda$ \\
Inclinação da linha de descarregamento & $k^{\prime}$ \\
Coesão & $C^{*}$ \\
Ângulo de atrito & $\phi$ \\
\hline
\end{tabular}




\section{5.}

\section{Análise inversa}

A estimativa de parâmetros dos modelos constitutivos pode ser feita de forma direita ou pelo método de análise inversa. No primeiro caso, os parâmetros são determinados particularmente para cada modelo constitutivo mediante soluções analíticas. No caso da análise inversa, a metodologia é distinta, os parâmetros dos modelos são determinados a partir de observações (ensaios de laboratório) a partir de métodos estatísticos.

O objetivo da metodologia de análise inversa é determinar parâmetros baseada na minimização do erro entre resultados experimentais e numéricos (Cekerevac et al., 2006), conforme ilustrado na Figura 19.

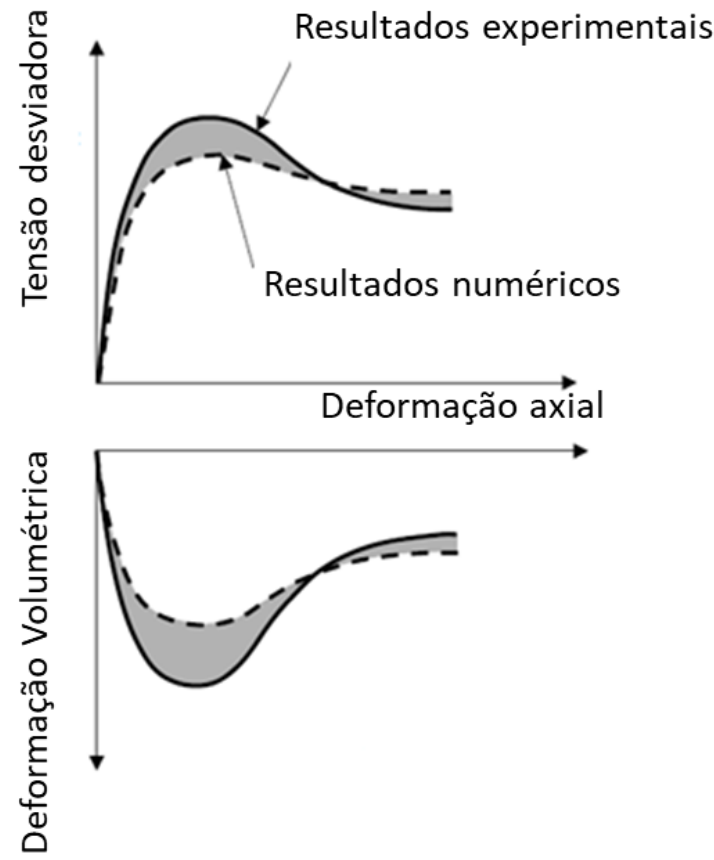

Figura 19 Diferença entre dados experimentais e dados numéricos (Cekerevac et al., 2006).

\subsection{1.}

\section{Análise inversa usando o DREAM}

DREAM (Differential Evoution Adaptive Metropolis), ilustrado esquematicamente na Figura 20, é um código implementado no MATLAB por (Vrugt Jasper et al., 2008; Vrugt et al., 2009) que usa inferência Bayesiana, 
podendo ser aplicado a numerosos campos, como a física, química e engenharia. Neste esquema é observado diferentes etapas: na etapa (1) são incorporados os parâmetros do modelo, alguns deles como variáveis a serem otimizados e outras como constantes; na etapa (2) são fornecidos os dados de entrada como o incremento de deformação axial e a tensão de confinamento no caso do ensaio triaxial drenado ( ver item 3.2), na etapa (3) representa os valores iniciais ou limite previos dos parâmetros a serem determinados; na etapa (4) representa o algoritmo do modelo constitutivo onde são compiladas as etapas previas ( ver item 3.2); na etapa (5) são gerados os resultados numéricos pelo modelo constitutivo; a etapa (6) representa os dados experimentais como deformação axial e deformação volumétrica ( ver item 3.2). Por fim as etapas (5) e (6) são compiladas no algoritmo DREAM o qual usa as Cadeias de Markov para determinar a distribuição posterior dos parâmetros otimizados.

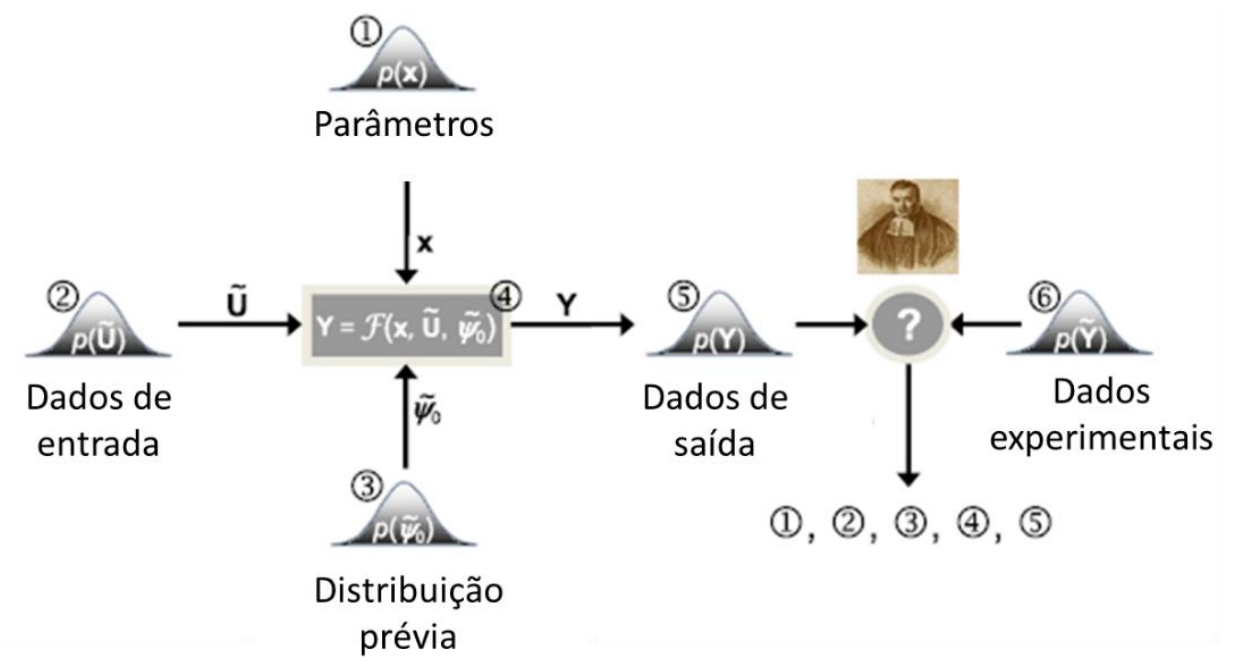

Figura 20 Esquema do DREAM : (1) parâmetros do modelo, (2) dados de entrada, (3) distribuição prévia, (4) estrutura do modelo, (5) saída de dados, (6) dados observados (Vrugt et al., 2016).

O algoritmo DREAM é uma ferramenta que permite conhecer a distribuição de parâmetros baseada em um sistema bayesiano. Seja $\tilde{Y}=\left\{\tilde{y}_{1}, \ldots . ., \tilde{y}_{n}\right\}$ o vetor de dados experimentais em um tempo $t=\{1, \ldots, n\}, n$ é o número total de dados do vetor $\tilde{Y}$. Neste caso, o vetor $\tilde{Y}$ está relacionado aos dados de entrada pela seguinte expressão 


$$
\tilde{Y} \leftarrow F\left(\mathrm{x}_{i}\right)+E_{r}
$$

onde $X_{i}$ é o número de parâmetros desconhecidos, $E_{r}$ o vetor de erros medidos $E_{r}\left(\mathrm{x}_{i}\right)=\tilde{Y}-Y\left(\mathrm{x}_{i}\right)=\left\{e_{1}\left(\mathrm{x}_{i}\right), \ldots e_{n}\left(\mathrm{x}_{i}\right)\right\}$ e $Y$ o vetor de dados numéricos. Adotando a formulação bayesiana a distribuição posterior de parâmetros (quantidade incerta de valores tratados como uma varivel aleatória, condicionada de uma evidência experimental) do modelo pode ser formulada como:

$$
p\left(\mathrm{x}_{i} / \tilde{Y}\right)=\frac{p\left(\mathrm{x}_{i}\right) p\left(\tilde{Y} / \mathrm{x}_{i}\right)}{p(\tilde{Y})}
$$

onde $p\left(\mathrm{x}_{i}\right)$ e $p\left(\mathrm{x}_{i} / \tilde{Y}\right)$ são a distribuições de parâmetros prévia e posterior, respectivamente, e $p\left(\tilde{Y} / \mathrm{x}_{i}\right)$ é a função objetivo ou de julgamento. Os dados de observações $p(\tilde{Y})$ atuam como uma constante de normalização.

$$
p(\tilde{Y})=\int_{x} p\left(\mathrm{x}_{i}\right) p\left(\tilde{Y} / \mathrm{x}_{i}\right) \mathrm{d} \mathrm{x}_{i}=\int_{x} p\left(\mathrm{x}_{i}, \tilde{Y}\right) \mathrm{dx}_{i}
$$

No entanto, $L\left(\mathrm{x}_{i} / \tilde{Y}\right)=p\left(\tilde{Y} / \mathrm{x}_{i}\right)$ é a principal responsável pela estimativa, definida como a função (erro residual) que reduz a distância entre as simulações do modelo e os dados das observações. Neste caso, se o erro residual não é correlacionado, este pode ser escrito da seguinte forma.

$$
L\left(\mathrm{x}_{i} / \tilde{Y}\right)=f_{\tilde{y} 1}\left(y_{1}\left(\mathrm{x}_{i}\right)\right) \times \ldots . . f_{\tilde{y} n}\left(y_{n}\left(\mathrm{x}_{i}\right)\right)=\prod_{t=1}^{n} f_{\tilde{y} t}\left(y_{t}\left(\mathrm{x}_{i}\right)\right)
$$

Sendo $f_{a}(b)$ a função de densidade de probabilidade de $a$ em $b$. Se o erro residual é assumido segundo uma distribuição normal, a equação (2.80) poderia ser reescrita como. 


$$
L\left(\mathrm{x}_{i} / \tilde{Y}\right)=\prod_{t=1}^{n} \frac{1}{\sqrt{2 \pi \hat{\sigma}_{t}^{2}}} \exp \left[-\frac{1}{2}\left(\frac{\tilde{y}_{t}-y_{t}\left(\mathrm{x}_{i}\right)}{\hat{\sigma}_{t}}\right)^{2}\right]
$$

Onde, $\hat{\sigma}_{t}=\left\{\hat{\sigma}_{t}, \ldots . \hat{\sigma}_{n}\right\}$ é o vetor de desvio padrão do erro de medição das observações. Esta formulação permite erros de medição homocedásticos (variância constante) ou heterocedásticos (variância dependente da magnitude). Por razoes de estabilidade numérica é conveniente trabalhar a equação (2.81) com logaritmo, assumindo a seguinte forma:

$$
L\left(\mathrm{x}_{i} / \tilde{Y}\right)=-\frac{n}{2} \log (2 \pi)-\sum_{t=1}^{n}\left\{\log \left(\hat{\sigma}_{t}\right)\right\}-\frac{1}{2} \sum_{t=1}^{n}\left(\frac{\tilde{y}_{t}-y_{t}\left(\mathrm{x}_{i}\right)}{\hat{\sigma}_{t}}\right)^{2}
$$

Se o erro $E_{r}\left(\mathrm{x}_{i}\right)=\tilde{Y}-Y\left(\mathrm{x}_{i}\right)=\left\{e_{1}\left(\mathrm{x}_{i}\right), \ldots e_{n}\left(\mathrm{x}_{i}\right)\right\}$ é de correlação espacial, pode ser levado explicitamente na função objetivo da equação (2.82). A maioria dos modelos são não-lineares. Neste caso, a distribuição posterior $p\left(\mathrm{x}_{i} / \tilde{Y}\right)$ não pode ser obtida pela aproximação analítica, porém métodos iterativos são usados para gerar uma amostra da distribuição posterior. Uma possibilidade é o uso do método de Monte Carlo, embora este método via cadeia de Markov (MCMC) seja mais eficiente e ofereça melhor distribuição posterior de parâmetros.

O DREAM pode ser considerado superior a outras adaptações do MCMC por procurar em um amplo espectro de espaço, fornecendo melhores soluções que outros algoritmos de otimização. O MCMC é baseado numa Cadeia de Markov que gera uma caminhada aleatória pelo espaço amostral e sucessivamente visita soluções com frequências estáveis de uma distribuição estacionária $\bar{\pi}(\cdot)$. O algoritmo RWM (random walk Metropolis) contribui em manter o balanço com respeito à distribuição $\bar{\pi}(\cdot)$. O Algoritmo MCMC gera movimentos de testes a partir do atual estado das cadeias de Markov $X_{t-1}$ até um novo estado $X_{p}$. A probabilidade $P_{a c c}\left(X_{t-1} \rightarrow X_{P}\right)$, que aceita esta proposta, é descrita como 


$$
P_{a c c}\left(X_{t-1} \rightarrow X_{P}\right)=\min \left[1, \frac{p\left(X_{P}\right) q\left(X_{P} \rightarrow X_{t-1}\right)}{p\left(X_{t-1}\right) q\left(X_{t-1} \rightarrow X_{P}\right)}\right]
$$

Neste caso $P_{a c c}\left(X_{t-1} \rightarrow X_{P}\right)$ é a distribuição de próximo passo não simétrica, onde $\left(X_{t-1} \rightarrow X_{P}\right)$ é o próximo passo que vai na frente e $\left(X_{P} \rightarrow X_{t-1}\right)$ o próximo passo de retorno e não tem a mesma probabilidade, $q\left(X_{t-1} \rightarrow X_{P}\right) \neq q\left(X_{P} \rightarrow X_{t-1}\right)$. Esta generalização é conhecida como MetropolisHastings $(\mathrm{MH})$ e amplia significativamente a distribuição proposta que pode ser usada na inferência posterior.

A metodologia do RWM consiste primeiro em testar o $X_{p}$ desde uma distribuição proposta $q(\cdot)$, que depende da presente localização $X_{t-1}$ e é simétrica $q\left(X_{t-1} \rightarrow X_{P}\right)=q\left(X_{P} \rightarrow X_{t-1}\right)$. No seguinte passo a proposta pode ser aceita ou rejeitada usando a equação (2.83). No entanto, com a simetria ela pode tornar-se a seguinte expressão.

$$
P_{a c c}\left(X_{t-1} \rightarrow X_{P}\right)=\min \left[1, \frac{p\left(X_{P}\right)}{p\left(X_{t-1}\right)}\right]
$$

Finalmente, se a proposta é aceita, a cadeia se move à $X_{p}$. Do contrário, elas permanecem na atual posição $X_{t-1}$. Repetindo estes três passos, obtém-se como resultado uma cadeia de Markov que tem uma única distribuição estacionária com posterior probabilidade de função de densidade $\bar{\pi}(\cdot)$. Na prática, isto significa que, se olhamos os valores de $X_{i}$ suficientemente longe dos valores desde o valor inicial arbitrário, isto é, após um período de burn-in, os estados da cadeia gerados sucessivamente poderiam ser distribuídas de acordo com $\bar{\pi}(\cdot)$, a posterior probabilidade de distribuição $X_{i}$. Burn-in é necessário para permitir que a cadeia explore o espaço de busca e atinja o regime estacionário. 
A eficiência do RWM é determinada pela escolha da distribuição proposta $q(\cdot)$ usada para criar movimentações básicas (transicionais) na cadeia de Markov. Quando a distribuição proposta é extremamente ampla, muitos candidatos são rejeitados, assim as cadeias não se misturam e convergem lentamente à distribuição alvo. Por outro lado, quando a distribuição proposta é muito estreita, quase todos os pontos candidatos são aceitos, no entanto, a distância movida é tão pequena que seria necessário um grande número de atualizações antes que o amostrador convirja para a distribuição alvo. A escolha da distribuição alvo é crucial e determina a aplicabilidade prática do MCMC em muitas áreas (Vrugt, 2016).

\subsection{2.}

\section{Análise inversa usando o MINPACK}

MINPACK é uma biblioteca de livre uso, implementada em FORTRAN 90, que resolve problemas não lineares por mínimos quadrados através do algoritmo Levenberg Marquardt.

\subsubsection{1. Metodologia de otimização}

As técnicas de otimização constituem-se em ferramenta útil para o uso eficiente de dados nas estimativas de parâmetros existentes em modelos matemáticos e para o auxílio na modelagem de um fenômeno (Beck \& Arnold, 1977; apud Barroso, 2002). De acordo com Guimarães (2006, 2009) um procedimento sistemático de otimização procura um conjunto de parâmetros do modelo que minimiza entre observações experimentais e os resultados correspondentes simulados pelo modelo. Para ter sucesso na otimização, é preciso ter uma função objetivo apropriada, a partir da seguinte formulação:

$$
F_{o}\left(p_{i}\right)=f\left(\left\{\sigma^{n u m}\left(p_{i}\right)\right\},\left\{\sigma^{\exp }\right\},\left\{\varepsilon^{n u m}\left(p_{i}\right)\right\},\left\{\varepsilon^{\exp }\right\}\right)
$$

onde $F\left(p_{i}\right)$ é a função objetivo, $\sigma^{\text {num }}$ e $\sigma^{\text {exp }}$ representam os vetores das tensões numéricas e experimentais, $\varepsilon^{\text {num }}$ e $\varepsilon^{\exp }$ representam os vetores das deformações numéricas e experimentais. A solução da equação (2.85) é obtida através de algoritmos de otimização, que, a partir do parâmetro inicial $p_{0}$, obtém, por 
processos iterativos, o vetor de parâmetros estimados $p^{*}$ correspondentes à função objetivo (Velloso, 2000). Na Figura 21 é apresentado um esquema com os principais componentes de um problema de análise inversa

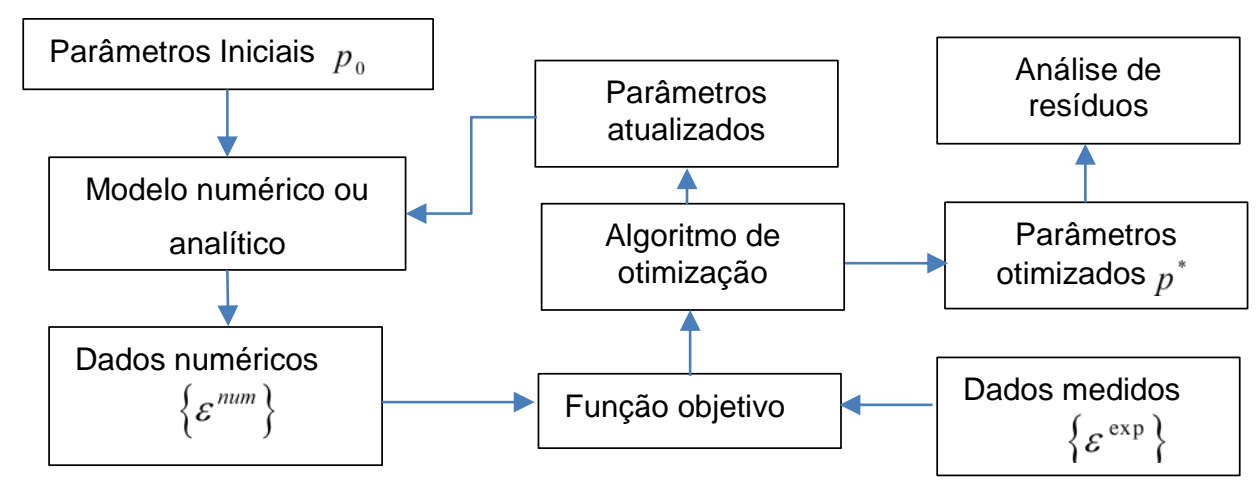

Figura 21. Principais componentes de um problema de análise inversa (Velloso 2000).

\subsubsection{2.}

\section{Critério de identificação de parâmetros}

Segundo Guimarães (2006), os critérios de identificação são utilizados para definir a função objetivo, sendo o mais conhecido e simples o método de mínimos quadrados (Beck \& Arnold, 1977; Velloso 2000; apud Barroso 2002). Este método é utilizado quando não se dispõe de nenhum tipo de informação adicional, só os valores medidos das deformações:

$$
F_{o}\left(p_{i}\right)=\left[\left\{\varepsilon^{*}\right\}-\left\{\varepsilon\left(p_{i}\right)\right\}\right]^{T}\left[\left\{\varepsilon^{*}\right\}-\left\{\varepsilon\left(p_{i}\right)\right\}\right]=\sum_{l=1}^{m} r_{l}^{2}\left(p_{i}\right)
$$

onde $r_{i}$ é o resíduo, ou seja, a diferença entre os valores medidos e os valores calculados. Segundo Velloso (2000), o método dos mínimos quadrados pode não apresentar resultados satisfatórios quando o vetor de observações $\varepsilon^{*}$ contém dados expressos em diferentes unidades. Neste caso, os resíduos de maior grandeza seriam predominantes. Além disso, algumas medidas podem ser mais confiáveis que outras, requerendo que os parâmetros estimados sejam menos influenciados pelas medidas menos precisas. Este é denominado Método dos mínimos quadrados ponderados: 


$$
F_{o}\left(p_{i}\right)=\left[\left\{\varepsilon^{*}\right\}-\left\{\varepsilon\left(p_{i}\right)\right\}\right]^{T} W\left[\left\{\varepsilon^{*}\right\}-\left\{\varepsilon\left(p_{i}\right)\right\}\right]=\sum_{l=1}^{m} w_{l l} r_{l}^{2}\left(p_{i}\right)
$$

onde $W$ é uma matriz diagonal de pesos com elementos não negativos

Os elementos de $W$ são determinados com base no conhecimento do problema. Para a escolha dos pesos pode-se utilizar considerações estatísticas. (Bard 1974, apud Velloso 2000) sugere a adoção da inversa da matriz de covariância dos valores medidos, $C_{y}$, como matriz de peso:

$$
F_{o}\left(p_{i}\right)=\left[\left\{\varepsilon^{*}\right\}-\left\{\varepsilon\left(p_{i}\right)\right\}\right]^{T} C_{y}^{-1}\left[\left\{\varepsilon^{*}\right\}-\left\{\varepsilon\left(p_{i}\right)\right\}\right]+\left[P_{i}-P_{0}\right]^{T} C_{P o}^{-1}\left[P_{i}-P_{0}\right]
$$

onde $C_{P o}^{-1}$ é uma matriz de covariância das estimativas iniciais dos parâmetros Po e $C_{y}^{-1}$ é a inversa da matriz de covariância dos valores medidos. O segundo termo da equação (2.88) atua como uma função de penalidade que mantém os parâmetros numa região próxima a estimativa inicial, $P_{0}$. Caso $p_{i}$ se afaste de $P_{0}$, a contribuição deste termo cresce quadraticamente, então a minimização da função objetivo será feita com êxito se $p_{i}$ permanecer próximo a $P_{0}$.

Segundo Velloso (2000), se as medidas forem não correlacionadas, a matriz de covariância das medidas $C_{y}$ é uma matriz diagonal, sendo seus elementos dados pelo quadrado do desvio padrão das medidas, $\sigma_{y}^{2}$ a variância. Se o segundo termo da equação (2.88) fosse desconsiderado, a função objetivo poderia ser escrita da seguinte forma:

$$
F_{o}\left(p_{i}\right)=\sum_{l=1}^{m} \frac{r_{l}^{2}\left(p_{i}\right)}{\sigma_{y l}^{2}}
$$

\subsubsection{3.}

\section{Algoritmo de otimização}

O objetivo do algoritmo de otimização é minimizar a função objetivo $F_{o}\left(p_{i}\right)$ , através de processo iterativo, partindo dos parâmetros iniciais $p_{0}$. 


$$
p_{i}{ }^{K+1}=p_{i}{ }^{K}+\Delta p_{i}{ }^{K}
$$

onde $k$ representa a iteração ( $\mathrm{K}=0,1,2,3 \ldots .$.$) e \Delta p_{i}{ }^{K}$ é o incremento no vetor de parâmetros $p_{i}{ }^{K}$. A equação (2.90) representa um processo iterativo que deve ser satisfeito até que as condições ótimas, ou algum outro critério de convergência seja satisfeito. $\mathrm{O}$ incremento $\Delta p_{i}{ }^{K}$ é determinado pela seguinte expressão

$$
\Delta p_{i}^{K}=\alpha^{k} d^{k}
$$

onde $\alpha^{k}$ é o tamanho do passo e $d^{k}$ é a direção de busca. Existem diversos métodos para o cálculo de $\Delta p_{i}{ }^{K}$. A exigência básica para a direção de busca $d^{k}$ é que a função objetivo seja reduzida quando se move uma pequena distância nesta direção (Aurora, 1989; Velloso, 2000). Na Figura 22 é apresentado o esquema de otimização:

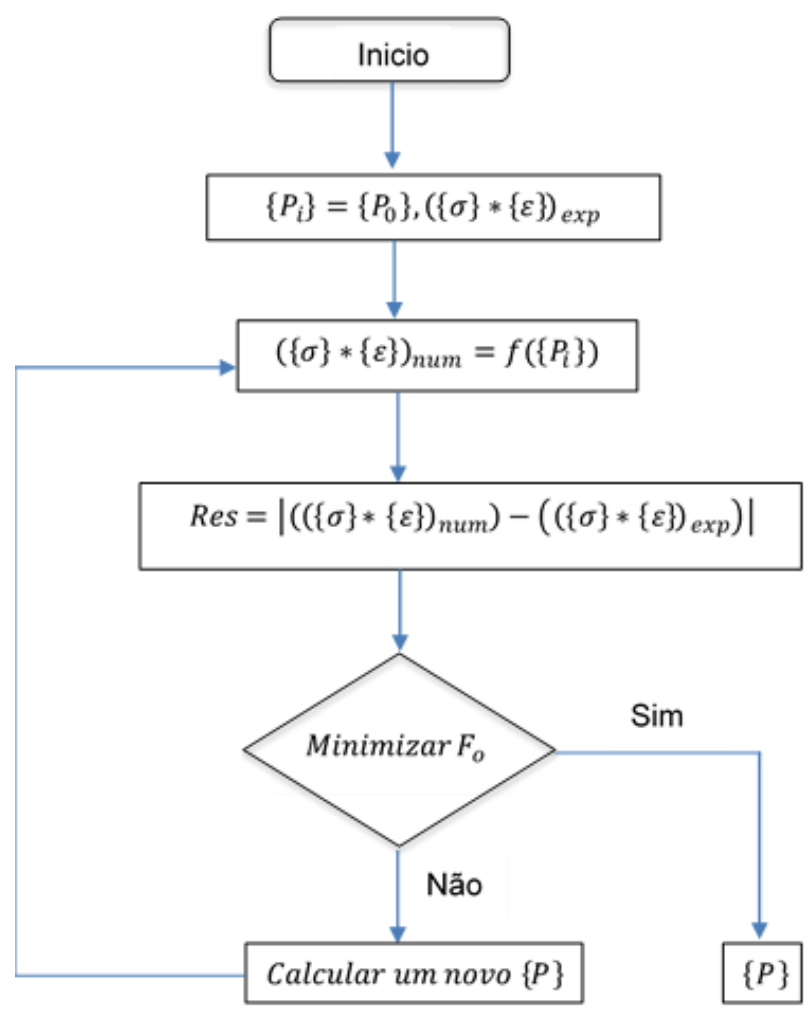

Figura 22 Algoritmo geral de otimização (Velloso 2000). 
Os métodos de otimização podem ser classificados de acordo com a ordem da derivada da função objetivo utilizada na determinação da direção de busca $d^{k}$ . Por exemplo, os métodos de ordem zero utilizam somente informações da função objetivo, enquanto os de primeira ordem utilizam seu gradiente, conforme a equação (2.92):

$$
g\left(p_{i}\right)=\left[\begin{array}{c}
\frac{\partial F_{o}\left(p_{i}\right)}{\partial p_{1}} \\
\vdots \\
\frac{\partial F_{o}\left(p_{i}\right)}{\partial p_{n p}}
\end{array}\right]
$$

onde $g\left(p_{i}\right)$ indica o gradiente da função objetivo $\partial F_{o}\left(p_{i}\right)$. O gradiente é um vetor construído pelas derivadas parciais da função objetivo em relação aos parâmetros $p_{i}$ (Gomes 2008).

Substituindo a equação (2.89), na equação (2.92), temos:

$$
g\left(p_{i}\right)=\left[\begin{array}{c}
\frac{\partial F_{o}\left(p_{i}\right)}{\partial p_{1}} \\
\vdots \\
\frac{\partial F_{o}\left(p_{i}\right)}{\partial p_{n p}}
\end{array}\right]=-2 \sum_{l=1}^{m} r_{l} \frac{\partial y_{l}\left(p_{i}\right)}{\partial p_{j}}
$$

Continuando com os métodos de otimização, além dos de ordem zero e de primeira ordem, os de segunda ordem utilizam a matriz hessiana, além de fazerem a inclusão de temos de segunda ordem (método de Newton - Raphson), o que acaba por melhorar a taxa de convergência (Aurora,1989 ,apud Barroso, 2002).

$$
H\left(p_{i}\right)=\left[\begin{array}{ccc}
\frac{\partial^{2} F_{o}\left(p_{i}\right)}{\partial p_{1}^{2}} & \ldots & \frac{\partial^{2} F_{o}\left(p_{i}\right)}{\partial p_{1} \partial p_{n p}} \\
\vdots & \ddots & \vdots \\
\frac{\partial^{2} F_{o}\left(p_{i}\right)}{\partial p_{n p} \partial p_{1}} & \cdots & \frac{\partial^{2} F_{o}\left(p_{i}\right)}{\partial p_{n p}^{2}}
\end{array}\right]
$$


onde $H(p)$ representa a matriz hessiana (positiva e definida), a qual é uma matriz simétrica de derivadas parciais em relação aos parâmetros $P_{j}$. O método de Newton-Raphson utiliza a expansão em série de Taylor até segunda ordem da função objetivo em torno do ponto corrente, fornecendo uma função quadrática para $\Delta P$.

$$
F_{o}\left(p_{i}+\Delta p_{i}\right)=F_{o}\left(p_{i}\right)+g^{T} \Delta p_{i}+\frac{1}{2} \Delta p_{i}^{T} H \Delta p_{i}
$$

Com as condições necessárias para a minimização desta função, obtém-se explicitamente a direção de busca $d^{k}$, seguindo a condição de o gradiente ser nulo, $g\left(p_{i}\right)=0$ (Velloso 2000).

O gradiente $g\left(p_{i}\right)$ e a $H\left(p_{i}\right)$ são obtidos a partir da derivação da função objetivo, através do método de Newton-Raphon, utilizando $\alpha^{k}=1$, o processo de iteração é repetido até obter melhores estimativas do vetor (Arora, 1989, apud Velloso, 2000). O gradiente pode ser escrito em termos de matriz jacobiana, ou matriz de sensibilidade:

$$
g=-2 J^{T} r
$$

onde a matriz jacobiana:

$$
J=\frac{\partial y\left(p_{i}\right)}{\partial p_{i}}=\left[\begin{array}{ccc}
\frac{\partial y_{1}\left(p_{i}\right)}{\partial p_{1}} & \cdots & \frac{\partial y_{1}\left(p_{i}\right)}{\partial p_{n p}} \\
\vdots & \ddots & \vdots \\
\frac{\partial y_{n}\left(p_{i}\right)}{\partial p_{1}} & \cdots & \frac{\partial y_{n}\left(p_{i}\right)}{\partial p_{n p}}
\end{array}\right]
$$

Reescrevendo a matriz hessiana:

$$
H\left(p_{i}\right)=-2 \sum_{l=1}^{m} r_{l} \frac{\partial y_{l}\left(p_{i}\right)}{\partial P_{j} \partial P_{k}}+2 J^{T} J
$$


O método de Newton-Raphson tem um alto custo computacional devido às derivadas de segunda ordem, as quais não podem ser obtidas analiticamente (Velloso, 2000). Por esta razão é um método pouco utilizado na solução de estimativa de parâmetros. Neste caso a matriz hessiana pode ser negativa e o algoritmo pode não convergir.

No método de Newton-Raphson não se calcula a hessiana diretamente, sendo utilizada uma aproximação através da construção de uma matriz positiva definida a cada iteração do algoritmo de otimização, de forma que produza uma aproximação, reduzindo o custo computacional (Velloso, 2000, Barroso, 2002). O método de Gauss Newton é baseado em uma aproximação linear, que procura minimizar a função e acaba por convergir melhor que o método de gradiente descendente. Neste caso matriz hessiana é dada por:

$$
H=2 J^{T} J
$$

\subsubsection{4.}

\section{Método de Levenberg Marquardt}

O método Levenberg Marquardt é uma técnica usada para resolver problemas não lineares, resultante da combinação de dois métodos de otimização; o método de gradiente descendente e o método de Gauss Newton. O método Levenberg Marquardt atua de forma mais similar ao método de gradiente descendente quando os parâmetros se afastam de seu valor ótimo. No caso contrário, quando os valores dos parâmetros são mais pertos do ótimo, o método atua como o método de Gauss Newton (Gavin, 2011). Este método realiza uma interpolação entre as séries de Taylor e o método de gradiente descendente para uma adequada representação do modelo não linear (Marquardt, 1963). Algumas formulações do método Levenberg Marquardt modificado apartir do método Gauss Newton, estão definidas em (Nielsen, 1999). Neste método a hessiana é aproximada por:

$$
H=2\left(J^{T} J+\lambda_{l} D\right)
$$

onde $D$ é uma matriz diagonal de ordem $n_{p}$, com os elementos iguais aos elementos da matriz $\left(J^{T} J\right)$, e $\lambda_{l}$ é o parâmetro de Levenberg, o qual garante a propriedade aferida pelo algoritmo. Como mencionado anteriormente, se este parâmetro é zero ou perto do ótimo valor, o método se torna o método de Gauss Newton. 


\section{3 \\ METODOLOGIA}

Neste capítulo é apresentada a metodologia usada para atingir as etapas descritas no Capítulo I. Na parte experimental, são apresentados os procedimentos para determinação da porosidade da rocha carbonática travertino, além de uma abordagem sobre os ensaios convencionais triaxiais à compressão CTC, uniaxiais UCS e compressão hidrostática HC realizados no laboratório de Engenharia Civil da PUC-Rio. Na parte numérica, são apresentados os algoritmos do tipo explícito dos modelos constitutivos elastoplásticos Lade-Kim isotrópico, CCMC isotrópico e CALK. Os modelos Lade-Kim e CALK foram implementado nos programas FORTRAN 90® e MATLAB 2017®, enquanto o modelo CCMC foi implementado no FORTRAN 90®. Posteriormente, é apresentada a metodologia de análise inversa para determinação de parâmetros usando dois códigos de otimização, MINPACK e DREAM, implementados no FORTRAN $90 \AA$ e MATLAB $2017 \AA$, respectivamente. Na Figura 23 é apresentado o esquema de desenvolvimento da pesquisa, que sera detalhada neste capítulo.

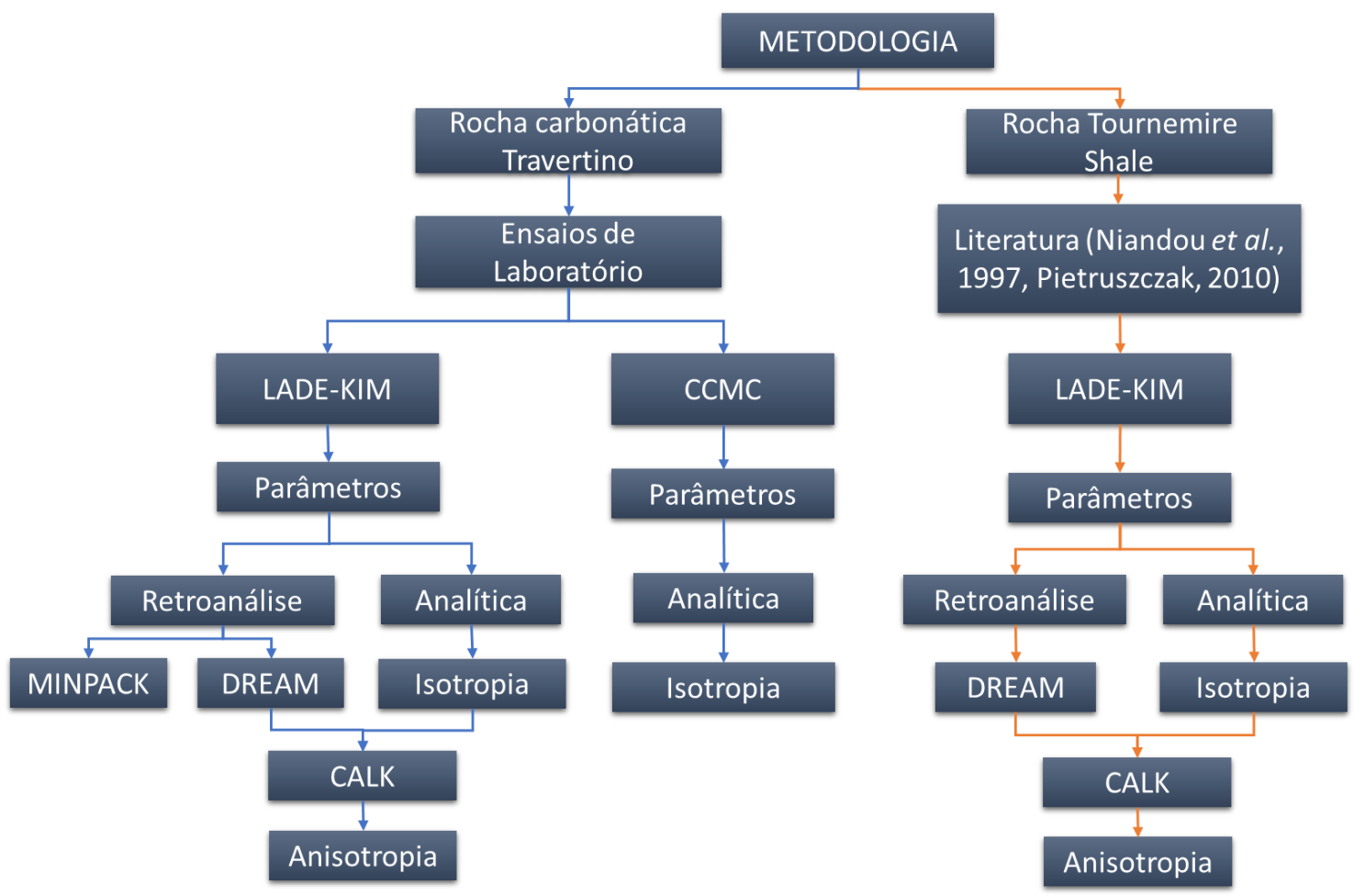

Figura 23 Esquema da metodologia desenvolvida na pesquisa. 


\section{1.}

\section{Procedimentos laboratoriais}

Os ensaios triaxiais à compressão, uniaxiais, hidrostáticos e procedimentos de determinação dos índices físicos, como a porosidade total da rocha carbonática travertino, foram executados no laboratório de Engenheira Civil da PUC-Rio. A seguir são apresentados os procedimentos laboratoriais.

\subsection{1.}

\section{Material usado na pesquisa}

O material usado na pesquisa é a rocha carbonática travertino romano, rocha análoga a uma das fácies dos carbonatos existentes no reservatório do Présal. Os blocos 1 e 2 foram extraídos de uma pedreira de Roma e importados para Brasil. O bloco 1, com dimensões de $83 \mathrm{~cm}$ de comprimento, $40 \mathrm{~cm}$ de largura e $22 \mathrm{~cm}$ de altura, foi amostrado como se observa na Figura 24 (a). Como resultado, foram obtidos 70 corpos de prova verticais no plano Z-X (camadas em orientação perpendicular ao eixo axial da amostra), CPV, e 30 corpos de prova horizontais no plano Y-Z (camadas em orientação paralela ao eixo axial da amostra), $\mathrm{CPH}$, observados na Figura 24. As dimensões dos corpos de prova cumprem a ASTM 7012-13. Os corpos de prova de travertino obtidas apresentam porosidade total entre $4 \%$ e $15 \%$, e relação diâmetro/altura dos corpos de prova teve uma média de 2.2. O bloco 2, com dimensões de $94 \mathrm{~cm}$ de comprimento, $84 \mathrm{~cm}$ de largura e $22 \mathrm{~cm}$ de altura, foi amostrado como se observa na Figura 24 (b). Foram obtidos 15 corpos de prova com camadas em orientação inclinada ao eixo axial da amostra, CPI.

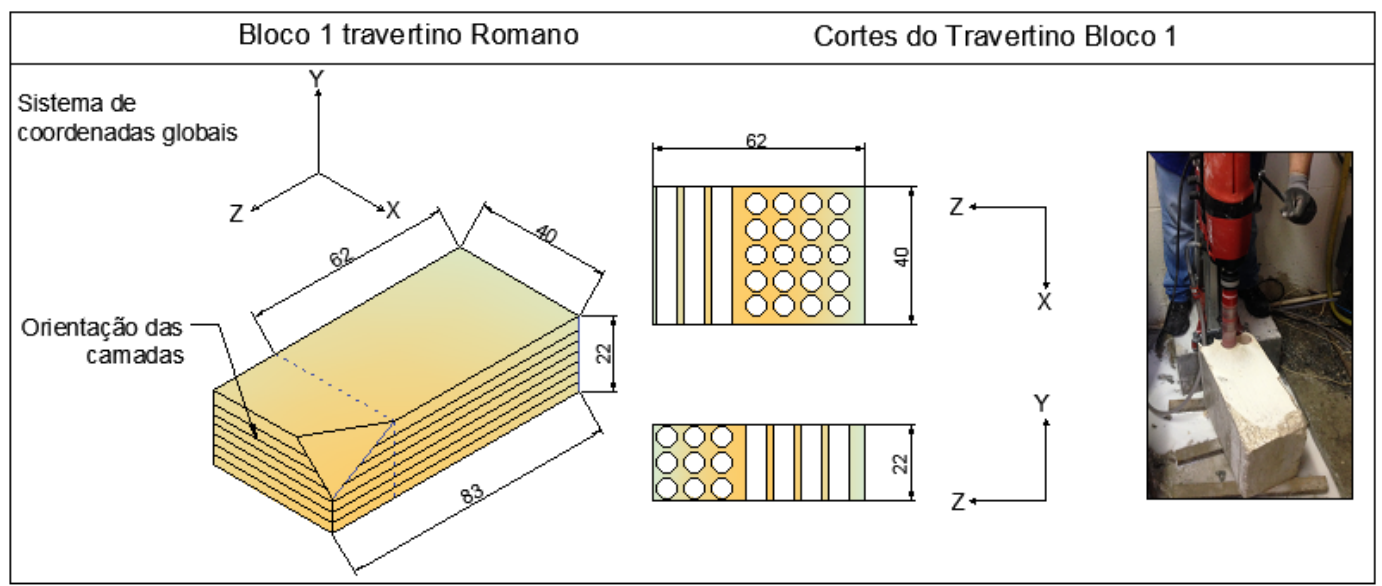

(a) 


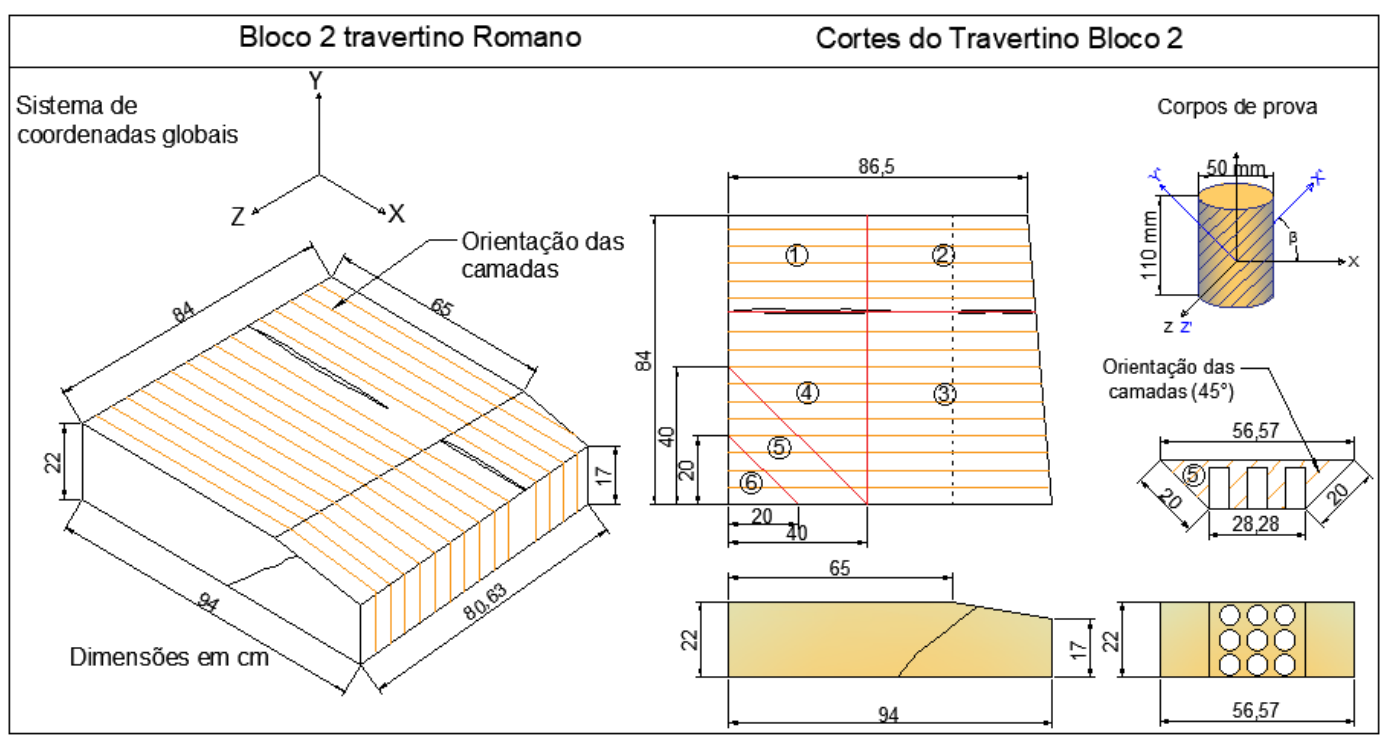

(b)

Figura 24 (a) Dimensões e cortes do bloco 1 da rocha travertino romano. (b) Dimensões do bloco 2 da rocha travertino romano.

\subsection{2.}

\section{Determinação da porosidade da rocha carbonática travertino}

O procedimento para a determinação da porosidade total $\phi_{T}$ do travertino é baseado em (Franklin et al., 1979), considerando parâmetros como a densidade relativa dos grãos $G_{s}$ e a geometria dos corpos de prova. A determinação do $G_{s}$ é baseada na norma ASTM D-854 e foi feita no laboratório de Geotecnia da PUCRio. A seguir é apresentado um resumo do processo de obtenção do $G_{s}$ :

- Triturar a rocha carbonática travertino até passar pela peneira número 40.

- Secar em estufa de $105^{\circ}$ até $110^{\circ}$ durante 24 horas e deixar esfriar.

- Pesar 25 g do material e separar em 4 piquinômetros preenchidos com $250 \mathrm{ml}$.

- Extrair o ar usando uma bomba de vácuo durante 10 minutos

- Preencher os piquinômetros até o topo com água destilada.

- Pesar novamente e calcular os valores do $G_{s}$ apartir das equações 3.1 a 3.3 de acordo com o procedimento acima citado. 
Na Figura 25 é ilustrado parte do processo de granulometria e pesagem realizados no laboratório da PUC-Rio.
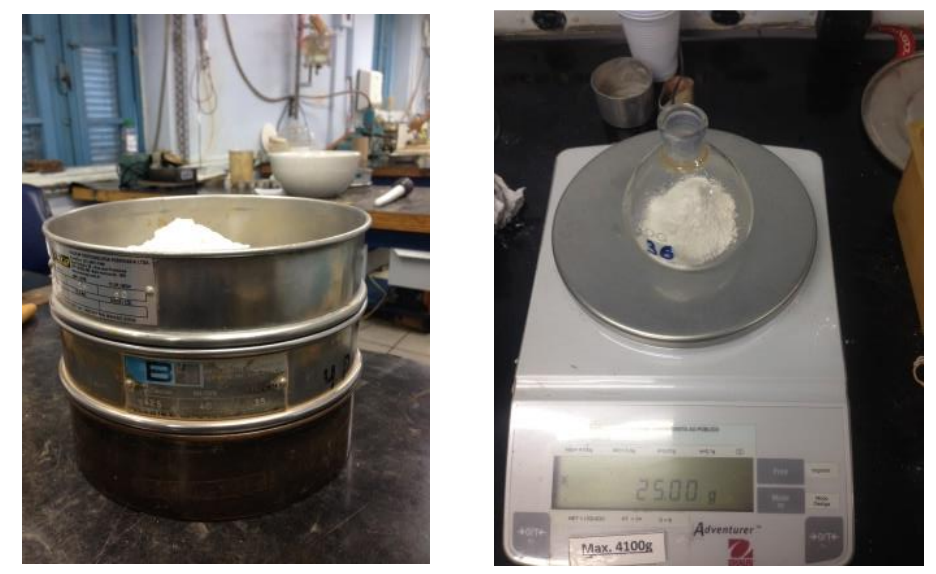

Figura 25 Determinação do Gs da rocha carbonática travertino.

$\mathrm{Na}$ Tabela 5 são apresentados os registros utilizados para calcular o valor de $G_{s}=2.7$, o qual é coerente com os dados apresentados na literatura (Huillca, 2014).

Tabela 5 Cálculo da densidade relativa dos grãos Gs.

\begin{tabular}{lcccc}
\hline \multicolumn{1}{c}{ Picnômetro } & 2 & 11 & 32 & 36 \\
\hline Volume do frasco $(\mathrm{ml})$ & 250 & 250 & 250 & 250 \\
Temperatura $\left({ }^{\circ} \mathrm{C}\right)$ & 23.5 & 23.5 & 23.5 & 23.5 \\
Mfa = Massa do frasco + água & 342.79 & 321.74 & 328.15 & 343.06 \\
Ms=Massa do solo $(\mathrm{g})$ & 25.00 & 25.00 & 25.00 & 25.00 \\
$\begin{array}{l}\text { Mfas=Massa do } \\
\text { frasco+água+solo(g) }\end{array}$ & 358.54 & 337.49 & 343.92 & 358.79 \\
Ms-Mfas+Mfa (g) & 9.25 & 9.25 & 9.23 & 9.34 \\
\hline Densidade relativa dos Grãos: & 2.700 & 2.700 & 2.706 & 2.704 \\
\hline
\end{tabular}

O volume total $V$ é obtido pela geometria das amostras, enquanto o volume de vazios $V_{v}$ é resultado da subtração do volume seco dos grãos $V_{s}$ (obtido através do processo de secagem em estufa de $105^{\circ}$ até $110^{\circ}$ durante 24 horas ) do volume de total $V$ (calculado pela geometria da amostra). Assim a porosidade total é determinada pelas seguintes relações matemáticas

$$
\phi_{T}=\frac{V_{v}}{V} \times 100 \quad(\%)
$$




$$
\begin{gathered}
V_{s}=\frac{P_{s}}{\gamma_{s}} \\
G_{s}=\frac{\gamma_{s}}{\gamma_{w}}
\end{gathered}
$$

onde $\gamma_{w}$ é o peso específico da água a $4^{\circ} \mathrm{C}\left(1 \mathrm{gf} / \mathrm{cm}^{3}\right.$ ou $\left.9.8 \mathrm{KN} / \mathrm{m}^{3}\right), \gamma_{s}$ é o peso específico dos grãos ou dos sólidos e $P_{s}$ é o peso dos constituintes sólidos da amostra (peso seco).

Calculada a porosidade total para cada amostra com a equação (3.1), os corpos de prova verticais e horizontais foram classificados pela porosidade total e pela orientação das camadas. Esta classificação está baseada na classificação de (Archie, 1952; Sander, 1967 apud Rodriguez, 2006). No entanto, no presente trabalho devido alguns valores ultrapasaram o limite de $8 \%$, com valores muito próximos a este limite, sendo o caso dos CPHs 13,14, 15, entre outros (Figura 26), os valores de baixa porosidade irão até $8,5 \%$. A partir de $8.5 \%$ até $16 \%$ foi considerado como porosidade média. No apêndice I são apresentadas as Tabelas A1, A2 e A3, que contém os resultados da porosidade total obtida em amostras com acamamento horizontal, inclinado e vertical com relação ao eixo axial. Nas Figura 26, 27 e 28 apresenta-se a distribuição das porosidades dos corpos de prova testados no laboratório.

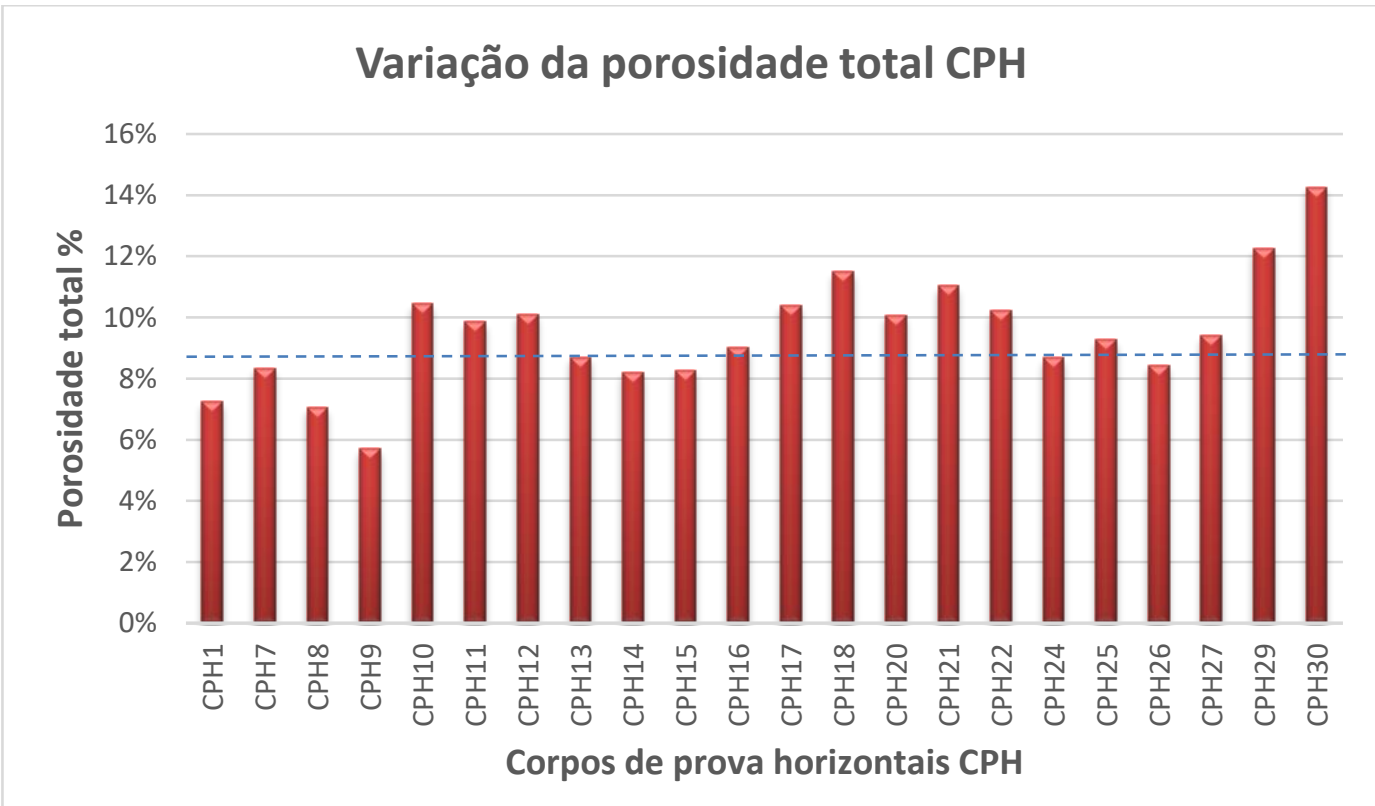


Figura 26 Variação da porosidade total $\mathrm{CPH}$, retirados do Bloco 1.

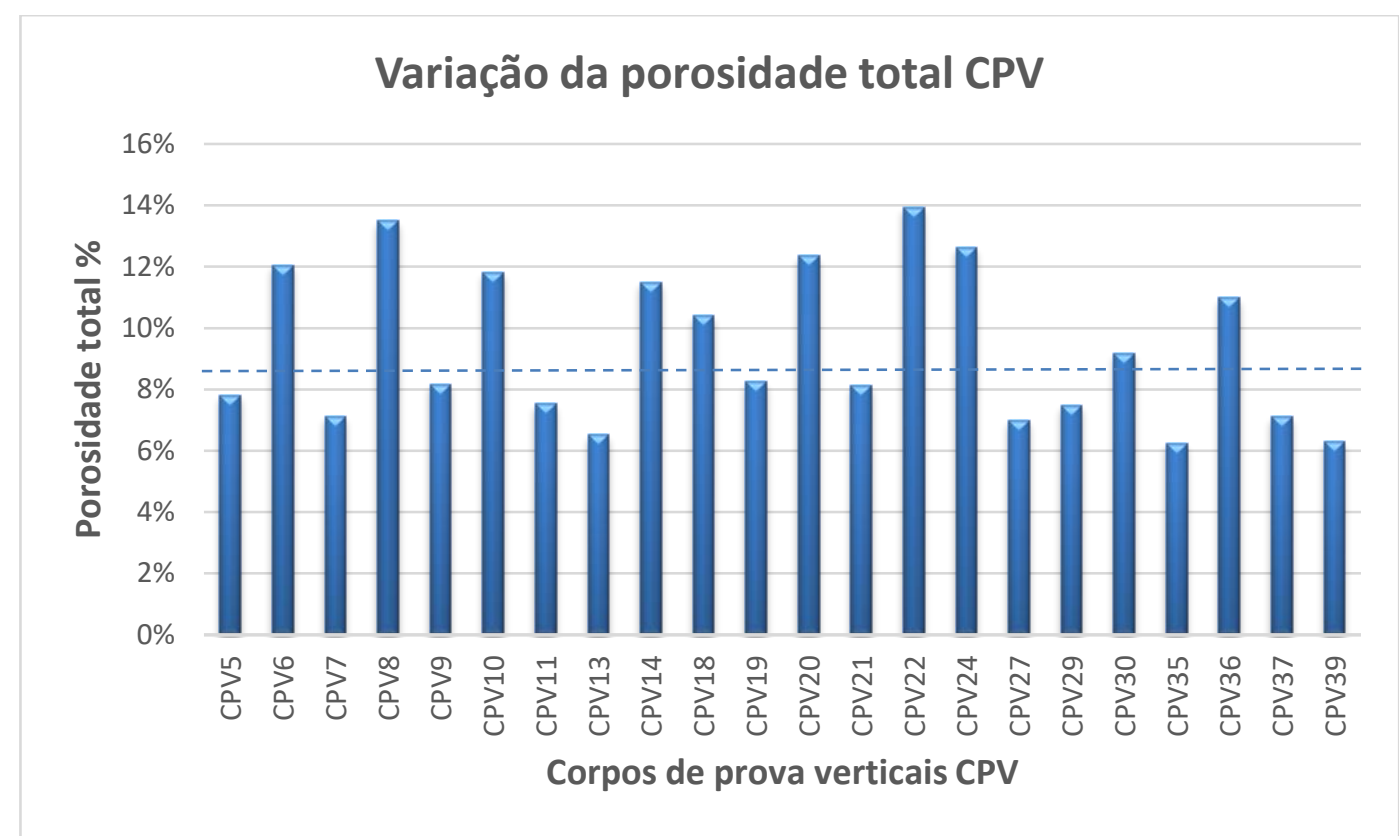

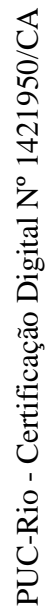

Figura 27 Variação da porosidade total CPV, retirados do Bloco 1.

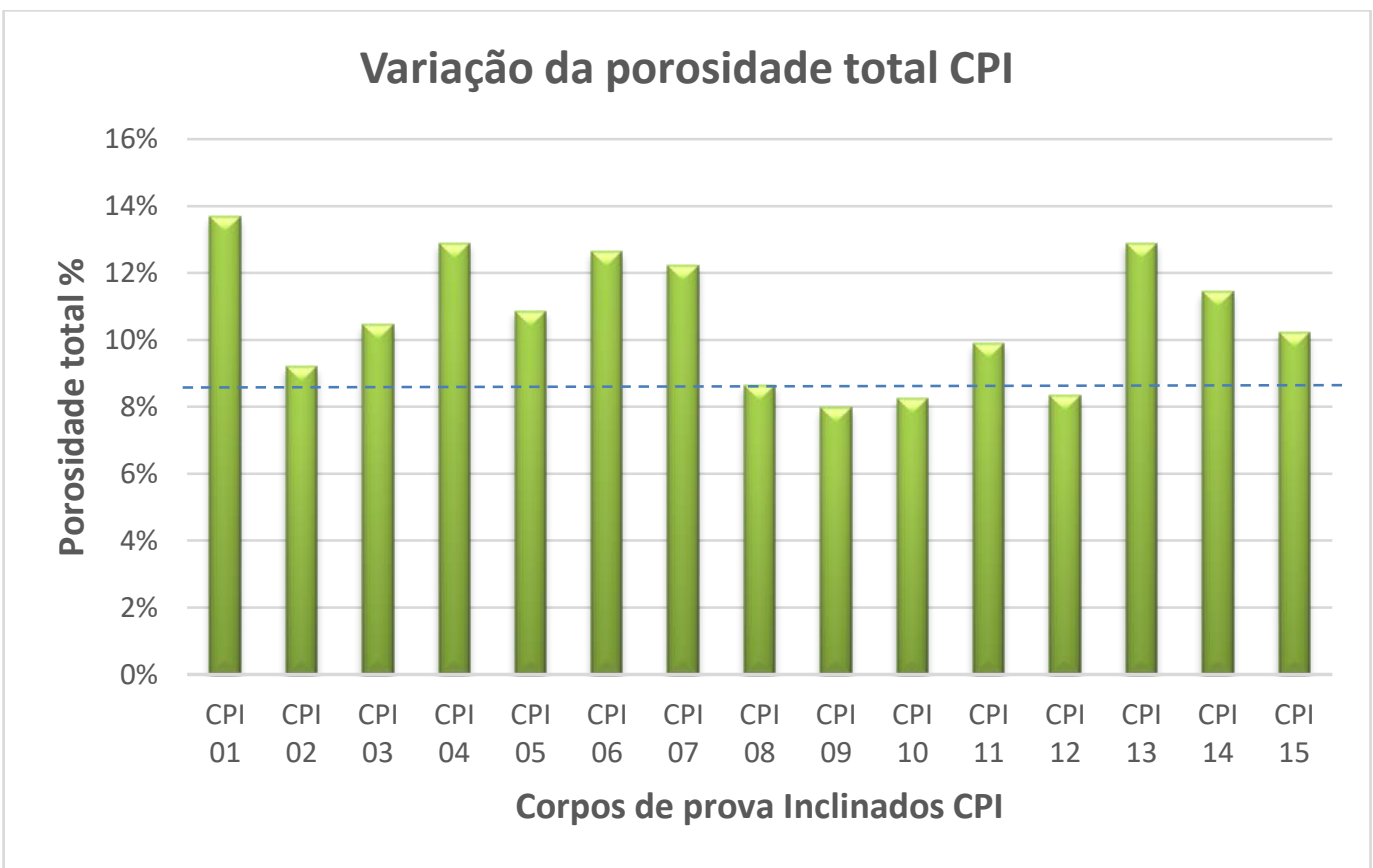

Figura 28 Variação da porosidade total CPI, retirados do Bloco 2. 


\subsection{3.}

\section{Classificação dos corpos de prova}

Os corpos de prova foram classificados de acordo com a porosidade total e a orientação do acamamento. Assim, nos corpos de prova verticais, CPV, o acamamento é ortogonal ao eixo axial da amostra, que coincide com a direção de carregamento, $\beta=0^{\circ}$; nos corpos de prova inclinados, CPI, o acamamento é inclinado ao eixo axial; enquanto nos corpos de prova horizontais, $\mathrm{CPH}$, o acamamento é paralelo ao eixo axial, $\beta=90^{\circ}$. A Tabela 6 ilustra os critérios de classificação segundo a direção do acamamento e os intervalos de porosidade baseados em (Rodriguez, 2006), com valores modificados segundo os resultados obtidos no laboratório e classificados previamente.

Tabela 6 Classificação dos corpos de prova da rocha travertino, pela porosidade e orientação das camadas.

\section{Classificação dos CP pela porosidade total}

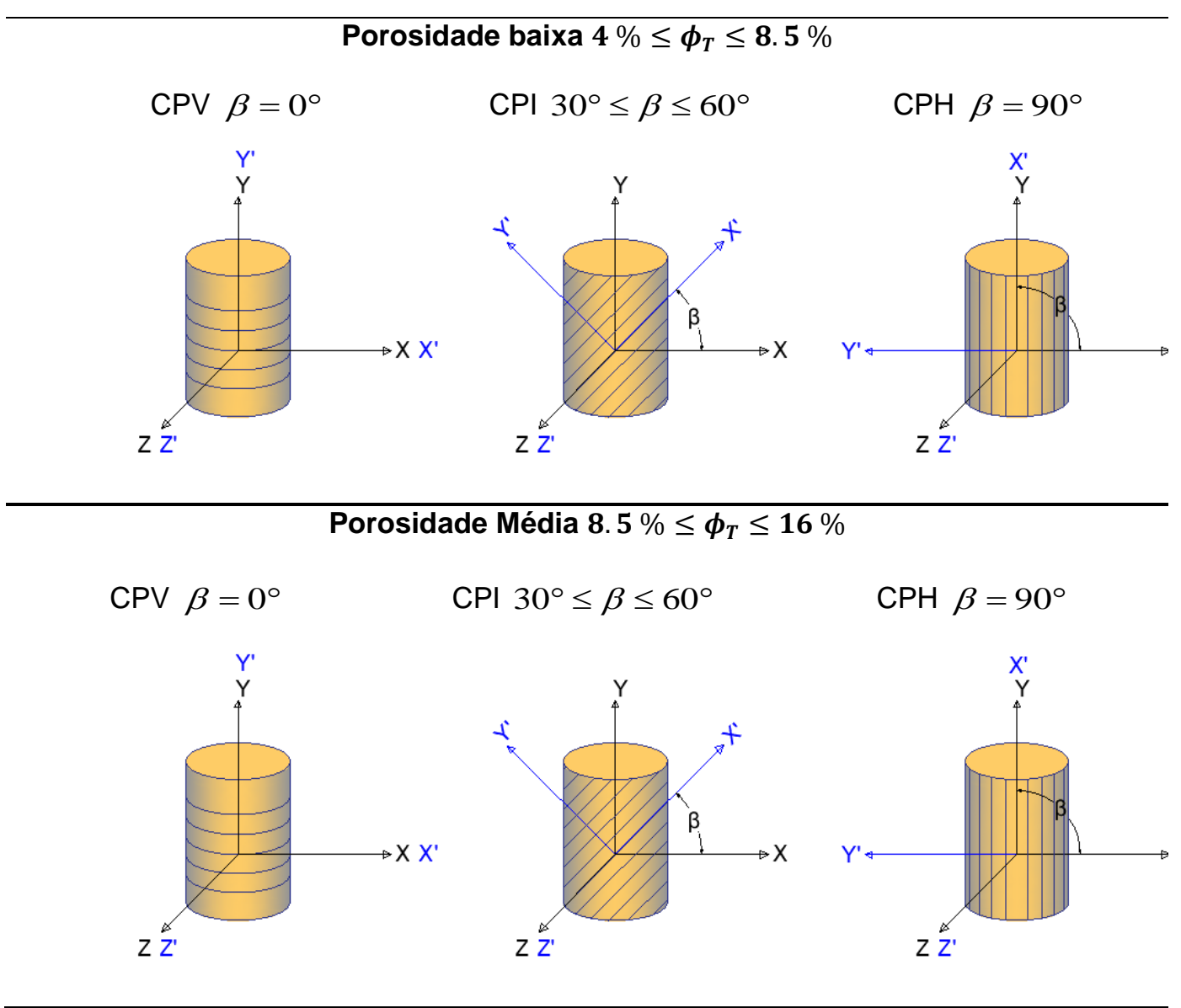




\subsection{4.}

\section{Ensaios triaxiais à compressão do travertino}

Os ensaios convencionais triaxiais à compressão drenados foram realizados no Laboratório de Estruturas e Materiais da PUC-Rio baseados na norma ASTM 7012-13 com o equipamento do fabricante GCTS, modelo RTR 1500, com capacidade de carregamento axial até $1500 \mathrm{KN}$, capacidade de carregamento dinamica até $800 \mathrm{KN}$, pressão de confinamento máxima de $210 \mathrm{MPa}$, diâmetro máximo da amostra de $100 \mathrm{~mm}$, velocidade máxima de $700 \mathrm{~mm} / \mathrm{minuto}$ e com control de temperatura até $200^{\circ} \mathrm{C}$. O equipamento triaxial é observado na Figura 29.

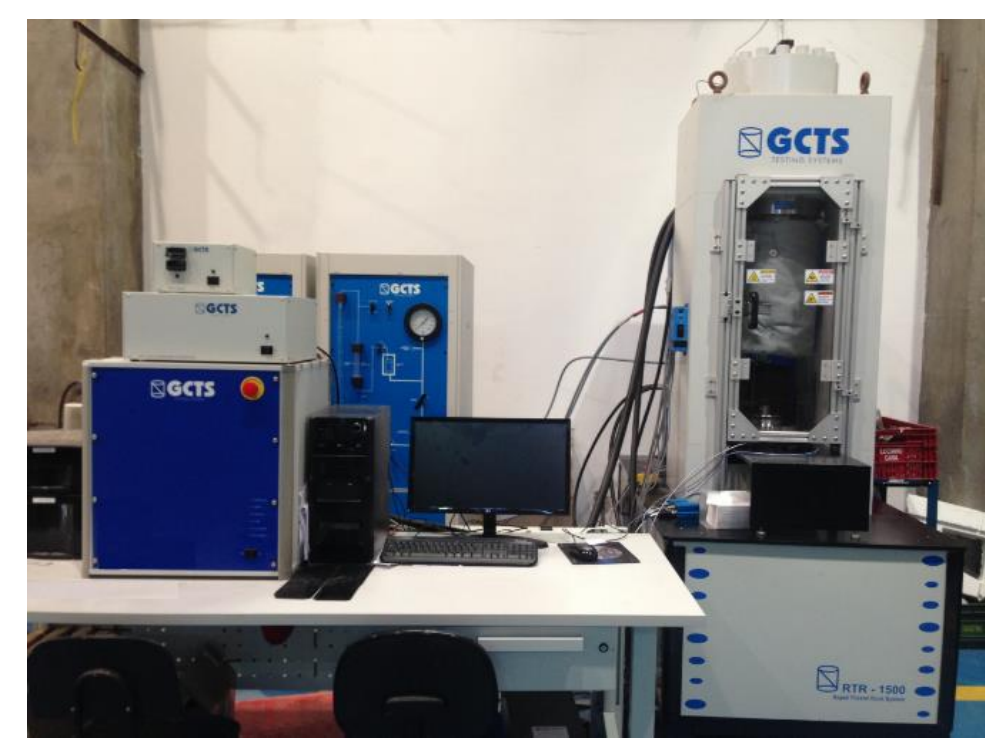

Figura 29 Equipamento triaxial usado nos ensaios do travertino, PUC-Rio.

Previamente no Laboratório de Geotecnia e Meio Ambiente da PUC-Rio, as amostras da rocha carbonática travertino foram revestidas com uma argamassa que é uma mistura homogênea de agregado miúdo, aglomerante inorgânico e água, com propriedades de aderência e endurecimento. Desta forma os poros externos foram preenchidos reduzindo o dano nas membranas por causa das tensões aplicadas durante o ensaio. Posterirmente cada amostra foi inserida na célula triaxial e submetida a tensões hidrostáticas de 10,20,30 MPa, a uma taxa de carregamento de $1 \mathrm{MPa} / \mathrm{min}$. Numa segunda etapa foi aplicada uma taxa de carregamento com controle de deformação axial de 50 microstrain/min. Ensaios de compressão simples (UCS), são incluídos neste grupo. Na Figura 30 observase o estado de tensões aplicadas no ensaio triaxial à compressão. 


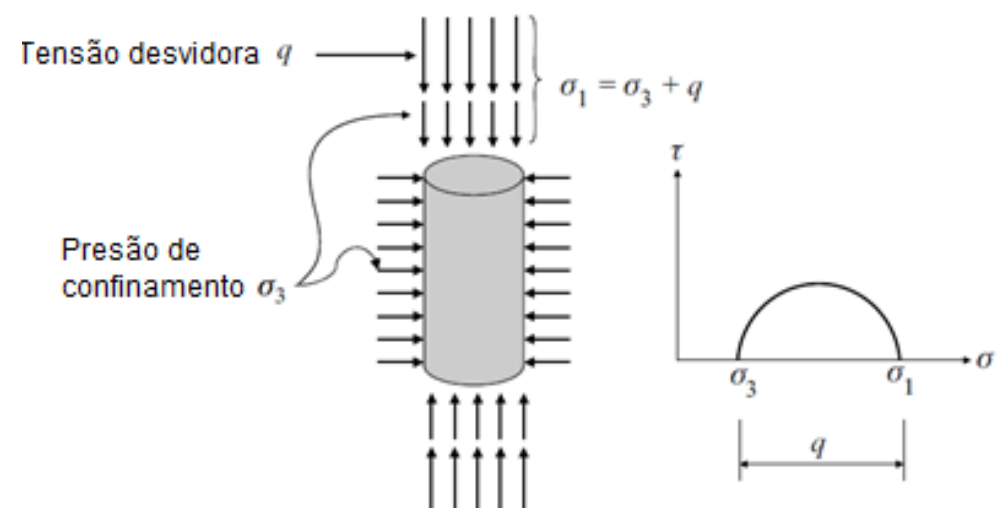

Figura 30 Esquema de ensaio triaxial à compressão (Davis \& Selvadurai, 2002).

Foi testado um grande número de amostras, $\mathrm{CPV}, \mathrm{CPI}$ e $\mathrm{CPH}$, sendo que em alguns ensaios foram observados problemas como furo de membrana, invalidando-os. As amostras selecionadas previamente e que tiveram sucesso nos ensaios triaxiais convencionais à compressão são apresentadas nas Tabela 7, 8 e 9 para corpos de prova verticais, inclinados e horizontais (direção do acamamento em relação ao eixo axial da amostra), respectivamente.

Tabela 7: Ensaios triaxiais em corpos de prova do travertino verticais.

\begin{tabular}{ccccc}
\hline $\begin{array}{c}\text { Corpo de } \\
\text { prova }\end{array}$ & $\begin{array}{c}\text { Relação } \\
\text { diámetro/altura }\end{array}$ & $\begin{array}{c}\text { Tensão de } \\
\text { confinamento MPa }\end{array}$ & $\begin{array}{c}\text { Porosidade } \\
\text { total \% }\end{array}$ & $\begin{array}{c}\text { Classificação } \\
\text { quanto à } \\
\text { porosidade }\end{array}$ \\
\hline CPV 67 & 2.32 & 0.0 & 7.25 & Baixa \\
CPV 71 & 2.25 & 0.0 & 12.44 & Média \\
CPV 7 & 2.16 & 10.0 & 7.13 & Baixa \\
CPV 54 & 2.12 & 10.0 & 11.77 & Média \\
CPV 13 & 2.16 & 20.0 & 6.52 & Baixa \\
CPV 14 & 2.13 & 20.0 & 11.49 & Média \\
CPV 27 & 2.16 & 30.0 & 6.99 & Baixa \\
CPV 30 & 2.13 & 30.0 & 9.18 & Média \\
\hline
\end{tabular}

Tabela 8 Ensaios triaxiais em corpos de prova do travertino inclinados.

\begin{tabular}{ccccc}
\hline $\begin{array}{c}\text { Corpo de } \\
\text { prova }\end{array}$ & $\begin{array}{c}\text { Relação } \\
\text { diámetro/altura }\end{array}$ & $\begin{array}{c}\text { Tensão de } \\
\text { confinamento MPa }\end{array}$ & $\begin{array}{c}\text { Porosidade } \\
\text { total \% }\end{array}$ & $\begin{array}{c}\text { Classificação } \\
\text { quanto à } \\
\text { porosidade }\end{array}$ \\
\hline CPI 07 & 2.23 & 0.0 & 12.21 & Média \\
CPI 11 & 2.23 & 10.0 & 9.88 & Média \\
CPI 05 & 2.23 & 20.0 & 10.86 & Média \\
CPI 03 & 2.23 & 30.0 & 10.45 & Média \\
\hline
\end{tabular}


Tabela 9 Ensaios triaxiais em corpos de prova do travertino horizontais.

\begin{tabular}{ccccc}
\hline $\begin{array}{c}\text { Corpo de } \\
\text { prova }\end{array}$ & $\begin{array}{c}\text { Relação } \\
\text { diámetro/altura }\end{array}$ & $\begin{array}{c}\text { Tensão de } \\
\text { confinamento MPa }\end{array}$ & $\begin{array}{c}\text { Porosidade } \\
\text { total \% }\end{array}$ & $\begin{array}{c}\text { Classificação } \\
\text { quanto à } \\
\text { porosidade }\end{array}$ \\
\hline CPH 14 & 2.21 & 0.0 & 8.21 & Baixa \\
CPH 11 & 2.20 & 0.0 & 9.86 & Média \\
CPH 8 & 2.18 & 10.0 & 7.05 & Baixa \\
CPH 12 & 2.18 & 10.0 & 10.11 & Média \\
CPH 7 & 2.14 & 20.0 & 8.34 & Baixa \\
CPH 20 & 2.20 & 20.0 & 10.08 & Média \\
CPH 13 & 2.13 & 30.0 & 8.70 & Média \\
CPH 22 & 2.18 & 30.0 & 10,21 & Média \\
\hline
\end{tabular}

Assim, observa-se que cada tipo de ensaio é repetido quatro vezes: dois para CPHs, com baixa e média porosidades, e dois CPVs, também com baixa e média porosidades, à exceção do ensaio com confinamento de $30 \mathrm{MPa}$. No caso dos CPIs os ensaios que tiveram sucesso foram todos com porosidade média.

\subsection{5.}

\section{Ensaios hidrostáticos com amostras de rocha travertino}

Os ensaios de hidrostáticos foram realizados no laboratório de Engenharia Civil da PUC-Rio com o equipamento do fabricante GCTS. As amostras CPV39, CPV22, CPH9 e CPH30 foram inseridas na célula triaxial com pressão de confinamento inicial de $0.0 \mathrm{MPa}$, sofrendo incrementos a uma taxa de carregamento de $1 \mathrm{MPa} / \mathrm{min}$, com ciclos de carregamento e descarregamento até a ruptura. Na Tabela 10 são apresentados os corpos de prova que foram submetidos ao ensaio hidrostático.

Tabela 10 Amostras de rocha carbonática travertino para ensaios hidrostáticos.

\begin{tabular}{cccc}
\hline Corpo de prova & $\begin{array}{c}\text { Relação } \\
\text { altura/diâmetro }\end{array}$ & $\begin{array}{c}\text { Porosidade total } \\
\%\end{array}$ & $\begin{array}{c}\text { Classificação } \\
\text { (Rodríguez, 2006) }\end{array}$ \\
\hline CPV39 & 2.1 & 5.92 & Baixa \\
CPV22 & 2.2 & 13.59 & Média \\
CPH9 & 2.2 & 5.32 & Baixa \\
CPH30 & 2.2 & 13.91 & Média \\
\hline
\end{tabular}




\section{2. Implementação dos modelos constitutivos}

Os algoritmos para representação dos modelos elastoplásticos Lade-Kim, CALK e Cam Clay Modificado com Coesão foram desenvolvidos nos programas FORTRAN $90 \AA$ e MATLAB 2017®, utilizando a formulação tipo explícito. Os algoritmos simulam o ensaio triaxial drenado. Aplicando um incremento de deformação axial $d \varepsilon_{1}$ e mantendo constante as tensões radiais $\left(\sigma_{2}=\sigma_{3}\right)$ Figura 31 (a), foi possível obter como resposta as deformações radiaix $\varepsilon_{1}, \varepsilon_{2}$ e a tensão axial $\sigma_{1}$, como podese observar na Figura 31 (b).

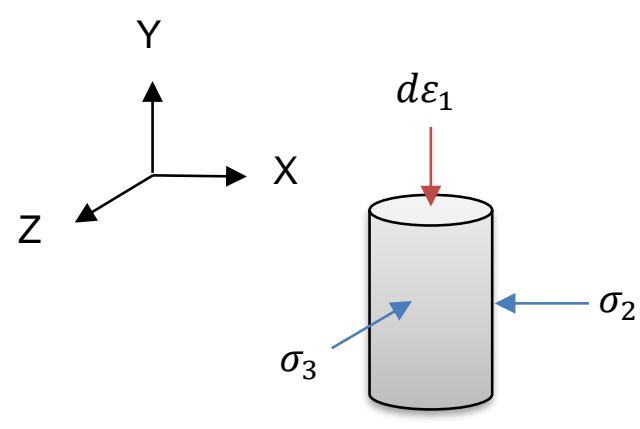

(a)

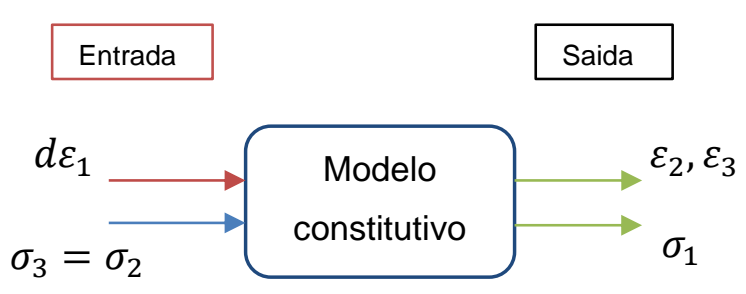

(b)

Figura 31 Esquemas de representação dos algoritmos implementados (a) esquema do ensaio triaxial drenado. (b) modelo conceitual das variveis de entrada e saida dos algortimos.

A formulação tipo explícito foi escolhida pela facilidade das derivada e por que soamente precisa conhecer as tensões e o parâmetro de endurecimento no incio para calcular as tensões posteriores. No entanto, a precisão depende do tamanho do incremento, geralmente incrementos pequenos garante a convergência do algoritmo. Por outra parte o algoritmo tiplo implicito é considerado melhor nas aproximações aos dos dados experimentais, já que trabalha com as tensões no fim do incremento, satisfazendo melhor o retorno das tensões para a condição da superfície de escoamento igual a zero. No entanto, este tipo de algoritmo implícito requer as derivadas de segunda ordem da função de escoamento e potencial plástico, o que torna um algoritmo de difícil implementação. A seguir são descritos, brevemente, os algoritmos dos modelos Lade-Kim e Cam Clay Modificado com Coesão e CALK. Tais modelos têm como 
objetivo representar o comportamento tensão vs deformação observado nos ensaios laboratoriais.

\subsection{1.}

\section{Algoritmo Lade-Kim isotrópico}

Como já mencionado no Capítulo 2, os incrementos de deformação total têm duas parcelas, uma elástica e outra plástica. Na relação tensão vs. deformação o algoritmo usa a lei de Hooke para calcular a parcela elástica e a regra de fluxo não associada para calcular a parcela plástica. Na equação (3.6) observa-se que os incrementos de deformação plástica estão em termos do multiplicador plástico e da função potencial plástica.

$$
\begin{gathered}
\{d \varepsilon\}=\left\{d \varepsilon^{e}\right\}+\left\{d \varepsilon^{p}\right\} \\
\left\{d \varepsilon^{e}\right\}=\left[D^{e}\right]^{-1}\{d \sigma\} \\
\left\{d \varepsilon^{p}\right\}=\Lambda\left\{\frac{\partial g_{p}}{\partial \sigma}\right\}
\end{gathered}
$$

As relações constitutivas como derivadas das funções de escoamento, potencial plástico e formulações em geral podem ser encontradas no Apêndice II. A seguir são apresentadas as etapas usadas no desenvolvimento do algoritmo.

Algoritmo tipo explícito do modelo Lade-Kim Isotrópico

Parâmetros de entrada:

Inicialize o vetor de parâmetros: $\left\{a, m, \eta_{1}, k_{u r}, n, v, \psi_{2}, \mu, C, P, h, \alpha\right\}$

$$
\psi_{1}=0.00155 \cdot m^{-1.27}
$$

Constantes do modelo: $\rho=\frac{p}{h}$

$$
D=\left(\frac{C}{27 \cdot \psi_{1}+3}\right)^{\rho}
$$

Vetor de tensões e deformações iniciais. $\{\varepsilon\},\{d \varepsilon\},\{\sigma\},\{d \sigma\}$

Cálculo dos Invariantes $I_{1} I_{2}, I_{3}, J_{1}, J_{2}, J_{3}$

Cálculo da matriz elástica $\left[D^{e}\right]$

Cálculo da tensão tentativa $\{d \sigma\}=\left[D^{e}\right]\{d \varepsilon\}$ 
Início: se $\varepsilon_{1}<\varepsilon_{\lim }\left(\varepsilon_{\lim }=\right.$ deformação axial limite $)$ execute:

Translação dos eixos das tensões para incluir a coesão, $\{\bar{\sigma}\}=\{\sigma\}+a \cdot P a$

Cálculo da função de escoamento em termo das tensões, $f_{s}^{\prime}(\{\sigma\})$ Equação (2.39)

Cálculo da função de escoamento em termos do trabalho plástico. $f_{w}^{\prime \prime}\left(W_{p}\right)$ Equação (2.46)

Cálculo da função de escoamento, $F=f_{s}^{\prime}(\{\sigma\})-f_{w}^{\prime \prime}\left(W_{p}\right)$

Verificação da condição de plasticidade.

Se $F \leq 0$, caso Elástico: Neste caso, o multiplicador plástico $\Lambda=0$ e o estado de tensões é elástico.

Obtém-se o novo Incremento de tensões, $\{d \sigma\}=\left[D^{e}\right]\{d \varepsilon\}$

Atualização do estado de tensões e deformações:

Estado de tensões: $\{\sigma\}=\{\sigma\}+\{d \sigma\}$

Estado de deformações: $\{\varepsilon\}=\{\varepsilon\}+\{d \varepsilon\}$

Se $F>0$, caso plástico: o multiplicador plástico $\Lambda>0$ no carregamento.

Cálculo das derivadas da função de escoamento em termos de tensão:

$$
\left\{\frac{\partial f_{s}^{\prime}}{\partial \sigma}\right\}=\frac{\partial f_{s}^{\prime}}{\partial I_{1}}\left\{\frac{\partial I_{1}}{\partial \sigma}\right\}+\frac{\partial f_{s}^{\prime}}{\partial I_{2}}\left\{\frac{\partial I_{2}}{\partial \sigma}\right\}+\frac{\partial f_{s}^{\prime}}{\partial I_{3}}\left\{\frac{\partial I_{3}}{\partial \sigma}\right\}
$$

Cálculo das derivadas da função de escoamento em termos do trabalho plástico:

$$
\begin{aligned}
\frac{\partial f_{w}^{\prime \prime}}{\partial W_{p}} & =\rho \cdot\left(D \cdot P_{a}\right)^{-\frac{1}{\rho}} \cdot W_{p}{ }^{\frac{1}{\rho}-1} \text { condição de endurecimento } \\
\frac{\partial f_{w}^{\prime \prime}}{\partial W_{p}} & =-\frac{A B}{P a} e^{-\frac{B \cdot W_{p}}{P_{a}}} \text { condição de amolecimento }
\end{aligned}
$$

Cálculo da derivada da função potencial plástico, $\left\{\frac{\partial g_{p}}{\partial \sigma}\right\}$, (Equação no Apêndice II)

Condição de plastificação:

$$
\begin{aligned}
& d F=\left\{\frac{\partial f_{s}^{\prime}}{\partial \sigma}\right\}^{T}\{d \sigma\}+\frac{\partial f_{w}^{\prime \prime}}{\partial W_{p}} d W_{p}=0 \\
& \text { Sendo } d W_{p}=\{\sigma\}^{T}\left\{d \varepsilon^{P}\right\} \text { e }\left\{d \varepsilon^{p}\right\}=\Lambda\left\{\frac{\partial g_{p}}{\partial \sigma}\right\}
\end{aligned}
$$

Cálculo do multiplicador plástico: 


$$
\Lambda=\frac{\left\{\frac{\partial f_{s}^{\prime}}{\partial \sigma}\right\}^{T}\left[D^{e}\right]\{d \varepsilon\}}{\left\{\frac{\partial f_{s}^{\prime}}{\partial \sigma}\right\}^{T}\left[D^{e}\right]\left\{\frac{\partial g_{p}}{\partial \sigma}\right\}-\frac{\partial f_{w}^{\prime \prime}}{\partial W_{p}}\{\sigma\}^{T}\left\{\frac{\partial g_{p}}{\partial \sigma}\right\}}
$$

Cálculo da matriz elastoplástica $\left[D^{e p}\right]$

$$
\left[D^{e p}\right]=\left[D^{e}\right]-\frac{\left[D^{e}\right]\left\{\frac{\partial g_{p}}{\partial \sigma}\right\}\left\{\frac{\partial f_{s}^{\prime}}{\partial \sigma}\right\}^{T}\left[D^{e}\right]}{\left\{\frac{\partial f_{s}^{\prime}}{\partial \sigma}\right\}^{T}\left[D^{e}\right]\left\{\frac{\partial g_{p}}{\partial \sigma}\right\}-\frac{\partial f_{w}^{\prime \prime}}{\partial W_{p}}\{\sigma\}^{T}\left\{\frac{\partial g_{p}}{\partial \sigma}\right\}}
$$

Obtém-se o Incremento de tensões: $\{d \sigma\}=\left[D^{e}\right]\left(\{d \varepsilon\}-\Lambda\left\{\frac{\partial g_{p}}{\partial \sigma}\right\}\right)=\left[D^{e p}\right]\{d \varepsilon\}$

Atualização do estado de tensões e deformações:

Estado de tensões: $\{\sigma\}=\{\sigma\}+\{d \sigma\}$

Estado de deformações: $\{\varepsilon\}=\{\varepsilon\}+\{d \varepsilon\}$

Subtrair a parcela $a \cdot P a$ das tensões e plotar resultados. $\{\sigma\}=\{\sigma\}-a \cdot P a$

Retornar até cumprir a condição $\varepsilon_{1}=\varepsilon_{\lim }$

\subsection{2.}

\section{Algoritmo do modelo CALK}

O modelo anisotrópico do Lade-Kim implementado neste trabalho, denominado CALK, precisa de 11 parâmetros isotrópicos, 2 parâmetros anisotrópicos (CN e CS) e o parâmetro anisotrópico $\eta_{1}$ do critério de ruptura. Estes fatores de escala (CN e CS), normal e cisalhante, respectivamente, estão presentes no tensor de tensões anisotrópicos e são responsáveis pela variação da resistência decorrente da orientação das camadas da rocha. $O$ parâmetro $\eta_{1}$ permite ajustar os picos das tensões desviadoras máximas em relação à orientação do acamamento.

O modelo CALK foi implementado nos programas FORTRAN $90 \AA$ e MATLAB $2017 \mathrm{a}{ }^{\circledR}$ com base no critério anisotrópico desenvolvido por (Mánica et al., 2016). Foi usado o algoritmo tipo explícito do modelo elastoplástico isotrópico 
Lade-Kim (Kim e Lade, 1988; Lade e Kim, 1988a; 1988b) como base para incorporar anisotropia no modelo. Como foi explicado no capitulo 2, o tensor anisótropico modifica o critério de escoamento e os gradientes das funções potencial plástica e de escoamento. Os invariantes anisotrópicos são calculados a partir das tensões anisotrópicas. A seguir é apresentado o algoritmo tipo explícito anisotrópico (a faixa cinza indica os passos da incorporação de anisotropia) do modelo constitutivo Lade-Kim.

\section{Algoritmo tipo explícito do modelo CALK}

Parâmetros de entrada:

Inicialize o vetor de parâmetros: $\left\{a, m, \eta_{1,} k_{u r}, n, v, \psi_{2}, \mu, C, P, h, \alpha\right\}$

$$
\psi_{1}=0.00155 \cdot m^{-1.27}
$$

Constantes do modelo: $\rho=\frac{p}{h}$

$$
D=\left(\frac{C}{27 \cdot \psi_{1}+3}\right)^{\rho}
$$

Vetor de tensões e deformações iniciais. $\{\varepsilon\},\{d \varepsilon\},\{\sigma\},\{d \sigma\}$

Cálculo dos Invariantes $I_{1} I_{2}, I_{3}, J_{1}, J_{2}, J_{3}$

Cálculo da matriz elástica $\left[D^{e}\right]$

Cálculo da tensão tentativa $\{d \sigma\}=\left[D^{e}\right]\{d \varepsilon\}$

Início: se $\varepsilon_{1}<\varepsilon_{\lim }\left(\varepsilon_{\lim }=\right.$ deformação axial limite) execute:

Translação dos eixos das tensões para incluir a coesão: $\{\sigma\}=\{\sigma\}+a \cdot P a$

Rotação de tensões: Globais à locais $\left\{\sigma^{r}\right\}=\left[M_{R}\right]\{\sigma\}\left[M_{R}\right]^{T}$ Equação (2.1)

Tensor anisotrópico: $\left[\sigma^{A n i}\right]$

Equação(2.3)

Cálculo de invariantes anisotrópicos $A I_{1}, A_{2}, A I_{3}$

Cálculo da função de escoamento em termo das tensões $f_{s}^{\prime}\left(\sigma^{A n i}\right)$ Equação (2.39)

Cálculo da função de escoamento em termos do trabalho plástico $f_{w}^{\prime \prime}\left(W_{p}\right)$ Equação (2.46)

Cálculo da função de escoamento $F=f_{s}^{\prime}\left(\left\{\sigma^{A n i}\right\}\right)-f_{w}^{\prime \prime}\left(W_{p}\right)$

Verificação da condição de plasticidade.

Se $F \leq 0$, caso Elástico: Neste caso o multiplicador plástico $\Lambda=0$ e o estado de tensões é elástico. 
Obtém-se o novo incremento de tensões: $\{d \sigma\}=\left[D^{e}\right]\{d \varepsilon\}$

Atualização do estado de tensões e deformações:

Estado de tensões: $\{\sigma\}=\{\sigma\}+\{d \sigma\}$

Estado de deformações: $\{\varepsilon\}=\{\varepsilon\}+\{d \varepsilon\}$

Se $F>0$, caso plástico: o multiplicador plástico $\Lambda>0$ no carregamento.

Cálculo das derivadas da função de escoamento em termos de tensão:

$$
\begin{aligned}
& \left\{\frac{\partial f_{s}^{\prime}}{\partial \sigma}\right\}=\left[\left(\frac{\partial f_{s}^{\prime}}{\partial A I_{1}}\left\{\frac{\partial A I_{1}}{\partial \sigma^{A n i}}\right\}+\frac{\partial f_{s}^{\prime}}{\partial A I_{2}}\left\{\frac{\partial A I_{2}}{\partial \sigma^{A n i}}\right\}+\frac{\partial f_{s}^{\prime}}{\partial A I_{3}}\left\{\frac{\partial A I_{3}}{\partial \sigma^{A n i}}\right\}\right)^{T} \cdot\left[\frac{\partial \sigma^{A n i}}{\partial \sigma}\right]\right]^{T} \\
& \text { Sendo }\left[\frac{\partial \sigma^{A n i}}{\partial \sigma}\right] \text { a Matriz jacobiana. } \quad \text { (Equação no Apêndice II ) }
\end{aligned}
$$

Cálculo das derivadas da função de escoamento em termos do trabalho plástico:

$$
\begin{aligned}
\frac{\partial f_{w}^{\prime \prime}}{\partial W_{p}} & =\rho \cdot\left(D \cdot P_{a}\right)^{-\frac{1}{\rho}} \cdot W_{p}{ }^{\frac{1}{\rho}-1} \text { condição de endurecimento } \\
\frac{\partial f_{w}^{\prime \prime}}{\partial W_{p}} & =-\frac{A B}{P a} e^{-\frac{B \cdot W_{p}}{P_{a}}} \text { condição de amolecimento }
\end{aligned}
$$

Cálculo da derivada da função potencial plástico: $\left\{\frac{\partial g_{p}}{\partial \sigma}\right\}$ (Equação no Apêndice II )

$$
\left\{\frac{\partial g_{p}}{\partial \sigma}\right\}=\left[\left(\frac{\partial g_{p}}{\partial A I_{1}}\left\{\frac{\partial g_{p}}{\partial \sigma^{A n i}}\right\}+\frac{\partial g_{p}}{\partial A I_{2}}\left\{\frac{\partial g_{p}}{\partial \sigma^{A n i}}\right\}+\frac{\partial g_{p}}{\partial A I_{3}}\left\{\frac{\partial g_{p}}{\partial \sigma^{A n i}}\right\}\right)^{T} \cdot \frac{\partial \sigma^{A n i}}{\partial \sigma}\right]^{T}
$$

$\left\{\partial g_{p} / \partial \sigma\right\}=\left\{\partial g_{p^{(1)}}+\partial g_{p^{(2)}}+\partial g_{p^{(3)}}, \partial g_{p^{(3)}}, \partial g_{p^{(3)}}, 0,0,0\right\}$ Sendo $1,2,3$ componentes do vetor

Condição de plastificação:

$$
\begin{aligned}
& d F=\left\{\frac{\partial f_{s}^{\prime}}{\partial \sigma}\right\}^{T}\{d \sigma\}+\frac{\partial f_{w}^{\prime \prime}}{\partial W_{p}} d W_{p}=0 \\
& \text { Sendo } d W_{p}=\{\sigma\}^{T}\left\{d \varepsilon^{p}\right\} \text { e }\left\{d \varepsilon^{p}\right\}=\Lambda\left\{\frac{\partial g_{p}}{\partial \sigma}\right\}
\end{aligned}
$$

Cálculo do multiplicador plástico: 


$$
\Lambda=\frac{\left\{\frac{\partial f_{s}^{\prime}}{\partial \sigma}\right\}^{T}\left[D^{e}\right]\{d \varepsilon\}}{\left\{\frac{\partial f_{s}^{\prime}}{\partial \sigma}\right\}^{T}\left[D^{e}\right]\left\{\frac{\partial g_{p}}{\partial \sigma}\right\}-\frac{\partial f_{w}^{\prime \prime}}{\partial W_{p}}\{\sigma\}^{T}\left\{\frac{\partial g_{p}}{\partial \sigma}\right\}}
$$

Cálculo da matriz elastoplástica $\left[D^{e p}\right]$

$$
\left[D^{e p}\right]=\left[D^{e}\right]-\frac{\left[D^{e}\right]\left\{\frac{\partial g_{p}}{\partial \sigma}\right\}\left\{\frac{\partial f_{s}^{\prime}}{\partial \sigma}\right\}^{T}\left[D^{e}\right]}{\left\{\frac{\partial f_{s}^{\prime}}{\partial \sigma}\right\}^{T}\left[D^{e}\right]\left\{\frac{\partial g_{p}}{\partial \sigma}\right\}-\frac{\partial f_{w}^{\prime \prime}}{\partial W_{p}}\{\sigma\}^{T}\left\{\frac{\partial g_{p}}{\partial \sigma}\right\}}
$$

Obtém-se o incremento de tensões: $\{d \sigma\}=\left[D^{e}\right]\left(\{d \varepsilon\}-\Lambda\left\{\frac{\partial g_{p}}{\partial \sigma}\right\}\right)=\left[D^{e p}\right]\{d \varepsilon\}$

Atualização do estado de tensões e deformações:

Estado de tensões: $\{\sigma\}=\{\sigma\}+\{d \sigma\}$

Estado de deformações: $\{\varepsilon\}=\{\varepsilon\}+\{d \varepsilon\}$

Subtrair a parcela $a \cdot P a$ das tensões e plotar resultados. $\{\sigma\}=\{\sigma\}-a \cdot P a$

Retornar até cumprir a condição $\varepsilon_{1}=\varepsilon_{\text {lim }}$

\subsection{3.}

\section{Algoritmo Cam Clay Modificado com Coesão (CCMC)}

O algoritmo CCMC tipo explícito foi implementado no FORTRAN 90. Baseado no modelo Cam Clay Modificado. Baseado no trabalho de (Ya et al., 2014) quem incorporou a coesão permitindo que, o modelo CCMC se ajuste à superfície de escoamento do modelo Mohr-Coulomb. No entanto, para o presente trabalho o tensor desviador $q$ foi mantido o mesmo do modelo CCM, considerando que a coesão se desloca nas tensões hidrostáticas. A seguir apresenta-se o esquema do modelo CCMC.

\section{Modelo constitutivo Cam Clay Modificado com Coesão}

Parâmetros de entrada:

Inicialize o vetor de parâmetros $\left\{v, e_{0}, \mathbf{p}_{c i}, k, \lambda, \mathrm{C}, \phi\right\}$

Vetor de tensões e deformações iniciais. $\{\varepsilon\},\{d \varepsilon\},\{\sigma\},\{d \sigma\}$ 
Início: se $\varepsilon_{1}<\varepsilon_{\lim }\left(\varepsilon_{\text {lim }}=\right.$ deformação axial limite) execute:

Cálculo de $\bar{P}, k^{\prime}, G, \mathrm{X}$

Cálculo da matriz elástica $\left[D^{e}\right]$

Vetor de tensões volumétricas $\{\bar{P}\}=\{\bar{P}, \bar{P}, \bar{P}, 0,0,0\}^{T}$

Vetor de tensões desviadoras $\left\{S_{c}\right\}=\{\sigma\}-\{\bar{P}\}$

Cálculo das tensões desviadoras $\bar{q}=\sqrt{\frac{3}{2}\left\{S_{c}\right\}^{T}\left\{S_{c}\right\}}$

Cálculo da função de escoamento $F=\frac{\bar{q}^{2}}{M_{\theta}^{2}}+\bar{P}\left(\bar{P}-P_{C}\right)$

Verificação da condição de plasticidade.

Se $F \leq 0$, caso Elástico: Neste caso o multiplicador plástico $\Lambda=0$ e o estado de tensões é elástico.

Obtém-se o novo incremento de tensões: $\{d \sigma\}=\left[D^{e}\right]\{d \varepsilon\}$

Atualização do estado de tensões e deformações:

Estado de tensões: $\{\sigma\}=\{\sigma\}+a \cdot P a$

Estado de deformações: $\{\varepsilon\}=\{\varepsilon\}+\{d \varepsilon\}$

Se $F>0$, caso plástico: o multiplicador plástico $\Lambda>0$ no carregamento.

Cálculo das derivadas da função de escoamento:

$$
\begin{aligned}
& \left\{\frac{\partial F}{\partial \sigma}\right\}=\frac{\partial F}{\partial \bar{P}}\left\{\frac{\partial \bar{P}}{\partial \sigma}\right\}+\frac{\partial F}{\partial \bar{q}}\left\{\frac{\partial \bar{q}}{\partial \sigma}\right\}=\frac{2 \bar{P}-P_{c}}{3}+\frac{3 S_{c}}{M^{2}} \\
& \frac{\partial F}{\partial \bar{P}}=2 \bar{P}-P_{c}
\end{aligned}
$$

Cálculo das derivadas de endurecimento:

$$
\frac{\partial F}{\partial P_{c}} \frac{\partial P_{c}}{\partial \varepsilon_{v}^{p}}=-\bar{P}_{c}\left(\frac{1+e}{\lambda-k^{\prime}}\right) P_{c}
$$

Cálculo do multiplicador plástico:

$$
\Lambda=\frac{\left\{\frac{\partial F}{\partial \sigma}\right\}^{T}\left[D^{e}\right]\{d \varepsilon\}}{\left\{\frac{\partial F}{\partial \sigma}\right\}^{T}\left[D^{e}\right]\left\{\frac{\partial F}{\partial \sigma}\right\}-\frac{\partial F}{\partial P_{c}} \frac{\partial P_{c}}{\partial \varepsilon_{v}^{p}} \frac{\partial F}{\partial \bar{P}}}
$$


Atualização das deformações plásticas volumétricas:

$$
\left\{d \varepsilon_{v}^{p}\right\}=\Lambda\left\{\frac{\partial F}{\partial \bar{P}}\right\} \quad\left\{d \varepsilon_{s}^{p}\right\}=\Lambda\left\{\frac{\partial F}{\partial \bar{q}}\right\}
$$

Atualização do parâmetro de endurecimento

$$
P_{c}=P_{c n} \exp ^{\left(\frac{1+e}{\lambda-k^{\prime}}\left\{d \varepsilon_{v}^{p}\right\}\right)}
$$

Cálculo da matriz constitutiva elastoplástica $\left[D^{e p}\right]$

$$
\left[D^{e p}\right]=\left[D^{e}\right]-\frac{\left[D^{e}\right]\left\{\frac{\partial F}{\partial \sigma}\right\}\left\{\frac{\partial F}{\partial \sigma}\right\}^{T}\left[D^{e}\right]}{\left\{\frac{\partial F}{\partial \sigma}\right\}^{T}\left[D^{e}\right]\left\{\frac{\partial F}{\partial \sigma}\right\}-\frac{\partial F}{\partial p_{c}} \frac{\partial p_{c}}{\partial \varepsilon_{v}^{p}} \frac{\partial F}{\partial p}}
$$

Obtém-se o novo incremento de tensões: $\{d \sigma\}=\left[D^{e p}\right]\{d \varepsilon\}$

Atualização do estado de tensões e deformações:

Estado de tensões: $\{\sigma\}=\{\sigma\}+\{d \sigma\}$

Estado de deformações: $\{\varepsilon\}=\{\varepsilon\}+\{d \varepsilon\}$

Retornar até cumprir a condição $\varepsilon_{1}=\varepsilon_{\text {lim }}$

\section{3.}

\section{Análise inversa}

Visando a análise inversa, o algoritmo isotrópico Lade-Kim foi incorporado nos códigos de otimização MINPACK e DREAM, usando FORTRAN 90® e MATLAB 2017®, respectivamente.

\subsection{1.}

\section{Implementação do modelo de Lade-Kim no MINPACK}

A implementação do modelo de Lade-Kim foi realizada no FORTRAN 90® usando a subrotina $L m d i F 1$ do MINPACK. Dados de entrada como $N, M_{p}, x_{(n)}$ são requeridos para inicialização do algoritmo. Neste caso o vetor $x_{(n)}$ representa o número os parâmetros calibrados previamente pela metodologia analítica, $M_{p}$ é o vetor dos dados experimentais dos ensaios triaxiais a diferentes tensões de confinamento 10, 20 e $30 \mathrm{MPa}$ e $N$ é o número de parâmetros (variáveis a 
otimizar) que poderiam ser otimizados em cada iteração. A função Fvec representa a função objetivo e é chamada pela subroutina LmdiF1, que minimiza a soma dos quadrados de $M_{p}$ e $N$. Por fim, a subrotina Fdjac computa a diferença do avanço para $M_{p}$ por $N$ na matriz Jacobiana. Na Figura 32 é apresentado o processo de incorporação do modelo de Lade-Kim no MINPACK.

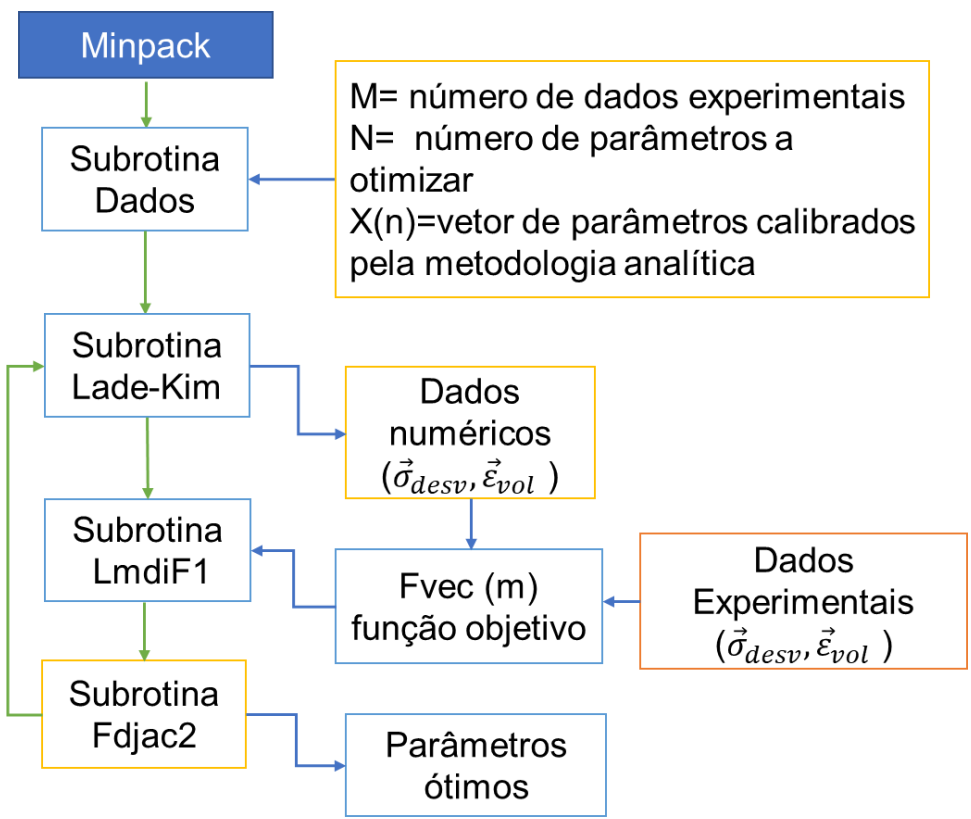

Figura 32. Incorporação de Lade-Kim no MINPACK.

A função objetivo Fvec define a discrepância entre a representação numérica, entre os valores calculados pelo modelo constitutivo de Lade-Kim, e os dados experimentais. A função inclui os vetores $\sigma^{\text {num }}$ e $\sigma^{\exp }$, que representam as tensões numéricas e experimentais, respectivamente, além de incluir os vetores $\varepsilon^{\text {num }}$ e $\varepsilon^{\text {exp }}$, que representam as deformações numéricas e experimentais, respectivamente.

$$
F_{v e c}=\sum_{K=1}^{n_{e}} \sum_{i=1}^{n_{p}}\left(\left\|\left\{\sigma_{d i}^{\exp }\right\}-\left\{\sigma_{d i}^{\text {num }}\right\}\right\|^{2}+\left\|\left\{\varepsilon_{v i}^{\exp }\right\}-\left\{\varepsilon_{v i}^{\text {num }}\right\}\right\|^{2}\right)
$$

onde $n_{e}$ é o número de ensaios triaxiais, $n_{p}$ é o número de registros feitos durante cada ensaio experimental. 


\subsection{2.}

\section{Implementação do modelo de Lade-Kim isotrópico no DREAM}

DREAM é um código de uso livre implementado no MATLAB $2017^{\circledR} @$ por (Vrugt et al., 2008; Vrugt et al., 2009). Os parâmetros ótimos são determinados pelo método estocástico das Cadeias de Markov. A eficácia deste método baseiase em que a distribuição de probabilidade do próximo estado depende do estado atual, e não na sequência de eventos que le precederam. Na Figura 33 é apresentado um esquema geral do funcionamento do modelo isotrópico Lade-Kim incorporado no DREAM.

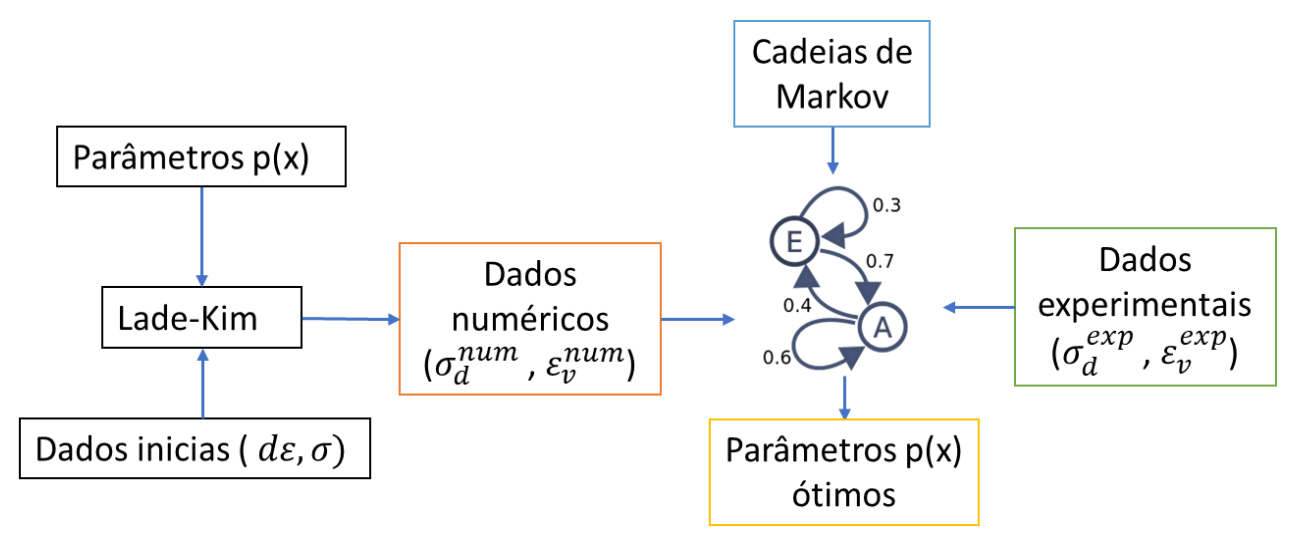

Figura 33 Esquema geral do modelo isotrópico Lade-Kim no DREAM.

O primeiro passo foi definir uma função tipo (.m file) que permite o DREAM explorar e gerar dados numéricos como tensões e deformações. Esta função (Func_name) é o algoritmo do modelo constitutivo elastoplástico isotrópico LadeKim. Na Figura 34 são observados os vetores numéricos das tensões desviadoras $\sigma_{d}^{n u m}$ e deformações volumétricas $\varepsilon_{v}^{\text {num }}$, obtidos como dados de saída $Y$.

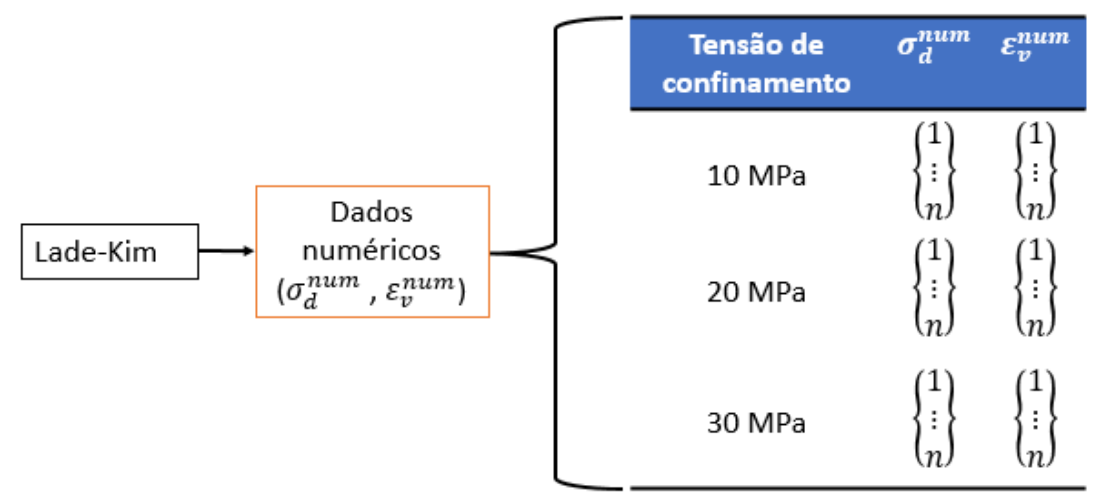

Figura 34 Esquema dos dados numéricos de saída do Lade-Kim no DREAM. 
Na Figura $34 n$ representa a quantidade de dados para cada tensão de confinamento, a qual deve ser igual tanto para os dados numéricos, quanto para os dados experimentais. O mesmo procedimento foi adotado para os dados experimentais, como ilustrado na Figura 35, indicando que, a partir dos ensaios experimentais, foram organizados vetores das tensões desviadoras $\sigma_{d}^{\exp } \mathrm{e}$ deformações volumétricas $\varepsilon_{v}^{\text {exp }}$. Deve-se observar o cuidado ao utilizar o mesmo incremento de deformação axial nas curvas tensão desviadora vs deformação axial e deformação axial vs volumétrica. Os dados experimentais $\tilde{Y}$ são carregados em um arquivo .txt e são chamados mediante o comando (Meas_info.Y).

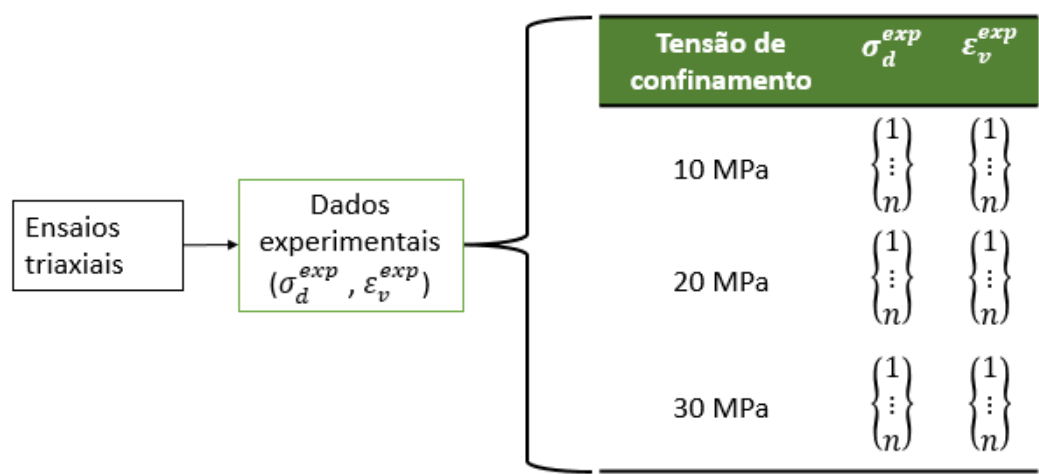

Figura 35 Esquema dos dados experimentais de entrada no DREAM.

O algoritmo DREAM oferece ao usuário múltiplas opções para escolher a função objetivo, dependendo do tipo de problema. Neste caso foi escolhida a equação (2.82) do capítulo 2, sendo o erro considerado explicitamente na equação. Assim, esta função (DREAMpar.lik=11) calcula o erro residual $E(x)=\tilde{Y}-Y\left(X_{i}\right)$, sendo $x_{i}$ o vetor de parâmetros ótimos. Quando são definidos aspectos preliminares como a função objetivo e os dados da distribuição prévia, a inferência bayesiana determina a distribuição posterior dos parâmetros do modelo constitutivo. Na Figura 36 é apresentado o esquema em círculo, sobre os processos da estimativa de parâmetros, neste trabalho aplicado às rochas sedimentares travertino romano e tournemire shale. 
(5) Comparação dados numéricos e experimentais

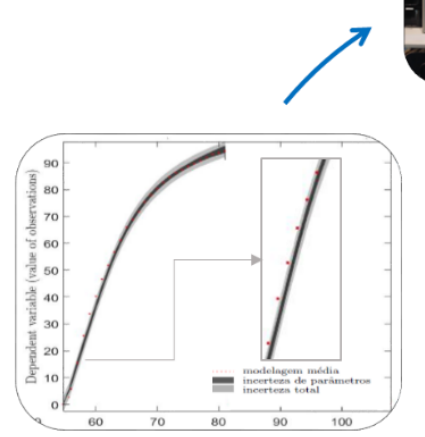

(4) Obtenção de parâmetros
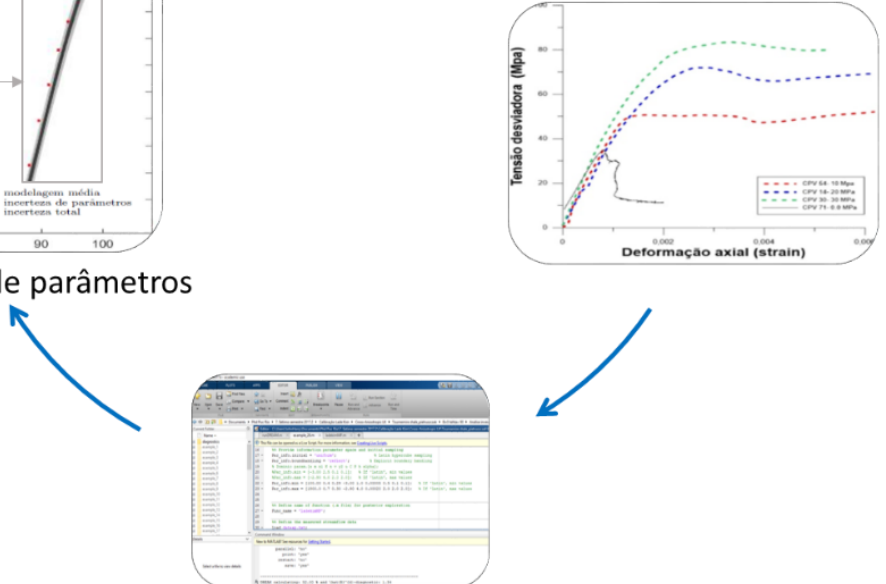

(3) Aplicação do DREAM
(2) Dados Experimentais

(1) Ensaios de Laboratório

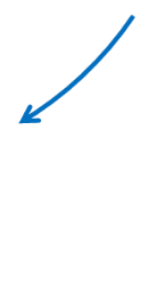

Figura 36 Esquema da sequência na obtenção de parâmetros ótimos. 


\section{4 \\ RESULTADOS E DISCUSSÃO}

Neste capítulo serão apresentados os resultados das etapas propostas nos capitulos 1 e 3 . Neste contexto, serão apresentados resultados dos ensaios de laboratório com uma análise comparativa das resistências máximas e uma breve descrição do tipo de ruptura, incluindo imagens obtidas do microtomógafo. A partir deles são apresentados os parâmetros da rocha carbonática travertino estimados utilizando dois tipos de metodologias: analítica (direta) e análise inversa. Para a metodologia analítica dos modelos constitutivos isotrópicos LadeKim e CCMC e para a análise inversa do modelo isotrópico Lade-Kim foram utilizados os algoritmos MINPACK e DREAM, desenvolvidos nas linguagens FORTRAN 90 e MATLAB 2017, respectivamente. Posteriormente é apresentada uma validação do modelo anisotrópico Lade-Kim para a rocha sedimentar tournemire shale (Niandou et al., 1997; Pietruszczak, 2010) e para a rocha carbonática travertino romano.

\section{1. \\ Resultados dos ensaios triaxiais de compressão}

No presente trabalho o tipo de ruptura nas amostras da rocha carbonática trevertino foi determinado baseado na forma da fissura observada na parte exterior após da finalização do ensaio. O módulo de Young (E) foi determinado no trecho de carregamento descarregamento de todas as curvas de tensão vs deformação. O coeficiente de poisson ( $v$ ) foi determinado no trecho de carregamento e descarregamento da curva deformação volumétrica vs deformação axial.

A seguir são apresentados os resultados dos ensaios com corpos de prova da rocha carbonática travertino, com diferentes porosidades e orientação das camadas em relação ao eixo axial. CPV corresponde ao acamamento ortogonal $\beta=0^{\circ}, \mathrm{CPI}$ ao acamamento inclinado $\beta=45^{\circ}$ e $\mathrm{CPH}$ ao acamamento paralelo $\beta=90^{\circ}$, com relação ao eixo axial, que coincide com o carregamento desviador aplicado. 
4.1.1.

CPV com porosidade $<8.5 \%\left(\beta=0^{\circ}\right)$

Foram executados os ensaios convencionais triaxiais nas amostras CPV 67, CPV 07, CPV13, CPV27, com pressões de confinamento de 0, 10, 20 e $30 \mathrm{MPa}$, respectivamente. Na Tabela 11 são apresentados os resultados dos parâmetros elásticos, tensão de ruptura máxima, tipo de ruptura (obtido através de análise visual do CP após o ensaio laboratorial) e porosidade total.

Tabela 11 Resultados dos ensaios triaxiais à compressão com corpos de prova verticais com porosidade $<8.5 \%$.

\begin{tabular}{ccccccc}
\hline CP & $\begin{array}{c}\text { Tensão } \\
\text { de conf. } \\
\text { (Mpa) }\end{array}$ & $\begin{array}{c}\text { Módulo } \\
\text { Young } \\
\text { E (GPa) }\end{array}$ & $\begin{array}{c}\text { Poisson } \\
(\mathrm{v})\end{array}$ & $\begin{array}{c}\text { Tensão } \\
\text { de } \\
\text { ruptura } \\
(\mathrm{MPa})\end{array}$ & $\begin{array}{c}\text { Porosid } \\
\text { ade } \\
\text { total \% }\end{array}$ & $\begin{array}{c}\text { Tipo de } \\
\text { Ruptura }\end{array}$ \\
\hline CPV 67 & 0.0 & 49.94 & 0.27 & 49.0 & 7.25 & Fendilhamento \\
CPV 7 & 10.0 & 58.29 & 0.25 & 99.4 & 7.13 & Cisalhamento \\
CPV 13 & 20.0 & 61.83 & 0.29 & 120.99 & 6.52 & $\begin{array}{c}\text { Cisalhamento } \\
\text { CPV 27 }\end{array}$ \\
\hline 30.0 & 64.52 & 0.24 & 116.67 & 6.99 & $\begin{array}{c}\text { Colapso de } \\
\text { poros }\end{array}$ \\
\hline
\end{tabular}

$\mathrm{Na}$ Figura 37 são apresentados os resultados dos ensaios triaxiais convencionais para corpos de prova verticais com porosidades menores de $8.5 \%$. Como pode se observar na Figura 37 (a), curva de tensão desviadora vs. deformação axial, o CPV 27 com pressão de confinamento de $30 \mathrm{MPa}$ compactou plasticamente sem atingir à ruptura comparado. Este comportamento é natural em altas tensões de confinamento em rochas com acamamento de poros colapsíveis. Se espera que com o aumento da tensão de confinamento a tensão desviadora aumente, mas isto não aconteceu para o CPV 27. Portanto foi descartado no processo da calibração. Além disso, pode-se observar na Figura 37 (b), curva deformação axial vs deformação volumétrica, que o CPV 27 com 30 MPa não apresentou uma transição nas deformações, passando de copressivo para dilatante, com relação ao CPV 13 e CPV 7. 


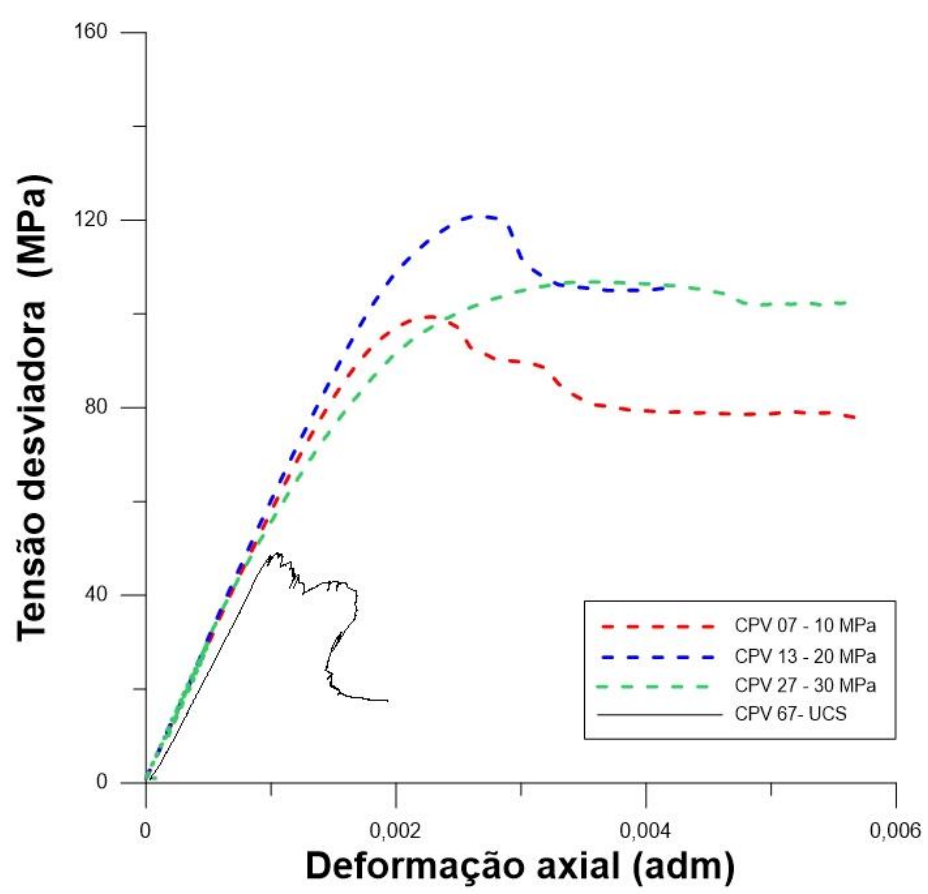

(a)

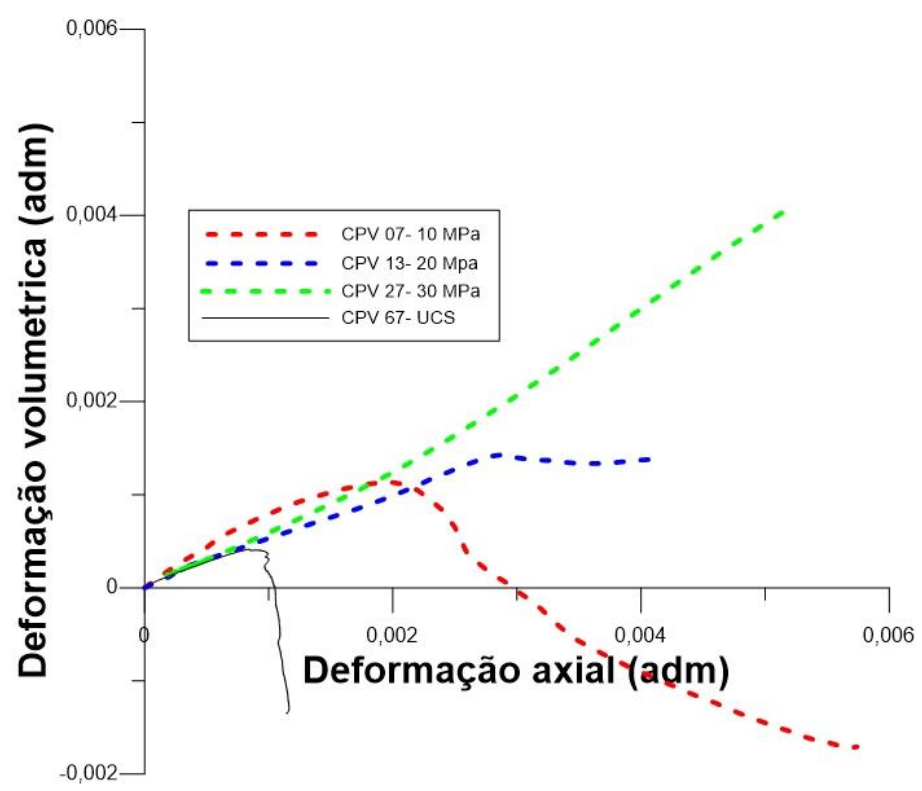

(b)

Figura 37 Resultados dos ensaios triaxiais do travertino com CPV e porosidades < $8.5 \%$. (a) curva tensão desviadora vs deformação axial, (b) curva deformação volumétrica vs deformação axial.

Na Figura 38 são apresentadas as imagens dos corpos de prova testados com camadas verticais ao acamamento para porosidades menores de $8.5 \%$. As características da rocha carbonática travertino, heterogênea e complexa na sua estrutura porosa, podem ocasionar resultados inesperados. Assim, de acordo com 
a Figura 38, existe uma zona visualmente densa localizada na parte superior e uma zona visualmente porosa localizada na parte baixa dos corpos de prova. A zona densa, após os ensaios, não apresentou fissuras externas. No entanto, pode-se observar que as fissuras nos corpos de prova ocorrem na zona visualmente mais porosa. No caso do CPV 13 e CPV 07, a linha preta indica ruptura por cisalhamento. No caso do corpo de prova CPV 27, observa-se fissuras dentro da faixa das linhas pretas, quase perpendiculares ao eixo axial, indicando um possível colapso dos poros. No caso do CPV 67, ensaio uniaxial à compressão simples, se observa uma ruptura paralela ao carregamento, padrão conhecido como fendilhamento.

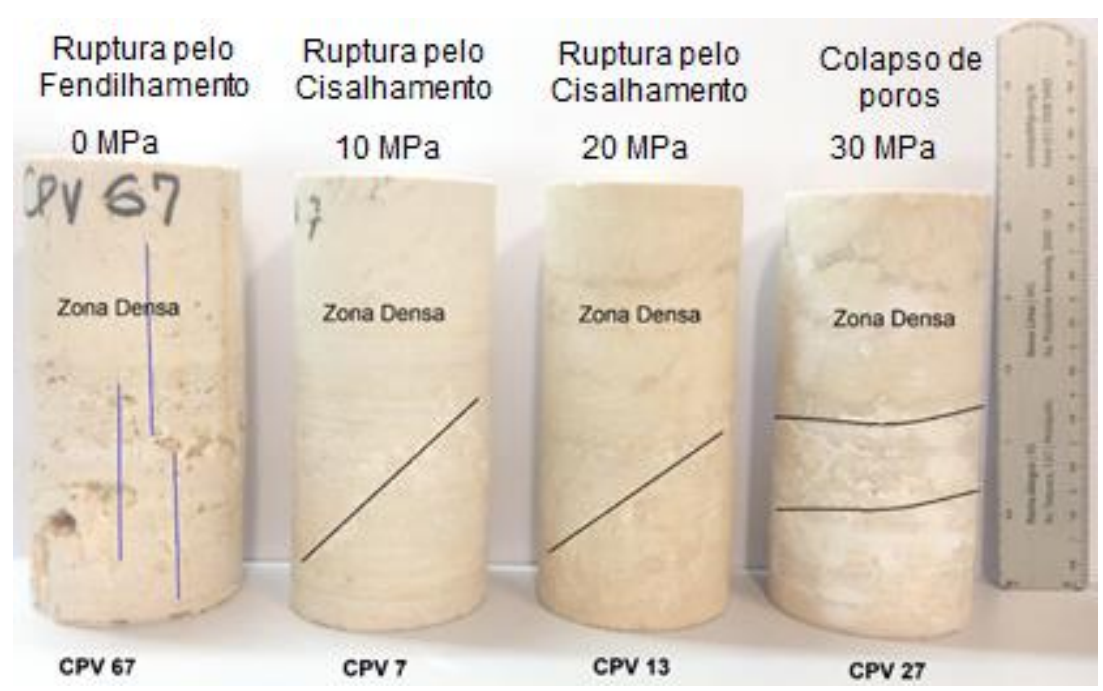

Figura 38 Ensaios triaxiais à compressão do travertino com porosidade $<8.5 \% \mathrm{e}$ orientação das camadas ortogonal ao eixo axial.

\subsection{2.}

CPV com porosidade $>8.5 \%\left(\beta=0^{\circ}\right)$

Foram testados os corpos de prova CPV 54, CPV 14 e CPV 30 da rocha carbonática travertino, com tensões de confinamento de 10, 20 e $30 \mathrm{MPa}$, respectivamente. Os resultados indicam uma ruptura por cisalhamento nos três casos. O CPV71, com pressão de confinamento de $0 \mathrm{MPa}$, apresentou uma ruptura por fendilhamento. Assim, estes tipos de ruptura cisalhamento e fendilhamento em rochas são os mais comuns devido à variação na tensão de confinamento de cada ensaio. Na Tabela 12 são apresentados os resultados dos parâmetros elásticos, tensão de ruptura máxima, tipo de ruptura e porosidade total. 
Tabela 12 Resultados dos ensaios triaxiais a compressão com corpos de prova verticais com porosidades $>8.5 \%$.

\begin{tabular}{ccccccc}
\hline CP & $\begin{array}{c}\text { Tensão } \\
\text { de conf. } \\
\text { MPa }\end{array}$ & $\begin{array}{c}\text { Módulo } \\
\text { Young } \\
\text { E (GPa) }\end{array}$ & $\begin{array}{c}\text { Poisson } \\
(\mathrm{v})\end{array}$ & $\begin{array}{c}\text { Tensão } \\
\text { de } \\
\text { uptura } \\
\text { (MPa) }\end{array}$ & $\begin{array}{c}\text { Porosi } \\
\text { dade } \\
\text { total } \\
\%\end{array}$ & Tipo de Ruptura \\
\hline CPV 71 & 0.0 & 37.0 & 0.30 & 34.74 & 12.44 & Fendilhamento \\
CPV 54 & 10.0 & 47.3 & 0.48 & 53.92 & 11.77 & Cisalhamento \\
CPV14 & 20.0 & 48.67 & 0.4 & 74.03 & 11.49 & Cisalhamento \\
CPV30 & 30.0 & 52.3 & 0.49 & 83.45 & 9.18 & Cisalhamento \\
\hline
\end{tabular}

Na Figura 39 (a), curva tensão desviadora vs deformação axial, foi observado que a resistência aumenta com o incremento da tensão confinante. $\mathrm{Na}$ Figura 39 (b), curva de deformação volumétrica vs deformação axial, não existiu transição de compressivo para dilatante, comumente apresentado nas rochas sedimentares.

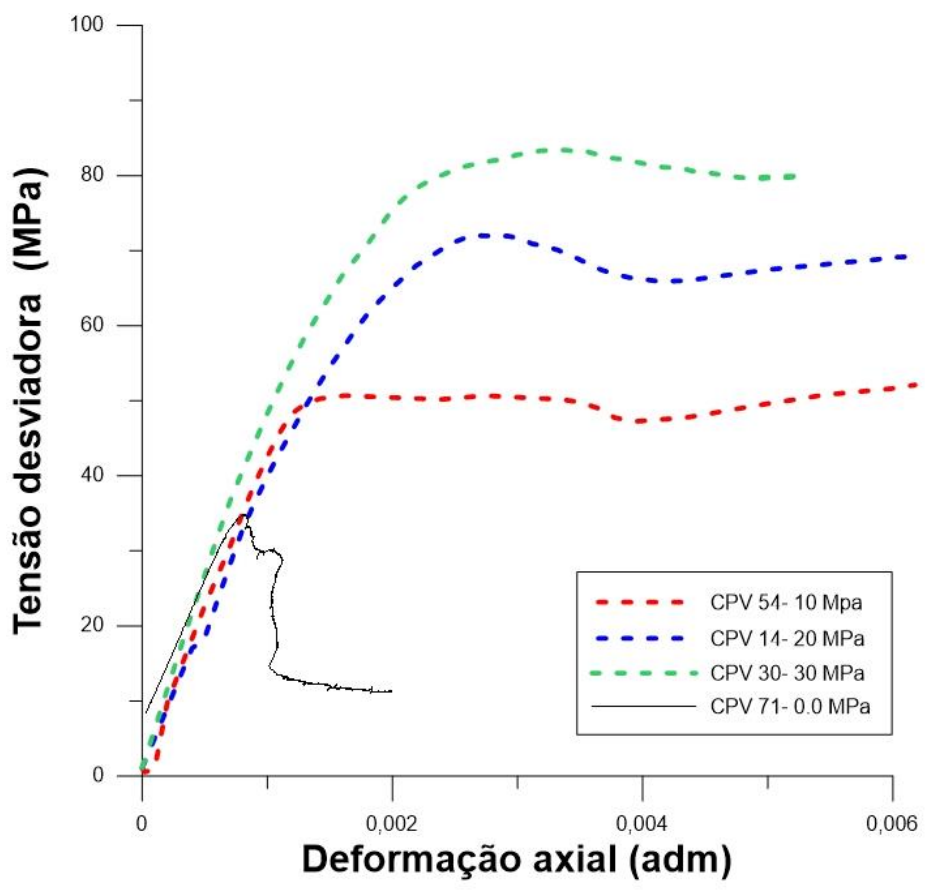

(a) 


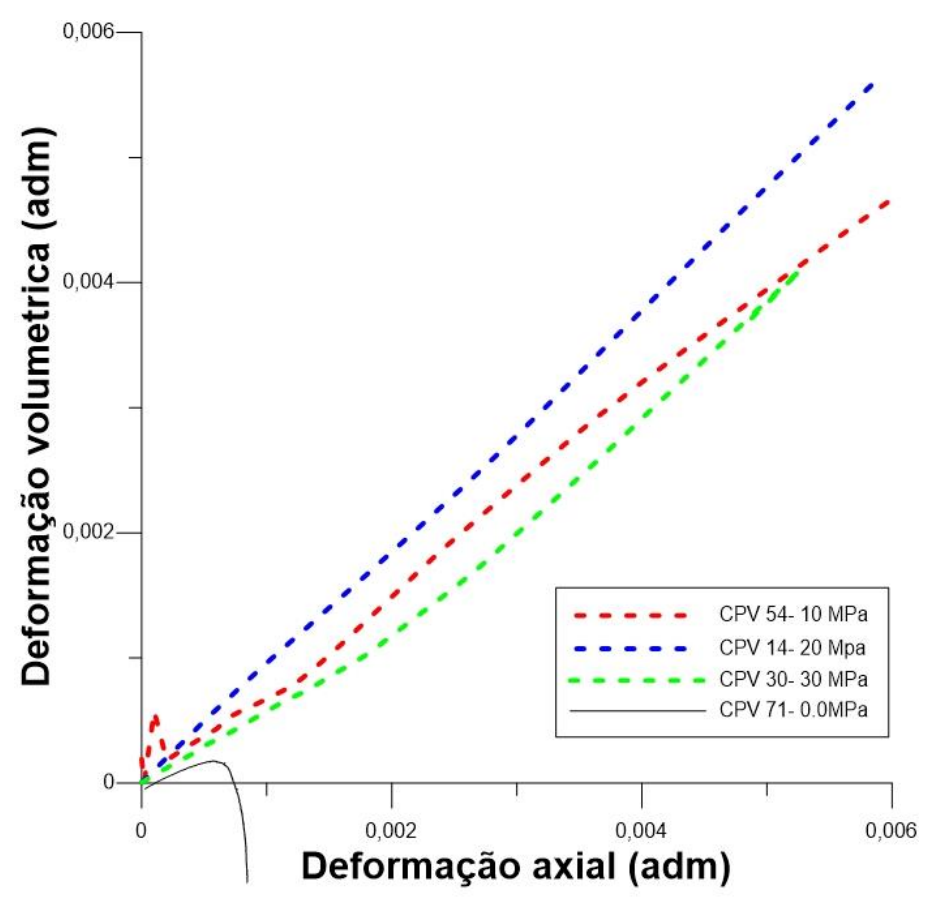

(b)

Figura 39 Resultados dos ensaios triaxiais do travertino CPV e porosidades $>8.5 \%$.(a) Curva tensão desviadora vs deformação axial, (b) Curva deformação volumétrica vs deformação axial.

Na Figura 40 são apresentadas as imagens dos CPV com porosidade > 8.5\%, A linha preta indica a ruptura por cisalhamento dos CPV 54, CPV 14 e CPV 30 , com tensões de confinamento 10,20,30 MPa, respectivamente. As linhas azuis indicam a ruptura por fendilhamento do CPV 71, ensaio UCS. Todos os corpos de prova foram preenchidos para evitar problemas como furo de membrana durante os ensaios laboratoriais.

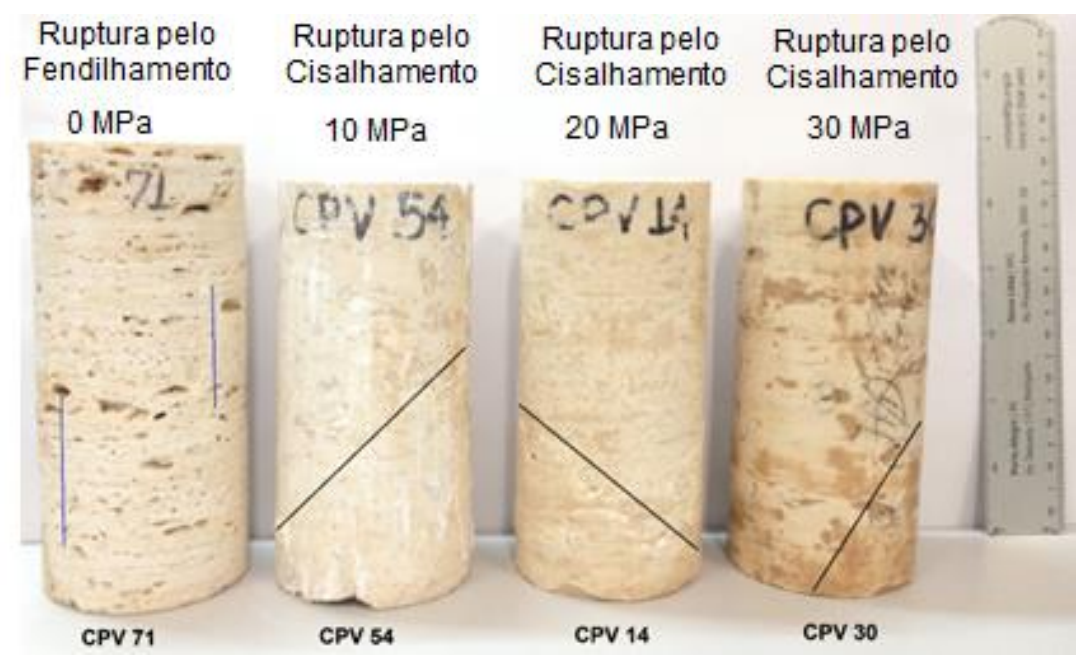

Figura 40 Ensaios triaxiais à compressão do travertino com porosidade $>8.5 \% \mathrm{e}$ orientação das camadas ortogonal ao eixo axial. 


\subsection{3.}

\section{CPH com porosidade $<8.5 \%\left(\beta=90^{\circ}\right)$}

Foram feitos ensaios triaxiais convencionais com $\mathrm{CPH}$ 08, $\mathrm{CPH} 07$ e $\mathrm{CPH}$ 13 com tensões confinantes de 10, 20 e $30 \mathrm{MPa}$, respectivamente. Os resultados indicam uma ruptura por cisalhamento, como se pode observar na Tabela 13. No entanto, no caso do $\mathrm{CPH} 07$, próximo à tensão de ruptura, o ensaio parou devido a um vazamento, mais os resultados foram considerados válidos no processo de calibração porque a curva apresentou o trecho da plastificação. $O$ ensaio uniaxial com a amostra $\mathrm{CPH} 14$ teve ruptura tipo fendilhamento, como esperado.

Tabela 13 Resultados dos ensaios triaxiais à compressão com corpos de prova horizontais com porosidade $<8.5 \%$.

\begin{tabular}{ccccccc}
\hline CP & $\begin{array}{c}\text { Tensão } \\
\text { de conf. } \\
\text { MPa }\end{array}$ & $\begin{array}{c}\text { Módulo } \\
\text { Young } \\
\text { E (GPa) }\end{array}$ & $\begin{array}{c}\text { Poisson } \\
(\mathrm{v})\end{array}$ & $\begin{array}{c}\text { Tensão } \\
\text { de } \\
\text { ruptura } \\
\text { (MPa) }\end{array}$ & $\begin{array}{c}\text { Porosi } \\
\text { dade } \\
\text { total } \\
\%\end{array}$ & Tipo de Ruptura \\
\hline $\mathrm{CPH} \mathrm{14}$ & 0.0 & 56.80 & 0.30 & 64.75 & 8.21 & Fendilhamento \\
$\mathrm{CPH} \mathrm{08}$ & 10.0 & 64.65 & 0.32 & 146.36 & 7.05 & Cisalhamento \\
$\mathrm{CPH} \mathrm{07}$ & 20.0 & 65.30 & 0.32 & 152.17 & 8.34 & Cisalhamento \\
$\mathrm{CPH} \mathrm{13}$ & 30.0 & 66.95 & 0.35 & 151.17 & 8.70 & Cisalhamento \\
\hline
\end{tabular}

Pode-se observar na Figura 41 (a) que os três corpos de prova horizontais $(\mathrm{CPH})$, com tensões de confinamento de 10,20 e $30 \mathrm{MPa}$, atingiram à máxima tensão desviadora quase no mesmo ponto. na Figura 41 (b) observa-se que o ensaio de compressão simples apresentou um comportamento de compressivo para dilatante, enquanto que os resultados dos ensaios triaxiais com tensões de confinamento de 10, 20 e $30 \mathrm{MPa}$ apresentaram comportamento somente compressivo.

Diferentemente dos resultados dos ensaios triaxiais com CPVs, os CPHs da Figura 41 (a) apresentam um comportamento frágil típica de materiais rígidos após de atingir a tensão de ruptura. Além disso, os CPHs apresentam maiores tensões de ruptura comparados aos CPVs, como será explicado no (item 4.2). 


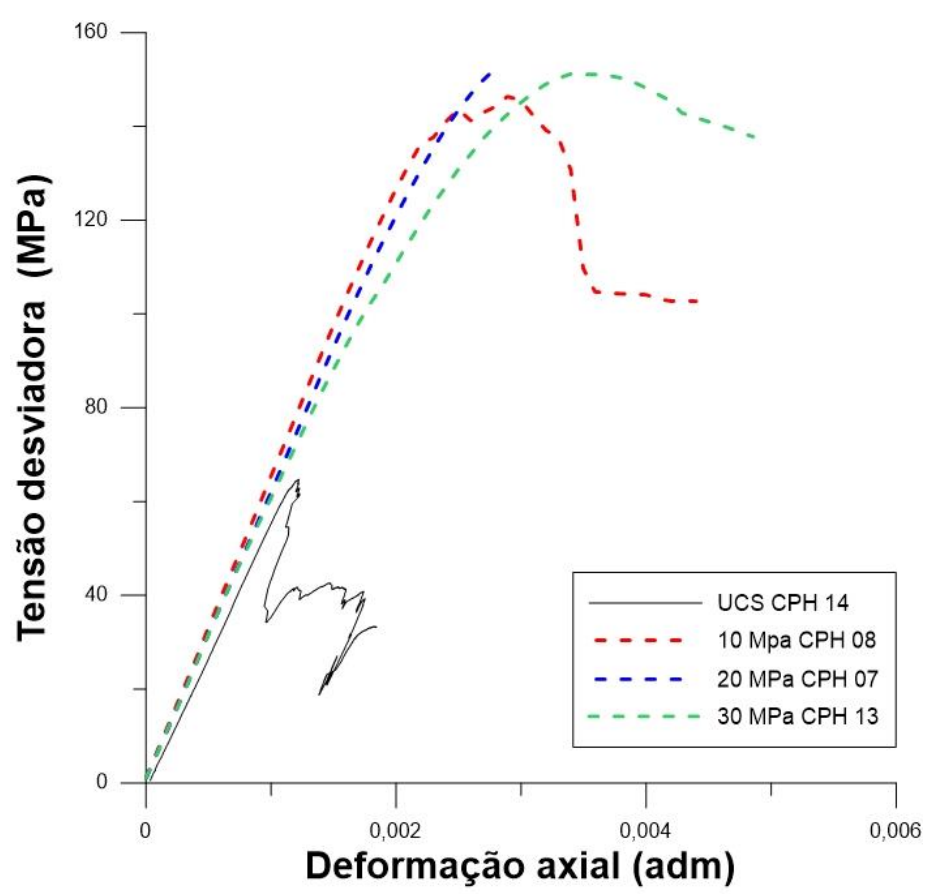

(a)

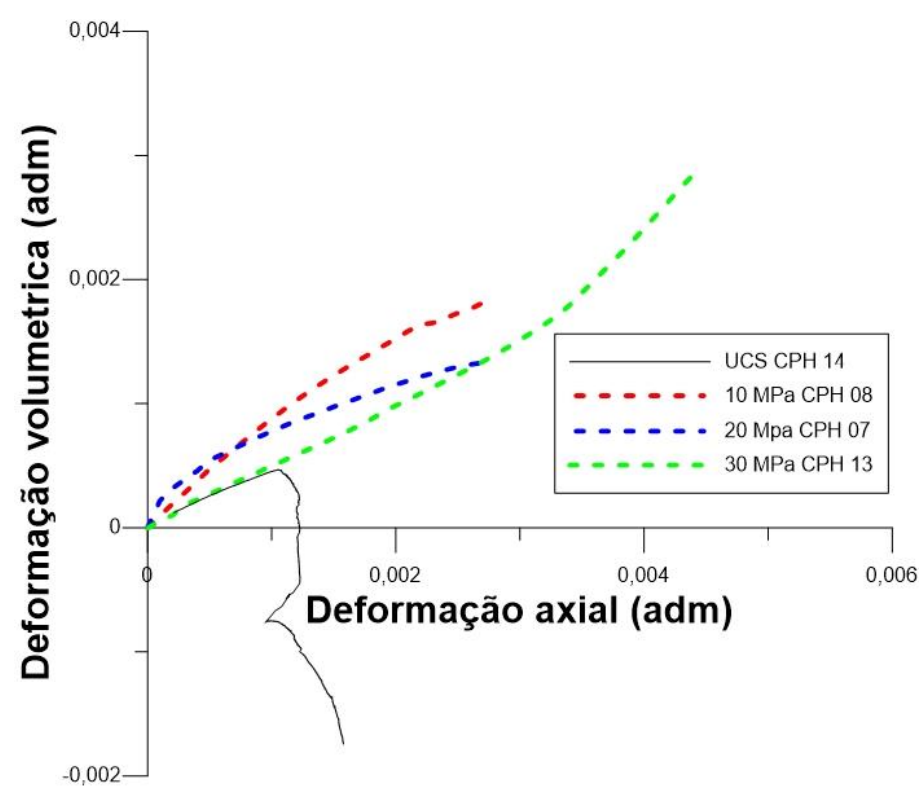

(b)

Figura 41 Resultados dos ensaios triaxiais do travertino $\mathrm{CPH}$ e porosidades < 8.5\%.(a) Curva tensão desviadora vs deformação axial (b) Curva deformação volumétrica vs deformação axial.

$\mathrm{Na}$ Figura 42 são apresentadas as imagens dos $\mathrm{CPH}$ com porosidade menores de $8.5 \%$, as linhas pretas indicam a ruptura por cisalhamento e as linhas azuis indicam a ruptura por Fendilhamento. 


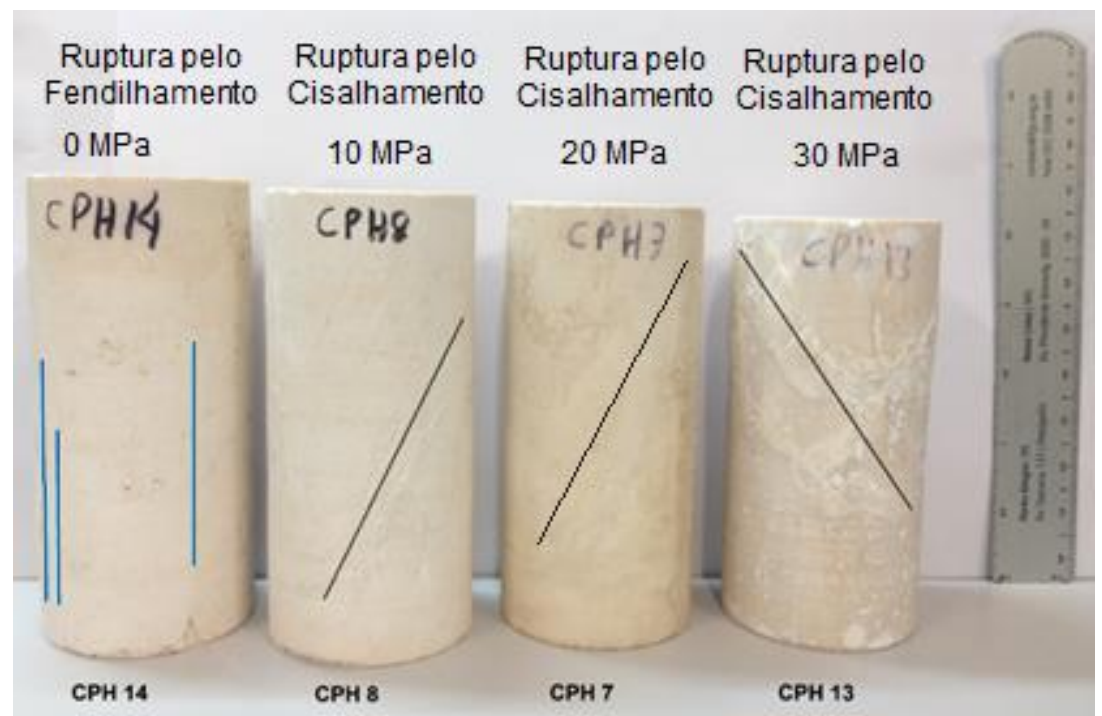

Figura 42 Ensaios triaxiais à compressão do travertino com porosidade $<8.5 \% \mathrm{e}$ orientação das camadas paralelo ao eixo axial.

\subsection{4.}

$\mathrm{CPH}$ com porosidade $>8.5 \%\left(\beta=90^{\circ}\right)$

Foram realizados ensaios triaxiais à compressão com tensões de confinamento de 0,10, 20 e $30 \mathrm{MPa}$ nas amostras de rocha carbonática travertino com orientação das camadas paralelo ao eixo axial. Os resultados na Tabela 14 indicam que as tensões de ruptura dos $\mathrm{CPH}$ com porosidades $>8.5 \%$ foram maiores comparados com os valores dos resultados dos ensaios triaxiais à compressão dos CPV com porosidades $>8.5 \%$, o que pode ser devido ao posicionamento das camadas em relação ao eixo axial, plano de ruptura e tensões de confinamento, entre outros (ver item 4.2).

Tabela 14 Resultados dos ensaios triaxiais a compressão com corpos de prova horizontais com porosidade $>8.5 \%$.

\begin{tabular}{ccccccc}
\hline CP & $\begin{array}{c}\text { Tensão } \\
\text { de conf. } \\
\mathrm{MPa}\end{array}$ & $\begin{array}{c}\text { Módulo } \\
\text { Young } \\
\mathrm{E}(\mathrm{GPa})\end{array}$ & $\begin{array}{c}\text { Poisson } \\
(\mathrm{v})\end{array}$ & $\begin{array}{c}\text { Tensão } \\
\text { de } \\
\text { ruptura } \\
(\mathrm{MPa})\end{array}$ & $\begin{array}{c}\text { Porosi } \\
\text { dade } \\
\text { total } \\
\%\end{array}$ & Tipo de Ruptura \\
\hline $\mathrm{CPH} \mathrm{11}$ & 0.0 & 57.69 & 0.39 & 69.80 & 9.86 & Fendilhamento \\
$\mathrm{CPH} \mathrm{12}$ & 10.0 & 60.11 & 0.39 & 128.03 & 10.11 & Cisalhamento \\
$\mathrm{CPH} \mathrm{20}$ & 20.0 & 62.14 & 0.38 & 139.31 & 10.08 & Cisalhamento \\
$\mathrm{CPH} 22$ & 30.0 & 66.08 & 0.38 & 160.41 & 10.21 & Cisalhamento \\
\hline
\end{tabular}


Na Figura 43 são apresentadas as curvas tensão desviadora vs deformação axial e deformação volumétrica vs deformação axial. Na Figura 43 (a) pode-se observar que ocorre uma queda abrupta depois da ruptura para todos os $\mathrm{CPH}$ na curva tensão desviadora vs deformação axial.

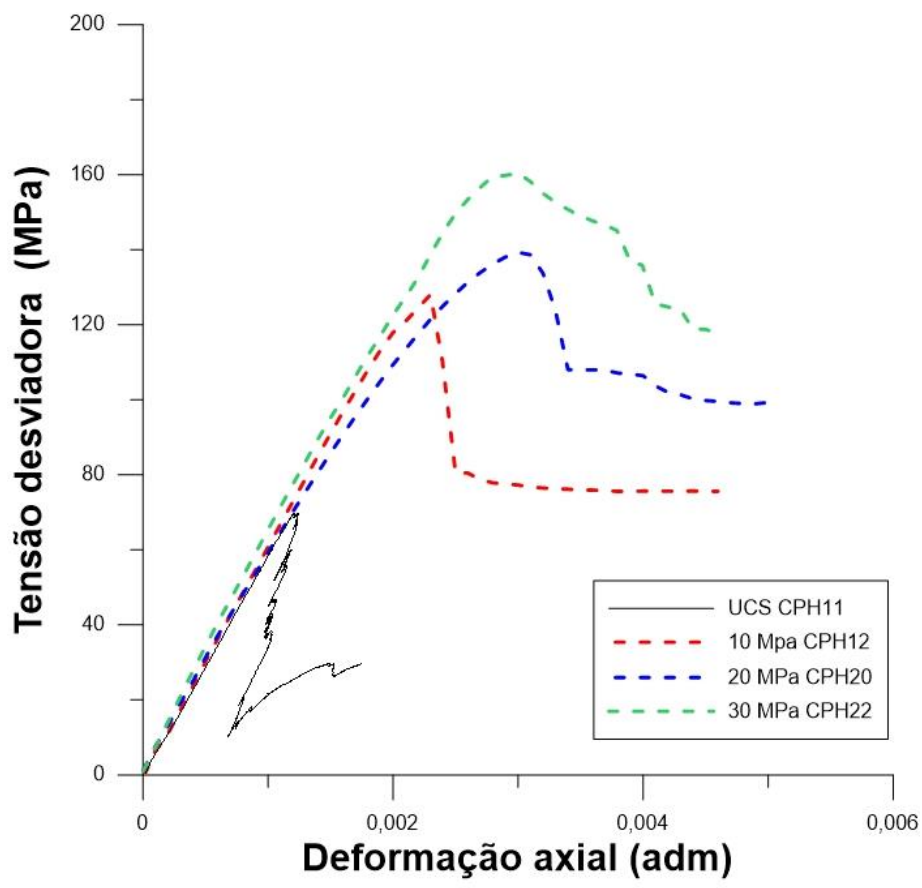

(a)

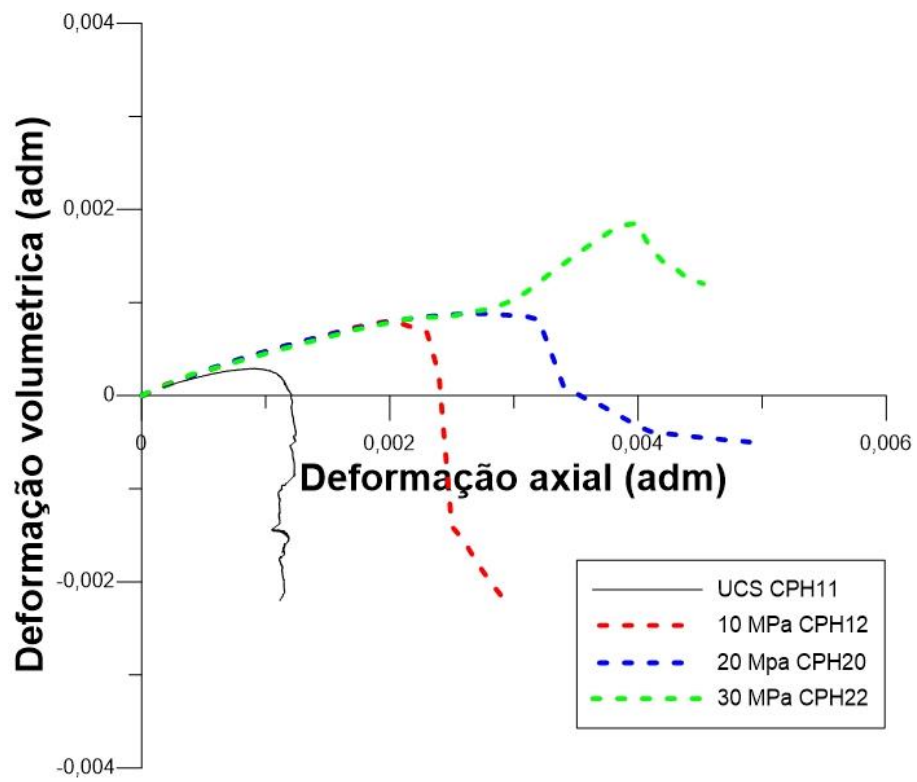

(b)

Figura 43 Resultados dos ensaios triaxiais do travertino $\mathrm{CPH}$ e porosidades $>8.5 \%$.(a) Curva tensão desviadora vs deformação axial, (b) curva deformação volumétrica vs deformação axial. 
Na Figura 44 as linhas pretas nos corpos de prova $\mathrm{CPH} 12, \mathrm{CPH} 20, \mathrm{CPH} 22$, indicam a ruptura cisalhante, enquanto as linhas azuis no $\mathrm{CPH} 11$ indicam a ruptura por fendilhamento.

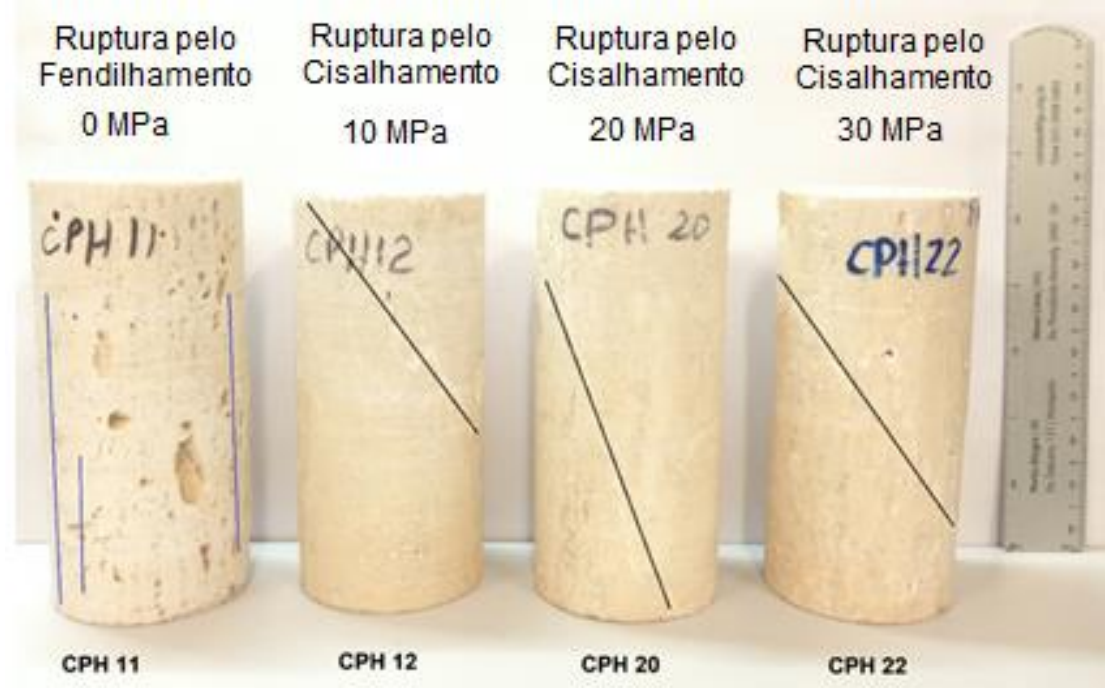

Figura 44 Ensaios triaxiais à compressão do travertino com porosidade $>8.5 \% \mathrm{e}$ orientação das camadas paralelo ao eixo axial.

\subsection{5.}

\section{CPI com porosidade $>8.5 \%\left(\beta=45^{\circ}\right)$}

Na Figura 45 são apresentadas os corpos de prova inclinados, CPI 11, CPI 05, CPI 03, com tensões de confinamento de 10, 20 e $30 \mathrm{MPa}$, usados para determinar a anisotropia da rocha carbonática travertino. Nos três casos, a direção do acamamento ficou a, aproximadamente, $45^{\circ}$ em relação ao eixo axial.

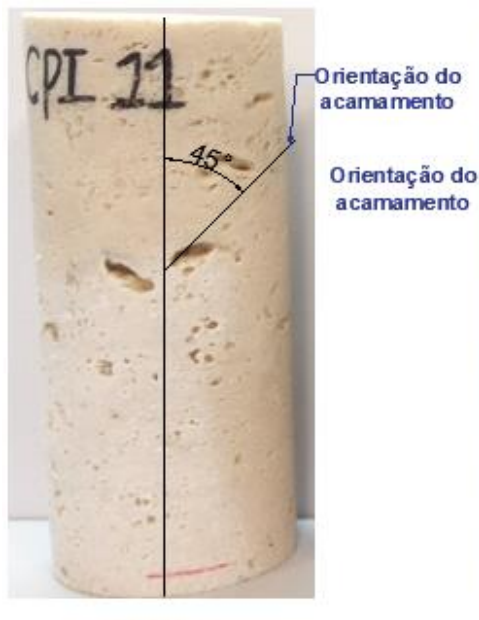

$10 \mathrm{MPa}$

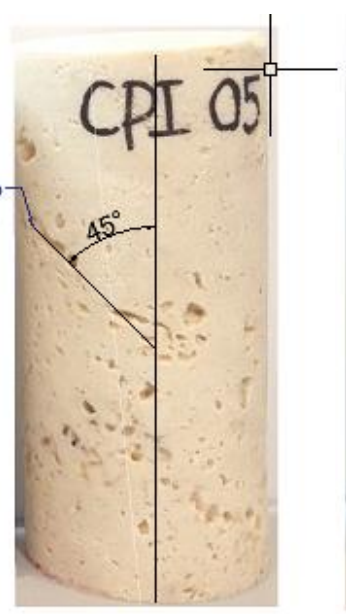

$20 \mathrm{MPa}$

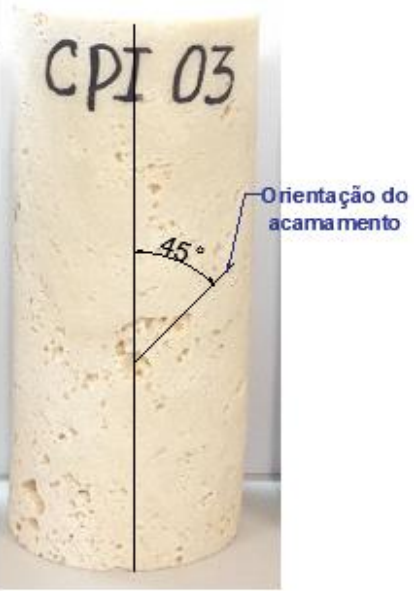

$30 \mathrm{MPa}$

Figura 45 Corpos de prova inclinados (CPI) com porosidades $>8.5 \%$. 
O tipo de ruptura apresentada nos ensaios triaxiais foi cisalhamento, enquanto a ruptura do UCS foi fendilhamento. Nesse caso, a ruptura pelo cisalhamento é coincidente com o plano de acamamento. No entanto, considerando as tensões de confinamento e porosidade, os resultados dos CPIs foram súperiores aos CPVs no que se refere à tensão de ruptura, (ver item 4.2). $\mathrm{Na}$ Tabela 15 são apresentados os valores dos parâmetros elásticos, tensão máxima e modo de ruptura dos CPI com porosidade superior a $8.5 \%$.

Tabela 15 Resultados dos ensaios triaxiais à compressão com corpos de prova inclinados com porosidade $>8.5 \%$.

\begin{tabular}{ccccccc}
\hline CP & $\begin{array}{c}\text { Tensão } \\
\text { de conf. } \\
\mathrm{MPa}\end{array}$ & $\begin{array}{c}\text { Módulo } \\
\text { Young } \\
\mathrm{E}(\mathrm{GPa})\end{array}$ & $\begin{array}{c}\text { Poisson } \\
(\mathrm{v})\end{array}$ & $\begin{array}{c}\text { Tensão } \\
\text { de } \\
\text { uptura } \\
(\mathrm{MPa})\end{array}$ & $\begin{array}{c}\text { Porosi } \\
\text { dade } \\
\text { total } \\
\%\end{array}$ & Tipo de Ruptura \\
\hline $\mathrm{CPI} 07$ & 0.0 & 49.49 & 0.43 & 48.68 & 12.21 & Fendilhamento \\
$\mathrm{CPI} 11$ & 10.0 & 62.73 & 0.43 & 64.9 & 9.88 & Cisalhamento \\
$\mathrm{CPI} 05$ & 20.0 & 50.51 & 0.49 & 73.65 & 10.86 & Cisalhamento \\
$\mathrm{CPI} 03$ & 30.0 & 61.39 & 0.39 & 103.29 & 10.45 & Cisalhamento \\
\hline
\end{tabular}

Na Figura 46 (a) e (b) são apresentados os resultados do comportamento geomecânico tensão-deformação e deformação volumétrica.

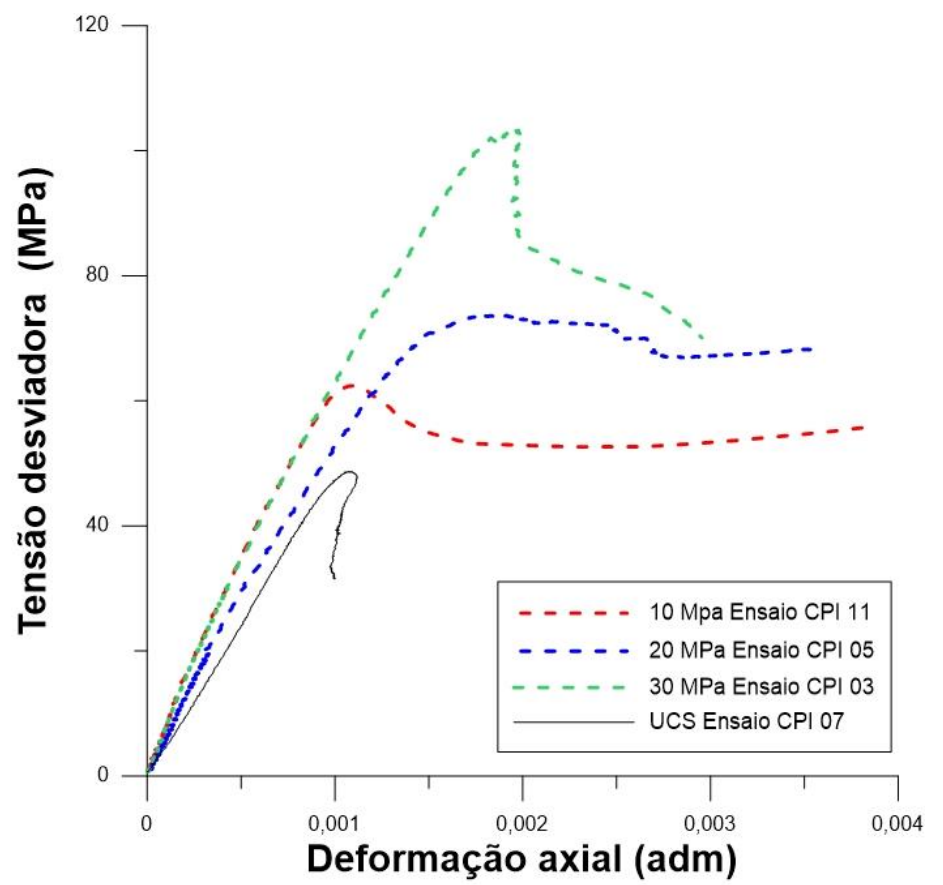

(a) 


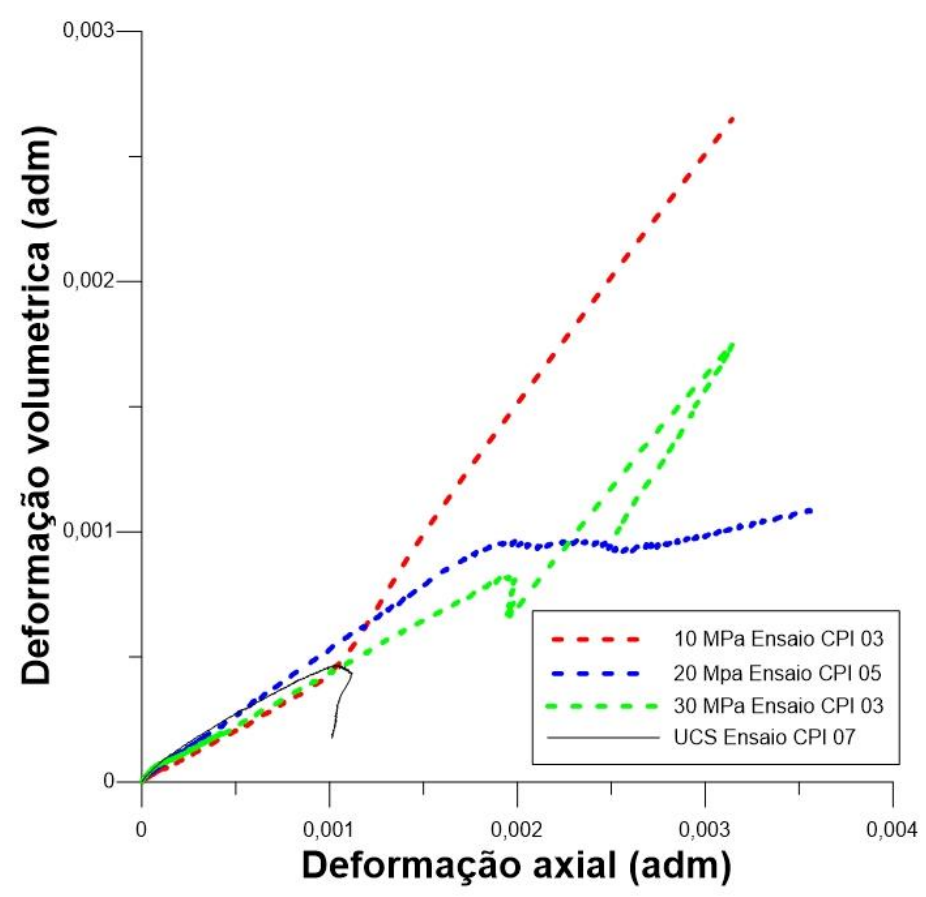

(b)

Figura 46 Resultados dos ensaios triaxiais do travertino CPI e porosidades $>8.5 \%$.(a) Curva tensão desviadora vs deformação axial, (b) Curva deformação volumétrica vs deformação axial.

\section{2.}

\section{Análise Comparativa da resistência entre CPV, CPI e CPH}

$\mathrm{Na}$ Tabela 16 são apresentados os valores das tensões máximas desviadoras obtidas nos ensaios triaxiais para resistência dos CPV, CPI e $\mathrm{CPH}$ da rocha carbonática travertino. Os resultados indicam que os valores das resistências para os $\mathrm{CPI}$ ( $\beta=45^{\circ}$ ) foram superiores comparados com os CPV ( $\left.\beta=0^{\circ}\right)$. Isto foi um comportamento inesperado e que não concorda com a revisão bibliográfica apresentada no capítulo 2 desta dissertação, item 2.1.2, no qual afirma-se que os menores valores de resistência ficam para ângulos entre $15^{\circ} \leq \beta \leq 65^{\circ}$. No entanto, é importante aclarar que os CPV foram extraídos do primer bloco enquanto os CPI do segundo bloco e as porosidades dos CPV na media foram de $12 \%$ e as porosidade dos CPI de $9 \%$. Isto pode influenciar os resultados obtidos no laboratório. Contudo, vereficou-se que o plano de ruptura coincidiu com o acamamento. Além disso, os resultados indicam que as resistências para $\mathrm{CPH}\left(\beta=90^{\circ}\right)$ foram maiores comparados com os $\mathrm{CPV}$ ( $\beta=0^{\circ}$ ), o que concorda com a revisão bibliográfica apresentada no capitulo 2. 
Em relação aos níveis de porosidade, na Tabela 16 se observa uma comparação entre os valores dos CPV com porosidades acima e abaixo de 8.5, com resistências maiores para porosidades $<8.5 \%$. O mesmo comportamento foi evidenciado nos valores comparados com os $\mathrm{CPH}$ com porosidades acima e abaixo de $8.5 \%$, a exceção da tensão confinante de $30 \mathrm{MPa}$.

Tabela 16 Comparação de valores de tensão desviadora máxima em CP do travertino com porosidades $>8.5 \%$ e porosidades $<8.5 \%$

\begin{tabular}{cccccc}
\hline \multirow{2}{*}{$\begin{array}{c}\text { Tensão de } \\
\text { confinamento }\end{array}$} & \multicolumn{5}{c}{ Tensão desviadora máx. (MPa) } \\
\cline { 2 - 6 } & \multicolumn{2}{c}{ Porosidade $>8.5 \%$} & Porosidade $>8.5 \%$ & Porosidade $<8.5 \%$ \\
\hline $\mathrm{MPa}$ & $\mathrm{CPV}$ & $\mathrm{CPH}$ & $\mathrm{CPI}$ & $\mathrm{CPV}$ & $\mathrm{CPH}$ \\
& $\beta=0^{\circ}$ & $\beta=90^{\circ}$ & $\beta=45^{\circ}$ & $\beta=0^{\circ}$ & $\beta=90^{\circ}$ \\
\hline 0 & 34.74 & 69.80 & 48.68 & 49.0 & 64.75 \\
10 & 53.92 & 128.03 & 64.9 & 99.4 & 146.36 \\
20 & 74.03 & 139.31 & 73.65 & 120.99 & 152.17 \\
30 & 83.45 & 160.41 & 103.29 & 116.67 & 151.17 \\
\hline
\end{tabular}

Na Figura 47 (a) observa-se que a resistência dos $\mathrm{CPH}$ é maior e que apresentaram uma ruptura frágil comparado com os resultados dos CPV e CPI com porosidade $>8.5 \%$. Isto indica que a pressão de confinamento e a orientação das camadas com relação ao eixo axial influenciam na resistência do travertino. Além disso, o tipo de ruptura cisalhante atravessa camadas e poros paralelos ao eixo axial, o que, teoricamente, representaria um ganho na resistência da rocha. Por outra parte pode-se observar que o trecho elástico das amostras com acamamento paralelo e inclinado com relação ao eixo axial da amostra são semelhantes, enquanto que as amostras com acamamento vertical apresentaron menor rigidez.

Na Figura 47 (b) observa-se que as tensões desviadoras de ensaios com tensões de confinamento de 10, 20 e $30 \mathrm{MPa}$ ficaram muito próximas. No entanto, o ensaio CPV 13 de $20 \mathrm{MPa}$ ficou abaixo do ensaio de CPH 07 de $20 \mathrm{MPa}$, isto pelo fato que a rocha é anisotrópica e por que a distribuição de poros muda de uma amostra para outra, impactando na resistência da rocha. Além disso o trecho elástico foi semelhante em amostras com acamento vertical e horizontal com relação ao eixo axial da amostra. 


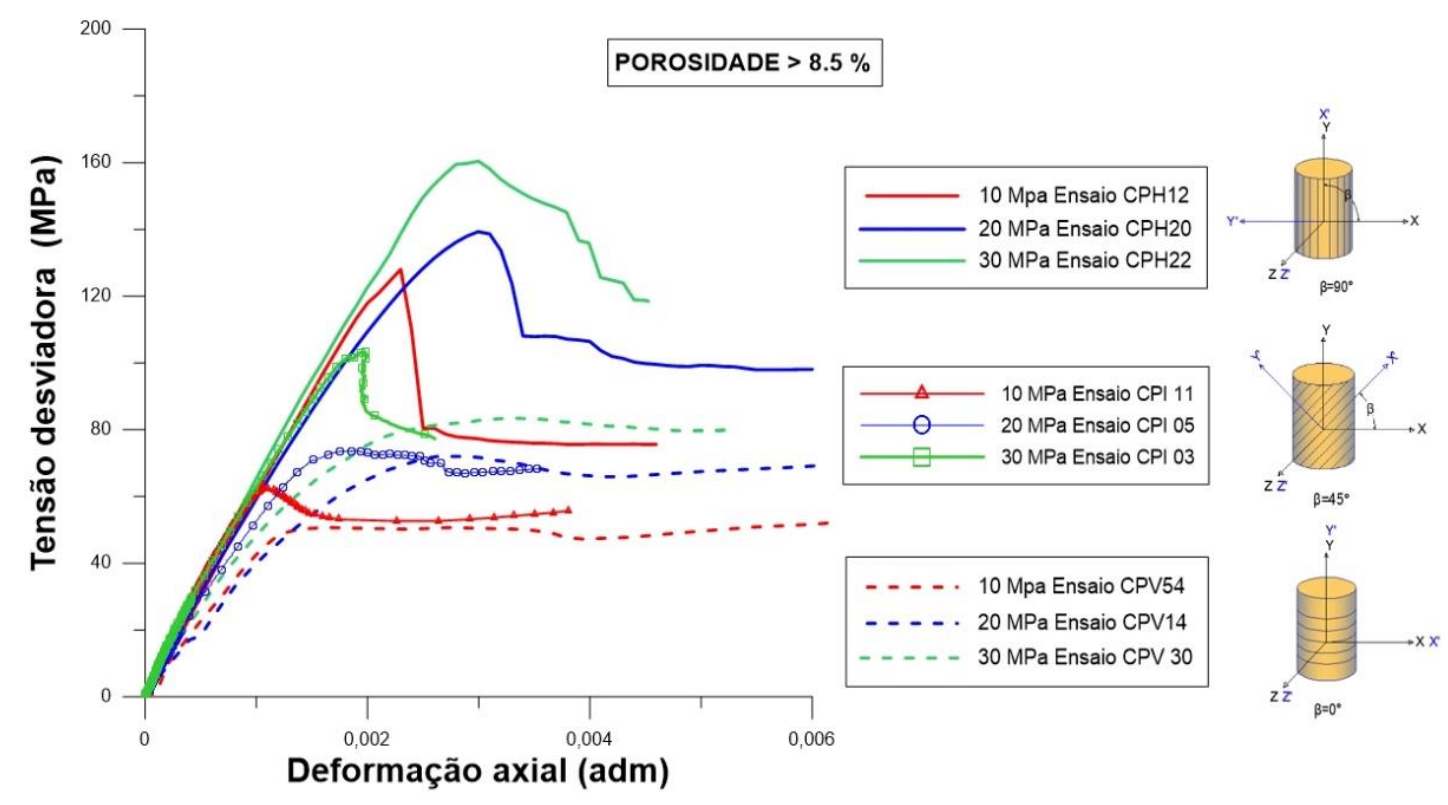

(a)

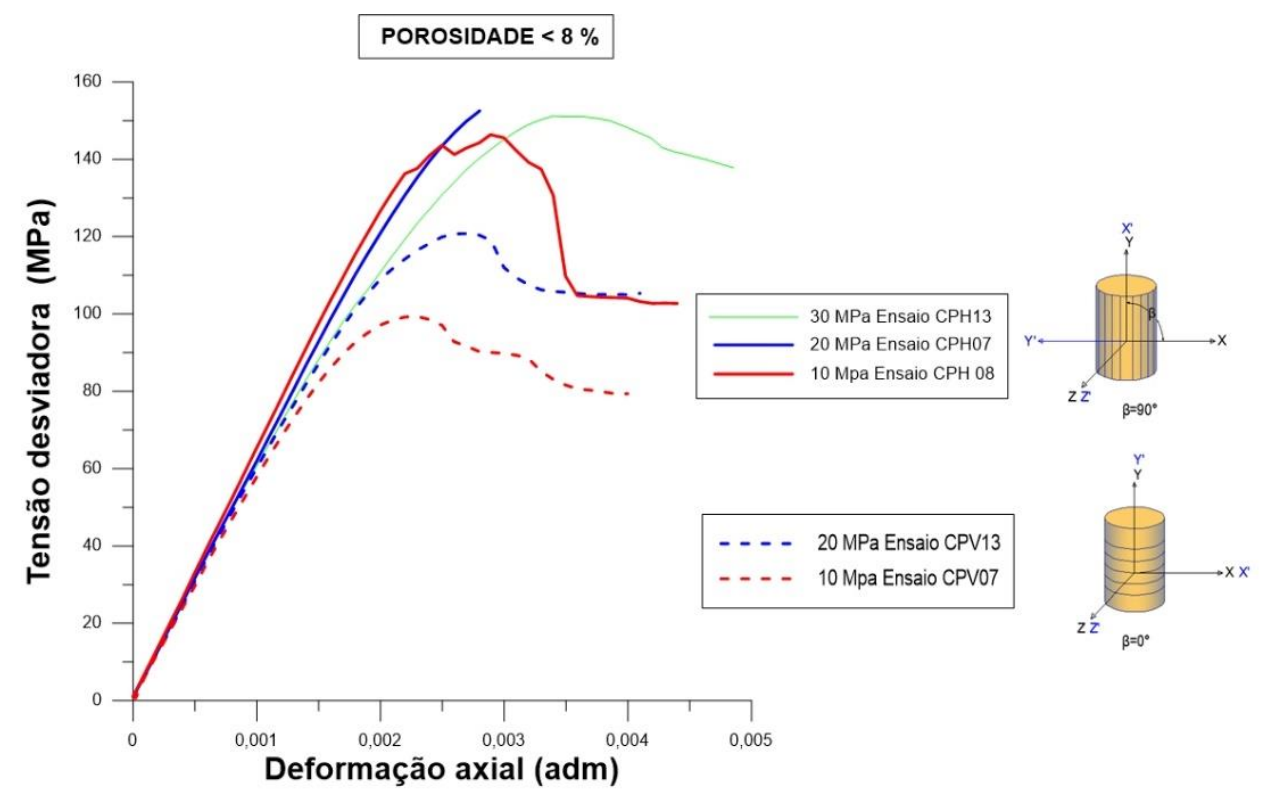

(b)

Figura 47 Resultados ensaios triaxiais na curva tensão desviadora vs deformação axial (a) com porosidades $>8.5 \%$ (b) com porosidades $<8.5 \%$.

\subsection{1.}

\section{Imagens de o microtomógafo}

As Figura 48 e 49 apresentam as imagens de microtomógafo correspondentes aos CPV 30 e $\mathrm{CPH} 22$, ambas submetidas a ensaios triaxiais 
com tensão confinante de $30 \mathrm{MPa}$ e porosidade maior de $8.5 \%$, analisados após o teste no laboratório. Estas amostras foram escolhidas com o propósito de observar a superfície de ruptura interna e quantificar a porosidade total. Na Figura 48 (a) é observado que externamente o CPV 30 não apresentou sinais claros da superfície de ruptura. No entanto, na Figura 48 (b) e (c) claramente é evidenciada a ruptura pelo cisalhamento. Além disto, foi estimada a porosidade a partir de um volume retangular 3D observado na Figura 48 (b) e (c). O volume possui áreas vermelhas que indicam os poros isolados, poros interconectados e a fissura inclinada que representa a ruptura cisalhante (elipse preta). A porosidade total medida após o teste com o microtomógafo foi de $8.81 \%$, a qual é similar à porosidade total medida em laboratório, $9.18 \%$, antes do teste. Por fim na Figura 48 (d) foi medido o ângulo igual a $15^{\circ}$ da superfície de ruptura em relação ao eixo axial.

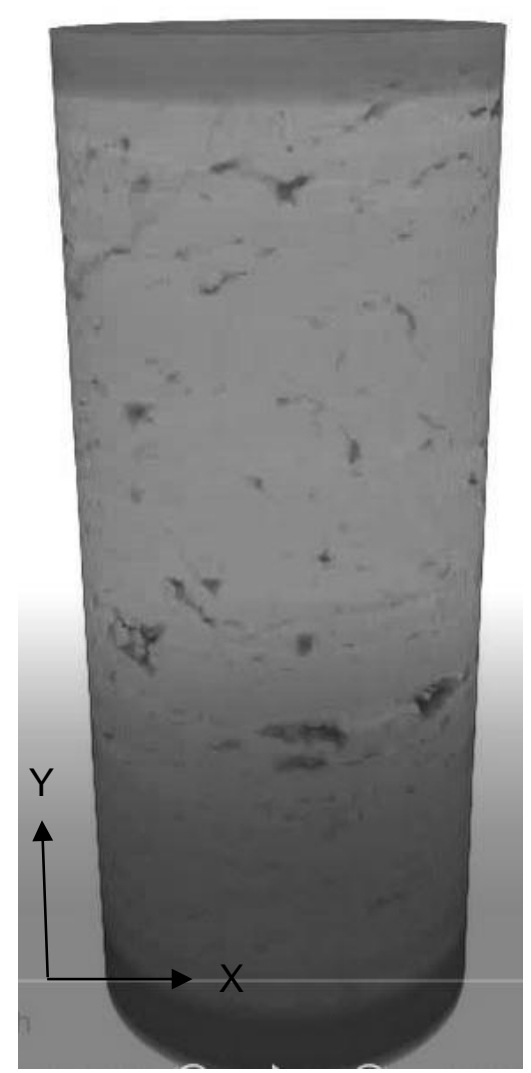

(a)

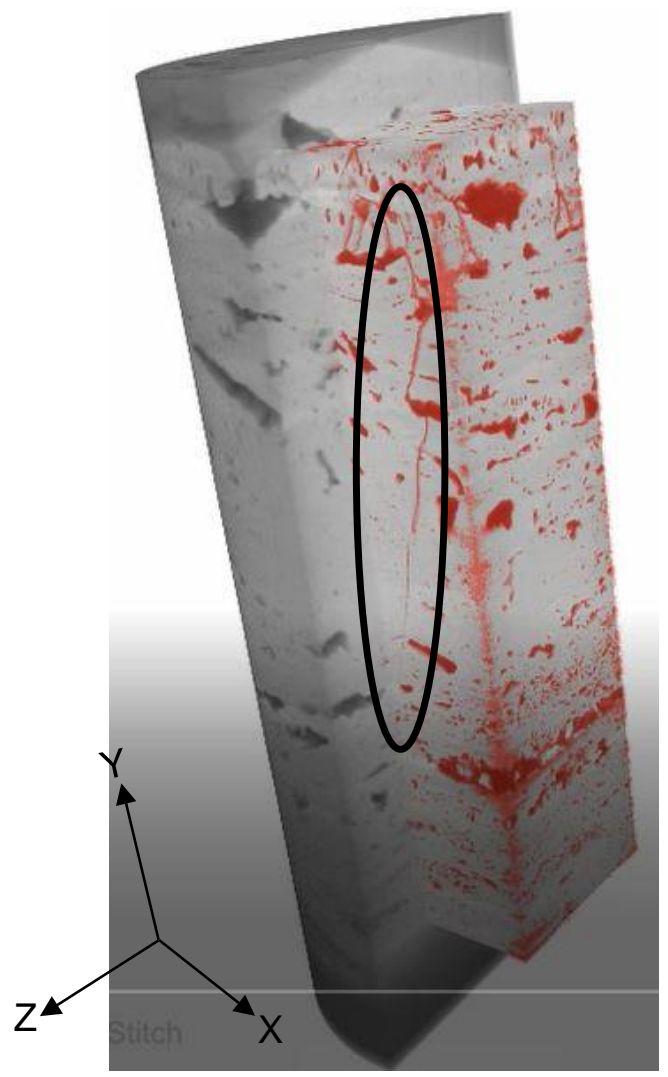

(b) 


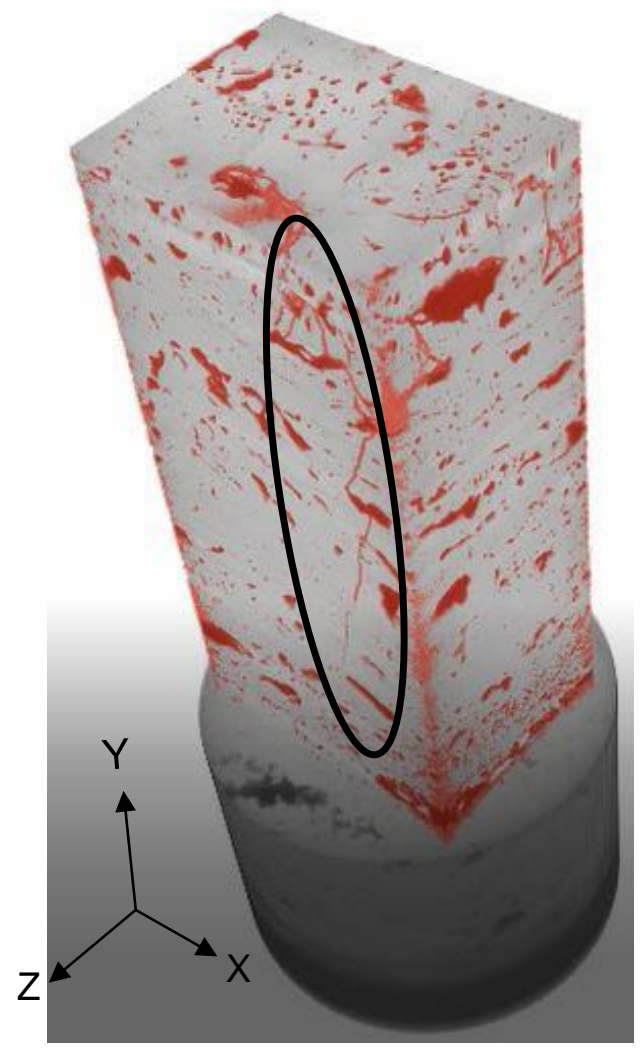

(c)

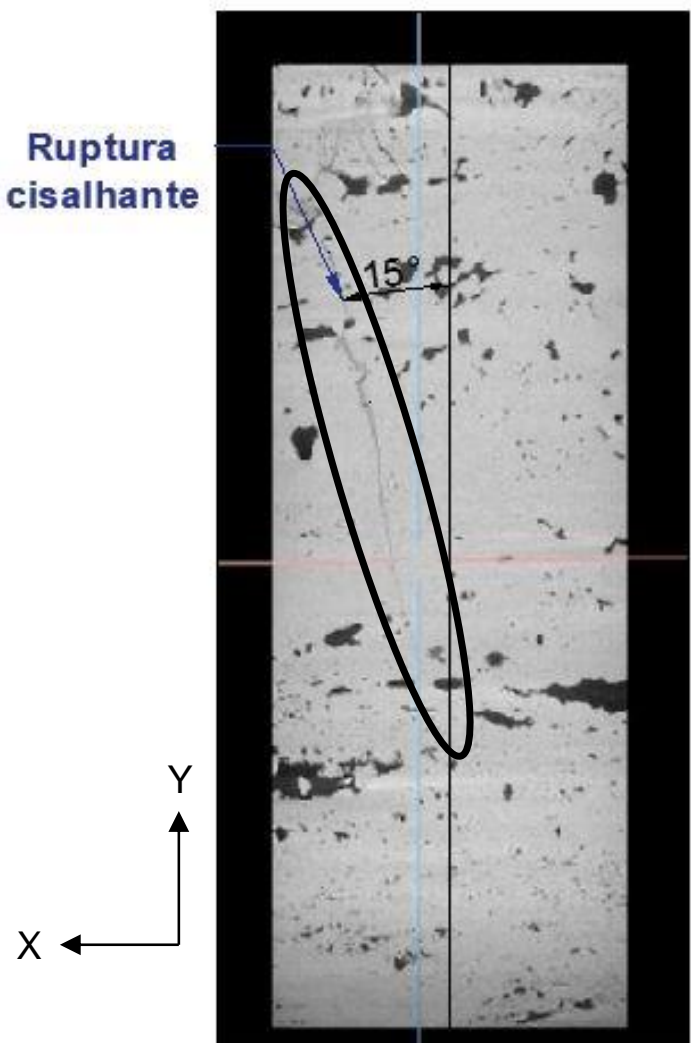

(d)

Figura 48 Imagem com microtomógafo para o CPV 30.

Na Figura 49 (a) e (b) são apresentadas as imagens do CPH 22 após o ensaio triaxial com tensão de confinamento de $30 \mathrm{MPa}$. Neste caso, a Figura 49 (a) mostra a ruptura por cisalhamento (elipse preta) na parte exterior e interior da amostra, o ângulo de inclinação da fissura varia aproximadamente entre $15^{\circ} \mathrm{e} 20^{\circ}$. Além disso, pode ser observado nas duas imagens que perto da fissura cisalhante o sistema de poros interconectados, representado pelas áreas vermelhas, é de maior concentração. A porosidade total obtida a partir da imagem microtomógrafica foi de $9.7 \%$, um pouco menor que a obtida no laboratório. No entanto, alguns poros não foram capturados pelo processamento de imagem, o que poderia resultar na porosidade total mais próxima àquela obtida no laboratório, $10.21 \%$ 


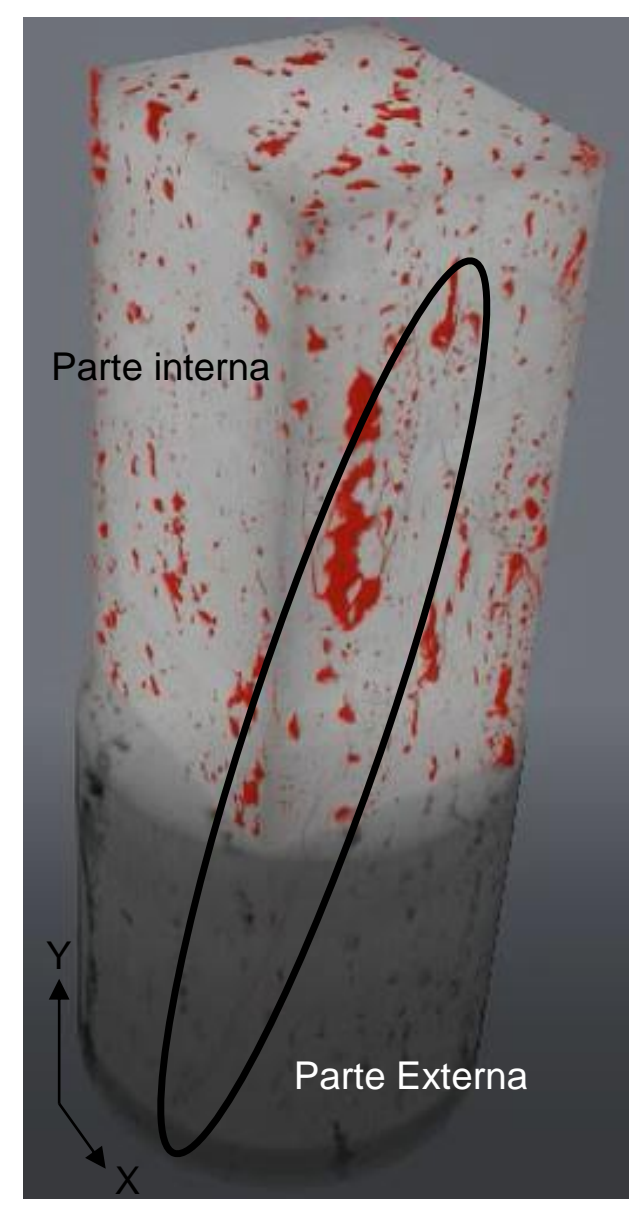

(a)

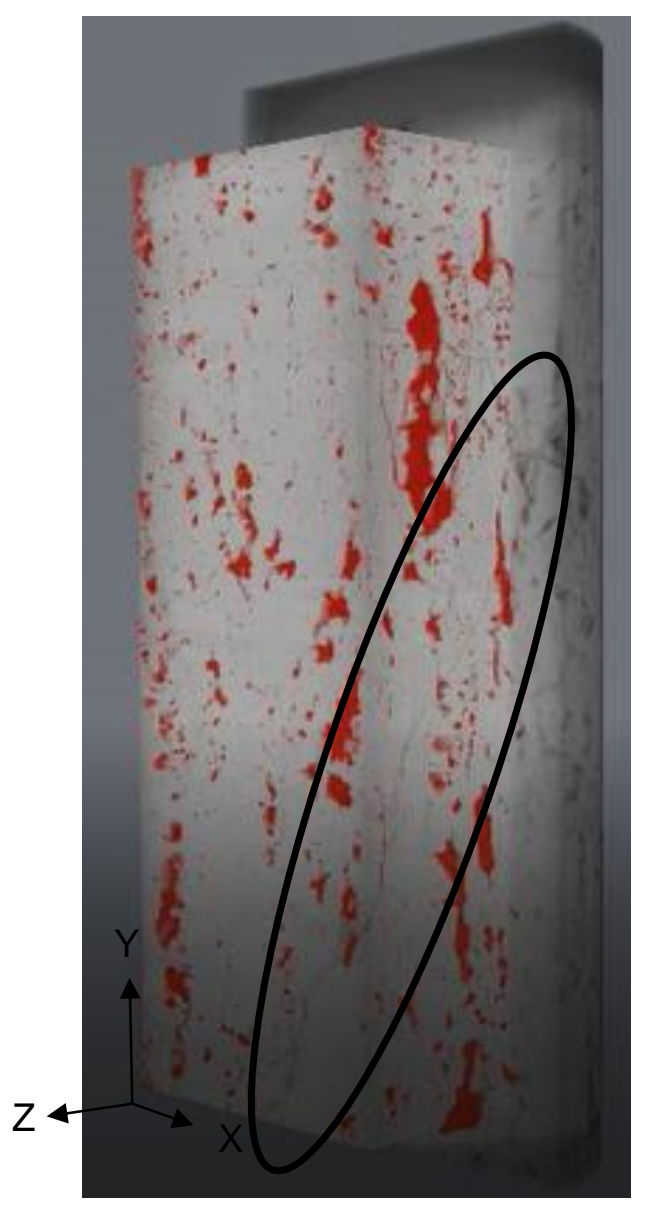

(b)

Figura 49 Imagem microtomógafo do CPH 22.

\section{3.}

\section{Resultados dos ensaios hidrostáticos}

No capítulo 3 foram apresentados os corpos de prova submetidos a ensaio hidrostático. No entanto, os ensaios CPV39, CPH9 e CPH30 apresentaram problemas na etapa inicial e nenhum deles chegou à ruptura devido ao vazamento (rasgmento da membrana termoretráctil e a amostra foi contaminada pelo fluido confinante) ocorrido durante a fase de incremento da pressão de confinamento. Na Tabela 17 são apresentados os resultados obtidos nos ensaios hidrostáticos, lembrando que o único ensaio que não furo membrana foi o CPV22. 
Tabela 17 Resultados dos ensaios hidrostáticos com CP horizontais e verticais.

\begin{tabular}{cccccc}
\hline CP & $\begin{array}{c}\text { Tensão de } \\
\text { conf. MPa }\end{array}$ & $\begin{array}{c}\text { Módulo } \\
\text { volumetrico } \\
(\mathrm{GPa})\end{array}$ & $\begin{array}{c}\text { Tensão de } \\
\text { ruptura } \\
(\mathrm{MPa})\end{array}$ & $\begin{array}{c}\text { Porosidade } \\
\text { total \% }\end{array}$ & $\begin{array}{c}\text { Tipo de } \\
\text { Ruptura }\end{array}$ \\
\hline CPV39 & 0.0 & --- & --- & 6.31 & Vazamento \\
CPV22 & 0.0 & 19.37 & 51.52 & 13.94 & $\begin{array}{c}\text { Posivel } \\
\text { cisalhamento } \\
\text { Vazamento }\end{array}$ \\
CPH9 & 0.0 & ---- & --- & 5.71 & Vazamento \\
CPH30 & 0.0 & ---- & --- & 14.26 & \\
\hline
\end{tabular}

Como se observa na Figura 50, o vug no $\mathrm{CPH} 30$ causou dano à membrana de cobertura, vazando e causando a finalização antecipada do teste. Assim, os ensaios CPV39, CPH9 e CPH30 foram descartados para o processo de calibração do modelo constitutivo representativo da rocha carbonática travertino. Na Figura 50 observa-se que o corpo de prova CPV22 (corpo de prova vertical com porosidade de $5.35 \%$ ) não apresentou fissuras externas que indicassem o tipo de ruptura, mas atingiu a ruptura, Figura 51 . Por isto ele foi usado para a determinação de parâmetros do modelo isotrópico Lade-Kim com porosidades menores e maiores a $8.5 \%$, e orientação das camadas vertical e horizontal com relação ao eixo axial.

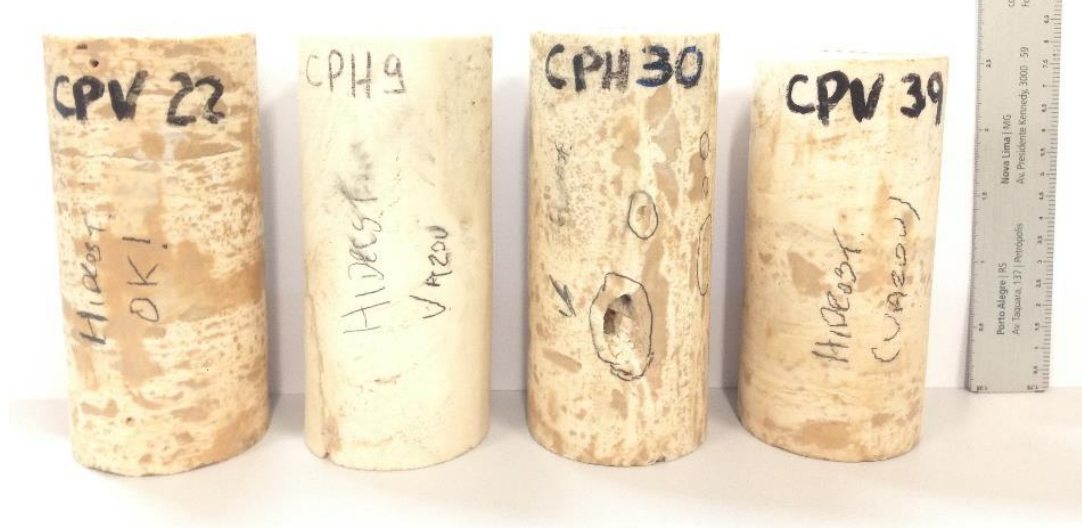

Figura 50 Amostras da rocha carbonática travertino utilizadas em ensaios hidrostáticos. 
Na Figura 51 é apresentada a variação volumétrica com relação à tensão hidrostática para o corpo de prova CPV22.

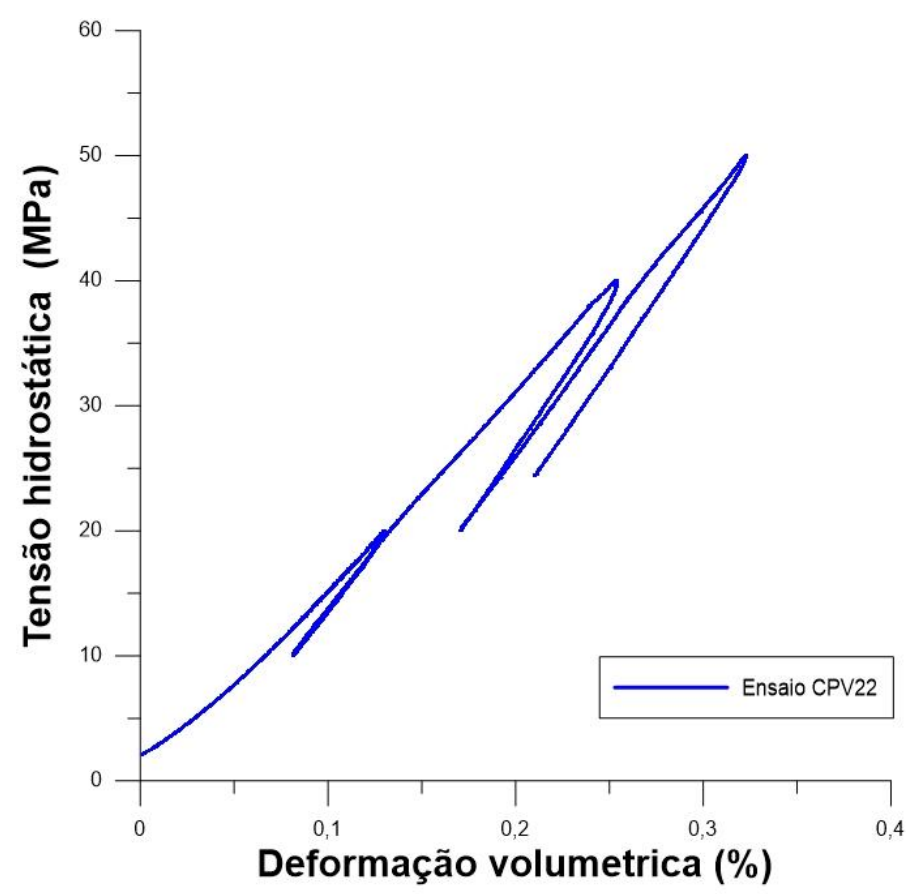

Figura 51 Ensaio hidrostático CPV22

\section{4.}

Calibração analítica do modelo Lade-Kim

O modelo isotrópico Lade-Kim requer 12 parâmetros que podem ser determinados a partir de ensaios de laboratório triaxiais à compressão, com diferentes pressões de confinamento, hidrostáticos e uniaxiais. O procedimento para realizar a determinação de parâmetro é baseado em (Lade e Kim, 1988 b; Lade, 2005).

\subsection{1.}

\section{Parâmetros elásticos}

Parâmetros como $K$ e $n$ podem ser determinados através do gráfico Log $\left(E / P_{A}\right)$ vs. $\log \left(\sigma_{3} / P_{a}\right)$ Equação (4.1) obtida da Equação (2.23), sendo que o primeiro é determinado como o intercepto entre o melhor ajuste dos pontos e a linha vertical correspondente à 1.0, enquanto o segundo corresponde à inclinação desta linha, como ilustrado nas Figura 52 e Figura 53. 


$$
\log \left(\frac{E}{P_{a}}\right)=\log (K)+n \log \left(\frac{\sigma_{3}}{P_{a}}\right)
$$

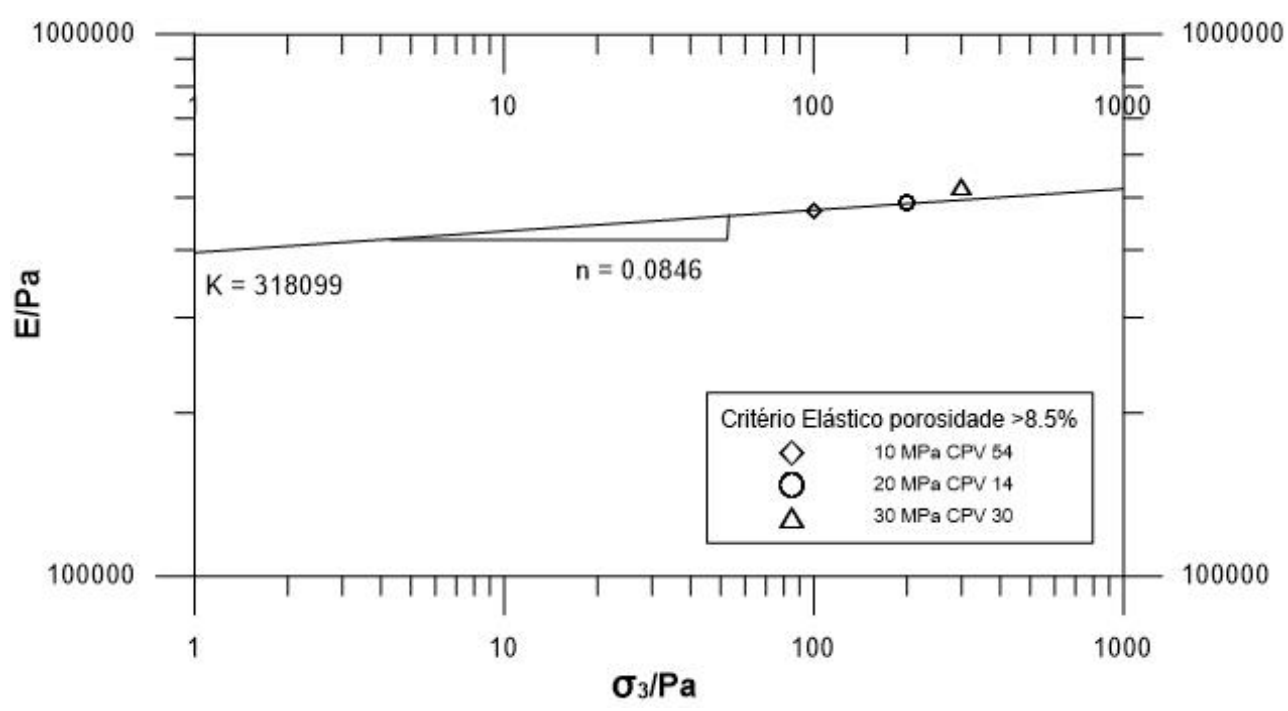

(a)

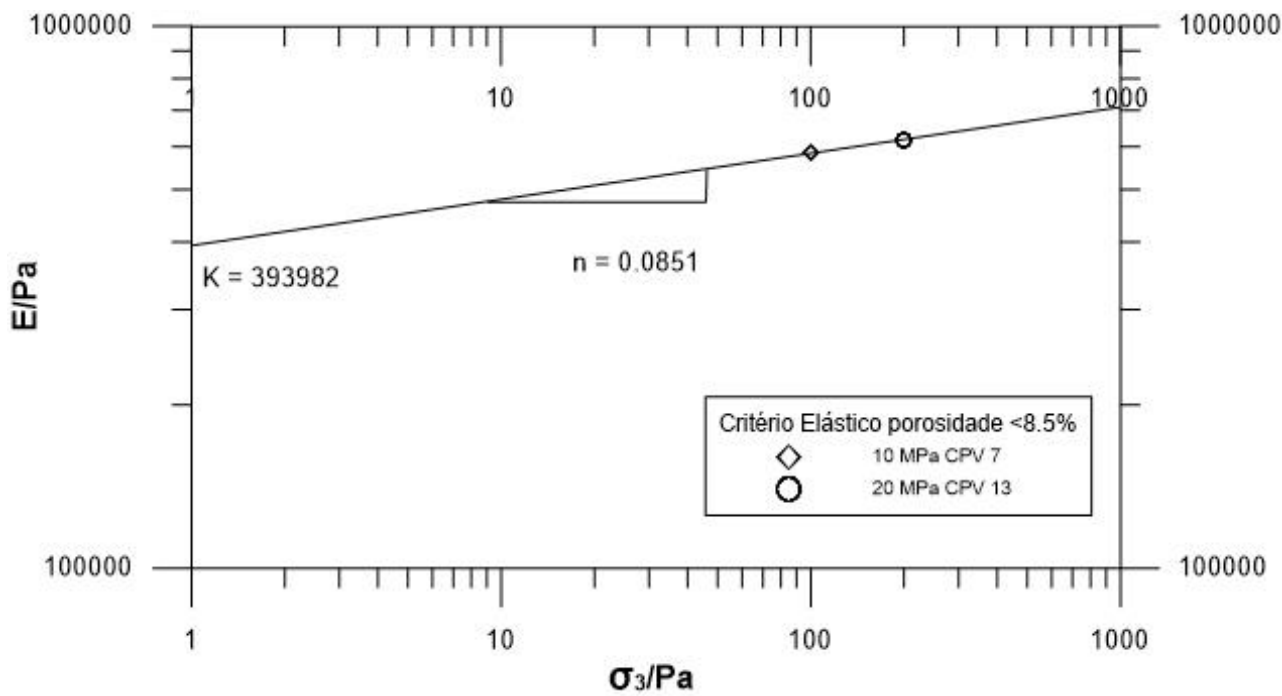

(b)

Figura 52 Parâmetros $K$ e $n$ do modelo Lade-Kim da rocha carbonática travertino, CPV. $\left(\beta=0^{\circ}\right)$. (a) Porosidade $>8.5 \%$, (b) porosidade $<8.5 \%$. 


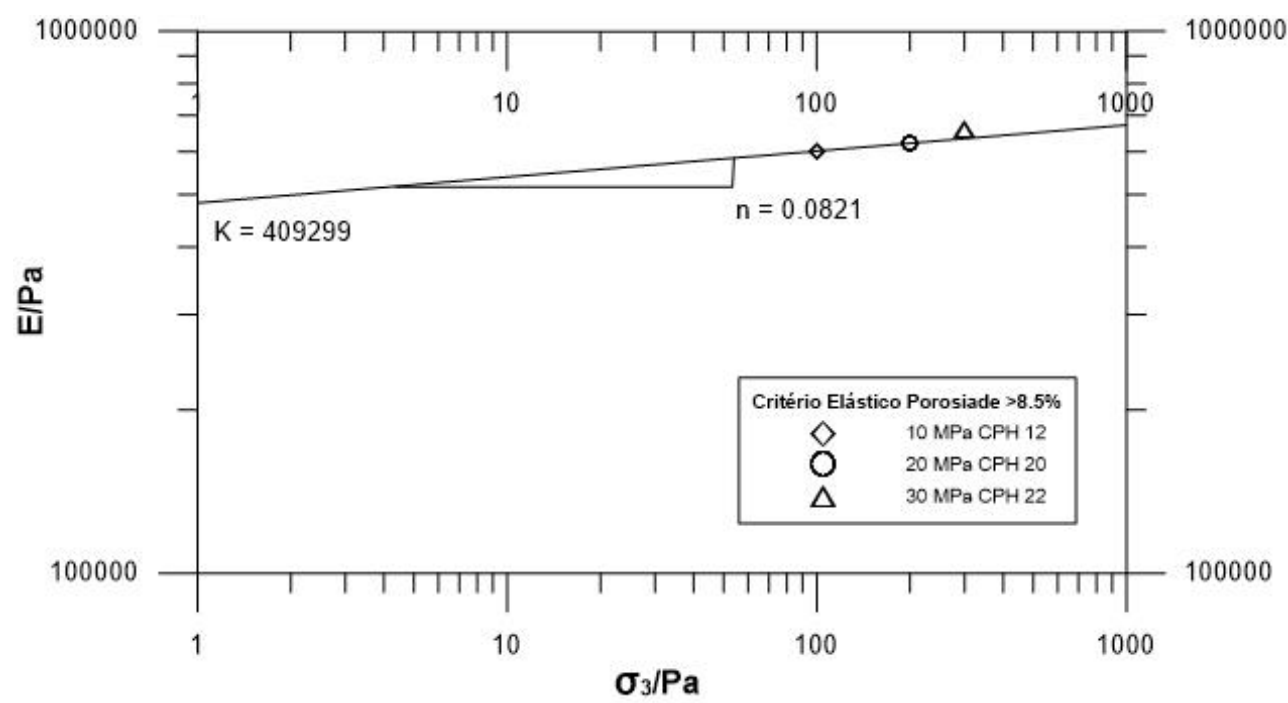

(a)

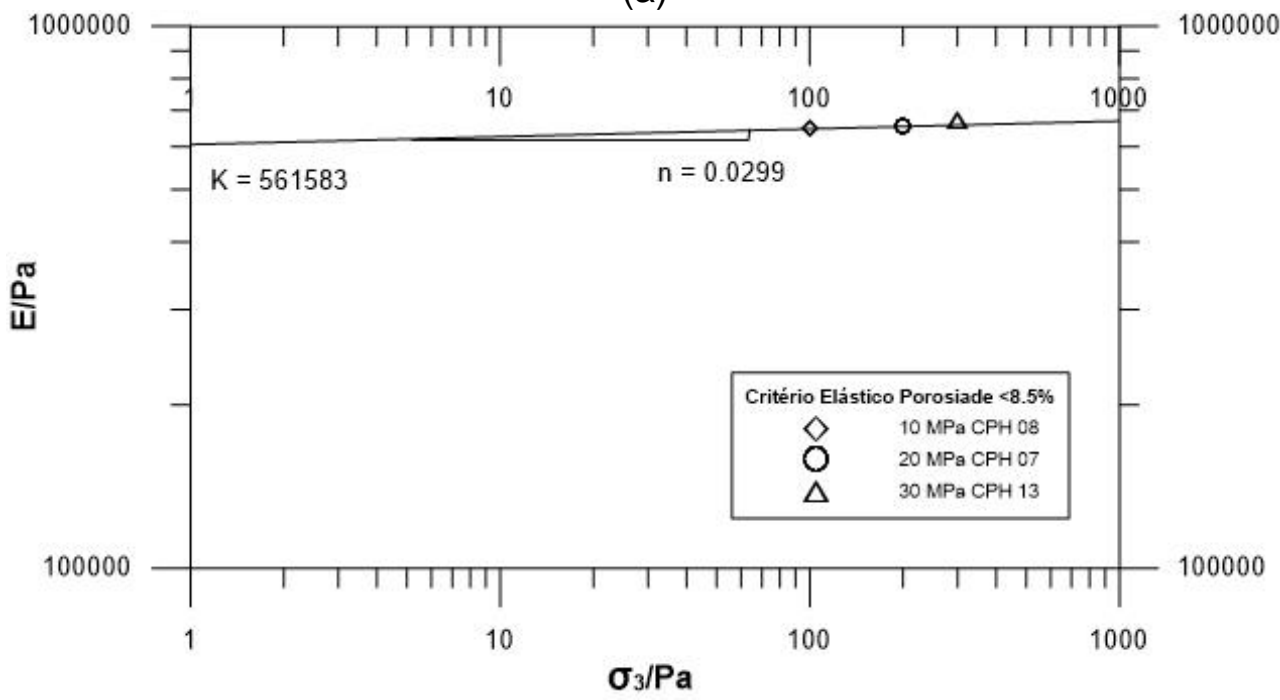

(b)

Figura 53 Parâmetros $k$ e $n$ do modelo Lade-Kim da rocha travertino, CPH. ( $\left.\beta=90^{\circ}\right)$ (a) porosidade $>8.5 \%$ (b) porosidade $<8.5 \%$.

Na Tabela 18 são apresentados os resultados dos parâmetros elásticos $K$ e $n$ do modelo Lade-Kim para a rocha carbonática travertino.

Tabela 18 Variação de parâmetros elásticos $k$ e $n$ do travertino com o modelo Lade-Kim.

\begin{tabular}{cccc}
\hline $\mathrm{CP}$ & Porosidade & $K$ & $n$ \\
\hline $\mathrm{CPV} \beta=0^{\circ}$ & $<8.5 \%$ & $393,982.0$ & 0.0851 \\
$\mathrm{CPV} \beta=0^{\circ}$ & $>8.5 \%$ & $318,099.0$ & 0.0846 \\
$\mathrm{CPH} \beta=90^{\circ}$ & $<8.5 \%$ & $561,583.0$ & 0.0299 \\
$\mathrm{CPH} \beta=90^{\circ}$ & $>8.5 \%$ & $409,299.0$ & 0.0821 \\
\hline
\end{tabular}




\subsection{2.}

\section{Parâmetros de ruptura}

Os parâmetros do critério de ruptura são determinados a partir do gráfico $\log \left(I_{1}^{3} / I_{3}-27\right)$ vs. Log $\left(P_{a} / I_{1}\right)$, Equação (4.2). O valor de $\eta_{1}$ é determinado como o intercepto entre o melhor ajuste e a linha vertical correspondente à $\left(P_{a} / I_{1}\right)=1.0$. A inclinação da linha reta corresponde ao exponente $m$, como mostra a Figura 54 e Figura 55.

$$
\log \left(\frac{I_{1}^{3}}{I_{3}}-27\right)=\log \eta_{1}+m \log \left(\frac{P_{a}}{I_{1}}\right)
$$

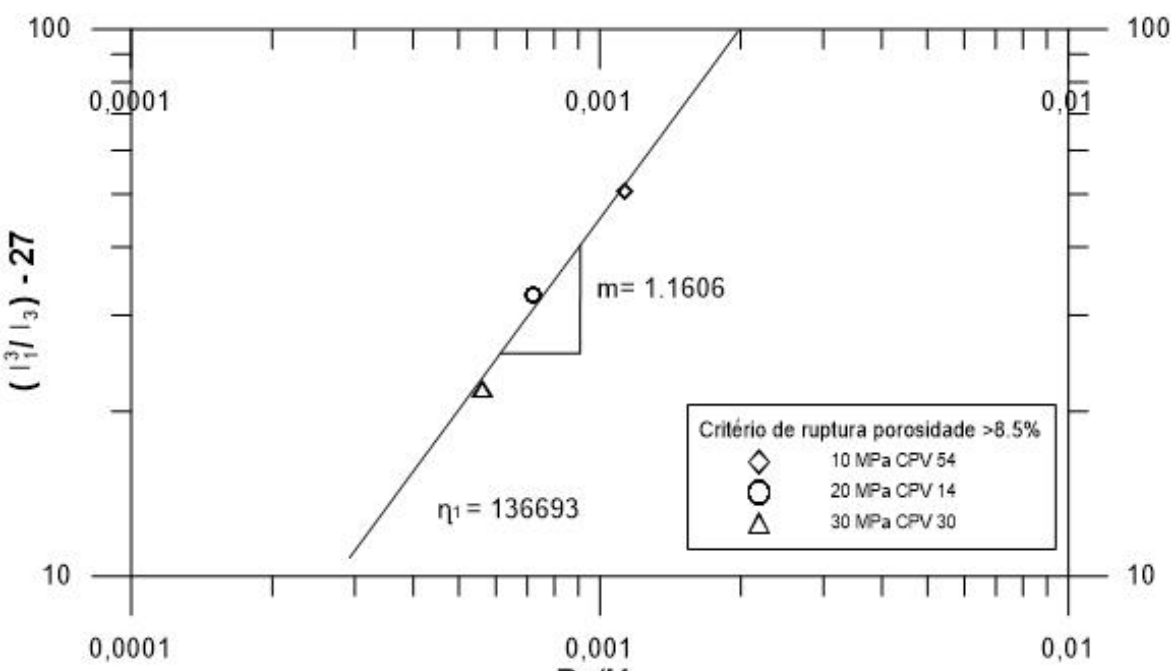

(a)

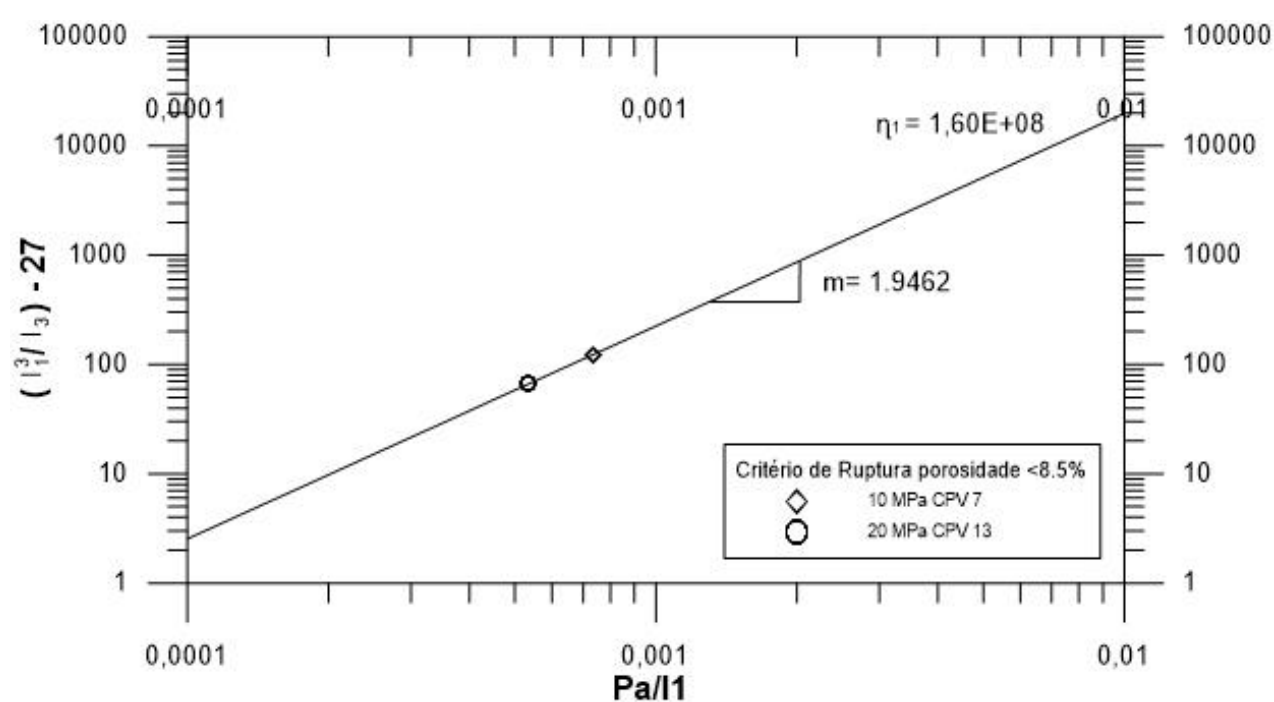

(b) 
Figura 54 Parâmetros $\eta_{1}$ e $m$ do modelo Lade-Kim da rocha travertino, CPV. ( $\beta=0^{\circ}$ ) (a) porosidade $>8.5 \%$ (b) porosidade $<8.5 \%$.

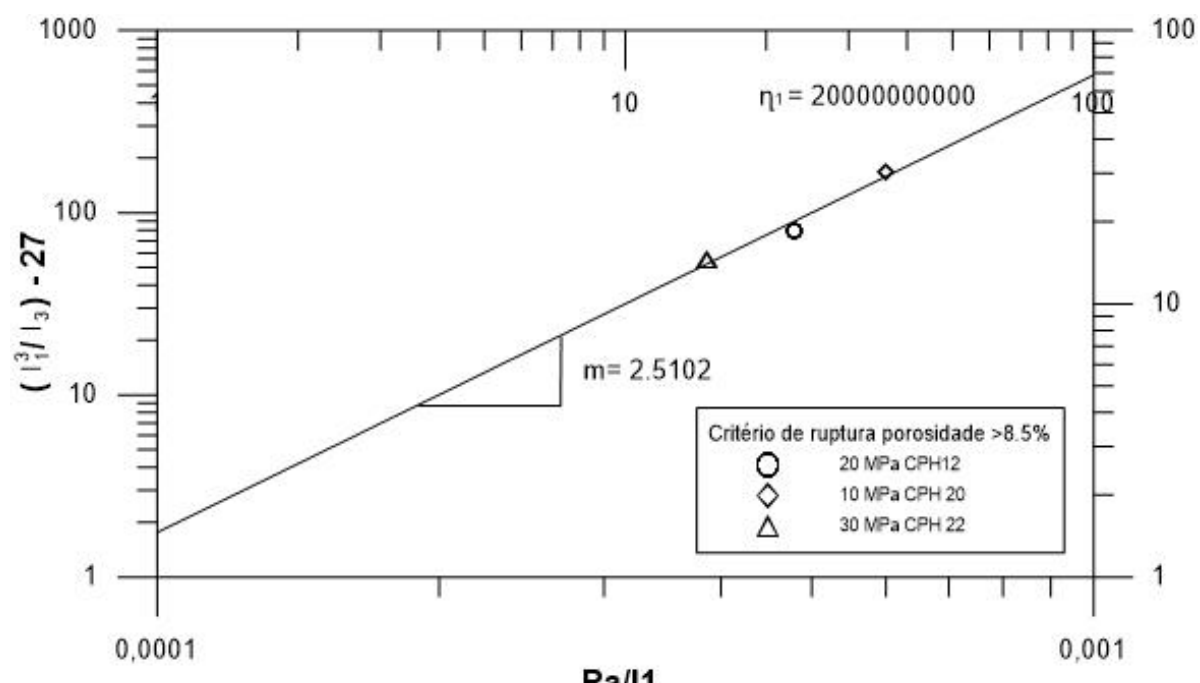

(a)

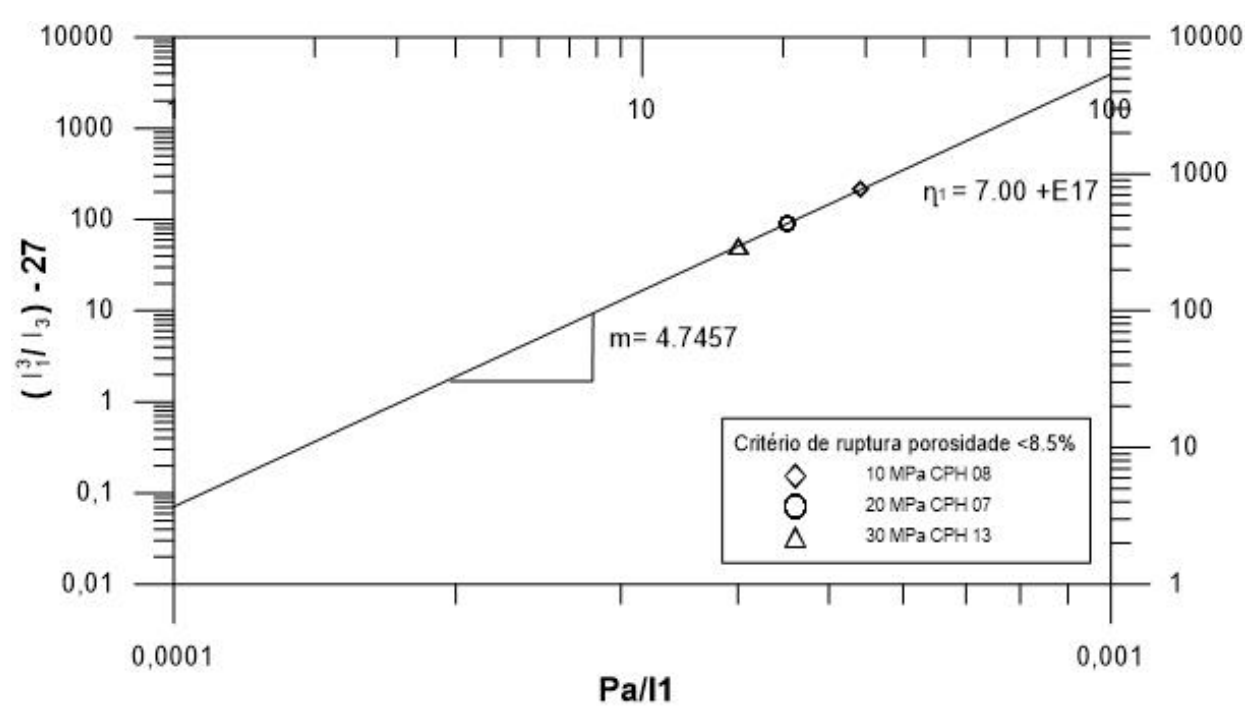

(b)

Figura 55 Parâmetros $\eta_{1}$ e $m$ do modelo Lade-Kim da rocha travertino $\mathrm{CPH}$. ( $\beta=90^{\circ}$ ). (a) Porosidade $>8.5 \%$, (b) porosidade $<8.5 \%$. 
A partir dos resultados apresentados na Tabela 19, observa-se que os parâmetros do critério de ruptura variam com a porosidade e com a orientação das camadas. No caso dos CPVs, os valores de $\eta_{1}$ são muito menores.

Tabela 19 Variação de parâmetros de ruptura do travertino no modelo Lade-Kim.

\begin{tabular}{cccc}
\hline $\mathrm{CP}$ & Porosidade & $m$ & $\eta_{1}$ \\
\hline $\mathrm{CPV}\left(\beta=0^{\circ}\right)$ & $<8.5 \%$ & 1.9462 & $1,60 \mathrm{E}+08$ \\
$\mathrm{CPV}\left(\beta=0^{\circ}\right)$ & $>8.5 \%$ & 1.1606 & 136,693 \\
$\mathrm{CPH}\left(\beta=90^{\circ}\right)$ & $<8.5 \%$ & 4.7457 & $7,0 \mathrm{E}+17$ \\
$\mathrm{CPH}\left(\beta=90^{\circ}\right)$ & $>8.5 \%$ & 2.5102 & $2,0 \mathrm{E}+10$ \\
\hline
\end{tabular}

Com o objetivo de incluir a coesão presente na rocha carbonática travertino, é usado o procedimento desenvolvido por (Kim e Lade 1984). No Capítulo 2 foi descrito o procedimento para obtenção do parâmetro a que representa a coesão. Para isso, foram utilizados os resultados dos ensaios de compressão simples (UCS) e as constantes adimensionais do Capítulo 2, Tabela 2, para rochas sedimentares, $T_{o}=-0.22, t_{i}=0.75$, além da pressão atmosférica, $P_{a}$, nas mesmas unidades das tensões (MPa), Na Tabela 20 são apresentados os resultados:

Tabela 20 Coesão da rocha carbonática travertino do modelo Lade-Kim

\begin{tabular}{cccc}
\hline $\mathrm{CP}$ & Porosidade & UCS (Mpa) & $a$ \\
\hline $\mathrm{CPV}\left(\beta=0^{\circ}\right)$ & $<8.5 \%$ & 49.0 & 22.91 \\
$\mathrm{CPV}\left(\beta=0^{\circ}\right)$ & $>8.5 \%$ & 34.74 & 17.72 \\
$\mathrm{CPH}\left(\beta=90^{\circ}\right)$ & $<8.5 \%$ & 64.75 & 28.2 \\
$\mathrm{CPH}\left(\beta=90^{\circ}\right)$ & $>8.5 \%$ & 69.80 & 29.88 \\
\hline
\end{tabular}

\subsection{3.}

\section{Parâmetros da função potencial plástico}

A partir dos resultados obtidos dos ensaios triaxias no item 4.1 e usando as equações (2.35), (2.36) e (2.37), foram determinados os paramtros $\psi_{2}$ e $\mu .0$ 
valor do parâmetro $\psi_{2}$ é determinado quando $\xi_{x}=0$ e o valor $1 / \mu$ é a inclinação da linha reta, como se mostra na Figura 56 à Figura 57

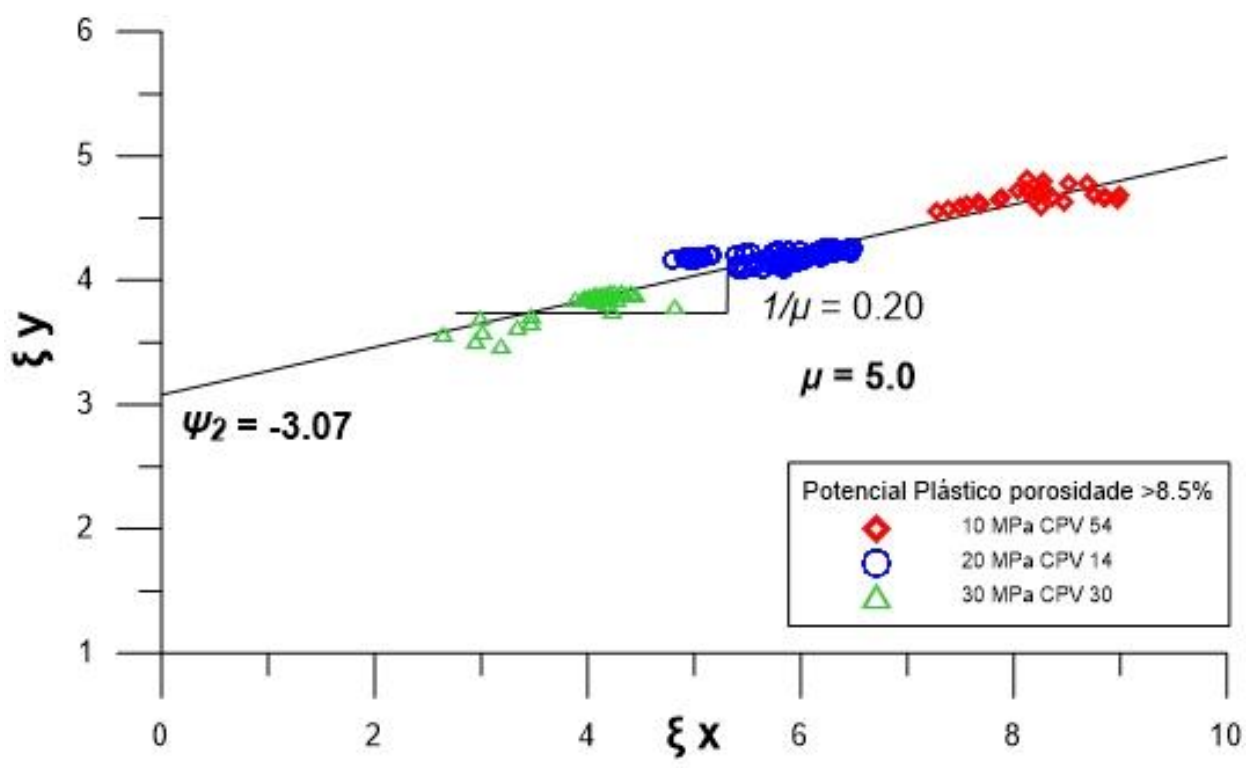

(a)

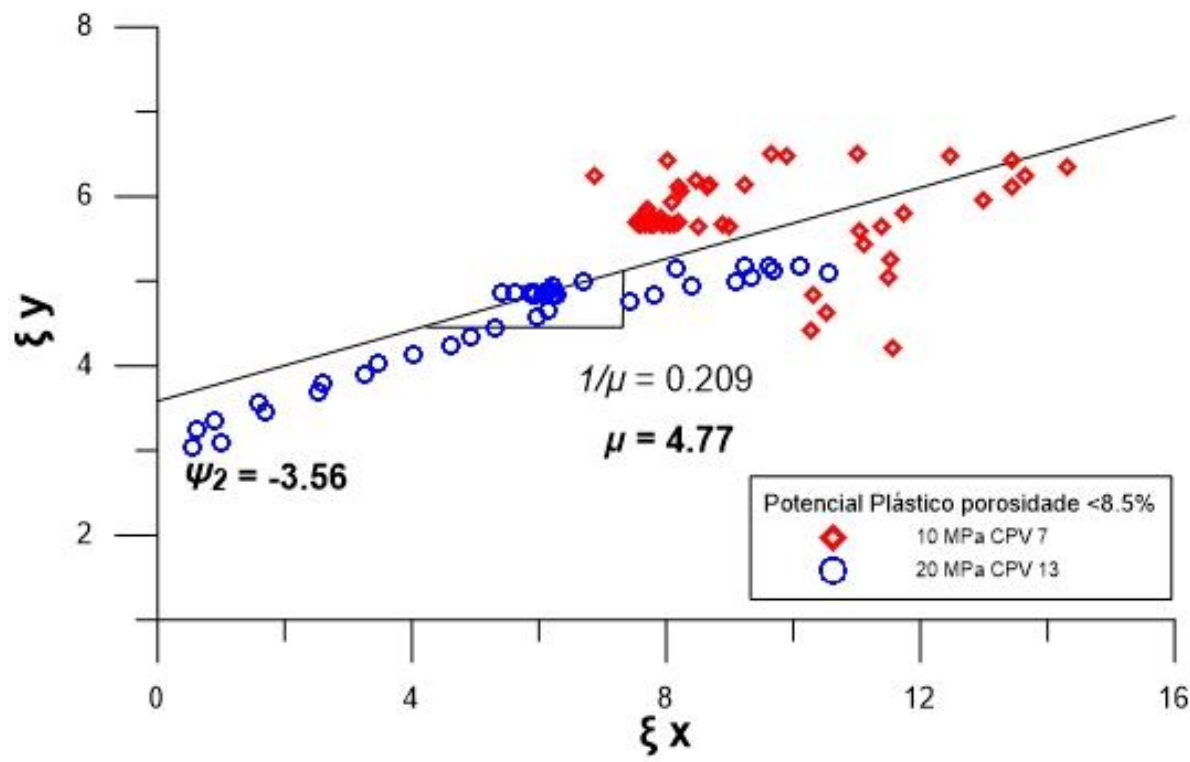

(b)

Figura 56 Parâmetros $\psi_{2}$ e $\mu$ do modelo Lade-Kim da rocha travertino CPV ( $\beta=0^{\circ}$ ). (a) Porosidade $>8.5 \%$, (b) porosidade $<8.5 \%$. 


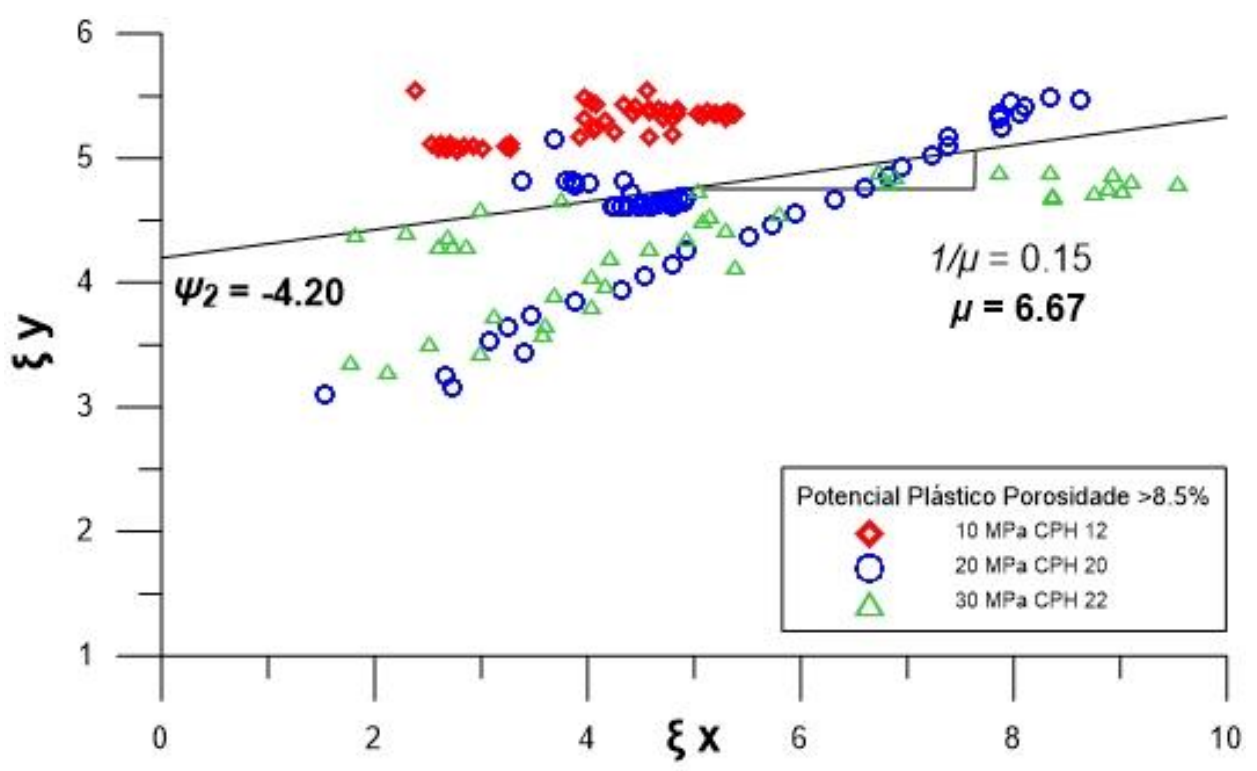

(a)

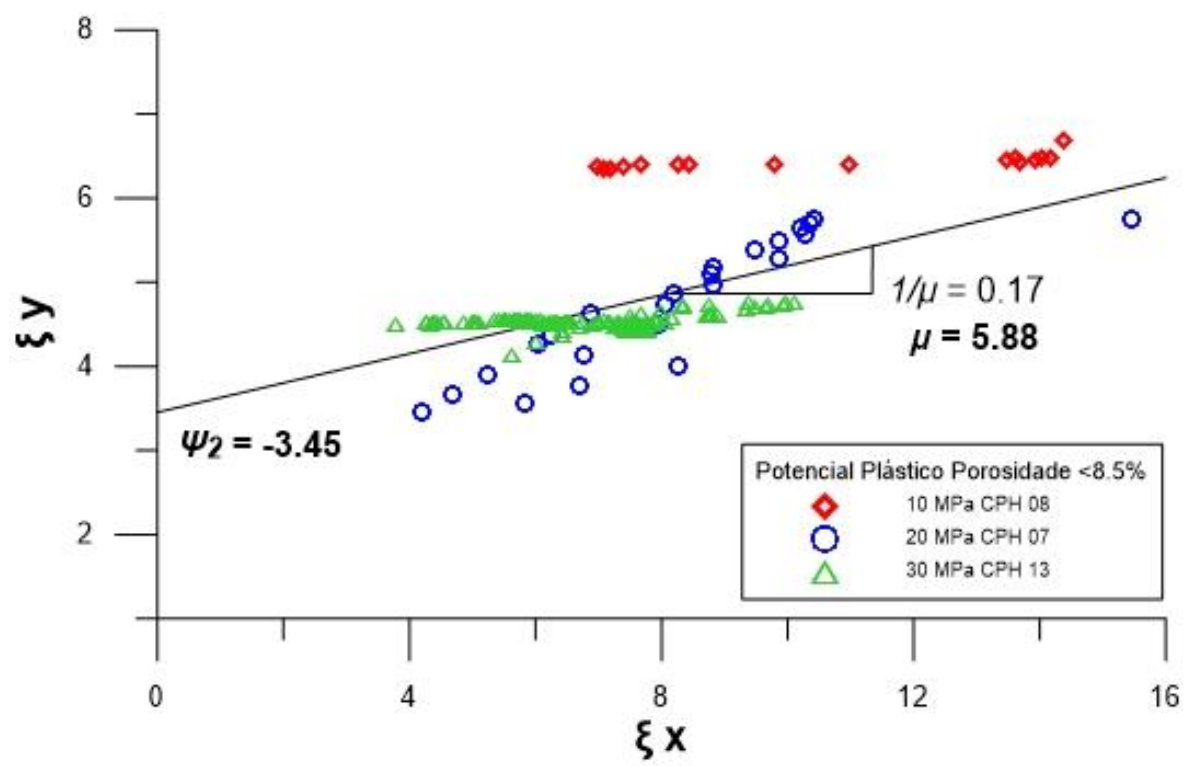

(b)

Figura 57 Parâmetros $\psi_{2}$ e $\mu$ do modelo Lade-Kim da rocha travertino, $\mathrm{CPH}$. ( $\beta=90^{\circ}$ ). (a) Porosidade $>8.5 \%$, (b) porosidade $<8.5 \%$.

Os parâmetros da função potencial plástica são muito suscetíveis ao processo de calibração, devido ao tipo de rocha, heterogênea e porosa. Eles dependem da qualidade dos resultados obtidos dos ensaios triaxiais compressão. Neste contexto é importante mencionar que, para determinar os valores dos parâmetros em todos os casos, alguns pontos da função potencial plástica foram 
aferidos. Como consequência disto, alguns valores tiveram resultados fora do esperado, e outros valores negativos. Para um bom ajuste, os parâmetros devem ser cuidadosamente selecionados e devem cumprir a condição de irreversibilidade, que sugere que o trabalho plástico seja sempre positivo. Neste caso o trabalho plástico depende dos incrementos de formação plástica e das tensões, porém somente foram usados dados com incrementos de deformação plástica positivos. Esta condição garante a determinação dos parâmetros. No entanto, para que a condição de irreversibilidade seja cumprida, deve-se satisfazer condições do modelo Equação (2.53).

Outro aspecto importante é a sensibilidade dos parâmetros. Neste caso, uma pequena variação dos parâmetros pode impactar, de forma negativa ou positiva, na representação das curvas tensão vs. deformação axial e este vs. deformação volumétrica. Porém, alguns deles foram ajustados, como apresentado na Tabela 21, para representar as curvas anteriormente mencionadas. No caso do valor de $\psi_{2}$, os valores foram determinados a partir da equação (2.53), enquanto o valor de $\mu$ foi adotado um valor menor dos obtidos na calibração.

Tabela 21 Variação de parâmetros da função potencial plástico do travertino para o modelo Lade-Kim.

\begin{tabular}{cccc}
\hline $\mathrm{CP}$ & Porosidade & $\mu$ & $\psi_{2}$ \\
\hline $\mathrm{CPV}\left(\beta=0^{\circ}\right)$ & $<8.5 \%$ & 3.0 & -2.9 \\
$\mathrm{CPV}\left(\beta=0^{\circ}\right)$ & $>8.5 \%$ & 4.0 & -2.9 \\
$\mathrm{CPH}\left(\beta=90^{\circ}\right)$ & $<8.5 \%$ & 4.0 & -3.0 \\
$\mathrm{CPH}\left(\beta=90^{\circ}\right)$ & $>8.5 \%$ & 2.0 & -3.0 \\
\hline
\end{tabular}

\subsection{4.}

\section{Parâmetros de endurecimento e amolecimento}

Os parâmetros $C$ e $P$ foram determinados através do melhor ajuste dos resultados do ensaio hidrostático no gráfico $\log W_{P} / P_{a}$ vs. Log $I_{1} / P_{a}$ usando a Equação (2.48). Onde $P$ é a inclinação da linha de ajuste e $C$ corresponde ao intercepto do eixo $\left(I_{1} / P_{a}\right)=1.0$. Como descrito no item 4.3, dentre os resultados dos ensaios hidrostáticos, somente foi considerado o CPV22 como único ensaio apropriado para calibração dos parâmetros e pode ser observado na Figura 58: 


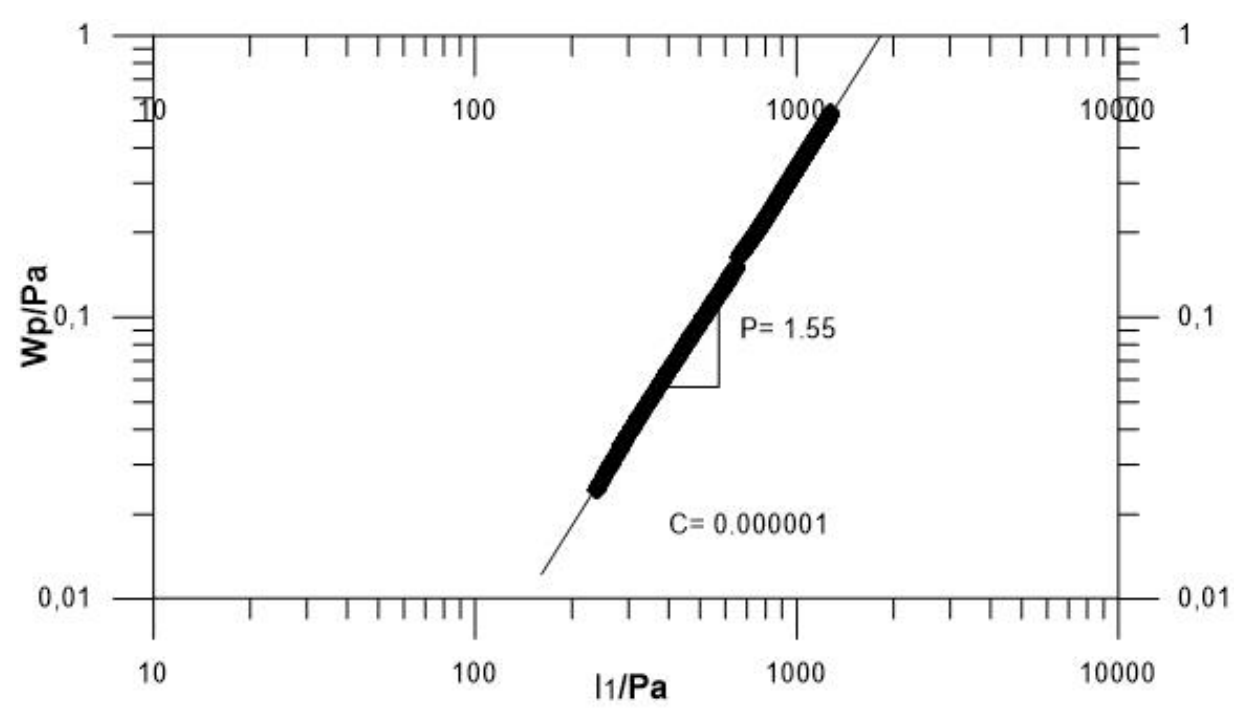

Figura 58 Determinação dos parâmetros $C$ e $P$ do travertino.

No entanto, como já mencionado anteriormente, estes parâmetros foram levemente modificados para representar as curvas tensão vs deformação axial e esta vs deformação volumétrica da rocha carbonática travertino. Pode-se observar na Tabela 22 que o parâmetro $C$ foi mantido igual em todas as orientações, sendo que é o responsavel por gerar deslocamento na curva tensão vs deformação, no eixo das deformações axiais. Por outro lado, o parâmetro $P$ sofreu pequenas alterações. A Tabela 22 apresenta a variação dos parâmetros em função da porosidade e da orientação das camadas em relação ao eixo axial.

Tabela 22 Variação de parâmetros de endurecimento do travertino com o modelo Lade-Kim.

\begin{tabular}{cccc}
\hline $\mathrm{CP}$ & Porosidade & $C$ & $P$ \\
\hline $\mathrm{CPV}\left(\beta=0^{\circ}\right)$ & $<8.5 \%$ & 0.000001 & 1.50 \\
$\mathrm{CPV}\left(\beta=0^{\circ}\right)$ & $>8.5 \%$ & 0.000001 & 1.55 \\
$\mathrm{CPH}\left(\beta=90^{\circ}\right)$ & $<8.5 \%$ & 0.000001 & 1.55 \\
$\mathrm{CPH}\left(\beta=90^{\circ}\right)$ & $>8.5 \%$ & 0.000001 & 1.50 \\
\hline
\end{tabular}




\subsection{5.}

\section{Parâmetros da função de escoamento}

Como já foi mensonado no Capítulo 2, o parâmetro $h$ é um valor constante, enquanto $q$ depende do estado de tensões. Durante a compressão isotrópica, $q=0$; durante o endurecimento, $0<q<1$ e, na tensão de ruptura, $q=1$. Neste caso, o valor de $q$ varia com as tensões $S$, Equação (2.44). O valor de $\alpha$ da equação (2.45) é determinado quando o nível de tensões $S=0.8$, como pode ser observado na Figura 59 e Figura 60.

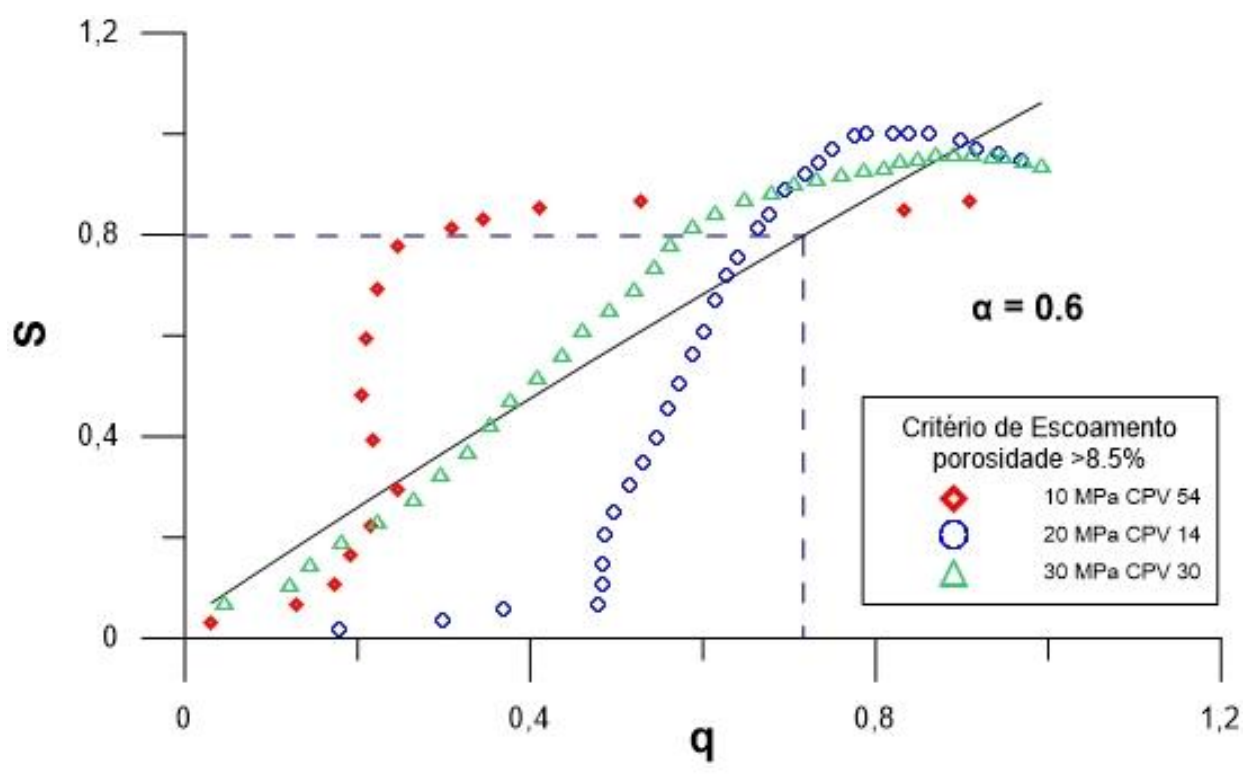

(a)

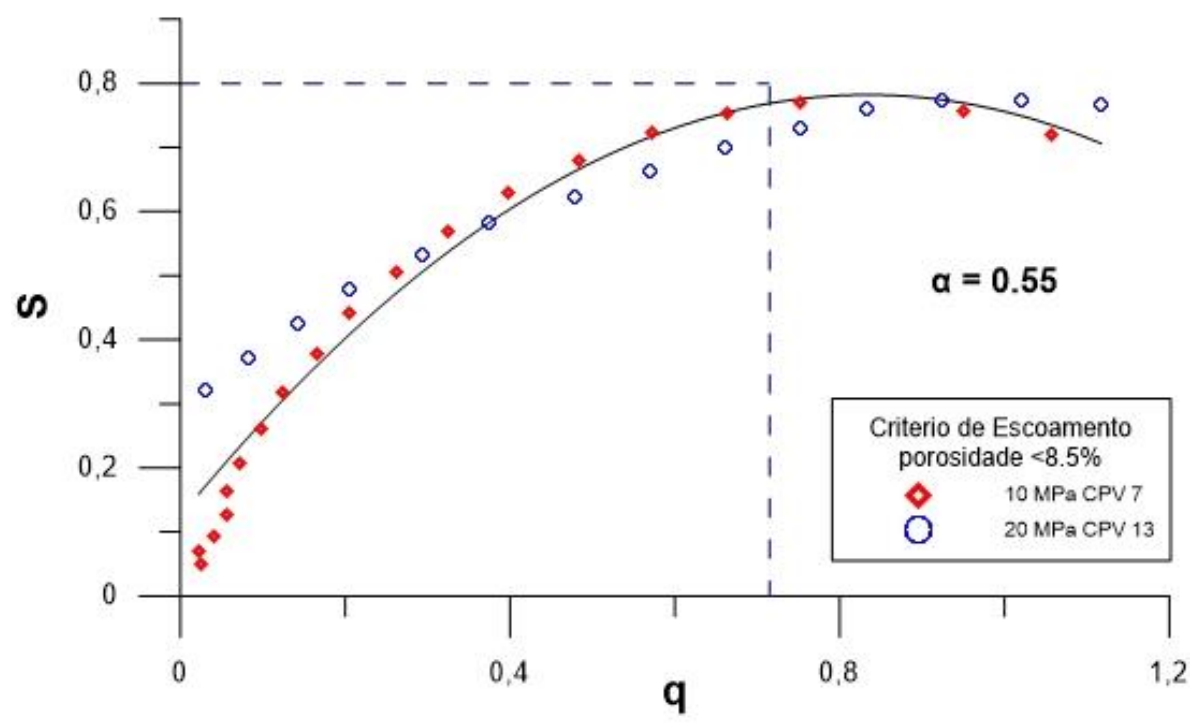

(b) 
Figura 59 Parâmetro $\alpha$ do modelo Lade-Kim da rocha travertino, $\operatorname{CPV}\left(\beta=0^{\circ}\right)$. (a) Porosidade $>8.5 \%$, (b) porosidade $<8.5 \%$.

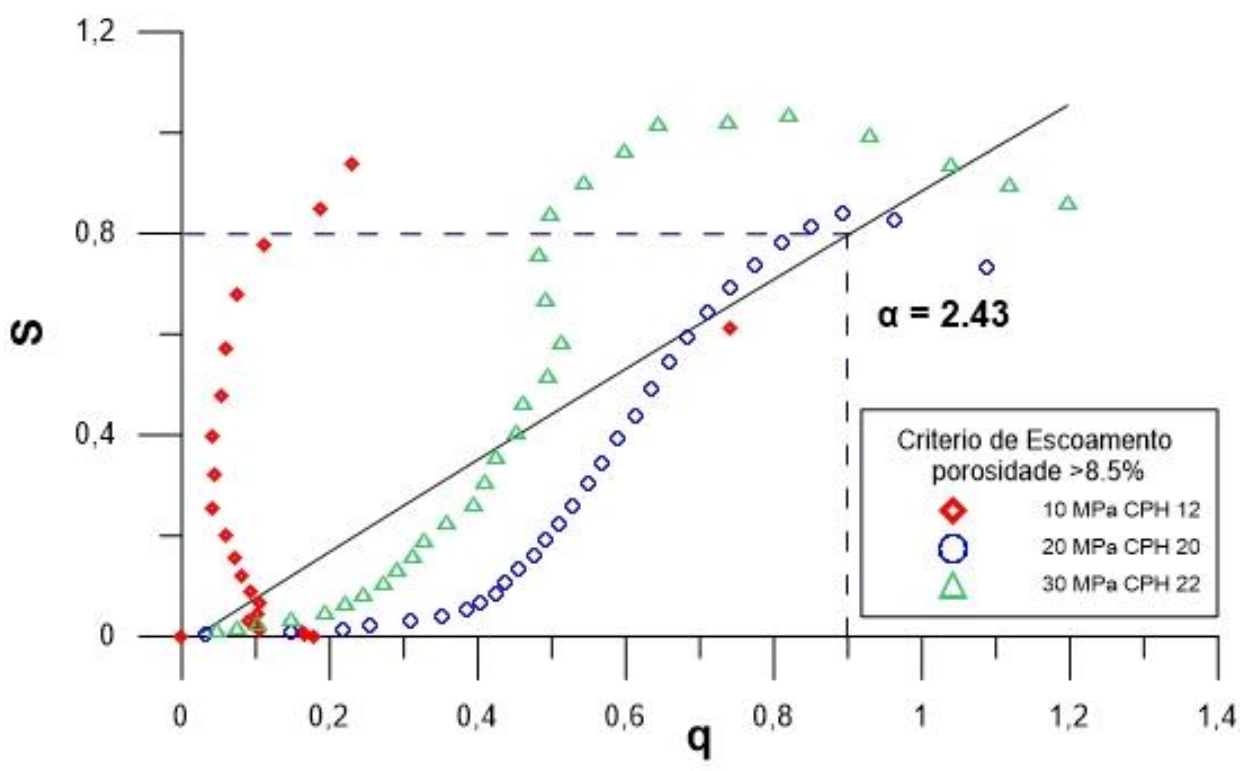

(a)

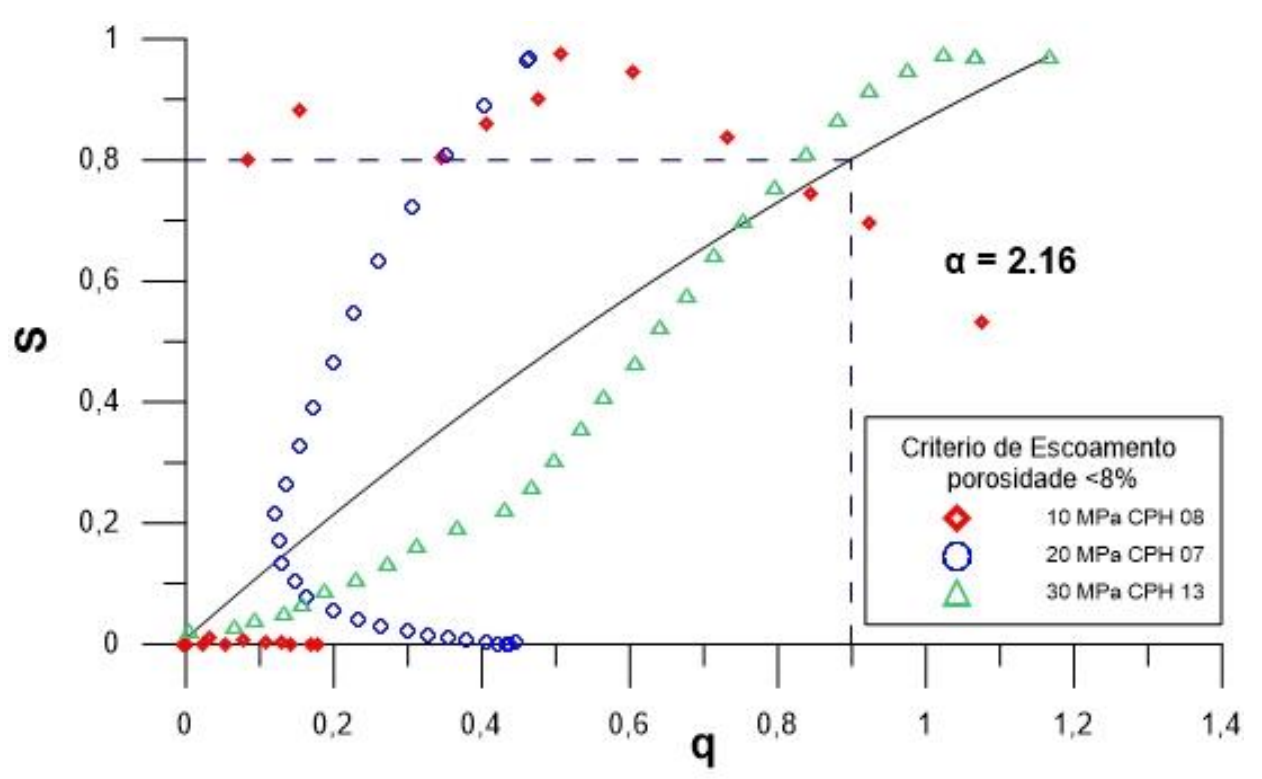

(b)

Figura 60 Parâmetro $\alpha$ do modelo Lade-Kim da rocha travertino, $\mathrm{CPH}$ ( $\beta=90^{\circ}$ ). (a) Porosidade $>8.5 \%$, (b) porosidade $>8.5 \%$. 
Os parâmetros da função de escoamento são muito suscetíveis à calibração devido ao tipo de rocha, heterogênea e porosa. Neste caso, para obter uma melhor representação nas curvas tensão vs. deformação e volumétrica no algoritmo de Lade-Kim, os parâmetros foram levemente modificados. Assim é importante esclarecer que uma pequena variação dos parâmetros pode resultar em resultados diferentes. Na tabela a seguir pode-se observar a variação dos parâmetros da função de escoamento com a porosidade e a orientação das camadas, paralela e ortogonal em relação ao eixo axial.

Tabela 23 Variação de parâmetros de ruptura do travertino com Lade-Kim.

\begin{tabular}{cccc}
\hline $\mathrm{CP}$ & Porosidade & $\boldsymbol{h}$ & $\boldsymbol{\alpha}$ \\
\hline $\mathrm{CPV}\left(\beta=0^{\circ}\right)$ & $<8.5 \%$ & 0.893 & 0.3 \\
$\mathrm{CPV}\left(\beta=0^{\circ}\right)$ & $>8.5 \%$ & 0.60 & 0.2 \\
$\mathrm{CPH}\left(\beta=90^{\circ}\right)$ & $<8.5 \%$ & 1.0 & 0.2 \\
$\mathrm{CPH}\left(\beta=90^{\circ}\right)$ & $>8.5 \%$ & 1.20 & 2.0 \\
\hline
\end{tabular}

\subsection{6. \\ Resultados dos parâmetros para o modelo Lade-Kim isotrópico}

Finalmente, foi realizado o processo de calibração com o modelo elastoplástico Lade-Kim com endurecimento isotrópico para a rocha carbonática travertino em função da porosidade e da orientação das camadas. Pode-se concluir que os parâmetros que tiveram maior variação são $\eta_{1}, K$. No entanto, isso não garante que eles sejam responsáveis pelas mudanças nas curvas tensão vs deformação. Como foi mencionado anteriormente, deve existir uma coerência entre eles para um melhor ajuste das curvas. Durante as simulações foi observado que uma pequena variação nos parâmetros dos critérios da função potêncial plástica e da função de escoamento mudaram o comportamento das curvas tensão vs deformação e deformação volumétrica. Na Tabela 24 são apresentados os 12 parâmetros do modelo Lade-Kim obtidos pelo método de calibração direta ou analítica 
Tabela 24 Parâmetros da rocha carbonática travertino com o modelo Lade-Kim.

\begin{tabular}{lccccc}
\hline \multicolumn{1}{c}{ Critério } & Parâmetros & $\mathrm{CPV}<8.5 \%$ & $\mathrm{CPV}>8.5 \%$ & $\mathrm{CPH}<8.5 \%$ & $\mathrm{CPH}>8.5 \%$ \\
\hline $\begin{array}{l}\text { Critério de } \\
\text { Ruptura }\end{array}$ & $a$ & 22.91 & 17.72 & 28.24 & 29.9 \\
& $m$ & 1.9462 & 1.16060 & 4.7457 & 2.5102 \\
& $\eta_{1}$ & $1,60 \mathrm{E}+08$ & 136,693 & $7,0 \mathrm{E}+17$ & $2,0 \mathrm{E}+10$ \\
Critério elástico & $K$ & 393,982 & 318,099 & 561,583 & 409,299 \\
& $n$ & 0.0851 & 0.0846 & 0.0299 & 0,0821 \\
\hline Função & $v$ & 0.27 & 0.30 & 0.34 & 0.38 \\
potencial & $\psi$ & -2.9 & -2.9 & -3.0 & -3.0 \\
plástica & $\mu$ & 3.0 & 4.0 & 4.0 & 2.0 \\
\hline Endurecimento & $C$ & 0.000001 & 0.000001 & 0.000001 & 0.000001 \\
& $P$ & 1.5 & 1.55 & 1.55 & 1.50 \\
\hline $\begin{array}{l}\text { Função de } \\
\text { escoamento }\end{array}$ & $\boldsymbol{C}$ & 0.3 & 0.2 & 0.2 & 2.0 \\
\hline
\end{tabular}

\section{5.}

\section{Validação do modelo isotrópico Lade-Kim}

Os parâmetros calibrados foram validados no algoritmo Lade-Kim isotrópico desenvolvido nos programas MATLAB2017a® e FORTRAN 90®. Foram comparados com os resultados do laboratório através das curvas tensão desviadora vs. deformação axial e deformação volumétrica vs deformação axial. Neste contexto, elas são apresentadas, organizadas por porosidade total, orientação de acamamento ortogonal (CPV), inclinado (CPI) e paralelo (CPH) em relação ao eixo axial das amostras.

\subsection{1.}

\section{CPV com porosidade $<8.5 \%\left(\beta=0^{\circ}\right)$}

Na Figura 61 (a), observa- se que o modelo isotrópico Lade-Kim representa adequadamente a curva tensão desviadora vs deformação axial para os casos com tensão de confinamento de 10 e $20 \mathrm{MPa}$, CPVs 7 e 13, respectivamente. $\mathrm{Na}$ Figura 61(b) observa- se que o CPV 7, com tensão confinante de $10 \mathrm{MPa}$, apresenta maior deformação volumetrica ligeiramente maior na parte compressiva que o CPV 13, com tensão confiante de $20 \mathrm{MPa}$, quando se esperaria o contrário. Contudo, o modelo Lade-Kim reproduz bem a tensão de confinamento de $20 \mathrm{MPa}$, 
a qual é de maior interesse para o comportamento do reservatório, considerando as condições in situ de campos do Pré-Sal.

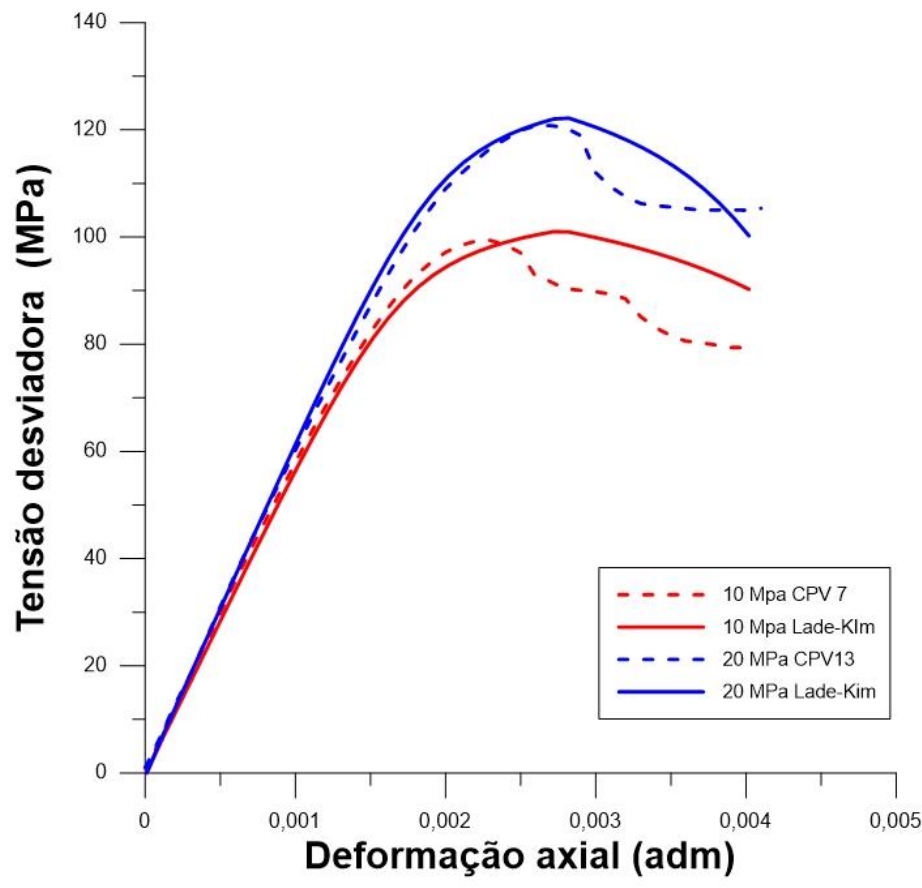

(a)

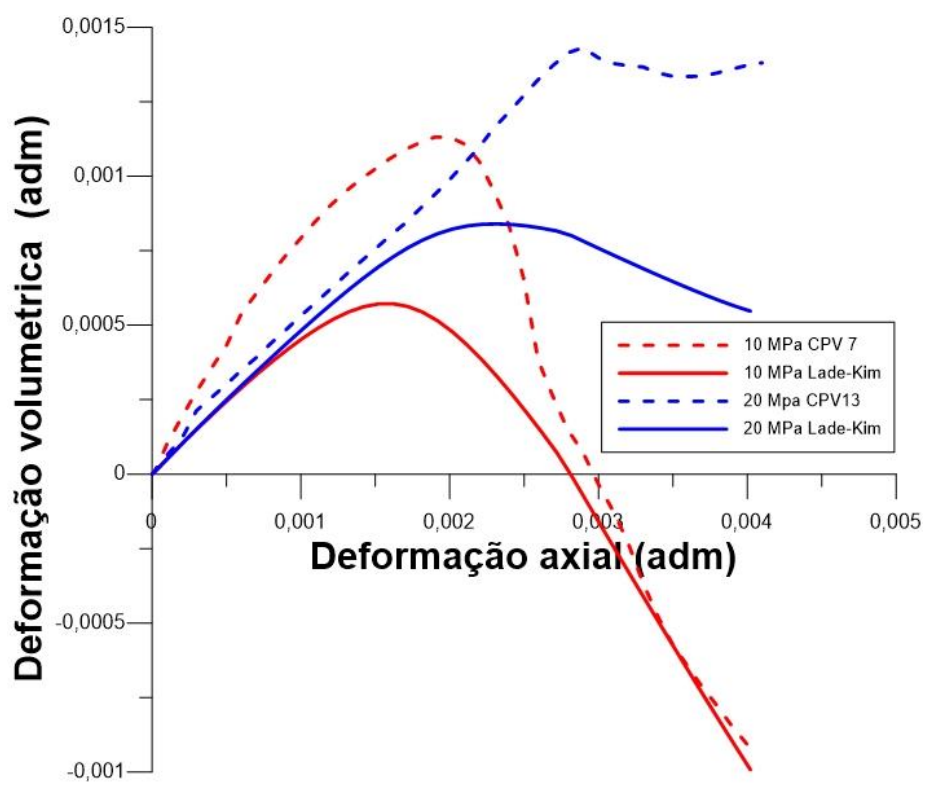

(b)

Figura 61 Comparação entre ensaio laboratorial e modelagem numérica com o modelo de Lade-Kim para CPV com porosidade $<8.5 \%$. (a) Curva tensão vs deformação axial, (b) deformação volumétrica vs deformação axial. 


\subsection{2.}

CPV com porosidade $>8.5 \%\left(\beta=0^{\circ}\right)$

Na Figura 62 (a) observa-se que o modelo elastoplástico de Lade-Kim representa adequadamente a curva tensão desviadora vs deformação axial com tensões de confinamento de 10, 20 e 30 MPa obtidas em laboratorio. Neste caso, pode-se concluir que os parâmetros calibrados anteriormente foram adequados para representar o comportamento elastoplástico com orientação de acamamento vertical, independentemente da porosidade. Além disso, resultados experimentais mostram que a rocha apresenta um comportamento dúctil após a ruptura, o que foi bem representado pelo amolecimento do modelo Lade-Kim.

Na Figura 62 (b) é possível observar que os resultados experimentais de defromação para tensões de confinamento de 10 e $20 \mathrm{MPa}$ ficam maiores que a tensão confinante de $30 \mathrm{MPa}$. Contudo, o modelo isotrópico Lade-Kim reproduz com boa precisão a tensão de confinamento de $30 \mathrm{MPa}$, a qual pode ser considerada de maior interesse para o comportamento geomecanico do reservatório.

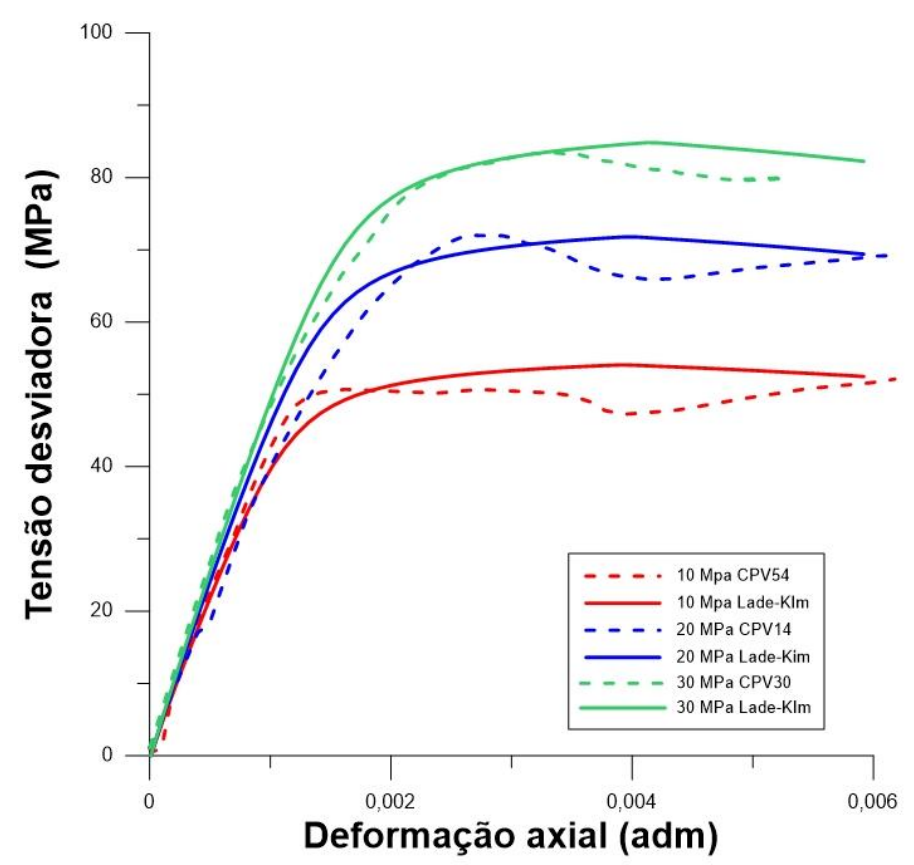

(a) 


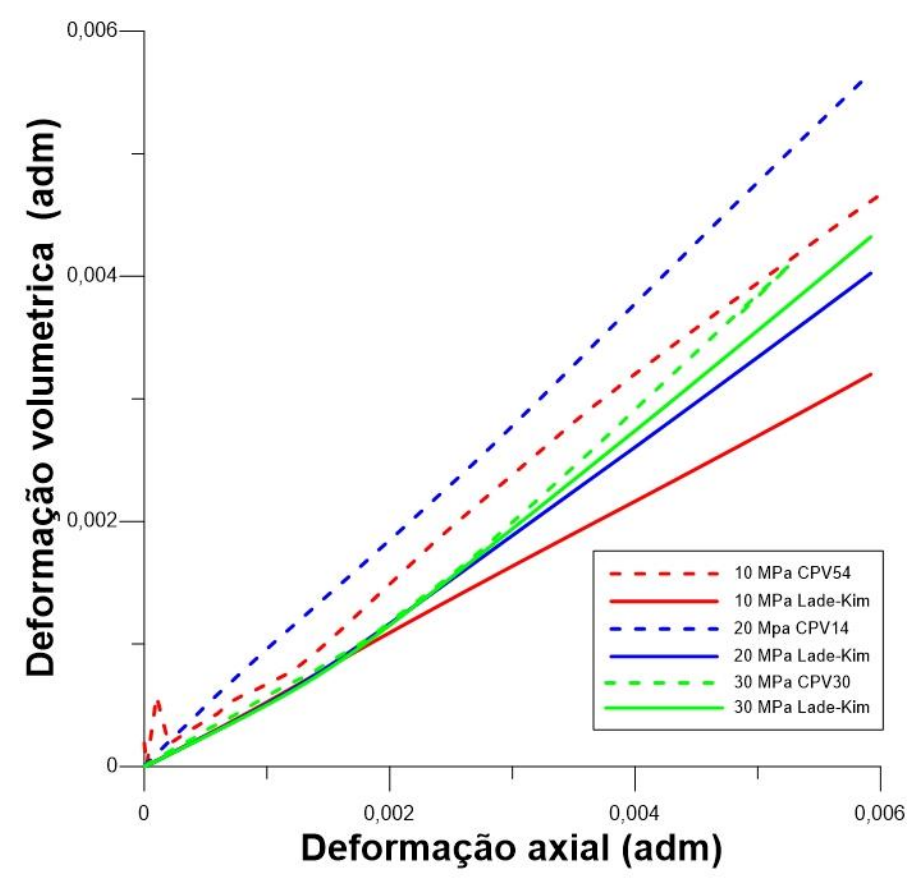

(b)

Figura 62 Comparação entre ensaio laboratorial e modelagem numérica com o modelo de Lade-Kim para CPV com porosidade $>8.5 \%$. (a) Curva tensão vs deformação axial, (b) deformação volumétrica vs deformação axial.

\subsection{3. \\ CPH com porosidade $<8.5 \%\left(\beta=90^{\circ}\right)$}

Como pode ser observado na Figura 63 (a), o modelo isotrópico Lade-Kim reproduz com boa concordância as curvas tensão desviadora vs deformação axial. Além disso observa-se que o modelo atinge com precisão as tensões de ruptura, em especial para a tensão confinante de $30 \mathrm{MPa}$, onde o amolecimento foi bem representado.

Na Figura 63 (b) o esperado era que a curva do ensaio $\mathrm{CPH}$ 08, com confinamento de $10 \mathrm{MPa}$, ficasse abaixo das curvas de 20 e $30 \mathrm{MPa}$, o que indica que este tipo de rocha apresenta comportamentos inesperados nos resultados do laboratório. Ainda assim, o modelo acompanha razoavelmente o complexo comportamento do carbonato. 


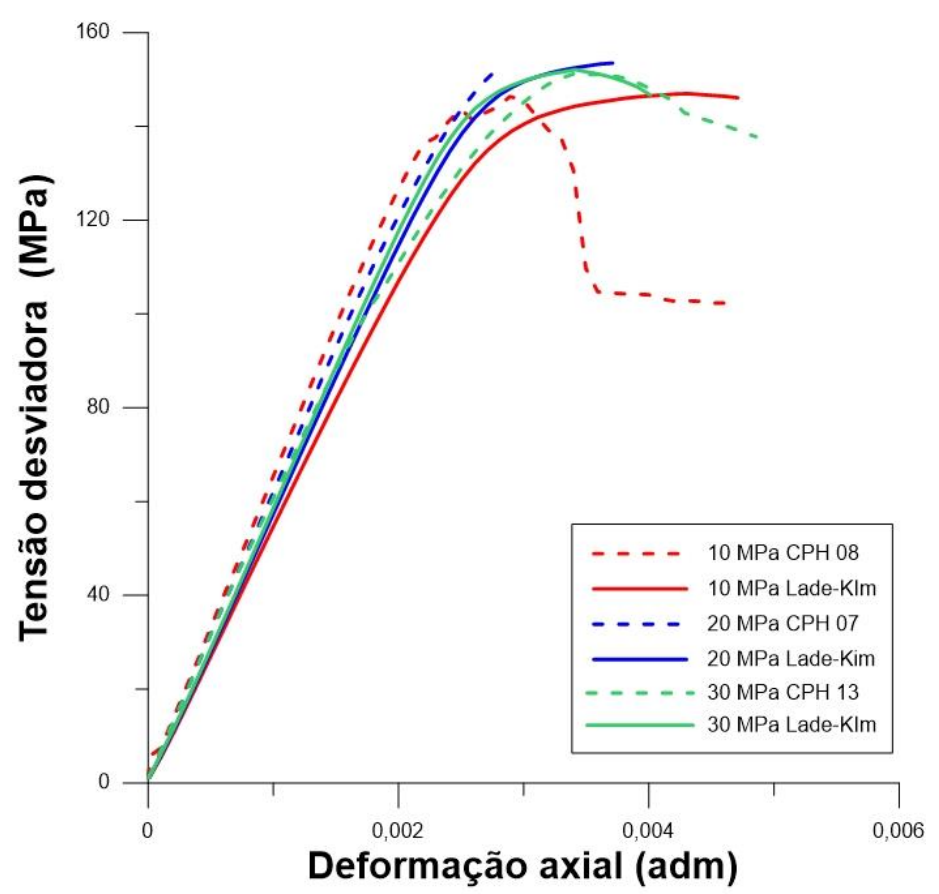

(a)

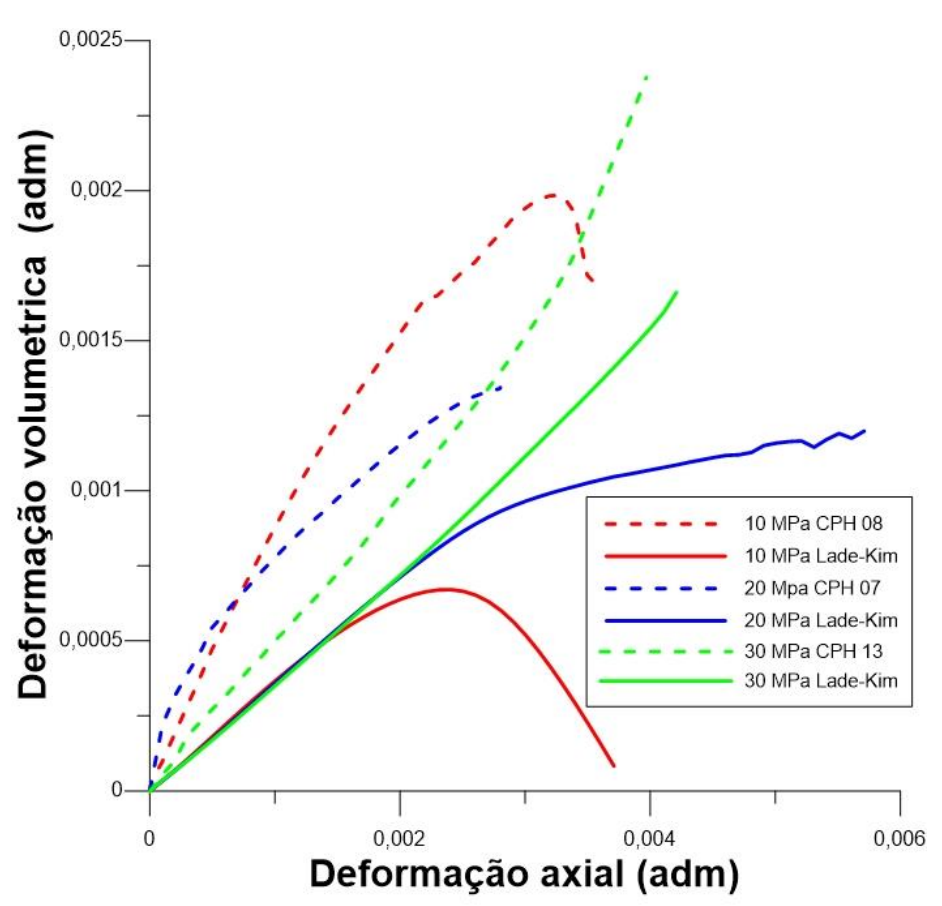

(b)

Figura 63 Comparação entre ensaio laboratorial e modelagem numérica com o modelo de Lade-Kim para $\mathrm{CPH}$ com porosidade $<8.5 \%$. (a) Curva tensão vs deformação axial, (b) deformação volumétrica vs deformação axial. 


\subsection{4.}

\section{CPH com porosidade $>8.5 \%\left(\beta=90^{\circ}\right)$}

Na Figura 64 (a) o modelo elastoplástico Lade-Kim representa com boa concordância o comportamento frágil observado nos resultados dos ensaios triaxiais com amostras horizontais da rocha carbonática travertino com porosidade superior a $8.5 \%$. Além disso, se conclui que a resistência para os $\mathrm{CPH}$ foi maior quando comparada com os CPV com porosidade maior a $8.5 \%$ para as tensões de confinamento de 10, 20 e $30 \mathrm{MPa}$. Na Figura 64 (b) o modelo isotrópico de Lade-Kim representa razoavelmente as deformações volumétricas para tensões de confinamento de 10, 20 e $30 \mathrm{MPa}$. Se observa que, devido a uma sequência coerente nos resultados de laboratório, onde a tensão de ruptura máxima aumenta com a tensão de confinamento, a calibração teve maior sucesso. Os resultados numéricos ficaram próximos aos experimentais. Mas isto nem sempre acontece devido ao fato de o travertino ser uma rocha heterogênea que apresenta características anisotrópicas.

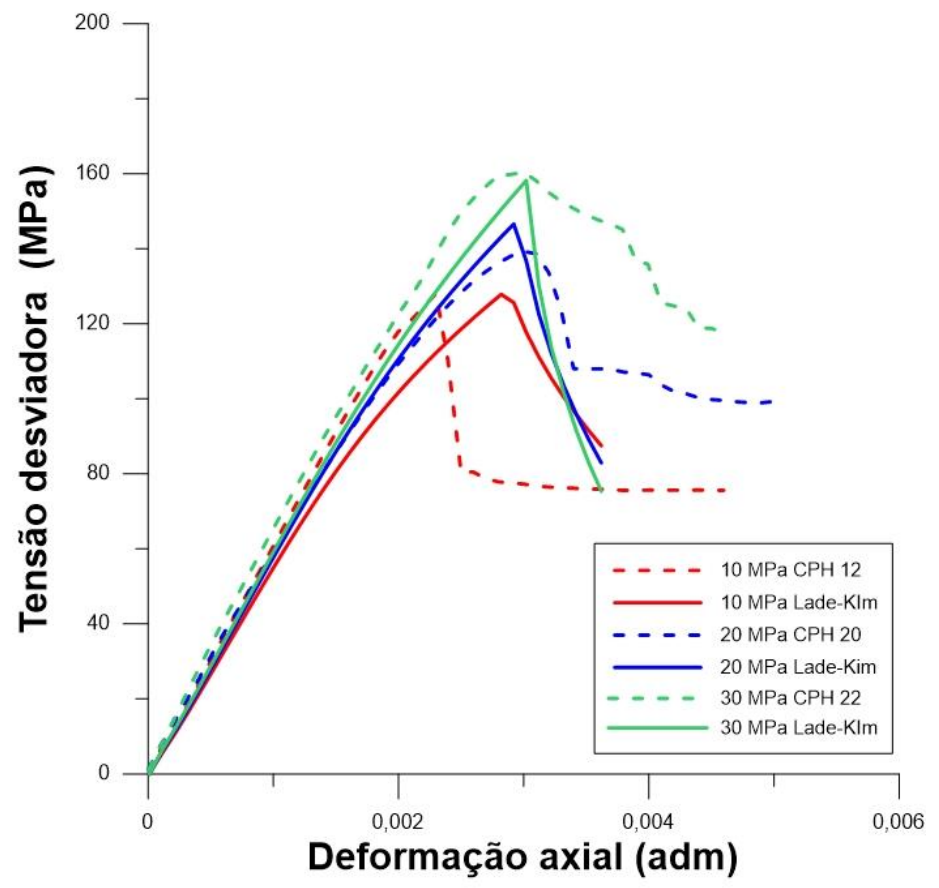

(a) 


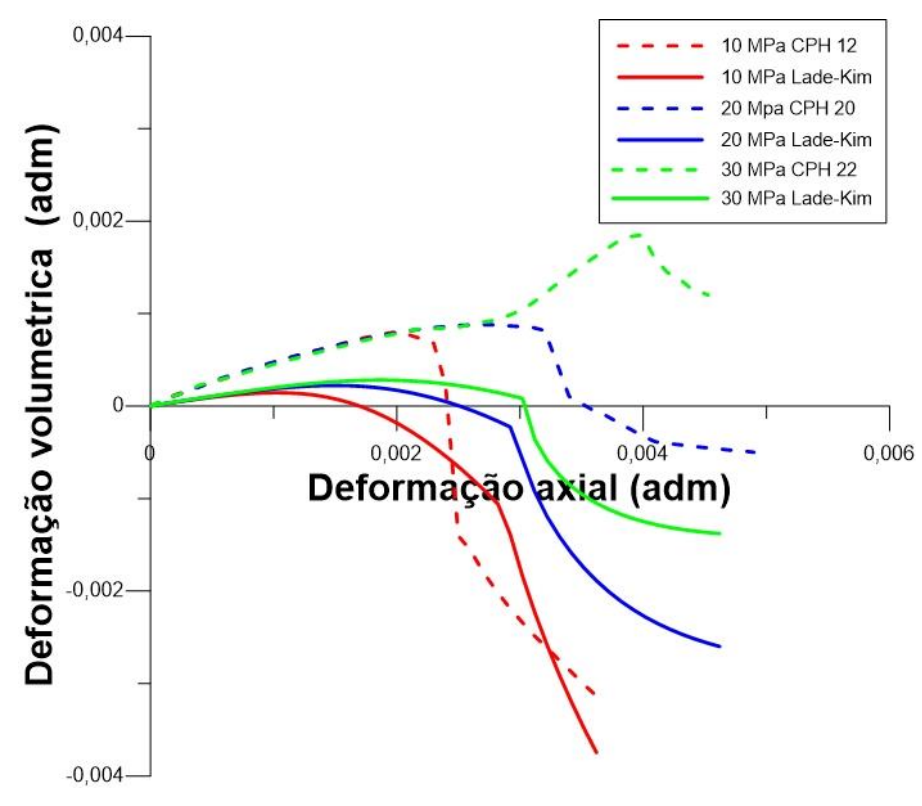

(b)

Figura 64 Comparação entre ensaio laboratorial e modelagem numérica com o modelo de Lade-Kim para CPH com porosidade $>8.5 \%$. (a) Curva tensão vs deformação axial, (b) deformação volumétrica vs deformação axial.

\section{6.}

\section{Calibração analítica do modelo CCMC}

O modelo elastoplástico CCMC contém 7 parâmetros a serem determinados. Neste caso, os parâmetros foram calibrados a partir dos resultados obtidos dos ensaios convencionais triaxiais a compressão, hidrostático e de compressão simples. Deste modo, será testado o modelo CCMC com a rocha carbonática travertino CPV com porosidades acima de $8.5 \%$.

\subsection{1.}

\section{Parâmetros $\lambda$ e $k$}

Os valores de $\lambda$ e $k^{\prime}$ estão relacionados com os valores do índice de compressão $\left(C_{C}\right)$ e índice de expansão $\left(C_{S L}\right)$ e são apresentados a seguir. Na Figura 65 de $e-\log 10 \bar{P}$, o índice de compressão é a inclinação da linha de carregamento, enquanto o índice de descarregamento é representado pela inclinação da linha de descarregamento. A variação de porosidade total é calculada usando a equação (2.74) proposta por Wan (2002). 


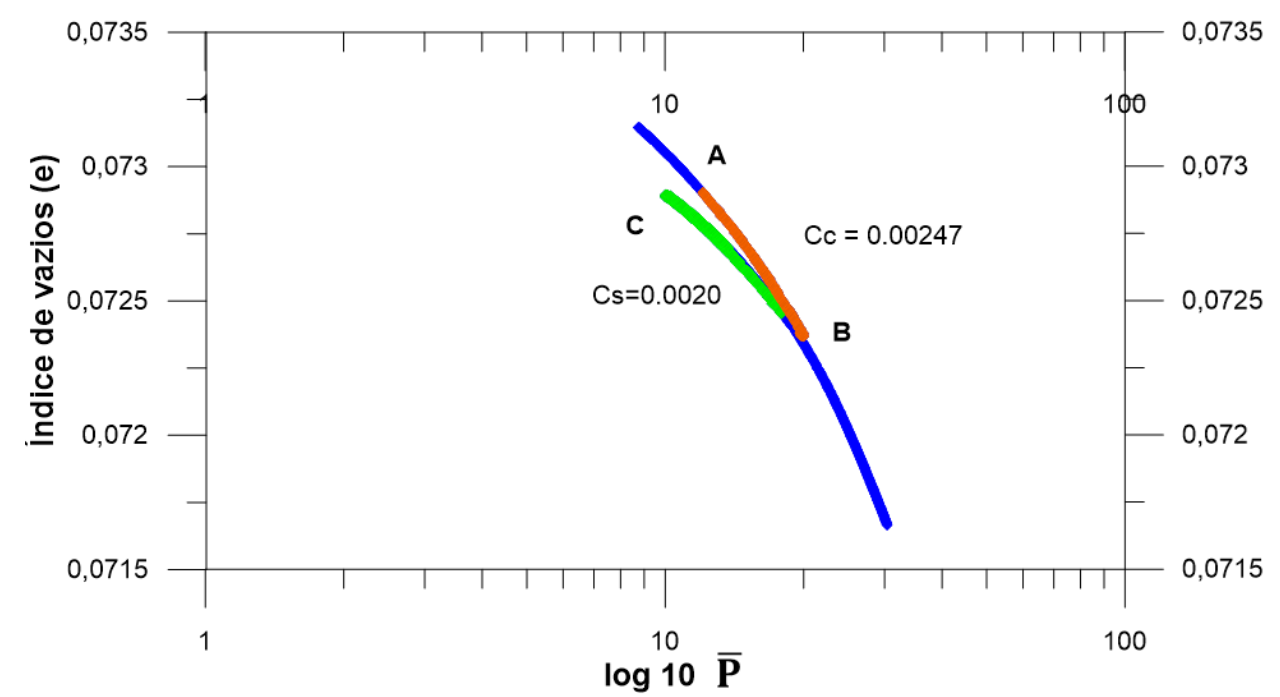

Figura 65 Gráfico $e$ vs. Log $\bar{P}$ da rocha carbonática travertino para CPV com porosidades $>8.5 \%$.

$$
\begin{gathered}
C_{C}=\frac{e_{A}-e_{B}}{\log _{10} P_{B}-\log _{10} P_{A}}=0.002473 \\
C_{S L}=\frac{e_{C}-e_{B}}{\log _{10} P_{B}-\log _{10} P_{C}}=0.002033 \\
\lambda=\frac{C_{c}}{\ln 10}=0.001074 \\
\boldsymbol{k}^{\prime}=\frac{C_{S}}{\ln 10}=0.0008829
\end{gathered}
$$

Os valores obtidos no processo de calibração foram ajustados para uma melhor representação das curvas tensão vs deformação, apresentados à diante. Assim estes valores foram mais próximos aos resultados experimentais, exceto para tensão confinante de $10 \mathrm{MPa}$. Finalmente são apresentados os valores dos parâmetros $\lambda=0.00085$ e $k^{\prime}=0.00070$.

\subsection{2.}

\section{Parâmetros coesão $C^{\star}$ e ângulo de atrito $\Phi$}

Os parâmetros $C^{*}$ e $\phi$ representam a coesão e o ângulo de atrito, respectivamente, e podem ser determinados usando o critério de Mohr-Coulomb. Na Figura 66 se observa o círculo de Mohr para tensões de confinamento de 10, 20 e $30 \mathrm{MPa}$. 


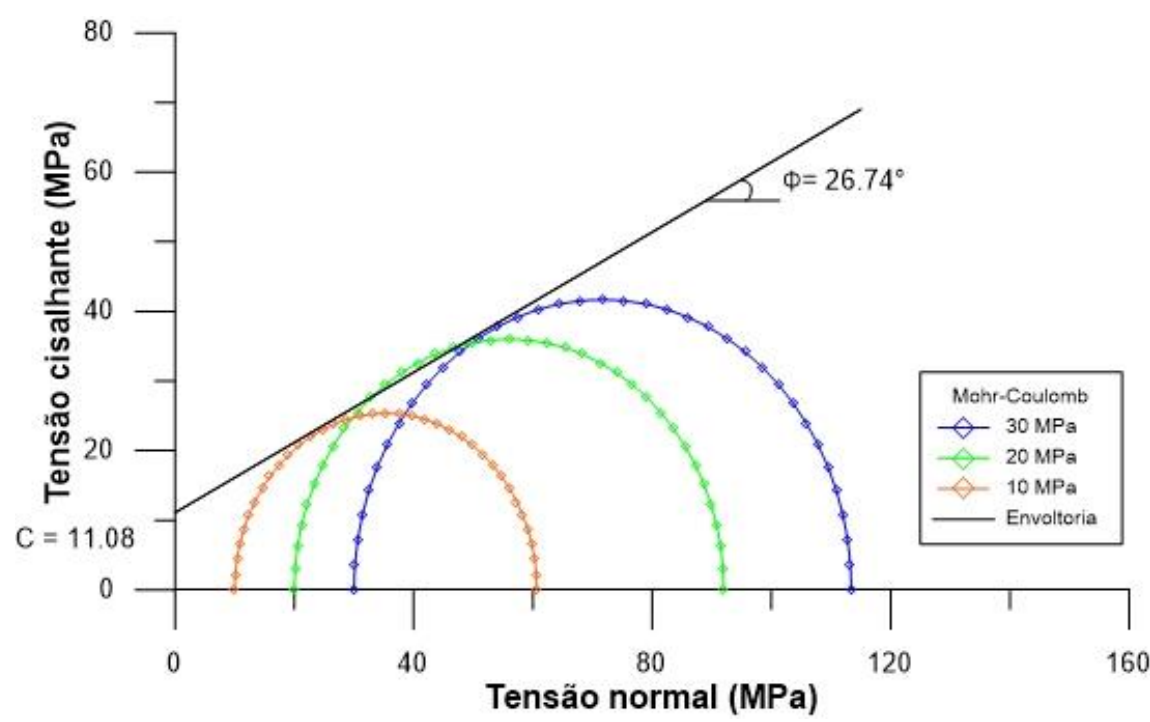

Figura 66 Parâmetros $C^{*}$ e $\phi$-círculo de Mohr para CPV >8.5\%.

\subsection{3.}

\section{Resultados dos parâmetros do modelo CCMC}

Como foi mencionado no capítulo 2 deste trabalho, o parâmetro $M$ é a inclinação da linha de estado crítico é determinado para o modelo CCMC pelo ângulo de atrito ou pelo ângulo de Lode, equação (2.64). Os valores do coeficiente de Poisson $v$, o índice de vazios inicial $e$ e a tensão de pré-adensamento inicial $P_{c i}$, foram determinados com base no item 2.5 do capitulo 2. Na Tabela 25 são apresentados os resultados dos parâmetros do modelo CCMC para a rocha carbonática travertino para os CPVs com porosidades maiores que $8.5 \%$.

Tabela 25 Parâmetros do modelo CCMC para CPV com porosidade $>8.5 \%$

\begin{tabular}{lcc}
\hline \multicolumn{3}{c}{ Parâmetros do modelo constitutivo elastoplástico CCMC. } \\
\hline \multicolumn{1}{c}{ Criterio } & Parámetro & valor \\
\hline Coeficiente de Poisson & $v$ & 0.3 \\
Índice de vazios & $e$ & 0.13 \\
Tensão de pré-adensamento (MPa) & $P_{c i}$ & $10,20,30$ \\
Inclinação da linha de carregamento & $\lambda$ & 0.00085 \\
Inclinação da linha de descarregamento & $k$ & 0.00075 \\
Coesão (MPa) & $C^{*}$ & 11.08 \\
Ângulo de atrito (graus) & $\phi$ & 26.735 \\
\hline
\end{tabular}




\section{7.}

\section{Validação do modelo CCMC}

Foi validado o algoritmo tipo explícito do modelo elastoplástico CCMC desenvolvido no FORTRAN 90. Neste caso, foi testado usando os parâmetros obtidos dos ensaios de laboratório realizados no CPV com porosidades acima de $8.5 \%$ da rocha carbonática travertino.

A Figura 67 (a) mostra resultados da curva tensão desviadora vs deformação axial, onde se observa um afastamento entre a curva referente à tensão confinante de $10 \mathrm{MPa}$ em relação ao algoritmo CCMC. No entanto se evidenciou um bom ajuste para tensões de 20 e $30 \mathrm{MPa}$. Neste caso o algoritmo mostra a capacidade de representar muito bem para altas tensões de confinamento. Na Figura 67 (b), curva deformação volumétrica vs deformação axial, o modelo CCMC não conseguiu representar o comportamento compressivo da rocha carbonática travertino par todas as tensões de confinamento, provavelmente por causa da lei de fluxo associado. A lei de fluxo não associado poderia acompanhar melhor os dados experimentais na compressão e dilatância do material.

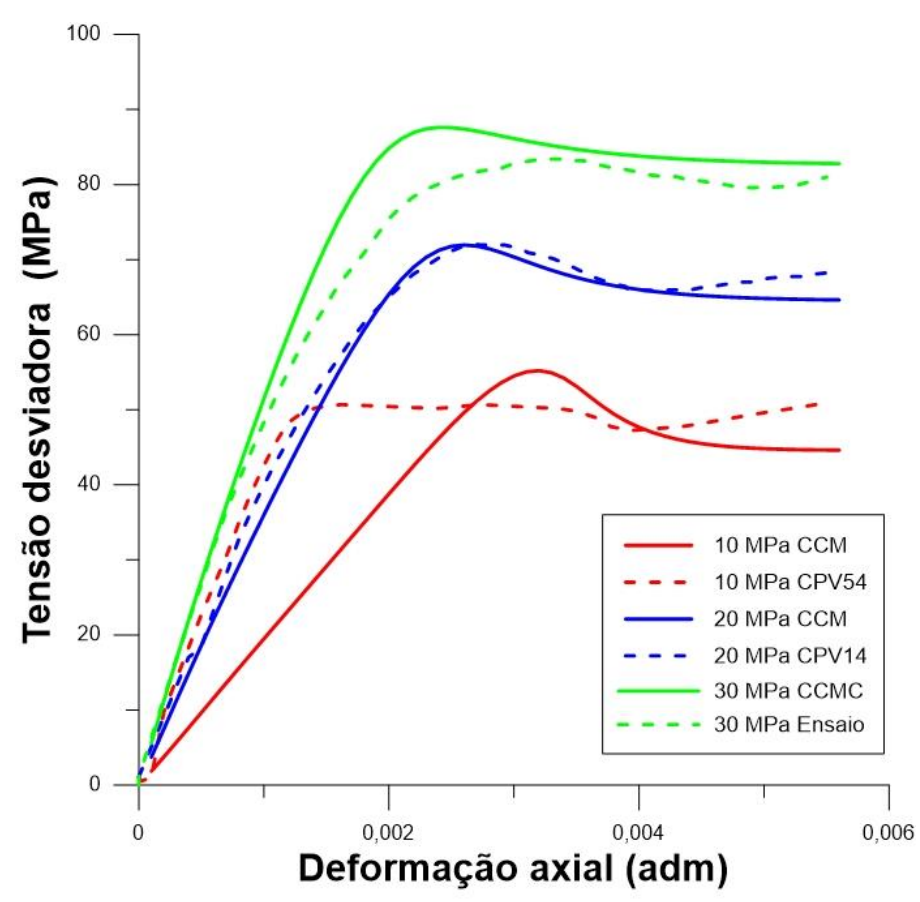

(a) 


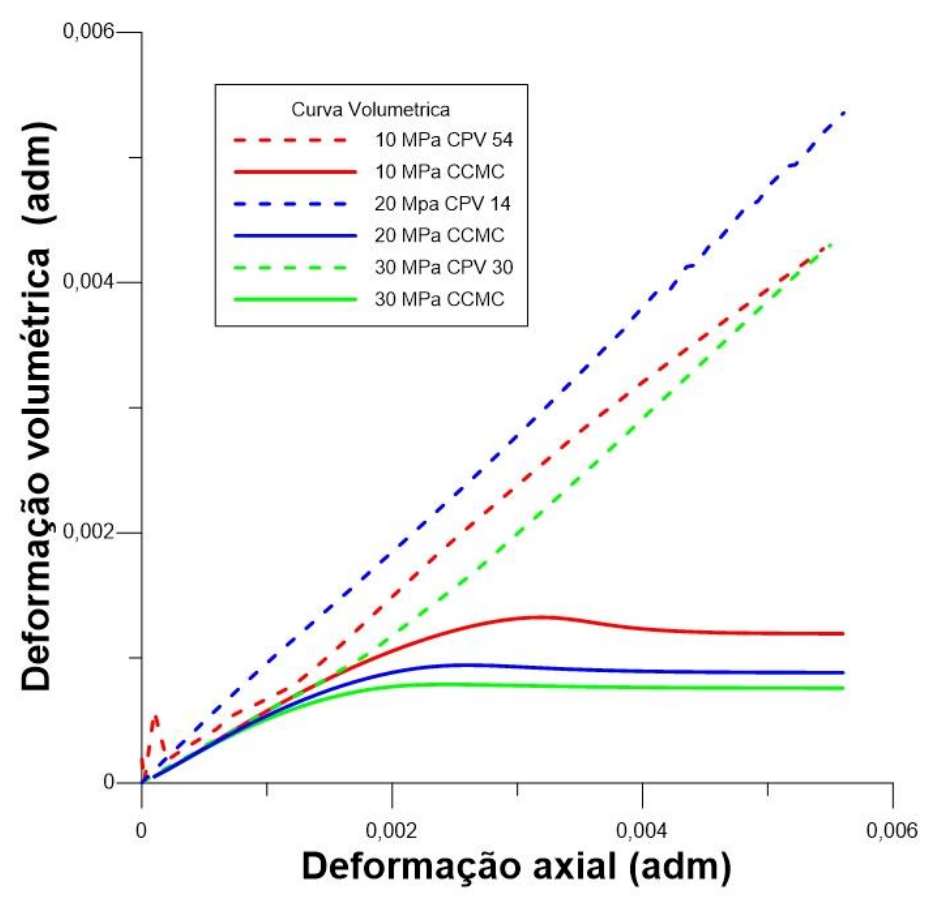

(b)

Figura 67 Comparação entre ensaio laboratorial e modelagem numérica com o modelo de CCMC para CPV com porosidade $>8.5 \%$. (a) curva tensão vs deformação axial (b) deformação volumétrica vs deformação axial.

\section{8.}

\section{Comparação entre os modelos constitutivos Lade-Kim e CCMC}

A seguir é feita uma comparação entre dois modelos elastoplásticos validados com dados do ensaio CPV com porosidade total acima de $8.5 \%$ e tensão de confinamento de $30 \mathrm{MPa}$. Neste caso, foi escolhido este ensaio por apresentar tensões de confinamento mais próximas as apresentadas no reservatório do Presal. Na Figura 68 (a) pode-se observar que os dois modelos podem representar o comportamento experimental da curva tensão desviadora vs deformação axial. No entanto, o modelo Lade-Kim apresenta melhores resultados. Na Figura 68 (b) se observa que o modelo CCMC não conseguiu representar as deformações volumétricas comparado com o modelo Lade-Kim. Isto leva a uma importante conclusão, o modelo elastoplástico Lade-Kim é apropriado para a representação do comportamento mecânico da rocha travertino, considerando as condições próximas às de reservatório em termos de tensão confinante. Contudo, para futuras pesquisas o algoritmo do CCMC pode ser modificado, incorporando uma superfície potencial plástica que permita obter melhores resultados nas deformações volumétricas. 


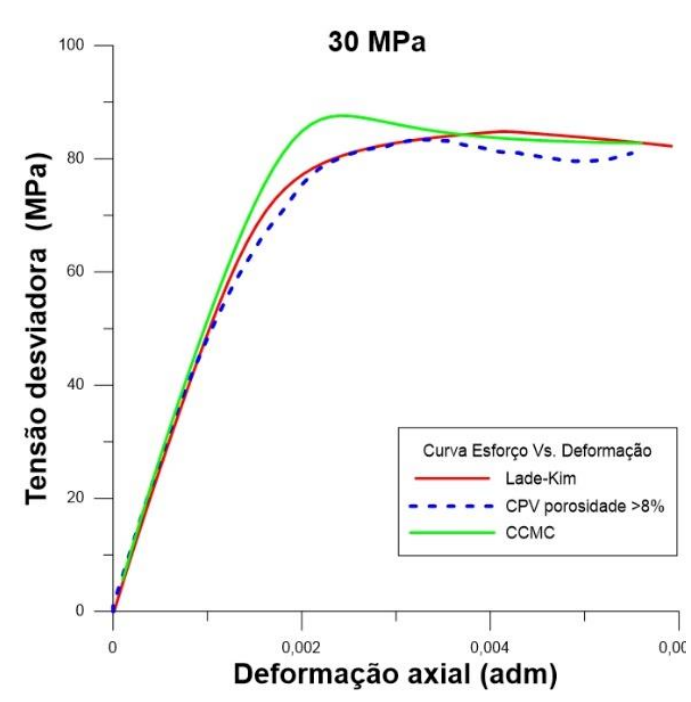

(a)

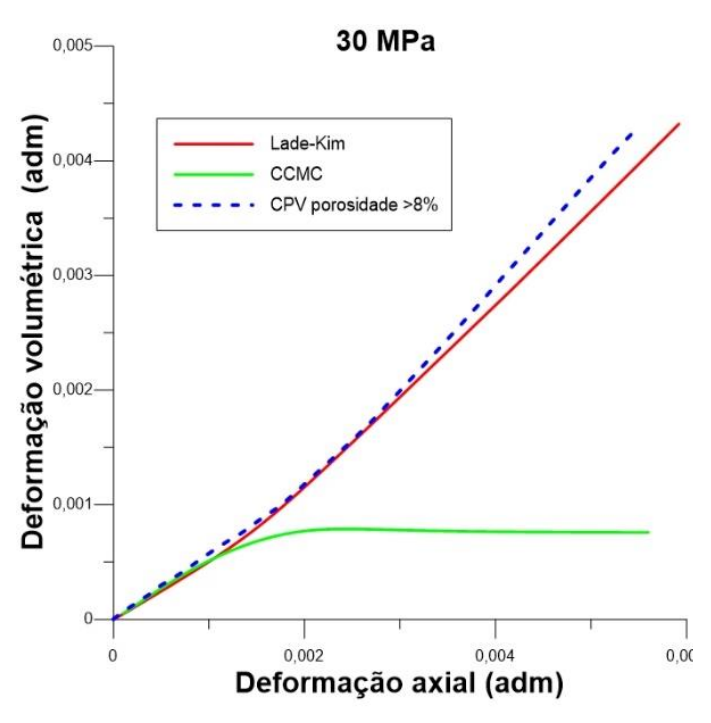

(b)

Figura 68 Comparação entre dados laboratoriais e modelos de Lade-Kim e CCMC para CPV com porosidades $>8.5 \%$ da rocha carbonática travertino. (a) Curva tensão vs deformação axial, (b) deformação volumétrica vs deformação axial.

\section{9. \\ Análise inversa usando MINPACK}

Baseado nos Capítulos 2 e 3, foi feita a retroanálise para os resultados dos ensaios com amostras da rocha carbonática travertino para CPV com porosidade $>8.5 \%$ e menores que $8.5 \%$. Neste caso, foi implementado o modelo constitutivo elastoplástico isotropico Lade-Kim como uma subroutina no algoritmo de otimização MINPACK no FORTRAN $90 \AA$. O software é de uso livre e pode ser modificado pelo usuário, otimizando a quantidade desejada de parâmetros de cada modelo.

\subsection{1.}

\section{CPV com porosidade $<8.5 \%$}

Foram fixados 10 dos 12 parâmetros do modelo Lade-Kim. Desta forma, somente dois parâmetros sofriam variações em cada iteração. Foram realizadas mais de 30 simulações combinando parâmetros do critério de ruptura, critério elástico, função potencial plástico, endurecimento e função de escoamento. No entanto, nem todas as simulações tiveram sucesso, devido ao fato de que uma variação de parâmetros pode finalizar a simulação ou não representar as curvas 
tensão deformação e deformação volumétrica. Desta forma, os parâmetros que se aproximaram aos resultados experimentais foram $\psi_{2}$ e $\alpha$. Assim, o parâmetro $\psi_{2}$ foi condicionado para não ter valores abaixo de -2.6 nem acima de -3.0 e, desta forma, garantir o sucesso na otimização de parâmetros. A Tabela 26 apresenta os parâmetros obtidos no processo de retroanálise usando o algoritmo MINPACK.

Tabela 26 Parâmetros ótimos do travertino vertical com porosidade $<8.5 \%$, usando MINPACK

\begin{tabular}{lccc}
\hline \multicolumn{1}{c}{ Critério } & Parâmetros & Analítico & Minpack \\
\hline \multirow{3}{*}{ Critério de Ruptura } & $\mathrm{a}$ & 22.91 & 22.91 \\
& $\mathrm{~m}$ & 1.9462 & 1.9462 \\
& $\eta_{1}$ & $1,60 \mathrm{E}+08$ & $1,60 \mathrm{E}+08$ \\
\hline \multirow{2}{*}{ Critério elástico } & $\mathrm{K}$ & 393982 & 393982 \\
& $\mathrm{n}$ & 0.0851 & 0.0851 \\
& $\boldsymbol{V}$ & 0.27 & 0.27 \\
\hline \multirow{2}{*}{ Função potencial } & $\psi_{2}$ & -2.9 & $\mathbf{- 2 . 7 0}$ \\
plástica & $\boldsymbol{C}$ & 3.0 & 3.0 \\
\hline \multirow{2}{*}{ Endurecimento } & $\mathrm{C}$ & 0.000001 & 0.000001 \\
\hline Função de & $\alpha$ & 1.5 & 1.5 \\
escoamento & $\boldsymbol{h}$ & 0.3 & $\mathbf{0 . 2 8 5 7}$ \\
\hline
\end{tabular}

O tempo de execução foi de 7 min e 22 seg, com 19 iterações até atingir os parâmetros ótimos. Na Figura 69 são apresentados os resultados da otimização com o MINPACK nas curvas tensão vs deformação e deformação volumétrica para tensões de confinamento de 10 e $20 \mathrm{MPa}$, onde se pode observar um melhor ajuste aos dados experimentais, comparados com dados da calibração analítica do modelo isotrópico Lade-Kim.

Na Figura 69 (a) observa-se que as linhas que representam os dados numéricos usando MINPACK são semelhantes aos obtidos na calibração analítica, enquanto que na Figura 69 (b) observa-se que são mais próximas aos dados experimentais. Neste caso, se conclui que os parâmetros $\psi_{2}$ e $\alpha$ não apresentam mudanças significativa na gráfica tensão vs deformação, enquanto que na gráfica de deformação axial vs deformação volumétrica, o modelo teve uma importante movimentação. 


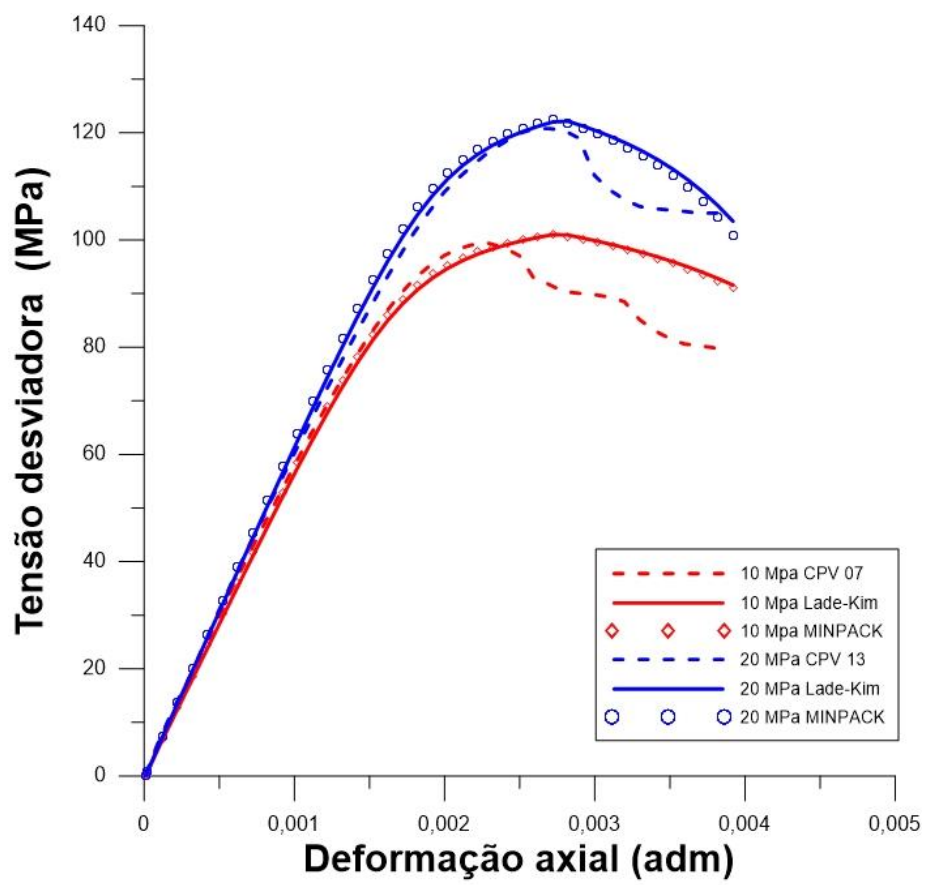

(a)

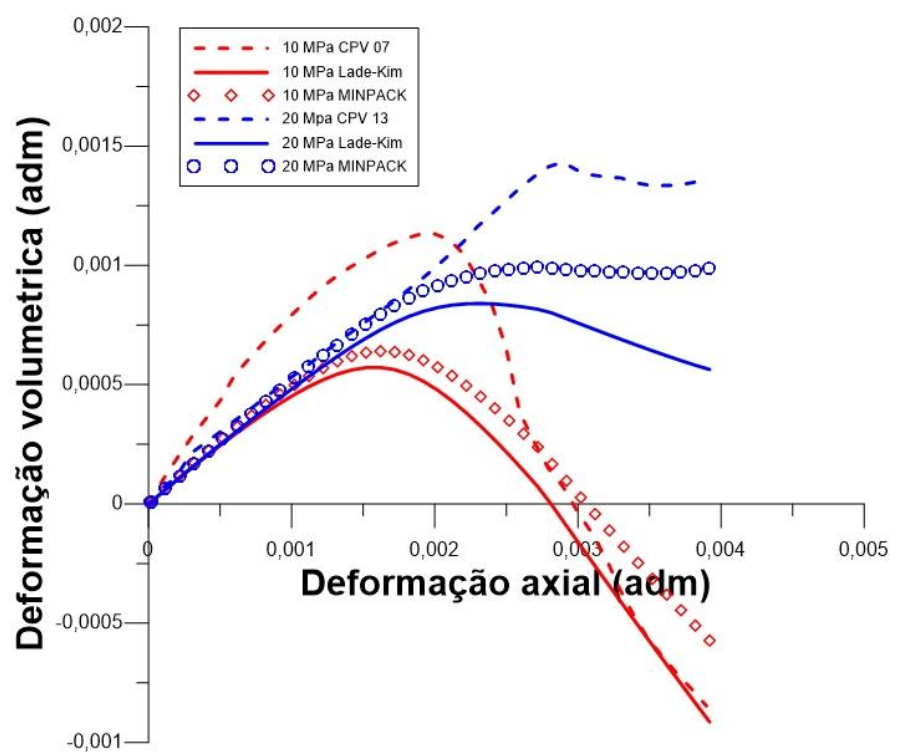

(b)

Figura 69 Comparação entre ensaios triaxiais, modelo Lade-Kim e MINPACK, da rocha carbonática travertino, CPV com porosidade $<8.5 \%$. (a) Curva tensão vs deformação axial, (b) deformação volumétrica vs deformação axial.

\subsection{2.}

\section{CPV com porosidade $>8.5 \%$}

Foram fixados 10 dos 12 parâmetros do modelo Lade-Kim, de forma que somente dois parâmetros variavam em cada iteração. No entanto, foram realizadas cerca de 15 simulações com diferentes parâmetros de ruptura, potencial plástico, endurecimento e escoamento. Contudo, os mais 
representativos no ajuste aos dados experimentais, neste caso particular, foram os parâmetros $\psi_{2}$ e $\mu$ da função potencial plástico, sendo que o primeiro foi condicionado para não ter valores abaixo de -2.8 nem acima de -2.90 , para garantir a não geração de erros nos dados numéricos. Na Tabela 27 são apresentados os resultados obtidos no retroanálise:

Tabela 27 Parâmetros ótimos do travertino vertical com porosidade $>8.5 \%$, usando MINPACK

\begin{tabular}{lccc}
\hline \multicolumn{1}{c}{ Critério } & Parâmetros & Lade-Kim & MINPACK \\
& & & \\
\multirow{3}{*}{ Critério de Ruptura } & $\mathrm{a}$ & 17.72 & 17.72 \\
& $\mathrm{~m}$ & 1.16060 & 1.16060 \\
& $\eta_{1}$ & 136,693 & 136,693 \\
\hline \multirow{2}{*}{ Critério elástico } & $\mathrm{K}$ & 318,099 & 318,099 \\
& $\mathrm{n}$ & 0.0846 & 0.0846 \\
Função potencial & $\boldsymbol{V}$ & 0.30 & 0.30 \\
plástica & $\psi_{2}$ & -2.9 & -2.873 \\
& $\boldsymbol{\mu}$ & 4.0 & 4.1737 \\
Endurecimento & $\mathrm{C}$ & 0.000001 & 0.000001 \\
& $\mathrm{P}$ & 1.55 & 1.55 \\
\hline Função de & $\alpha$ & 0.2 & 0.2 \\
escoamento & $\boldsymbol{h}$ & 0.60 & 0.60 \\
\hline
\end{tabular}

O tempo de execução foi de 11 min e 73 seg, com 14 iterações. O tempo foi maior comprado com o anterior, mas com menor iterações. Na Figura 70 são apresentados os resultados na curva tensão vs deformação e deformação volumétrica para tensões de confinamento de 10, 20 e $30 \mathrm{MPa}$. Neste caso, podese observar que a variação dos parâmetros $\psi_{2}$ e $\mu$ da função potencial plástico otimizados causaram alterações na curva de deformação volumétrica, Figura 70 (b). Além disso, observa- se que os resultados obtidos com MINPACK são mais próximos aos experimentais, comparados com os obtidos pela calibração analítica. No caso do CPV 30, os resultados numéricos indicam que o ajuste foi bem próximo aos dados experimentais, lembrando que a pressão de confinamento de $30 \mathrm{MPa}$ representa melhor as condições de reservatório. 


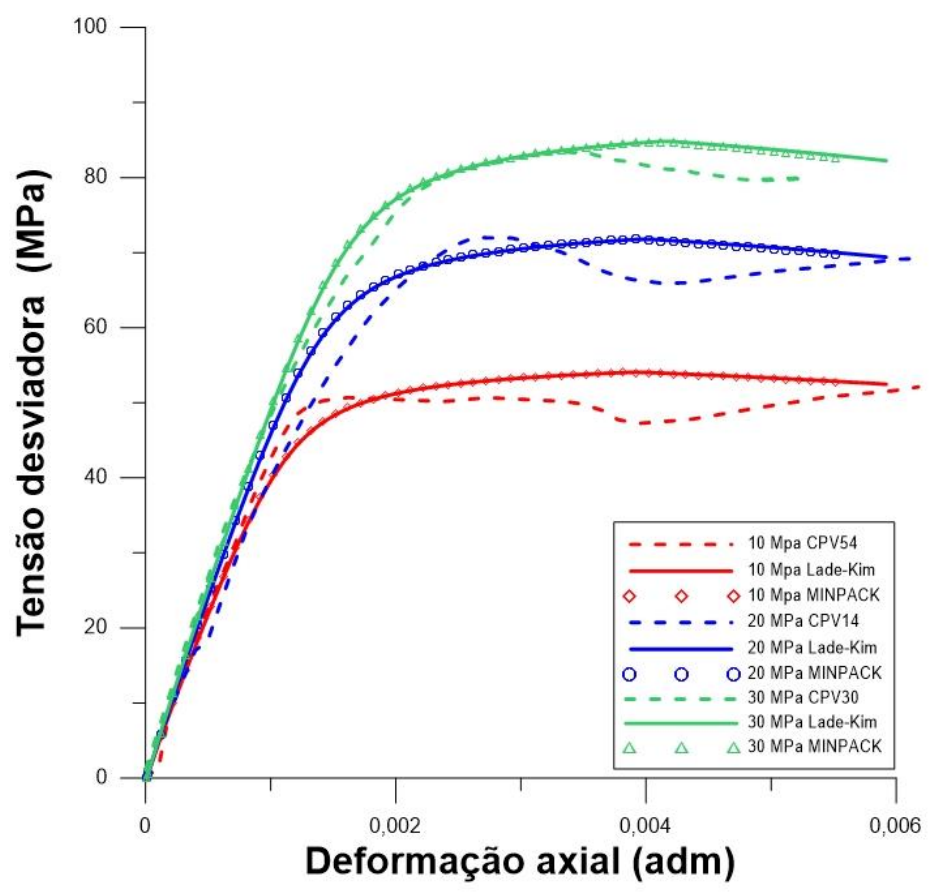

(a)

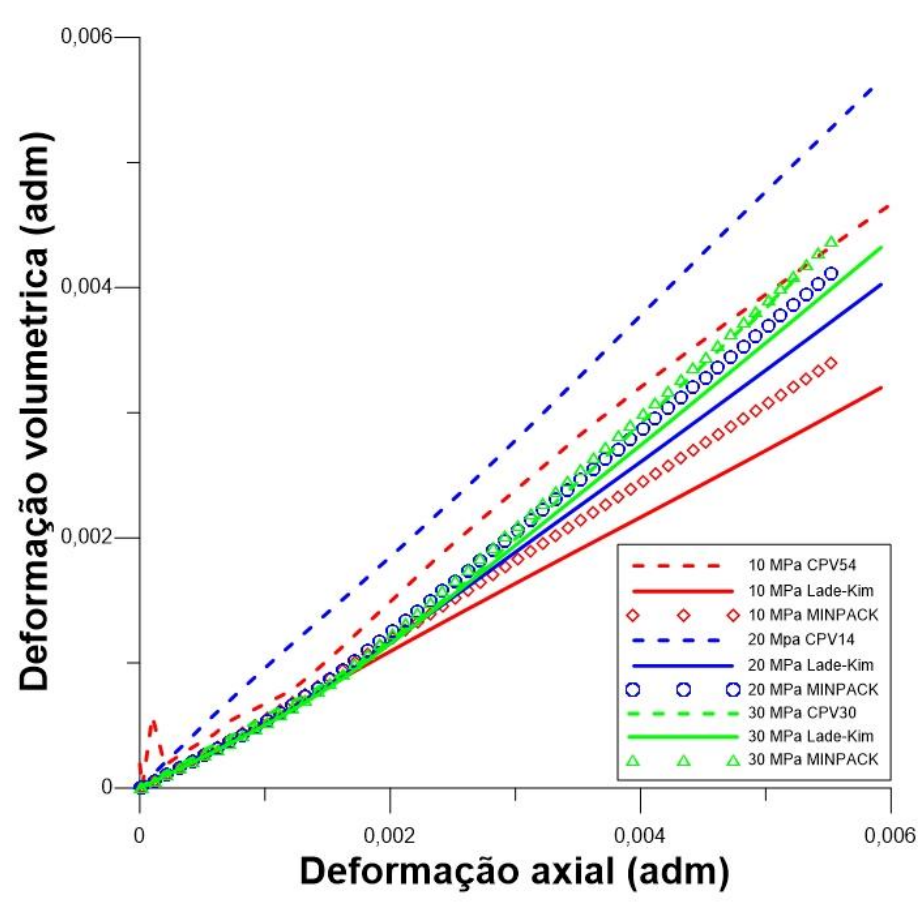

(b)

Figura 70 Comparação entre ensaios triaxiais, modelo Lade-Kim e MINPACK, da rocha carbonática travertino, $\mathrm{CPV}$ com porosidade $>8.5 \%$. (a) Curva tensão vs deformação axial, (b) deformação volumétrica vs deformação axial. 


\subsection{0.}

\section{Análise inversa usando DREAM}

A retroanálise, usando o algoritmo DREAM, foi realizada para dois tipos de rochas sedimentares. A primeira é a rocha carbonática travertino para CPV com porosidades maiores e menores de $8.5 \%$, e a segunda é a rocha sedimentar Tournemire shale. Foi usado o modelo elastoplástico com endurecimento isotrópico Lade-Kim, incorporado no DREAM, implementado no programa MATLAB R2017a.

\subsection{1. \\ Rocha travertino para CPV com porosidade $>8.5 \%$}

Foi realizada uma grande quantidade de simulações, com diferentes números de parâmetros, diversos números de gerações e cadeias de Markov. No entanto, a maioria apresentou problemas de convergência devido ao limite e sensibilidade dos parâmetros, junto com um alto custo computacional. Assim, definir os limites dos parâmetros é um aspecto fundamental para evitar que parâmetros gerem erros no processo de otimização e pelo custo computacional. Assim, eles devem ser selecionados com base nas restrições particulares de cada modelo constitutivo. Neste caso para selecionar os limites foram testados diversos parâmetros até encontrar os melhores ajustes. Além disso, foi indispensável testar primeiro com parâmetros calibrados analiticamente para determinar os limites do modelo isotrópico Lade-Kim. Na Tabela 28 são apresentados os dados de entrada na simulação com o algoritmo DREAM.

Tabela 28 Parâmetros de entrada no DREAM para o travertino com porosidades $>8.5 \%$

\begin{tabular}{ll}
\hline & DREAMPar \\
\hline DREAMPar.d $=12$ & Número de parâmetros \\
DREAMPar.N $=10$ & Número de cadeias de Markov \\
DREAMPar.T $=10000$ & Número de gerações \\
DREAMPar.lik $=11$ & Função objetivo \\
DREAMPar.thinning $=10$ & Controla a velocidade de processamento \\
\hline
\end{tabular}

DREAMPar.d é a quantidade de parâmetros a retroanalisar, DREAMPar.N é o número de cadeias de Markov que vão na procura da melhor distribuição posterior possível, DREAMPar.T é o número de gerações usadas para obter a convergência da simulação, DREAMPar.lik é a função objetivo e 
DREAMPar.thinning é usado para reduzir ou acelerar o processo de busca na distribuição posterior. $\mathrm{Na}$ Tabela 29 são apresentados os limites usados para determinar os 12 parâmetros do modelo isotrópico Lade-Kim, usando o algoritmo DREAM. No entanto, eles foram previamente calibrados analiticamente (item 4.4) para definir seus limites, numa tentativa de redução do custo computacional.

Tabela 29 Limites de parâmetros do DREAM para o travertino com porosidade $>8.5 \%$

\begin{tabular}{|c|c|c|c|c|c|c|c|c|c|c|c|c|}
\hline & $a$ & $\mathrm{~m}$ & $\eta_{1}$ & Kur & $\mathrm{N}$ & $\mathrm{v}$ & $\psi_{2}$ & $\mu$ & $C$ & $P$ & $\mathrm{~h}$ & $\alpha$ \\
\hline & $\mathrm{X} 1$ & $\mathrm{X} 2$ & $\mathrm{X} 3$ & $\mathrm{X} 4$ & $\mathrm{X} 5$ & $\mathrm{X} 6$ & $\mathrm{X} 7$ & $\mathrm{X} 8$ & X9 & $\mathrm{X} 10$ & $\mathrm{X} 11$ & $\mathrm{X} 12$ \\
\hline Min & 17 & 1.0 & 120000 & 200000 & 0.01 & 0.1 & -2.9 & 3.0 & 5. E-07 & 1.0 & 0.1 & 0.1 \\
\hline $\operatorname{Max}$ & 21 & 1.4 & 400000 & 400000 & 0.50 & 0.4 & -2.5 & 6.0 & 3. E-06 & 2.0 & 0.7 & 0.5 \\
\hline
\end{tabular}

O tempo da simulação foi de 3 horas e 24 min numa computadora de processador core i7. Pode-se observar na Figura 71 traços da métrica R-stat para cada um dos 12 parâmetros usando as últimas 50\% amostras das cadeias de Markov. Este teste de convergência compara a variância dos parâmetros do modelo Lade-Kim entre cadeias e nas cadeias. Assim, uma convergência estacionária pode ser declarada quando os 12 parâmetros convergem para abaixo do valor critico 1.2. Os resultados na Figura 71 mostram que, aproximadamente, 3000 avaliações do modelo Lade-Kim são requeridas pelo DREAM para convergir de forma bem sucedida para uma condição estacionária, com valores de Rconvergência $<1.2$.

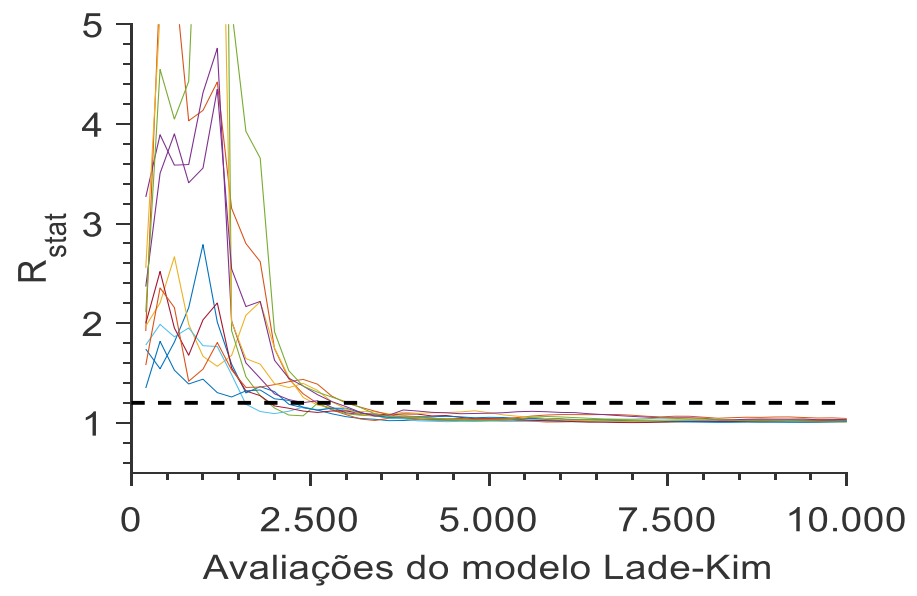

Figura 71 Convergência com DREAM com 12 parâmetros do modelo Lade-Kim para CPV $>8.5 \%$. 
A distribuição dos parâmetros foi bem definida para alguns deles. A partir da análise da Figura 72 os parâmetros com melhor distribuição foram $m, n, h$. O parâmetro elástico $v$ e o parâmetro da função potencial plástica $\mu$ possuem uma distribuição normal, no entanto a distribuição posterior se estende amplamente pelos limites prévios estabelecidos anteriormente. Além disso, o parâmetro $\psi_{2}$ possui uma distribuição aproximadamente uniforme abrangendo toda a faixa de distribuição prévia. Isso indica que os parâmetros da função potencial plástico respondem por grande parte da incerteza predicativa do modelo Lade-Kim. Em trabalhos futuros estes resultados podem ser melhorados fazendo um analise de sensibilidade determinando quais podem ser realmente otimizados e quais devem ficar como constantes.

Na Figura 72 é apresentada um histograma da distribuição marginal posterior dos parâmetros do modelo Lade-Kim, na qual a solução ótima do DREAM é indicada por um símbolo $X$ em vermelho.
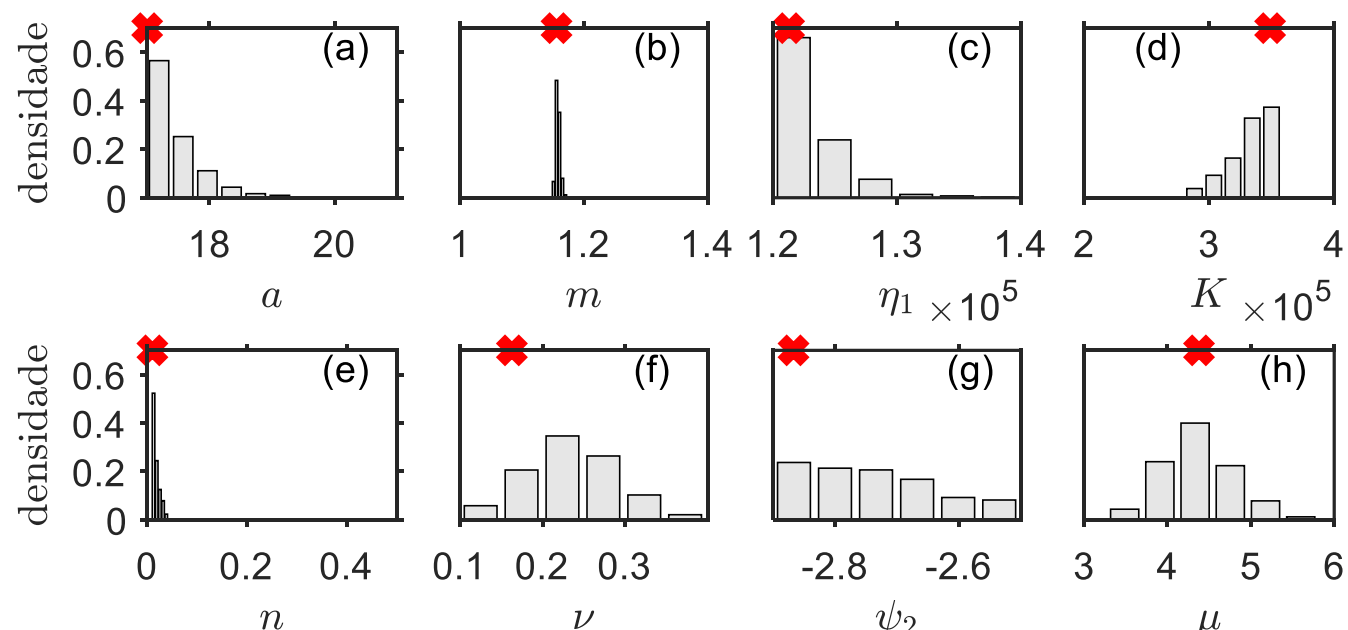

1.41 .2
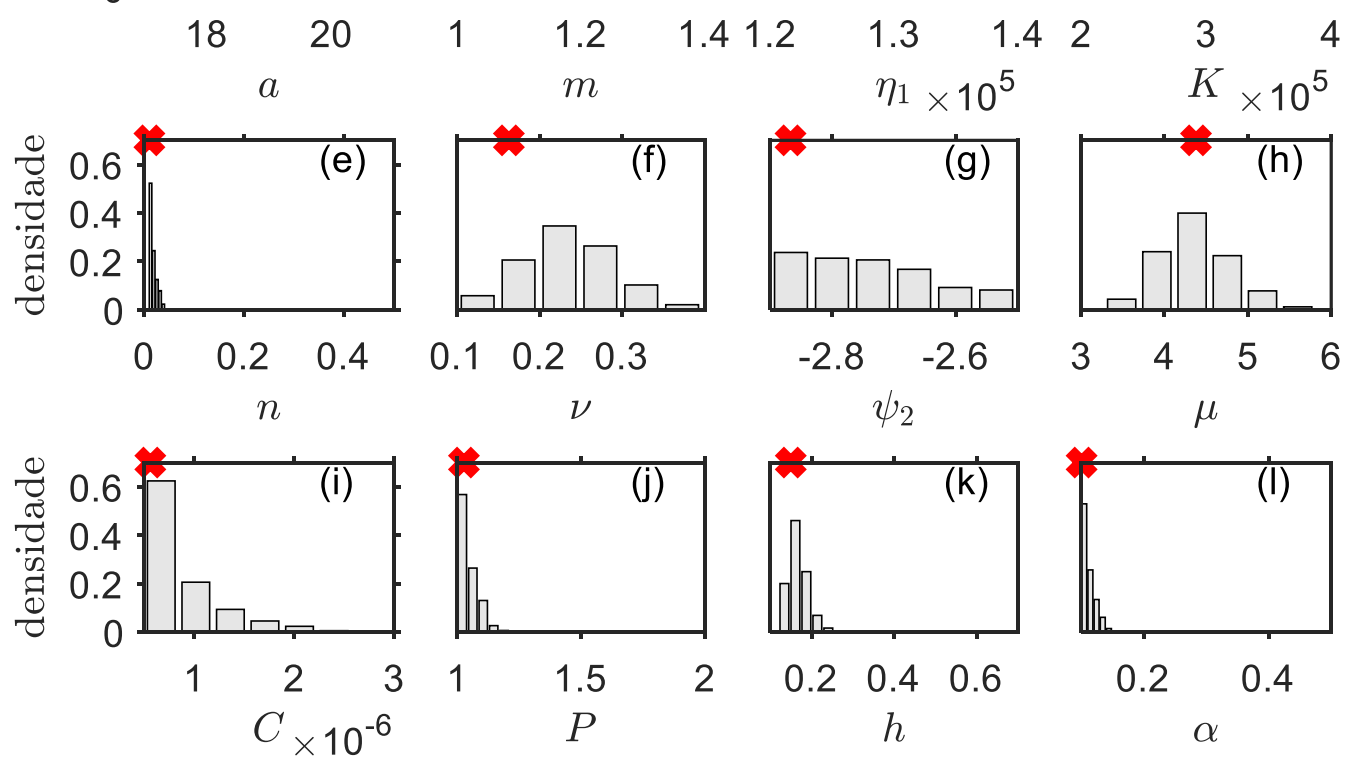

$0.1 \quad 0.2 \quad 0.3$
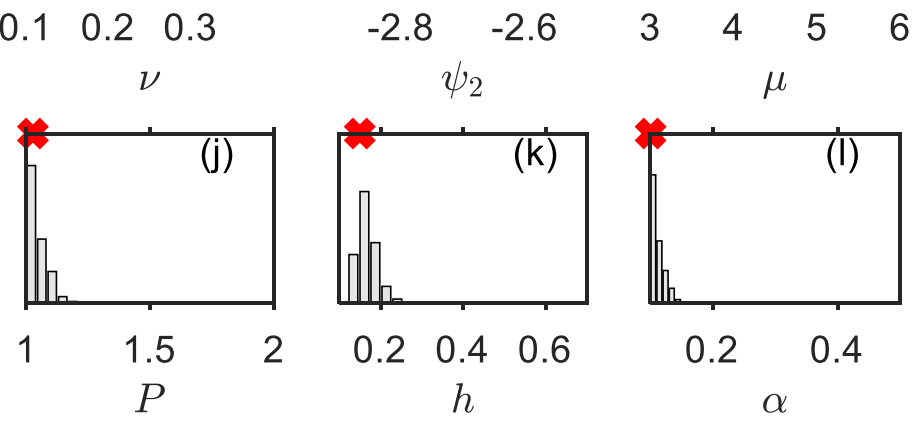

Figura 72 Distribuição utilizada no DREAM para 12 parâmetros CPV >8.5\%. 
Na Figura 73 (a), (b) e (c) observa-se as curvas tensão desviadora vs deformação axial, para cada ensaio, com tensão de confinamento de 10, 20 e 30 $\mathrm{MPa}$, respectivamente. Os resultados indicam que 0 modelo simula adequadamente os dados experimentais definidos pelas linhas vermelhas. $O$ algoritmo DREAM permite identificar intervalos de $95 \%$ de incerteza preditiva com relação aos parâmetros do modelo Lade-Kim (hachura em cinza escuro) e também intervalos de $95 \%$ da incerteza total (hachura em cinza claro), em que a raiz quadrada do erro médio quadrático (RMSE), que mede a distância média entre os valores de tensão desviadora observados e os simulados, é adicionado a cada simulação como um erro normalmente distribuído. Além disso, pode-se observar que a incerteza de parâmetros é bem pequena e definida na parte elástica não linear e aumenta na parte do endurecimento e escoamento. Neste contexto, pode-se concluir que a incerteza de parâmetros total aumenta com o incremento de deformações plásticas na zona de endurecimento.

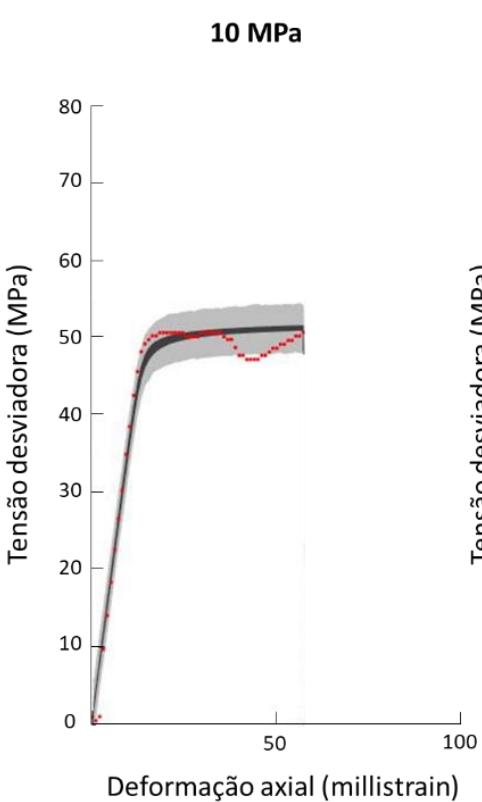

(a)

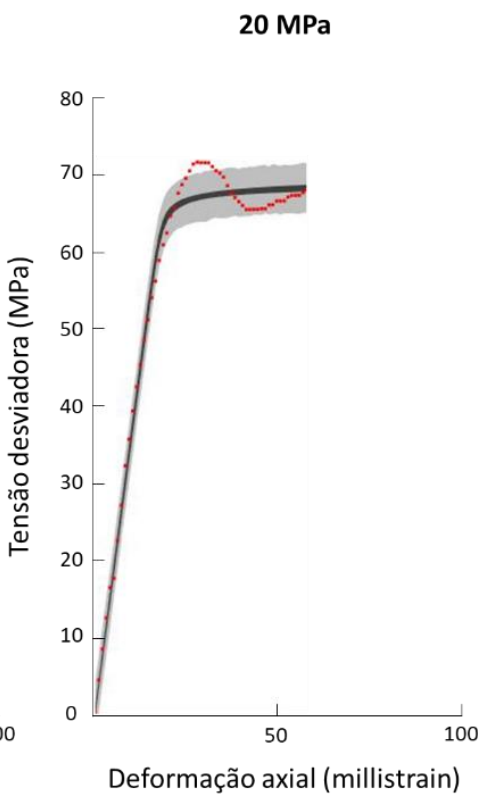

(b)

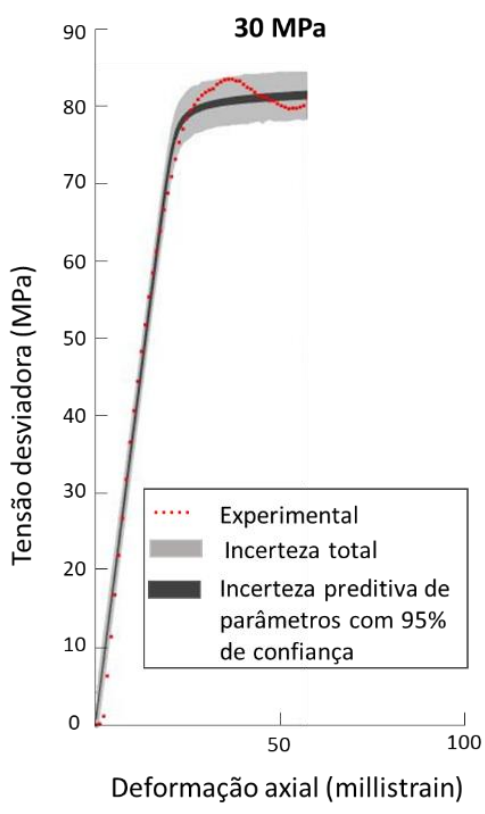

(c)

Figura 73 Incerteza de parâmetros usando o algoritmo DREAM -Curvas tensão desviadora vs deformação axial para CPV > $8.5 \%$.

$\mathrm{Na}$ Tabela 30 são apresentados os resultados obtidos pela retroanálise através do algoritmo DREAM e com a calibração analítica do Lade-Kim, com 12 parâmetros para CPV com porosidade $>8.5 \%$. Observa-se que os parâmetros que 
tiveram maiores mudanças são aqueles do critério elástico e da lei de endurecimento, lembrando que estes resultados são particulares de este caso.

Tabela 30 Parâmetros da rocha carbonática travertino para o modelo Lade-Kim, determinados analiticamente e através do DREAM. Com 12 parâmetros, para CPV $>8.5 \%$.

\begin{tabular}{lccc}
\hline \multicolumn{4}{c}{ Parâmetros isotrópicos do modelo constitutivo Lade-Kim } \\
\hline \multicolumn{1}{c}{ Critério } & Parâmetros & Analítico & DREAM \\
Critério de Ruptura & $\mathrm{a}$ & 17.72 & 17.0624 \\
& $\mathrm{~m}$ & 1.16060 & 1.1568 \\
& $\eta_{1}$ & $136,693.0$ & $120,764.41$ \\
\hline \multirow{2}{*}{ Critério elástico } & $\mathrm{K}$ & $318,099.0$ & $368,455.59$ \\
& $\mathrm{n}$ & 0.0846 & 0.0288 \\
Função potencial & $\boldsymbol{V}$ & 0.30 & 0.2874 \\
plástica & $\psi_{2}$ & -2.9 & -2.8221 \\
\hline \multirow{2}{*}{ Endurecimento } & $\mu$ & 4.0 & 4.8845 \\
\hline Função de & $\mathrm{C}$ & 0.000001 & 0.0000006554 \\
escoamento & $\mathrm{P}$ & 1.55 & 1.4691 \\
\hline
\end{tabular}

Na Figura 74 é feita uma comparação entre dados experimentais e as curvas calibradas analiticamente (direta) e através da otimização com o DREAM. Os resultados com o algoritmo DREAM se ajustam com maior precisão aos ensaios. $\mathrm{Na}$ Figura 74 (a) observa-se que as linhas que representam o DREAM são semelhantes no trecho elástico, enquanto que na parte de plastificação o DREAM apresentou resultados mais próximos aos experimentais. Na Figura 74 (b) as curvas obtidas a partir do DREAM se aproximam com maior precisão para tensões de 10 e $20 \mathrm{MPa}$. Para a curva da tensão confinante de $30 \mathrm{MPa}$ o ajuste com o DREAM resultou mais afastado devido a resultados inesperados nos ensaios de laboratório.

Concluísse que o uso do algoritmo DREAM fornece melhores resultados comprados com os obtidos usando a metodologia analítica do modelo Lade-Kim. No entanto esta é indispensável para definir os limites no processo de otimização. 


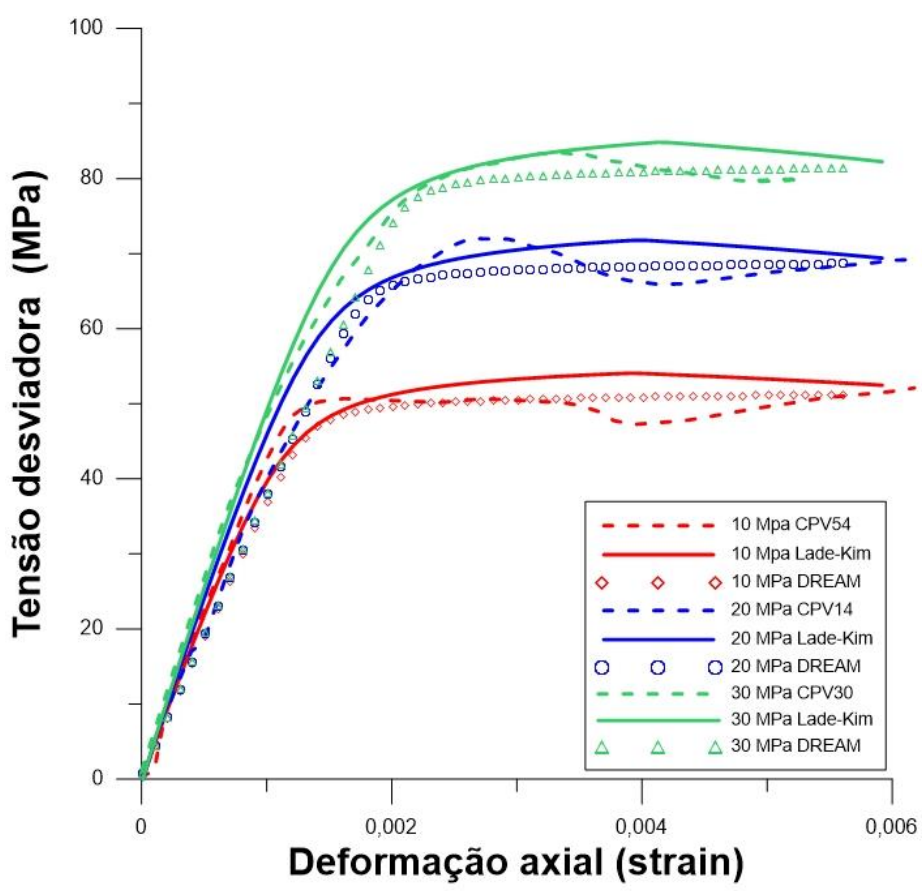

(a)

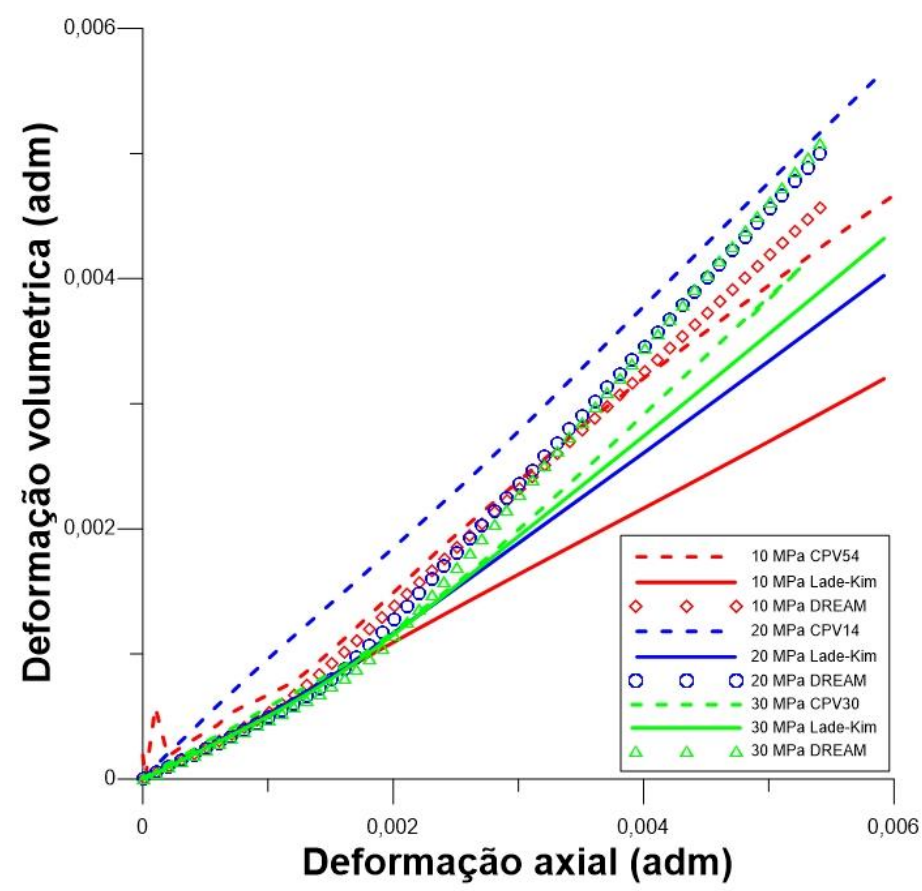

(b)

Figura 74 Comparação entre dados experimentais de ensaios triaxiais da rocha carbonática travertino com o modelo Lade-Kim, obtidos de forma analítica e através do DREAM, CPV com porosidades $>8.5 \%$. (a) curva tensão vs deformação axial (b) deformação volumétrica vs deformação axial. 
4.10.2.

\section{Rocha travertino CPV com porosidade $<8.5 \%$}

Foi testado o algoritmo DREAM, incluindo o amolecimento no modelo isotrópico Lade-Kim. Para os corpos de prova com porosidade $<8.5 \%$ foram utilizados 9 parâmetros, mas não foi possível obter convergência deles, devido a inconsistências nas derivadas na parte do amolecimento do algoritmo. Recomenda-se no futuro, melhorar o amolecimento do algoritmo tipo explícito de Lade-Kim feito no MATLAB 2017 e testar novamente para obter convergência. No entanto, o intervalo da incerteza dos parâmetros (hachura cinza escuro), obtidos na retroanálise e validados na curva tensão desviadora vs deformação axial, foram próximos aos resultados experimentais (linhas vermelhas), como pode ser observado na Figura 75.

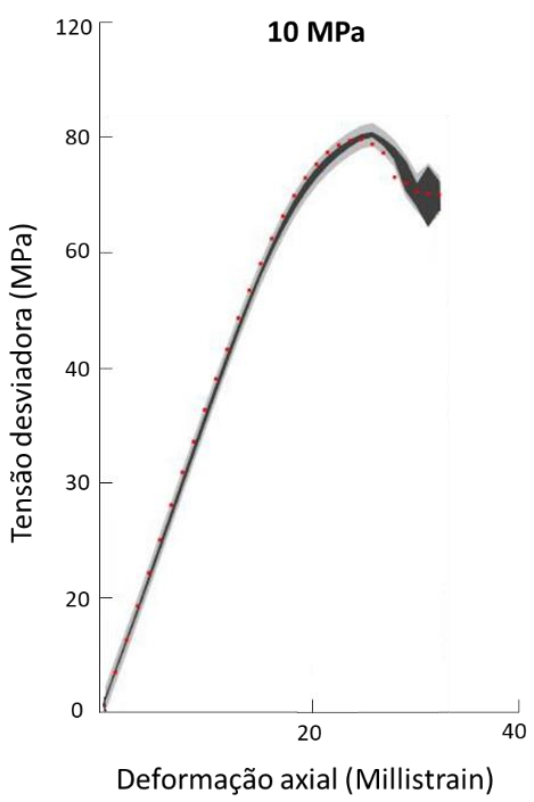

(a)

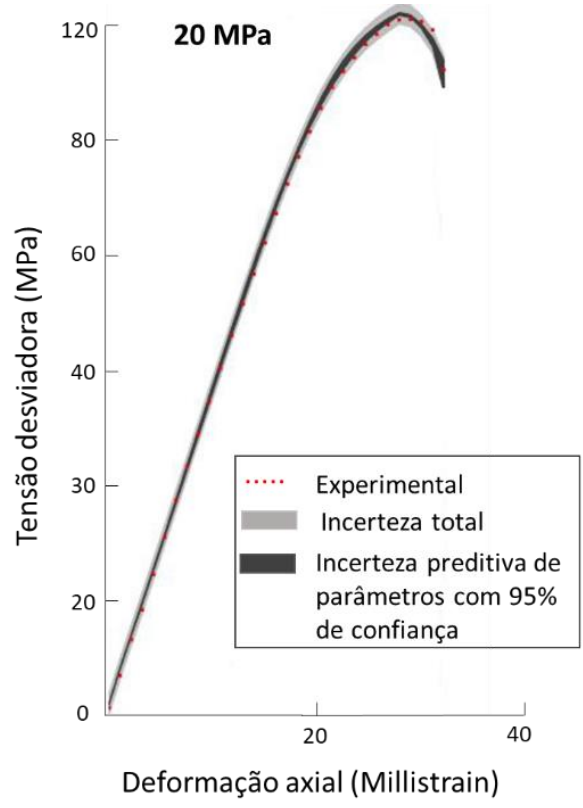

(b)

Figura 75 Incerteza de parâmetros usando o algoritmo DREAM -Curvas tensão desviadora vs deformação axial para CPV $<8.5 \%$.

Na Tabela 31 são apresentados os resultados obtidos pela retroanálise com o algoritmo DREAM e com a calibração analítica do Lade-Kim. Onde os três parâmetros de ruptura foram fixados e 9 parâmetros do modelo foram determinados pelo retroanálise, para CPV com porosidade $<8.5 \%$ 
Tabela 31 Parâmetros da rocha carbonática travertino usando o modelo Lade-Kim e o DREAM. Com 9 parâmetros, para CPV $<8.5 \%$.

\begin{tabular}{lccc}
\hline \multicolumn{4}{c}{ Parâmetros isotrópicos do modelo constitutivo Lade-Kim } \\
\hline \multicolumn{1}{c}{ Critério } & Parâmetros & Analítico & DREAM \\
& $\mathrm{a}$ & 22.91 & 22.91 \\
Critério de Ruptura & $\mathrm{m}$ & 1.9462 & 1.9462 \\
& $\eta_{1}$ & $160,000,000.0$ & $160,000,000.0$ \\
\hline \multirow{2}{*}{ Critério elástico } & $\mathrm{k}$ & 393982.0 & $393,672.6794$ \\
& $\mathrm{n}$ & 0.0851 & 0.1245 \\
Função potencial & $\boldsymbol{V}$ & 0.27 & 0.2226 \\
plástica & $\psi_{2}$ & -2.9 & -2.9320 \\
\hline \multirow{2}{*}{ Endurecimento } & $\mu$ & 3.0 & 3.6312 \\
\hline Função de & $\mathrm{C}$ & 0.000001 & $5.1543 \mathrm{E}-07$ \\
escoamento & $\mathrm{P}$ & 1.5 & 1.7898 \\
\hline
\end{tabular}

Na Figura 76 são apresentadas as curvas tensão desviadora vs deformação axial e deformação volumétrica vs deformação axial, com CPV $<8.5 \%$. Os resultados indicam que a retroanálise proporcionou a determinação de parâmetros que representam adequadamente as curvas da Figura 76, apesar da nãoconvergência. Observa-se, também, que os resultados obtidos pela retroanálise ajustam melhor os dados experimentais, comparados com os parâmetros calibrados analiticamente pelo modelo Lade-Kim. Na Figura 76 (a), curva tensão desviadora vs deformação axial, o ajuste com o amolecimento foi ótimo, o que indica que o modelo Lade-Kim implementado neste trabalho funciona bem, mas, como já mencionado, apresenta algumas inconsistências nas derivadas no trecho referente ao amolecimento. Na Figura 76 (b), curva deformação axial vs. volumétrica, pode-se observar que o ajuste foi melhor para as duas tensões de confinamento, sendo mais próximo o de $20 \mathrm{MPa}$, que representa melhor a condição de confinamento do reservatório. 


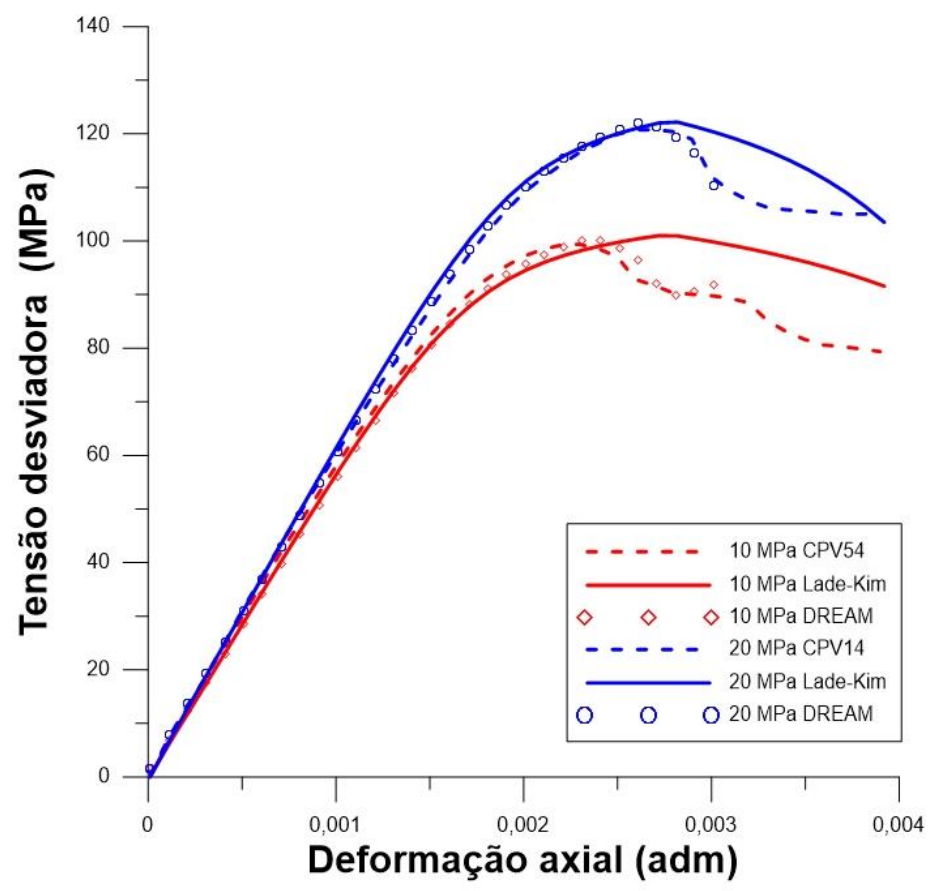

(a)

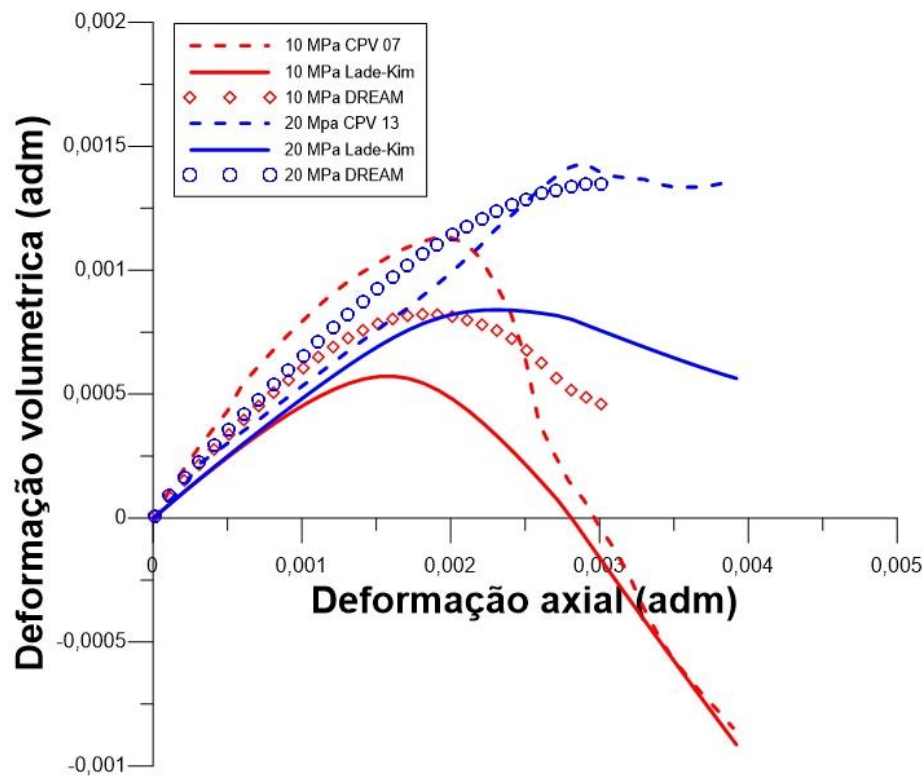

(b)

Figura 76 Comparação entre ensaios triaxiais da rocha carbonática travertino com o modelo Lade-Kim e DREAM, CPV com porosidades $<8.5 \%$.(a) Curva tensão vs deformação axial, (b) deformação volumétrica vs deformação axial. 
4.10.3.

Rocha sedimentar Tournemire shale

Foram determinados os parâmetros isotrópicos da rocha sedimentar Tournemire shale com porosidade entre $8.35 \%$ e $13.7 \%$, usando calibração analítica do modelo Lade-Kim. Neste caso, a calibração foi feita a partir dos resultados de ensaios triaxiais convencionais e hidrostáticos encontrados na literatura (Niandou et al., 1997; Pietruszczak, 2010) com tensões de confinamento de 30 e $50 \mathrm{MPa}$, com orientação das camada ortogonais ao eixo axial. A retroanálise para determinação de parâmetros foi realizado com o DREAM usando o modelo Lade-Kim, no MATLAB R2017a®.

Foi realizada uma otimização com 9 parâmetros fixos e 3 parâmetros variáveis. Na Tabela 32 são definidos os parâmetros de entrada.

Tabela 32 parâmetros de entrada DREAMpar da rocha Tournemire shale

\begin{tabular}{ll}
\hline & DREAMPar \\
\hline DREAMPar.d $=9$ & Número de parâmetros \\
DREAMPar.N $=10$ & Número de cadeias de Markov \\
DREAMPar.T $=10000$ & Número de gerações \\
DREAMPar.lik $=11$ & Função objetivo \\
DREAMPar.thinning $=10$ & Controla a velocidade de processamento
\end{tabular}

Na Tabela 33 são apresentados os limites dos parâmetros determinados usando valores próximos aos obtidos pela retroanálise com o DREAM.

Tabela 33 Limites de parâmetros do DREAM da rocha Tournemire shale

\begin{tabular}{cccccccccc}
\hline Parâmetros & $\mathrm{K}$ & $\mathrm{N}$ & $\boldsymbol{V}$ & $\psi_{2}$ & $\boldsymbol{\mu}$ & $\mathrm{C}$ & $\mathrm{P}$ & $\mathrm{h}$ & $\alpha$ \\
\hline Limites & $\mathrm{X} 1$ & $\mathrm{X} 2$ & $\mathrm{X} 3$ & $\mathrm{X} 4$ & $\mathrm{X} 5$ & $\mathrm{X} 6$ & $\mathrm{X} 7$ & $\mathrm{X} 8$ & $\mathrm{X} 9$ \\
\hline \multirow{2}{*}{$\begin{array}{c}\text { Min } \\
\text { Max }\end{array}$} & 100.0 & 0.4 & 0.29 & -3.00 & 1.0 & 0.00005 & 0.5 & 0.1 & 0.1 \\
\hline
\end{tabular}

O tempo de convergência foi de 9 horas 20 min. A convergência foi atingida aproximadamente entre $60 \%$ e $70 \%$ das iterações. A Figura 77 mostra uma convergência dos parâmetros com $\mathrm{R}<1.2$. 


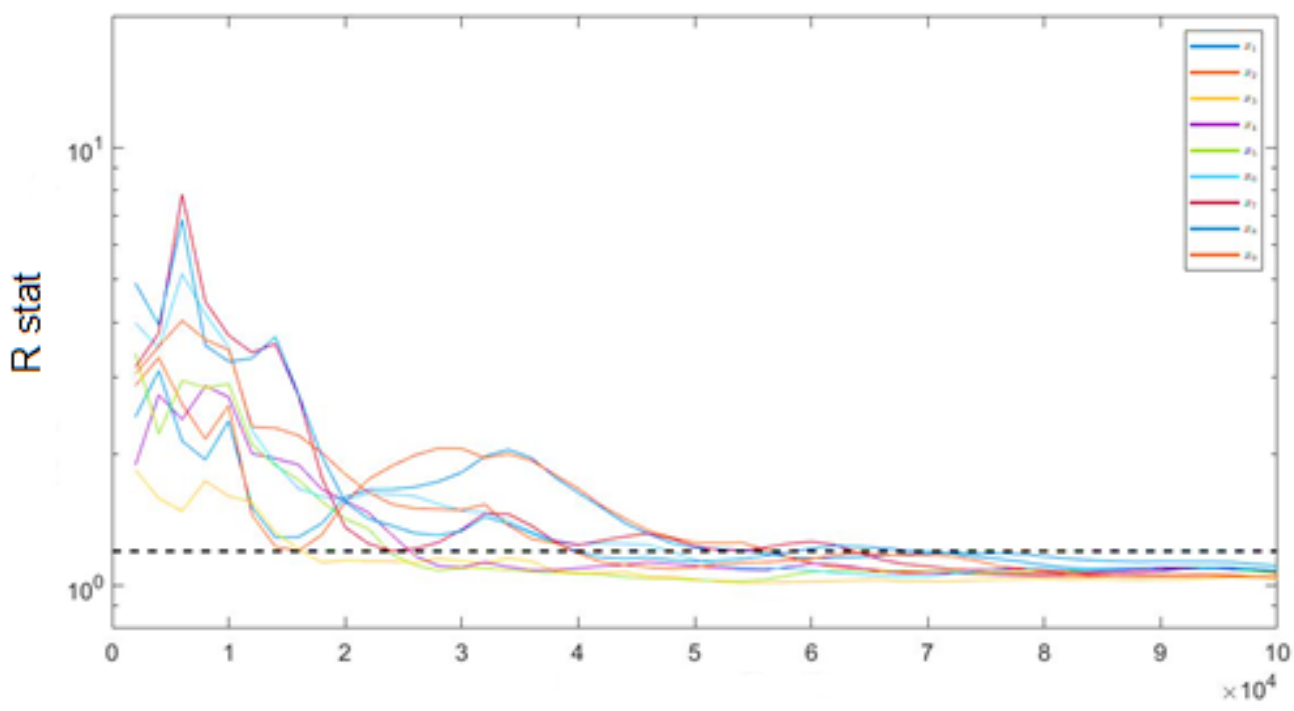

Avaliações do modelo Lade-Kim

Figura 77 Convergência de parâmetros da rocha Tournemire shale

Os parâmetros que tiveram uma melhor distribuição posterior na retroanálise foram $(K, \mu, P, h, \alpha)$, que atingiram o valor ótimo, indicado na Figura 78 pelo $\mathrm{X}$ azul. Além disso, os parâmetros $v$ e $C$ possuem uma distribuição aproximadamente uniforme abrangendo toda a faixa de distribuição prévia, indicando que esses parâmetros são mais sensíveis. Na Figura 78 são apresentados os parâmetros e suas distribuições.
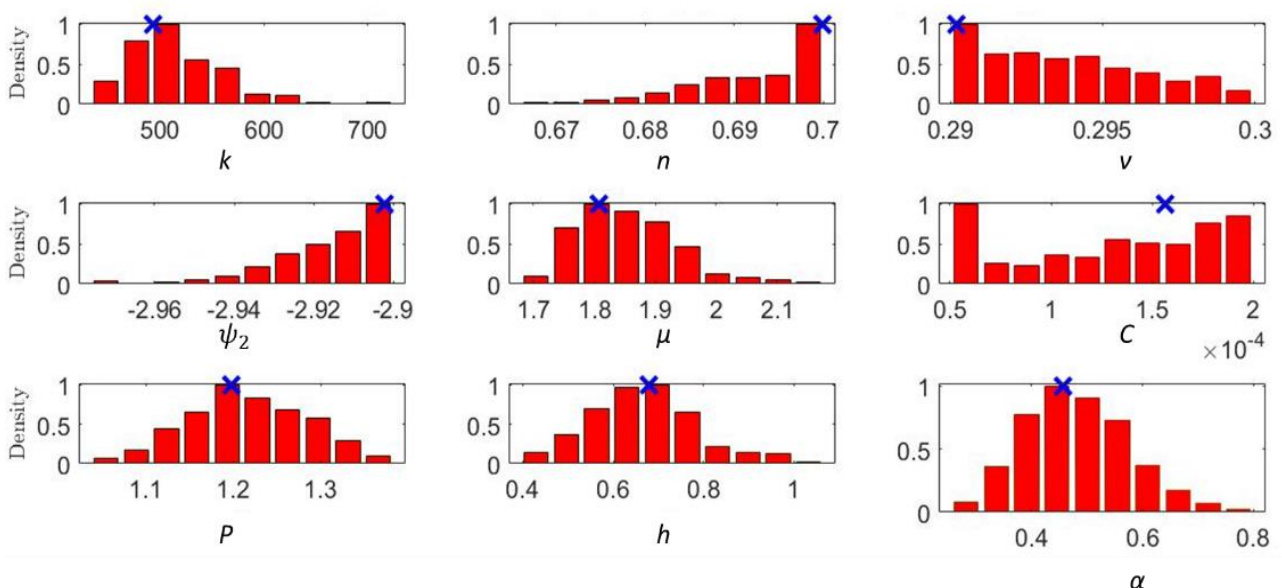

Figura 78 Distribuição de parâmetros com o DREAM para a rocha Tournemire shale

O modelo elastoplástico de Lade-Kim incorporado no DREAM é sensível à variação de parâmetros e uma mudança pequena nos valores pode alterar os 
resultados nas curvas tensão vs deformação e deformação volumétrica. Estas variações, para este caso particular, são mais evidentes para o parâmetro $K$ do critério elástico, o parâmetro $\mu$ da função potencial plástico e do $h$ da função de escoamento. Estes são os parâmetros que tiveram maior mudança nos valores. No entanto, não é possível assegurar que eles sejam os responsáveis pelo melhor ajuste. Embora o parâmetro $\psi_{2}$ não tenha mudado muito, ele é um parâmetro sensível que geralmente causa mudanças nas curvas tensão vs deformação. $\mathrm{Na}$ Tabela 34 são apresentados os resultados da calibração analítica do modelo Lade-Kim e da retroanálise usando DREAM.

Tabela 34 Parâmetros da rocha sedimentaria Tournemire shale usando o modelo Lade-Kim e o DREAM.

Parâmetros isotrópicos do modelo constitutivo Lade-Kim

\begin{tabular}{lccc}
\hline \multicolumn{1}{c}{ Critério } & Parâmetros & Analítico & DREAM \\
& $a$ & 20.0 & 20.0 \\
Critério de Ruptura & $m$ & 1.4402 & 1.4402 \\
& $\eta_{1}$ & 992,001 & 992,001 \\
\hline Critério elástico & $K$ & 159,80 & 492.5677 \\
& $n$ & 0.65 & 0.6998 \\
Função potencial & $\boldsymbol{H}$ & 0.30 & 0.2902 \\
plástica & $\psi_{2}$ & -3.0 & -2.9021 \\
\hline & $\boldsymbol{C}$ & 2.36 & 1.8082 \\
Endurecimento & $\boldsymbol{P}$ & 0.00009 & 0.0005657 \\
\hline Função de & $\alpha$ & 1.25 & 1.1978 \\
escoamento & $\boldsymbol{h}$ & 0.62 & 0.6782 \\
\hline
\end{tabular}

Os resultados da retroanálise indicam que o DREAM tem a capacidade de fornecer os parâmetros adequados para representar a rocha sedimentar tournemire shale. Pode-se observar na Figura 79 (a) e (b) que o DREAM teve o melhor ajuste comparado com os dados da literatura e com a calibração direta, na curva tensão vs deformação e deformação axial vs deformação volumétrica. 


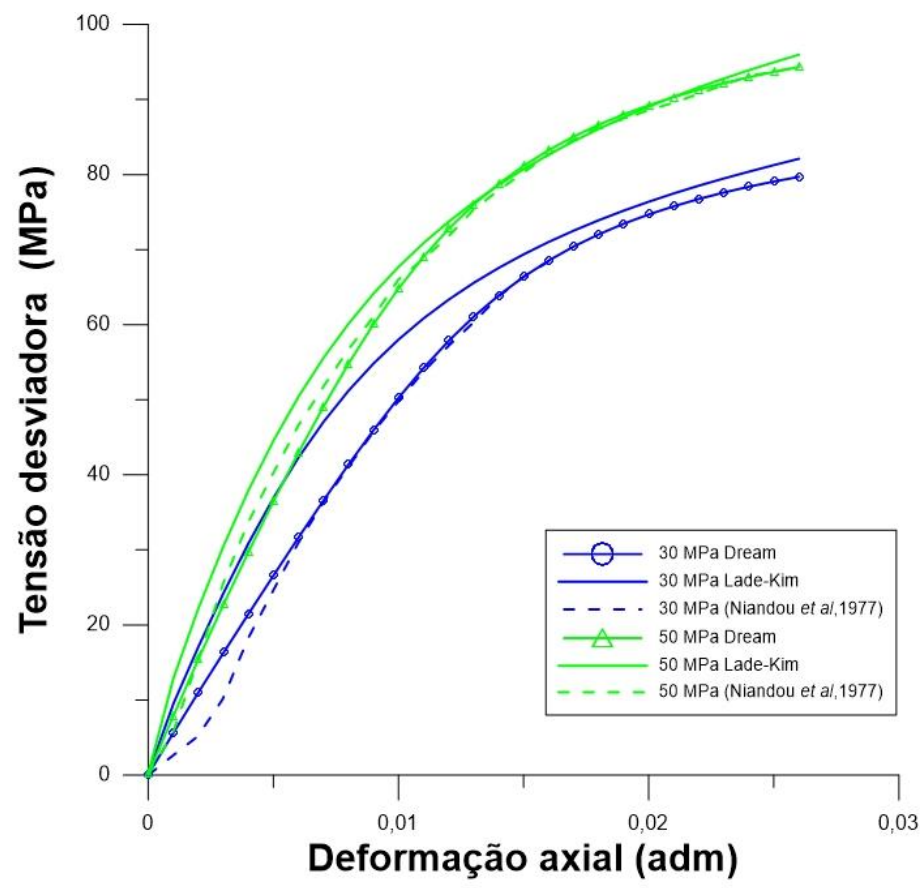

(a)

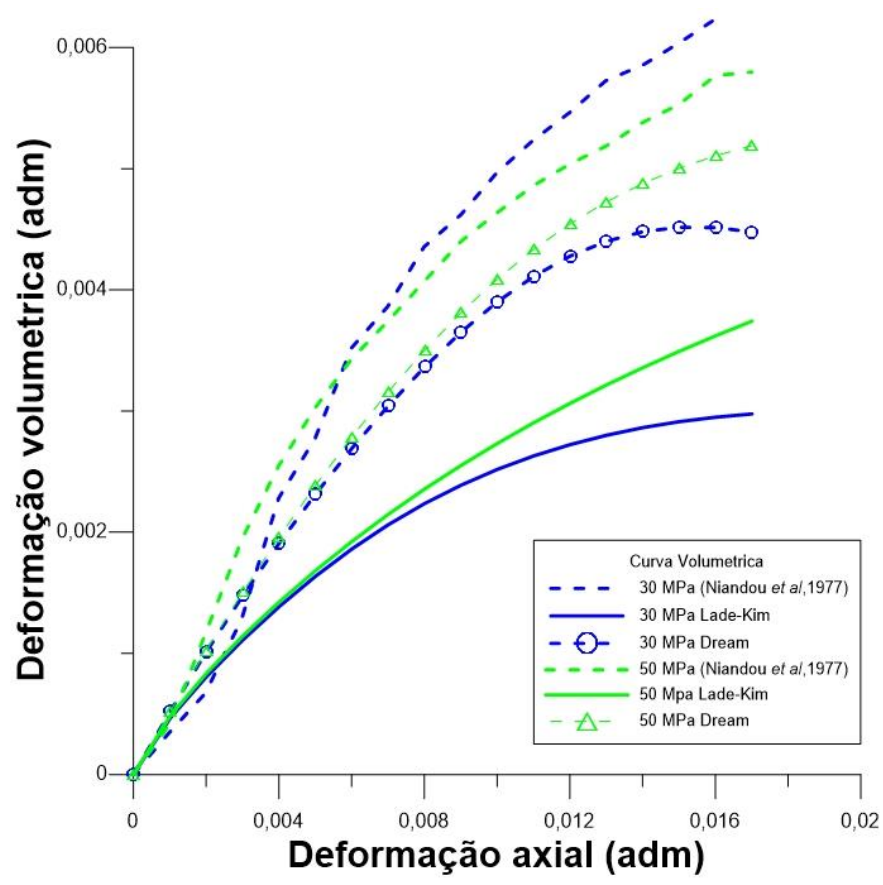

(b)

Figura 79 Comparação entre ensaios triaxiais da rocha sedimentaria Tournemire shale com o modelo Lade-Kim e DREAM. (a) Curva tensão vs deformação axial, (b) deformação volumétrica vs deformação axial. 


\subsection{1.}

\section{Comparação entre calibração analítica, DREAM e MINPACK}

Foi realizada a comparação entre a calibração analítica (calibração direta) e a retroanálise com os algoritmos DREAM e MINPACK. Para isto foram usados os CPVs com porosidade $>8.5 \%$ e com tensões de confinamento de 10, 20 e 30 MPa. Os resultados na Figura 80 a Figura 82 indicam que para as tensões de confinamento de 10 e $20 \mathrm{MPa}$ os algoritmos DREAM e MINPACK ajustam melhor os dados experimentais comparados com os obtidos pela calibração analítica. Além disso, pode-se observar através da curva deformação volumétrica que o DREAM fornece melhores ajustes comparados com o MINPACK para essas mesmas tensões de 10 e $20 \mathrm{MPa}$. Na Figura 82 (b) para tensão de confinamento de $30 \mathrm{MPa}$ os resultados observados na curva volumétrica indicam que o melhor ajuste aos dados experimentais foi obtido com o algoritmo MINPACK. Trabalhos futuros podem ser feitos com análises de sensibilidade prévia para definir os limites adequados para o algoritmo DREAM, que fornece informação da distribuição de cada parâmetro do modelo Lade-Kim. Uma das vantagens do algotimo MINPACK comparado ao DREAM é o baixo custo computacional. No entanto, o algortimo DREAM usa maior quantidade de parâmetros variáveis que 0 MINPACK.

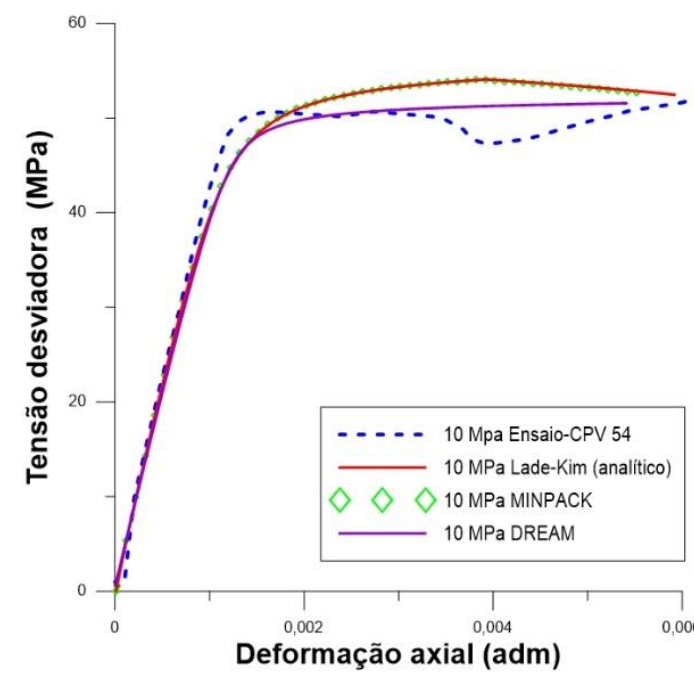

(a)

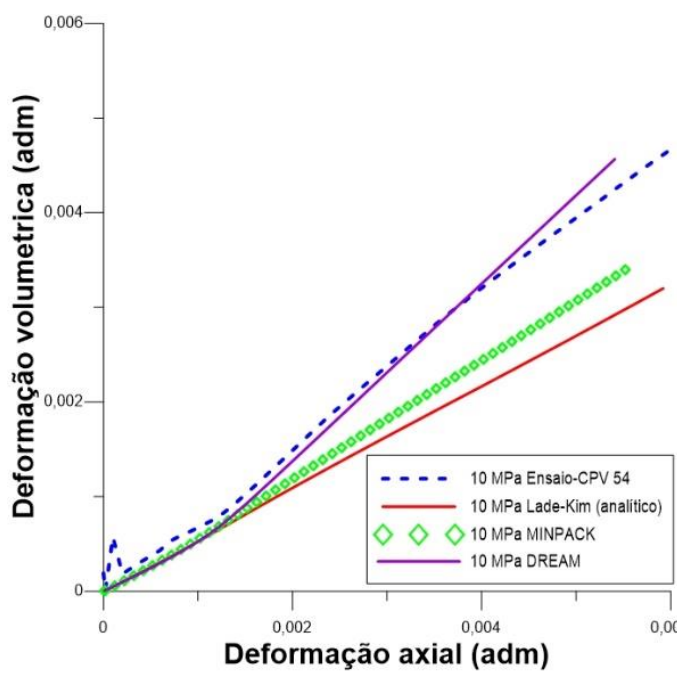

(b)

Figura 80 Comparação entre calibração analítica, MINPACK e DREAM para CPV com porosidade $>8.5 \%$ com tensão de confinamento de $10 \mathrm{MPa}$. (a) Curva tensão vs deformação axial (b) deformação volumétrica vs deformação axial. 


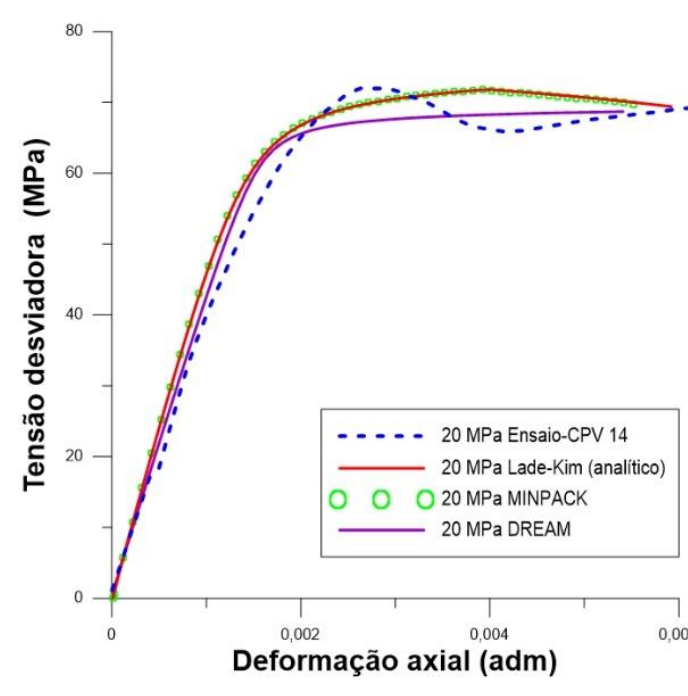

(a)

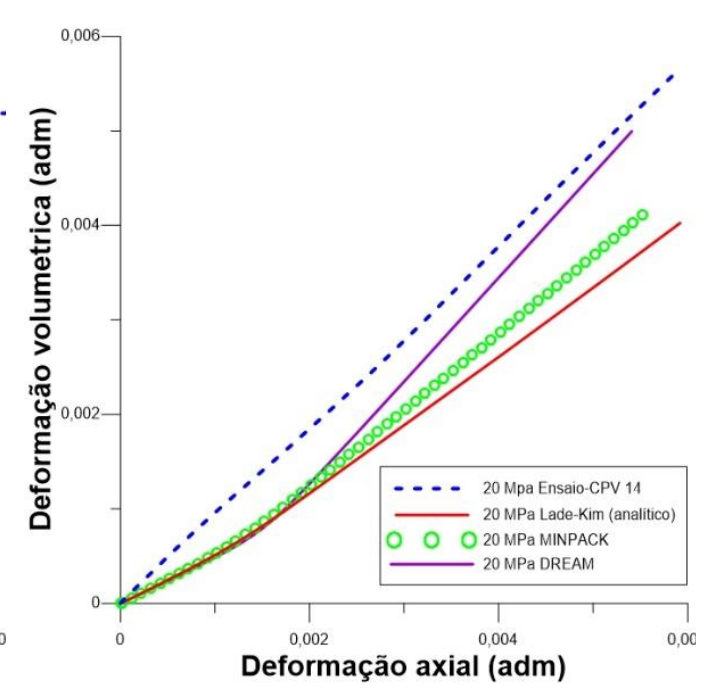

(b)

Figura 81 Comparação entre calibração analítica, MINPACK e DREAM para CPV com porosidade $8.5 \%$ com tensão de confinamento de $20 \mathrm{MPa}$. (a) Curva tensão vs deformação axial, (b) deformação volumétrica vs deformação axial.

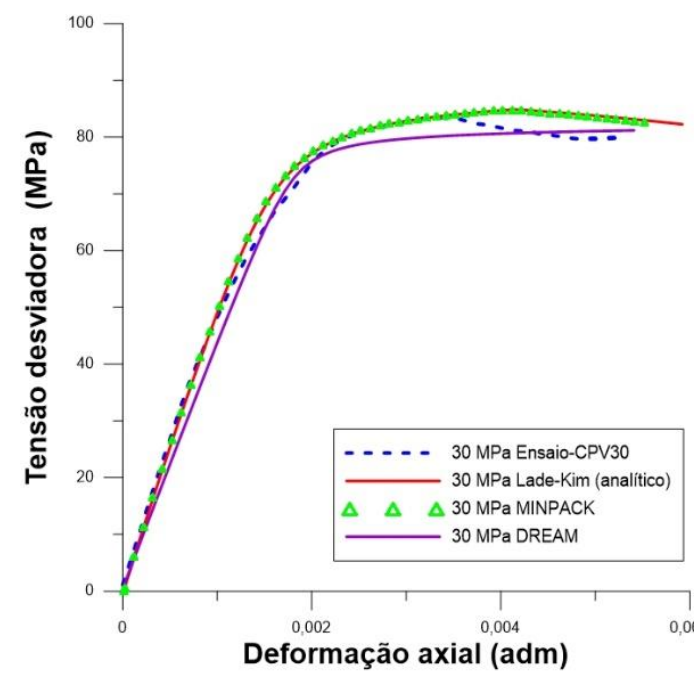

(a)

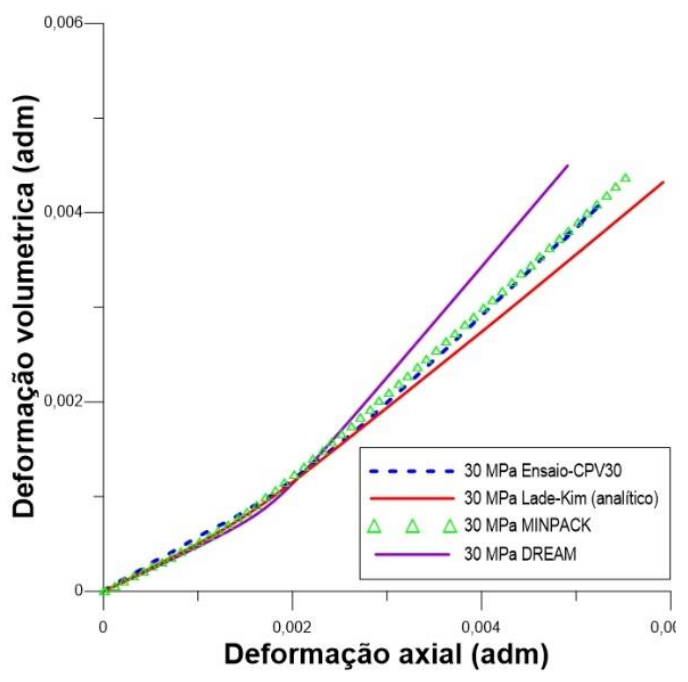

(b)

Figura 82 Comparação entre calibração analítica, MINPACK e DREAM para CPV com porosidade $>8.5 \%$ com tensão de confinamento de $30 \mathrm{MPa}$. (a) Curva tensão vs deformação axial, (b) deformação volumétrica vs deformação axial.

Na Tabela 35 são apresentados os valores dos parâmetros do modelo elastoplástico Lade-Kim obtidos pela calibração analítica e os algoritmos MINPACK e DREAM 
Tabela 35 Parâmetros do modelo Lade-Kim, calibração analítica, MINPACK e DREAM para CPV com porosidade $>8.5 \%$

\begin{tabular}{lcccc}
\hline \multicolumn{1}{c}{ Critério } & Parâmetros & Analítica & MINPACK & DREAM \\
& $\mathrm{A}$ & 17.72 & 17.72 & 17.0624 \\
Critério de & $\mathrm{m}$ & 1.16060 & 1.16060 & 1.1568 \\
Ruptura & $\eta_{1}$ & 136,693 & 136,693 & $120,764.4111$ \\
\hline \multirow{3}{*}{ Critério elástico } & $\mathrm{K}$ & 318,099 & 318,099 & 368455.5973 \\
& $\mathrm{n}$ & 0.0846 & 0.0846 & 0.0288 \\
Função potencial & $v$ & 0.30 & 0.30 & 0.2874 \\
plástica & $\psi_{2}$ & -2.9 & -2.873 & -2.8221 \\
\hline \multirow{2}{*}{ Endurecimento } & $\mu$ & 4.0 & 4.1737 & 4.8845 \\
\hline Função de & $\mathrm{C}$ & 0.000001 & 0.000001 & 0.0000006554 \\
escoamento & $\mathrm{P}$ & 1.55 & 1.55 & 1.4691 \\
\hline
\end{tabular}

\subsection{2.}

\section{Anisotropia em rochas sedimentares}

O modelo CALK, apresentado no Capítulo 3, é usado para determinar o comportamento anisotrópico das rochas sedimentares Tournemire shale e o travertino romano. O modelo CALK possui a capacidade de representar o comportamento isotrópico (sem variação da resistência com a orientação do acamamento) usando $C S$ e $C N$ iguais à unidade. Com o propósito de validar o modelo CALK na parte isotrópica, parâmetros isotrópicos destes materiais, foram determinados usando a metrologia inversa com o algoritmo DREAM e CALK com $C N=1.0$ e $C S=1.0$. Posteriormente, estes parâmetros isotrópicos foram usados como constantes para determinar os três parâmetros anisotrópicos $C N$, CS e $\eta_{1}$. Por fim, foi validado o modelo CALK comparando as curvas tensão desviadora vs deformação axial, usando diferentes tensões de confinamento e diferentes orientações de acamamento $\beta$.

\subsection{1.}

\section{Validação do modelo CALK na rocha carbonática travertino}

Como já foi mencionado o modelo CALK possui a capacidade de representar o comportamento isotrópico usando $C S$ e $C N$ iguais à unidade. Neste caso, 
resultados dos ensaios triaxiais com acamamento perpendicular ao eixo axial, $\beta=0^{\circ}$ ( ver Item 4.1.2), foram usados no algoritmo DREAM e CALK com CS=1.0 e $C N=1.0$ para determinar o comportamento isotrópico. Na Tabela 36 são comparados os parâmetros obtidos com a metodologia analítica e os resultados obtidos com o DREAM usando Lade-Kim isotrópico e CALK.

Tabela 36 Parâmetros da rocha carbonática travertino para o modelo Lade-Kim, determinados analiticamente e através do DREAM com CALK.

\begin{tabular}{lcccc}
\hline \multicolumn{5}{c}{ Parâmetros isotrópicos do modelo constitutivo Lade-Kim } \\
\hline \multicolumn{1}{c}{ Critério } & Parâmetros & Analítico & $\begin{array}{c}\text { DREAM } \\
\text { Lade-Kim }\end{array}$ & $\begin{array}{c}\text { DREAM } \\
\text { CALK }\end{array}$ \\
\hline $\begin{array}{l}\text { Critério de } \\
\text { Ruptura }\end{array}$ & $\mathrm{a}$ & 17.72 & 17.0624 & 18.7929 \\
& $\mathrm{~m}$ & 1.16060 & 1.1568 & 1.1511 \\
& $\eta_{1}$ & 136,693 & $120,764.4111$ & $193,786.399$ \\
Critério elástico & $\mathrm{K}$ & 318,099 & 368455.5973 & 382248.0728 \\
& $\mathrm{n}$ & 0.0846 & 0.028858 & 0.0363 \\
Função potencial & $\boldsymbol{V}$ & 0.30 & 0.287420 & 0.2769 \\
plástica & $\psi_{2}$ & -2.9 & -2.82215 & -2.8302 \\
\hline \multirow{2}{*}{ Endurecimento } & $\mu$ & 4.0 & 4.88456 & 5.2730 \\
& $\mathrm{C}$ & 0.000001 & 0.0000006554 & $5.004 \mathrm{e}-7$ \\
Função de & $\mathrm{P}$ & 1.55 & 1.469083 & 1.5902 \\
escoamento & $\alpha$ & 0.2 & 0.10076 & 0.3989 \\
\hline
\end{tabular}

$\mathrm{Na}$ figura 83 pode-se observar os resultados dos ensaios triaxiais da rocha carbonática travertino com acamamento perpendicular $\beta=0^{\circ}$ e os resultados numéricos obtidos usando o retroanálise com ao algoritmo DREAM e CALK com $\mathrm{CN}=1.0$ e $\mathrm{CS}=1.0$. Observa-se que existe um bom ajuste na Figura 83 (a) e um ajuste razoável na Figura 83(b). Se conclui que o modelo CALK, com CN e CS iguais para unidade, pode representar adequadamente o comportamento isotrópico da rocha carbonática travertino, para diferentes tensões de confinamento. 


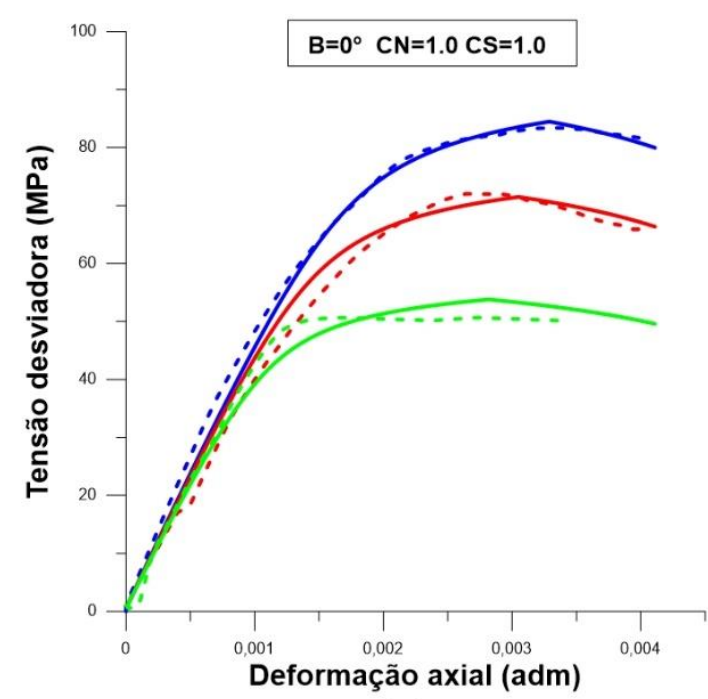

(a)

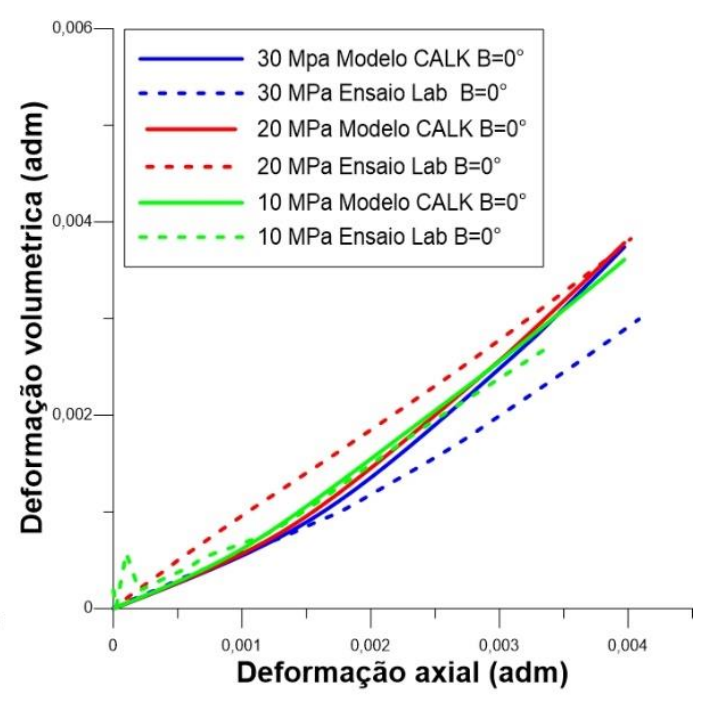

(b)

Figura 83 Comparação entre curvas laboratoriais de ensaios triaxiais CPV $>8.5 \%$ $\beta=0^{\circ}$ e a retroanálise usando o DREAM com o modelo numérico CALK CN=1.0 e $C S=1.0$ (caso isotrópico). (a) Curva tensão vs deformação axial, (b) deformação volumétrica vs deformação axial.

\subsubsection{1.}

\section{Parâmetros anistrópicos usando DREAM e CALK}

A partir dos parâmetros obtidos pelo DREAM com CALK (CN=1.0 e CS=1.0) foi realizada a retroanálise dos parâmetros anisotrópicos $C N$, CS e $\eta_{1}$, estabelecendo 11 parâmetros isotrópicos como constantes e três parâmetros anisotrópicos como variáveis no algoritmo DREAM. A retroanálise foi realizada para corpos de prova com porosidade $>8.5 \%$, com diferentes tensões de confinamento (10, 20 e $30 \mathrm{MPa}$ ) e com diferentes orientações de acamamento, ( $\beta=0^{\circ}, \beta=45^{\circ}$ e $\beta=90^{\circ}$ ) perpendicular, inclinada e paralela ao eixo axial da amostra, respectivamente.

Utilizando a metodologia Bayesiana, as simulações com o algortimo DREAM foram realizadas com 8 cadeias de Markov e 4000 gerações. Os parâmetros anisotrópicos foram procurados em cada iteração pelas cadeias de Markov até convergirem na distribuição normal posterior bem definida. A Tabela 37 mostra os limites de parâmetros $\mathrm{CN}$, CS e $\eta_{1}$ utilizados nas simulações. Além dos valores obtidos na convergência das simulações usando o código DREAM. 
Tabela 37 Limite de parâmetros e valores ótimos dos parâmetros anisotrópicos $\mathrm{CN}$, CS e $\eta_{1}$ da rocha carbonática travertino.

\begin{tabular}{cccc}
\hline Parâmetros & Mínimo & Máximo & Valor ótimo \\
\hline CN & 0.6 & 1.6 & 1.282 \\
CS & 0.5 & 1.5 & 1.083 \\
$\eta_{1}$ & $110,000.0$ & $400,000.0$ & $290,360.3507$ \\
\hline
\end{tabular}

Figura 84 (a), (b) e (c) apresenta a distribuição dos parâmetros anisotrópicos $\mathrm{CN}$, CS e $\eta_{1}$ e seus ótimos valores ótimos (cruz vermelha), respectivamente. Pode-se observar que a distribuição posterior em cada parâmetro foi bem sucedida, apresentando uma distribuição normal, sem nenhum truncamento lateral.

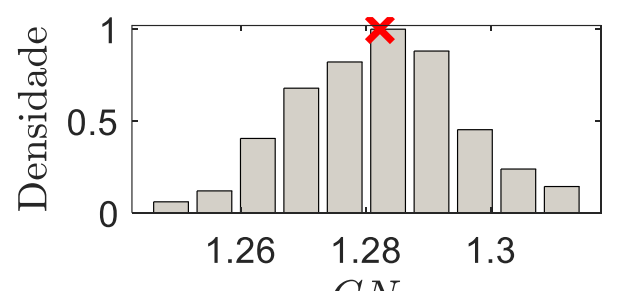

$C N$

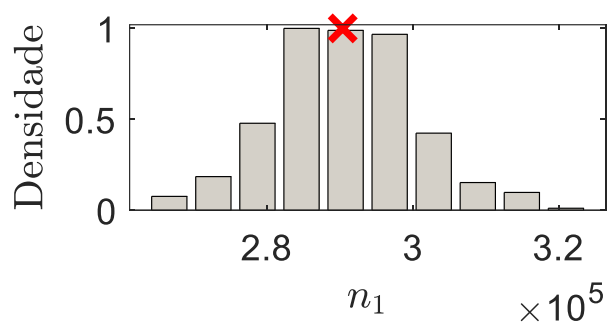

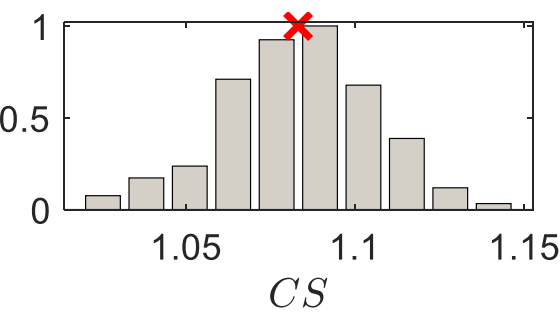

Distribuição de parâmetros X Valor ótimo

Figura 84 Distribuição posterior dos parâmetros anistrópicos $C N$, CS e $\eta_{1}$ da rocha carbonática travertino, usando o algoritmo DREAM.

$\mathrm{Na}$ Tabela 38, os resultados obtidos pelo modelo CALK mostram que existe uma aproximação numérica razoável comparada com dados experimentais. Observou-se que a tensão máxima desviadora aumenta com o aumento da tensao confinante, como esperado. Além disso, a tensão desviadora máxima numérica foi sempre maior para o acamamento paralelo ao eixo axial $\beta=90^{\circ}$ e menor para o plano de acamamento perpendicular ao eixo axial $\beta=0^{\circ}$. A Tabela 38 resume 
os valores das tensões desviadoras máximas dos dados experimentais e dados numéricos com respeito à tensão de confinamento e orientação do acamamento.

Tabela 38 Tensões máximas desviadoras experimentais e numéricas para amostras de travertino com porosidade maior que $8.5 \%$.

\begin{tabular}{ccccc}
\hline $\begin{array}{c}\text { Porosidade } \\
>8.5 \%\end{array}$ & $\begin{array}{c}\text { Tensão de } \\
\text { confinamento }\end{array}$ & \multicolumn{3}{c}{ Máxima tensão desviadora } \\
\cline { 3 - 5 } & & $\beta=90^{\circ}$ & $\beta=45^{\circ}$ & $\beta=90^{\circ}$ \\
\hline \multirow{2}{*}{ Ensaios de } & 10.0 & 50.69 & 62.41 & 128.41 \\
Laboratório & 20.0 & 72.03 & 73.65 & 139.63 \\
& 30.0 & 83.4 & 103.29 & 151.17 \\
\hline \multirow{2}{*}{ CALK } & 10.0 & 47.33 & 59.16 & 99.77 \\
& 20.0 & 63.51 & 81.97 & 98.12 \\
& 30.0 & 74.46 & 98.12 & 165.89 \\
\hline
\end{tabular}

A Figura 85 (a) curva tensão desviadora máxima vs orientação do acamamento, mostra os resultados do modelo CALK usando 11 parâmetros isotrópicos previamente determinados e três parâmetros anisotrópicos $\eta_{1}$ $=290360.3507, C N=1.282$ e $C S=1.083$, determinados pelo problema inverso usando o código DREAM. No entanto, para obter melhor ajuste aos dados experimentais, o parâmetro elástico $K$ mudou para 482.248,0728 e o parâmetro de endurecimento $C$ para 3,004e-7. Observa-se que o modelo CALK se aproxima das tensões desviadoras para diferentes ângulos do plano de acamamento $\beta$. Um bom ajuste foi observado para $\beta=45^{\circ}$ e um ajuste razoável para $\beta=0^{\circ} \mathrm{e}$ $\beta=90^{\circ}$. Nas simulações realizadas com o código DREAM, os parâmetros $\mathrm{CNe}$ CS do modelo CALK são responsáveis pela anisotropia, escalando as tensões normal e de cisalhamento, respectivamente, em relação à orientação do plano de acamamento. O parâmetro $C N$ influencia as tensões normais do tensor anisotrópico e seus efeitos de escala podem ser observados para os acamamentos em relação ao eixo axial $\beta=0^{\circ}$ e $\beta=90^{\circ}$. O parâmetro $C S$ influencia as tensões de cisalhamento do tensor anisotrópico e podemos observar o efeito de escala para o ângulo com acamamento $\beta=45^{\circ}$. Pode ser observado na Figura 85(a) e (b) que o modelo CALK pode representar o comportamento isotrópico (linha pontilhada) usando os parâmetros isotrópicos, $\mathrm{CN}$ e CS, iguais à unidade. Por outro lado, o valor do parâmetro anisotrópico $\eta_{1}$ foi fundamental para 
atingir os valores da tensão de ruptura para todas as orientações de acamamento. A Figura 85 (b) mostra uma análise de sensibilidade dos parâmetros CNe CS para uma tensão confinante de $30 \mathrm{MPa}$. Observou-se que uma decréscimo do parâmetro $C N$ provoca um aumento na resistência para $\beta=0^{\circ}$ e uma diminuição para $\beta=90^{\circ}$, enquanto um decréscimo do CS provoca uma aumento da resistência para $\beta=45^{\circ}$. No modelo CALK os efeitos de escala dos parâmetros anisotrópicos $C N$ e $C S$ não são uniformes, a superfície de escoamento conserva o centro no eixo hidrostático, aumentando a tensão relacionada ao eixo anisotrópico.

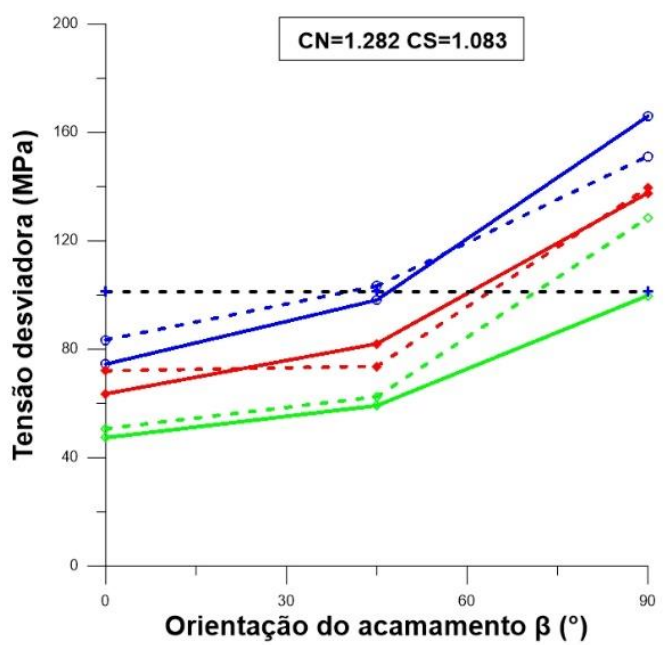

(a)

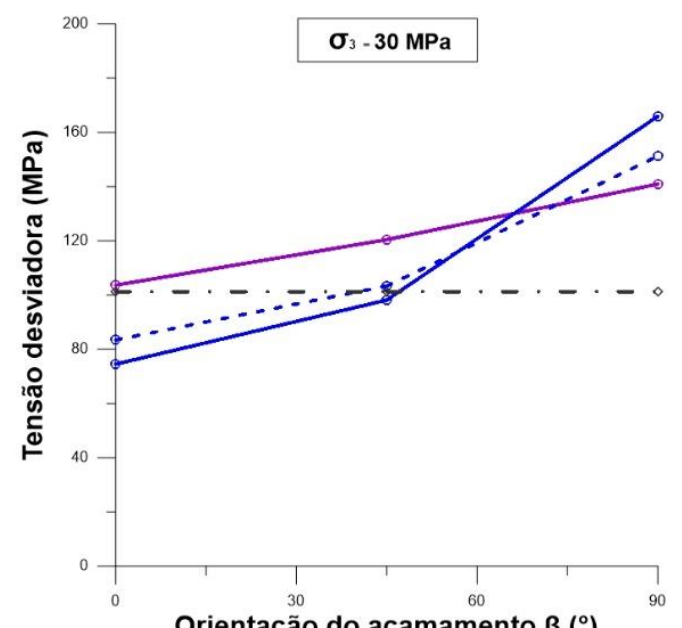

(b)

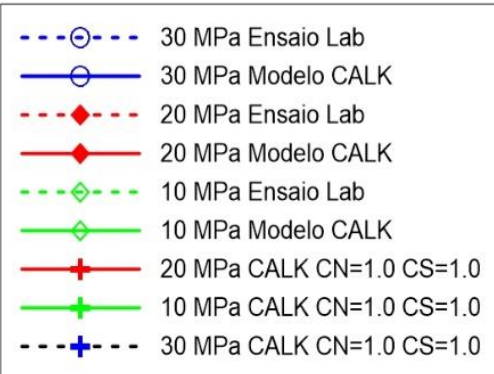

-. - $\odot$-.. $30 \mathrm{MPa}$ Ensaio Lab

$30 \mathrm{MPaCN}=1.1 \mathrm{CS}=1.0$

- $30 \mathrm{MPa}$ CN=1.282 CS=1.083

$-\cdots \quad 30 \mathrm{MPa}$ CALK CN=1.0 CS=1.0

Figura 85 Orientação das camadas vs tensão desviadora $(\mathrm{MPa})$ da rocha carbonática travertino, usando calibração analítica e o algoritmo anisotrópico de Lade-Kim, com porosidades $>8.5 \%$. (a) Ensaios laboratoriais vs modelo numérico CALK, (b) analíse de sensibilidade do modelo CALK.

A Figura 86 mostra os resultados dos testes laboratoriais triaxiais convencionais da rocha carbonática travertino, comparando com os resultados numéricos do modelo CALK. Na Figura 86 (a), observa-se que a curva numérica apresenta um bom ajuste para tensão de confinamento de $10 \mathrm{MPa}$, enquanto que para tensões de confinamento de 20 e $30 \mathrm{MPa}$, o valor da tensao de ruptura se 
torna um pouco menor com respeito aos dados evidenciados nos testes de laboratório. Um aumento no parâmetro $\eta_{1}$ poderia ajustar um pouco melhor, no entanto, aumentaria as tensões desviadoras máximas nas outras orientações de acamamento. O problema inverso utilizado na calibração, neste caso, forneceu o melhor ajuste para os parâmetros anisotrópicos a todas as orientações de acamamento $\beta$. Na Figura 86 (b), observa-se apenas uma pequena variação entre as curvas numéricas, mas elas representam as complexas trajetórias da deformação volumétrica compressiva experimental. Na Figura 86 (c), observa-se uma aproximação razoável do modelo CALK aos dados experimentais para $\beta=45^{\circ}$. Por outro lado, o gráfico mostra uma diferença de 0,0001 da deformação axial na tensão de ruptura numérica e experimental. A Figura 86 (d) mostra um ajuste razoável da deformação numérica volumétrica do modelo CALK com a deformação volumétrica experimental. Na Figura 86 (e), pode ser observado que tensões confinantes de 20 e $30 \mathrm{MPa}$ apresentam um excelente ajuste com valores da tensão desviadora similares aos obtidos no ensaio triaxial, enquanto que a tensão confinante de $10 \mathrm{MPa}$, não apresentou um bom ajuste. A Figura 86 (f) mostra que a deformação volumétrica experimental apresentou um comportamento compressivo, tornando-se dilatante no final, especialmente em tensões confinantes de 10 e $20 \mathrm{MPa}$. Ainda assim, o modelo CALK conseguiu representar apropriadamente as deformações volumétricas experimentais. Em conclusão, pode-se afirmar que o modelo CALK representa razoavelmente 0 complexo comportamento da rocha carbonática de travertino.

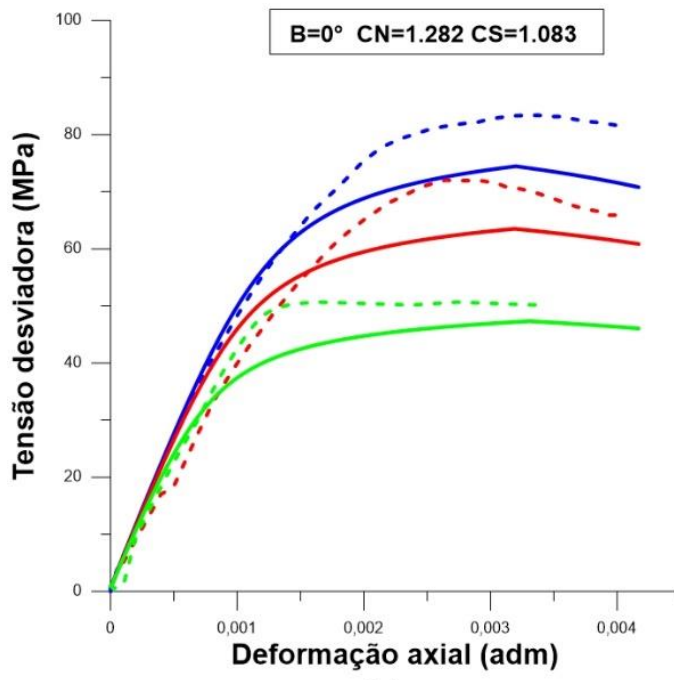

(a)

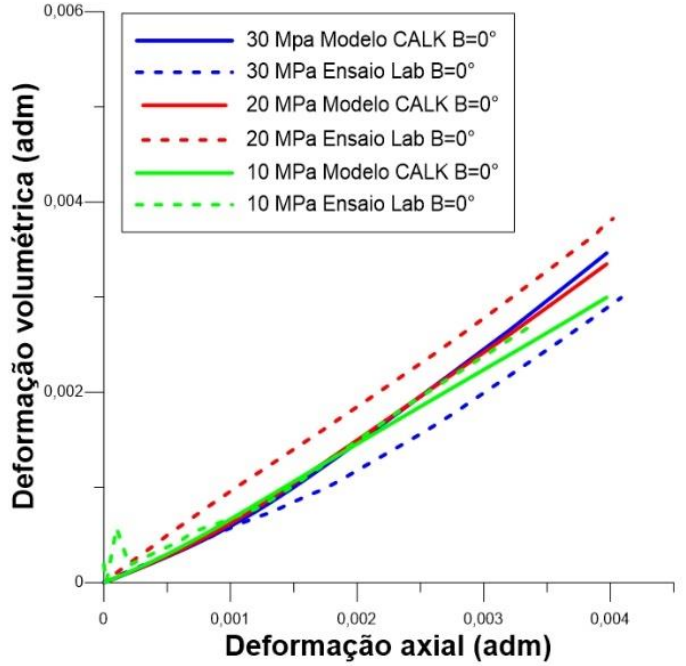

(b) 


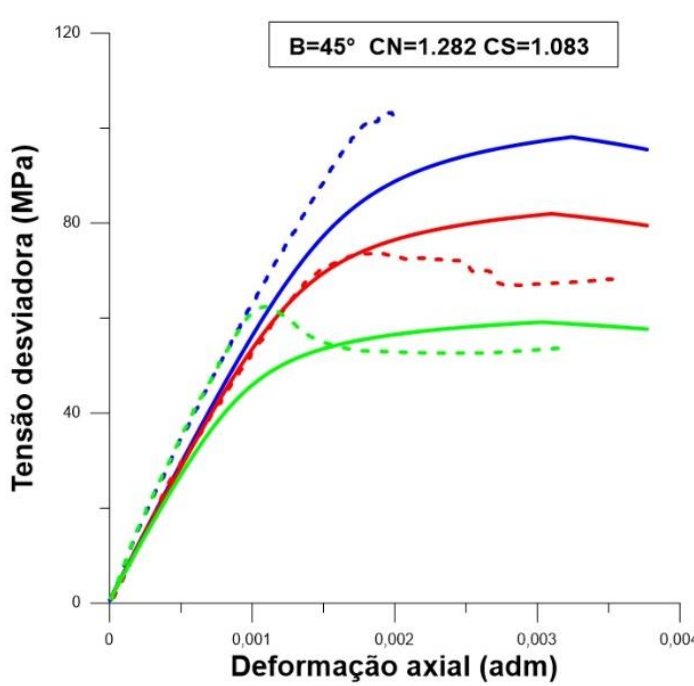

(c)

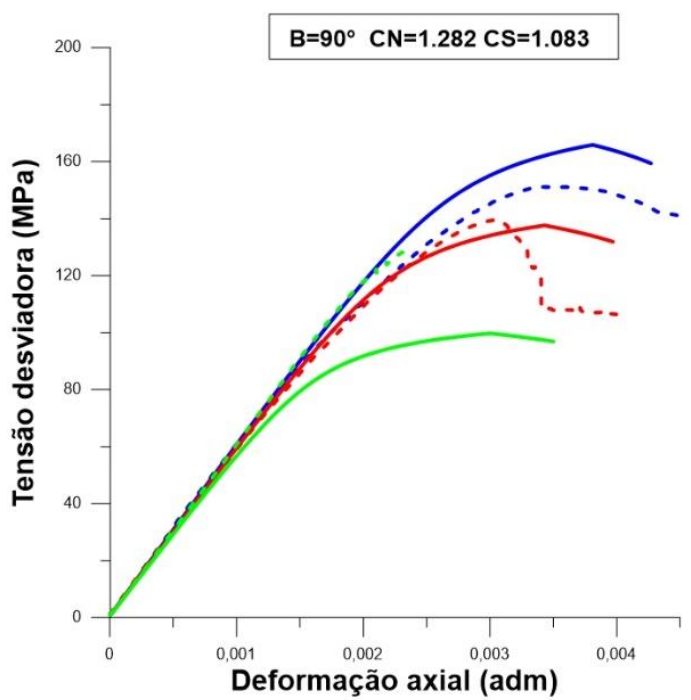

(e)

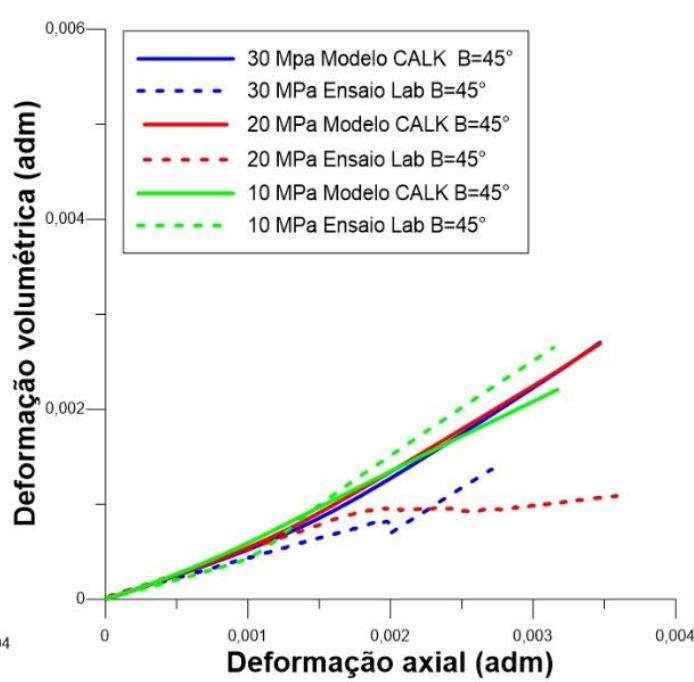

(d)

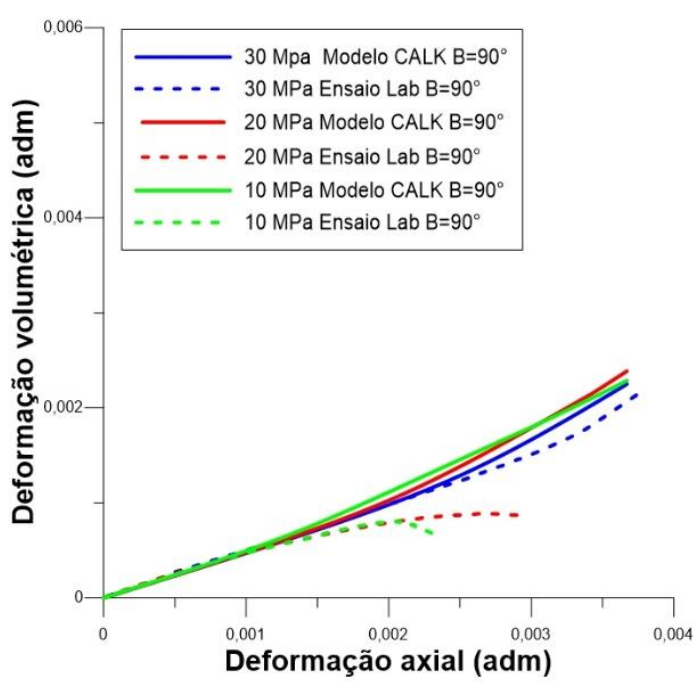

(f)

Figura 86 Comparação entre o modelo anisótropico Lade-Kim e ensaios triaxiais com tensões de confinamento de 10, 20 e $30 \mathrm{MPa}$ na rocha carbonática travertino com porosidades $>8.5 \%$. (a) Curva tensão desviadora vs deformação axial, (b) curva deformação volumétrica vs deformação axial para $\beta=0^{\circ}$; (c) Curva tensão desviadora vs deformação axial, (d) curva deformação volumétrica vs deformação axial para $\beta=45^{\circ}$

; (e) Curva tensão desviadora vs deformação axial, (f) curva deformação volumétrica vs deformação axial para $\beta=90^{\circ}$.

\subsection{2.}

\section{Validação do modelo CALK para a rocha Tournemire shale}

Para determinar o comportamento anisotrópico do Tournemire shale, foram determinados 12 parâmetros do modelo isotrópico de Lade-Kim usando o algoritmo DREAM e CALK com $C N=1.0$ e $C S=1.0$. Os parâmetros isotrópicos 
foram previamente determinados pela metodolodia analítica para estabelecer os limites do problema inverso. Assim, foram fixados 3 parâmetros calibrados analiticamente e 9 determinados com o algoritmo DREAM. Posteriormente os parâmetros anisotrópicos $\eta_{1}$ do critério de ruptura e dois parâmetros da escala CN e CS foram obtidos pela metodologia inversa usando o algoritmo DREAM. A Tabela 39 apresenta os parâmetros isotrópicos do modelo Lade-Kim para Tournemire shale, obtidos de ensaios de laboratório realizados em amostras com acamamento vertical ao eixo axial, $\beta=0^{\circ}$, utilizando a metodologia analítica do modelo Lade-Kim e o problema inverso com o algoritmo DREAM. Ensaios triaxiais e hidrostáticos convencionais realizados por (Niandou et al., 1997) foram utilizados na calibração pela metodologia analítica porposta por (Lade, 2005).

Tabela 39 Parâmetros da rocha Tournemire shale para o modelo Lade-Kim, determinados analiticamente e através do DREAM com CALK.

\begin{tabular}{lccc}
\hline \multicolumn{4}{c}{ Parâmetros isotrópicos do modelo constitutivo Lade-Kim } \\
\hline \multirow{1}{c}{ Critério } & Parâmetros & Analítico & DREAM CALK \\
Critério de Ruptura & $\mathrm{A}$ & 20.0 & 20.0 \\
& $\mathrm{M}$ & 1.4402 & 1.4402 \\
& $\eta_{1}$ & 992,001 & 992,001 \\
\hline \multirow{2}{*}{ Critério elástico } & $\mathrm{K}$ & 159,80 & 492.5677 \\
& $\mathrm{~N}$ & 0.65 & 0.6998 \\
Função potencial & $\boldsymbol{V}$ & 0.30 & 0.2902 \\
plástica & $\psi_{2}$ & -3.0 & -2.9021 \\
\hline \multirow{2}{*}{ Endurecimento } & $\boldsymbol{H}$ & 2.36 & 1.8082 \\
\hline \multirow{2}{*}{ Função de } & $\mathrm{C}$ & 0.00009 & 0.00015657 \\
escoamento & $\mathrm{P}$ & 1.25 & 1.1979 \\
\hline
\end{tabular}

Utilizando a metodologia Bayesiana no algoritmo DREAM, as simulações foram realizadas com 10 cadeias de Markov e 4000 gerações. Previamente, um limite de parâmetros foi estabelecido e, posteriormente, os parâmetros ótimos foram determinados. A Tabela 40 mostra os valores dos limites mínimo e máximo, além do valor ótimo das simulações. 
Tabela 40 Limite de parâmetros e valores ótimos dos parâmetros anisotrópicos $\mathrm{CN}, \mathrm{CS}$ e $\eta_{1}$ para a rocha Tournemire shale.

\begin{tabular}{cccc}
\hline Parâmetros & Mínimo & Máximo & Valor ótimo \\
\hline CN & 0.60 & 1.30 & 1.0833 \\
CS & 0.60 & 1.50 & 1.3854 \\
$\eta_{1}$ & $700,000.0$ & $200,0000.0$ & 1566667.0170 \\
\hline
\end{tabular}

A Figura 87 (a), (b) e (c) mostra os intervalos e o valor ótimo (cruz vermelha) de cada parâmetro anisotrópico, CN, CS e $\eta_{1}$. Neste caso, a distribuição normal posterior foi bem definida, indicando que os limites previamente definidos são adequados para as simulações.

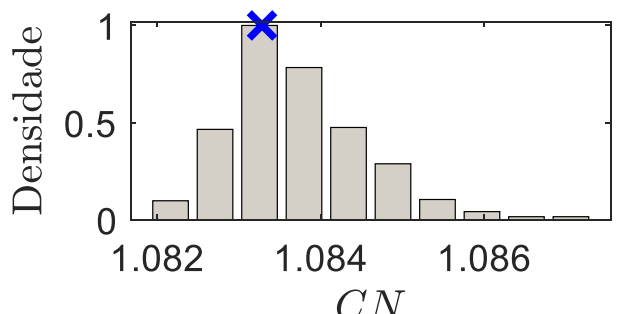

$C N$

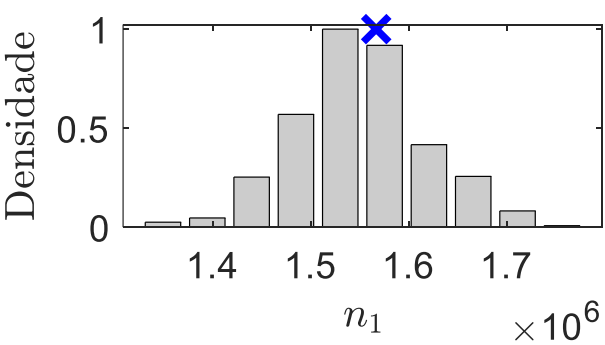

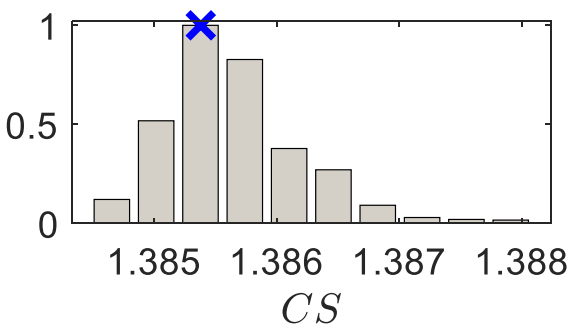

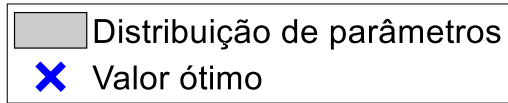

Figura 87 Distribuição posterior dos parâmetros anistrópicos CN, CS e $\eta_{1}$ para a rocha Tournemire shale, usando o algoritmo DREAM.

Os parâmetros anisotrópicos $C N, C S$ e $\eta_{1}$ foram obtidos pelo algoritimo DREAM a fim de reduzir a incerteza na determinação desses parâmetros. Posteriormente, esses valores foram validados no algoritmo explícito tipo CALK implementado no FORTRAN.90® e no MATLAB $2017 \AA$. A Tabela 41 resume os resultados da tensão desviadora máxima em relação à tensão de confinamento e orientação do plano de acamamento $\beta$. Neste caso, assim como a rocha carbonática travertino, a tensão máxima desviadora aumenta com o aumento da tensao confinante. Além disso, a tensão desviadora máxima foi sistematicamente 
maior para o acamamento paralelo, $\beta=90^{\circ}$, e menor para planos de acamamento entre $\beta=30^{\circ}$ e $\beta=45^{\circ}$.

Tabela 41 Tensões máximas desviadoras experimentais e numéricas para amostras de Tournemire shale.

\begin{tabular}{ccccccc}
\hline $\begin{array}{c}\text { Porosidade } \\
>8.5 \%\end{array}$ & $\begin{array}{c}\text { Tensão de } \\
\text { confinament } \\
\end{array}$ & 0 & \multicolumn{5}{c}{ Máximo tensão desviadora } \\
\cline { 3 - 7 } & 20.0 & 82.70 & ---- & 57.70 & 63.78 & 84.86 \\
\hline $\begin{array}{c}\text { Ensaios } \\
\text { Lab. }\end{array}$ & 40.0 & 88.67 & 68.38 & 69.59 & 72.97 & 108.05 \\
$\begin{array}{c}\text { (Niandou et } \\
\text { al., 1997; }\end{array}$ & 50.0 & 94.31 & ---- & 77.62 & 79.73 & 111.81 \\
$\begin{array}{c}\text { Pietruszczak } \\
\text { 2010) }\end{array}$ & & & & & & \\
\hline & 20.0 & 73.51 & 55.37 & 53.32 & 63.19 & 94.18 \\
CALK & 40.0 & 91.53 & 75.24 & 74.39 & 85.23 & 120.72 \\
& 50.0 & 97.41 & 81.54 & 81.04 & 94.20 & 130.16 \\
\hline
\end{tabular}

A Figura 88 mostra os resultados do modelo CALK usando 11 parâmetros isotrópicos do modelo Lade-Kim e três parâmetros anisotrópicos $\eta_{1}=$ 156,6667.0170, CN = 1.0833 e CS = 1.3854 para Tournemire shale. Nesse caso, observa-se que o modelo CALK acompanha as tensões desviadoras para diferentes orientaçãoes do plano de acamamento $\beta$. Um ajuste razoável foi observado para altas tensões de confinamento (20 MPa, $40 \mathrm{MPa}$ e $50 \mathrm{MPa}$ ) para diferentes orientações de acamamento, $\beta=0^{\circ}, \beta=30^{\circ}, \beta=45^{\circ}, \beta=60^{\circ} \mathrm{e}$ $\beta=90^{\circ}$. No entanto, usando os mesmos parâmetros do modelo CALK para menores tensões de confinamento, como $5 \mathrm{MPa}$, observou-se uma perda de rigidez e um comportamento dúctil na curva tensão desviadora vs deformação axial. Por esse motivo, a curva resultante não se ajusta aos dados experimentais e, consequentemente, não foi apresentada neste trabalho. No entanto, o modelo CALK é apropriado para representar o comportamento anisotrópico da rocha sedimentar de Tournemire, para altas tensões de confinamento, o qual é de maior interesse para a indústria de petróleo e gás. 


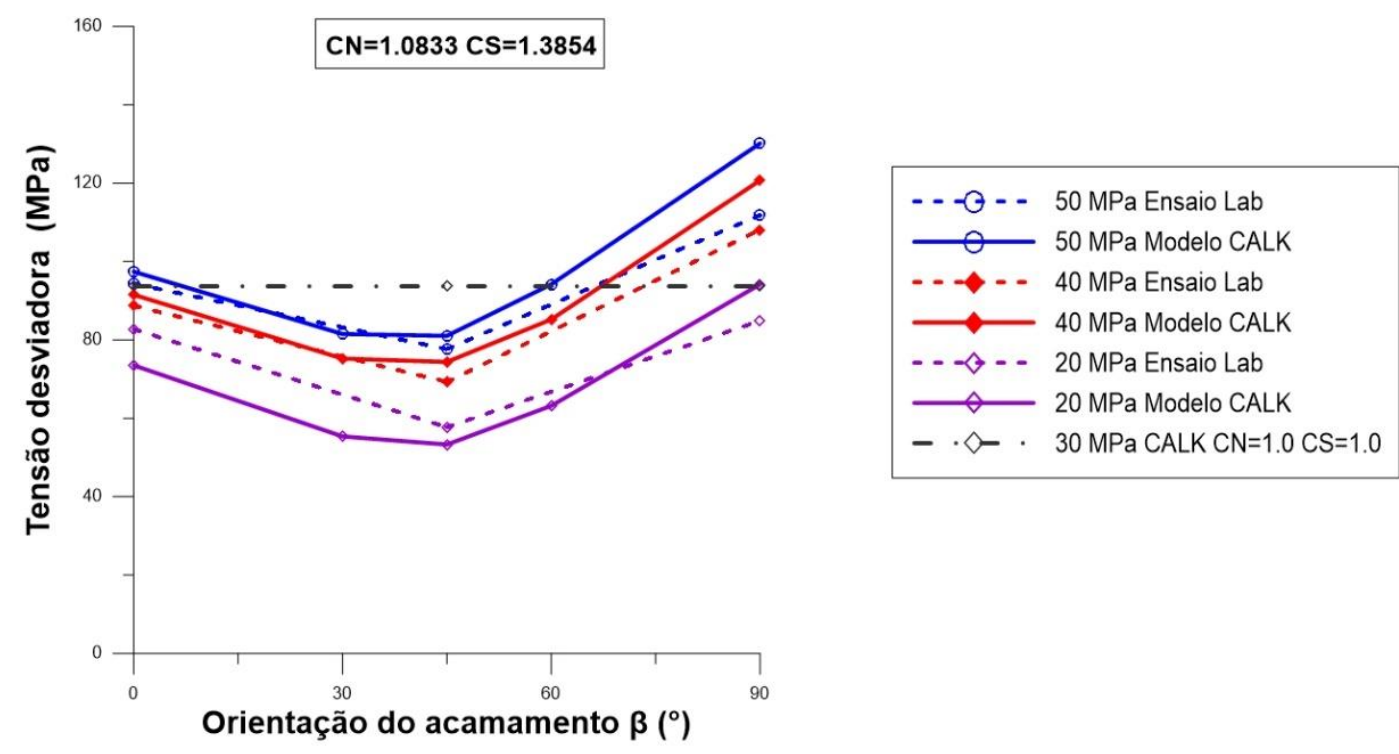

Figura 88 Orientação das camadas vs tensão desviadora $(\mathrm{MPa})$ da rocha Tournemire shale, usando a retroanálise com o DREAM e o modelo CALK.

A Figura 89 mostra os resultados dos ensaios triaxiais de compressão em amostras da rocha Tournemire shale comparados aos resultados numéricos do modelo CALK. Na Figura 89 (a) observa-se que as curvas numéricas ajustaram com sucesso os dados de laboratório para tensões de confinamento de 30, 40 e $50 \mathrm{MPa}$ em amostras com acamamento verticais $\beta=90^{\circ}$. A Figura 89 (b) mostra que o modelo CALK representa adequadamente as deformações volumétricas. $\mathrm{Na}$ Figura 89 (c) pode-se observar um bom ajuste do modelo CALK aos dados experimentais para amostras com acamamento inclinado $\beta=45^{\circ}$, além disso, observa-se que a resistência aumenta com as tensões de confinamento. $\mathrm{Na}$ Figura 89 (d) mostra-se que a transição de compressão para dilatação é bem prevista pelo modelo CALK para tensões de confinamento de 40 e $50 \mathrm{MPa}$ em amostras de acamamento inclinado. Na Figura 89 (e) observa-se que as tensões desviadoras máximas foram maiores na curva numérica em comparação com os dados experimentais. Como já mencionado, um aumento no parâmetro $\eta_{1}$ poderia ajustar um pouco melhor as curvas numéricas, mas teria um impacto sobre a resistência nas outras orientações. No entanto, pode-se observar que o modelo CALK representa razoavelmente o comportamento elastoplástico para tensões de confinamento de 30, 40 e $50 \mathrm{MPa}$, para amostras de acamamento paralelo ao eixo axial da amostra. Na Figura 89 (f) pode-se observar que a transição entre compressão volumétrica e dilatante é bem representada pelo modelo CALK para tensões de confinamento de 40 e $50 \mathrm{MPa}$ para amostras de acamamento paralelo, $\beta=90^{\circ}$. 


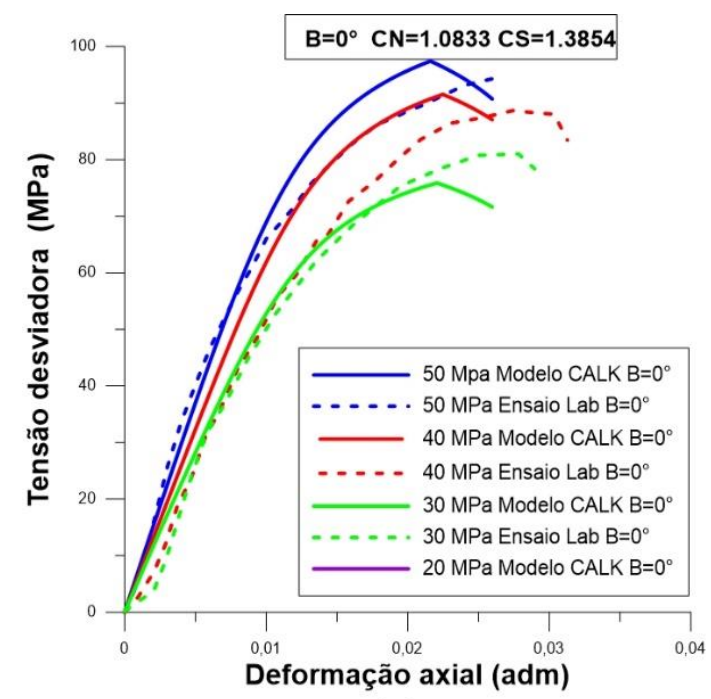

(a)

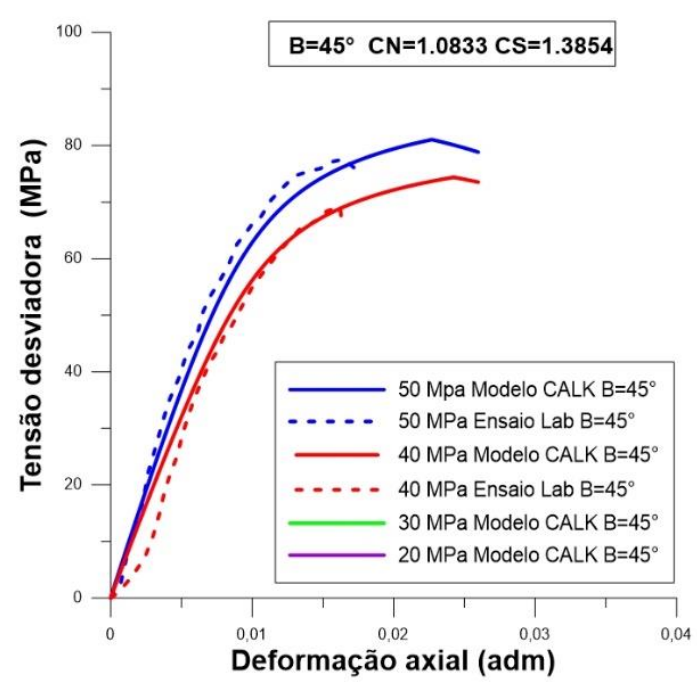

(c)

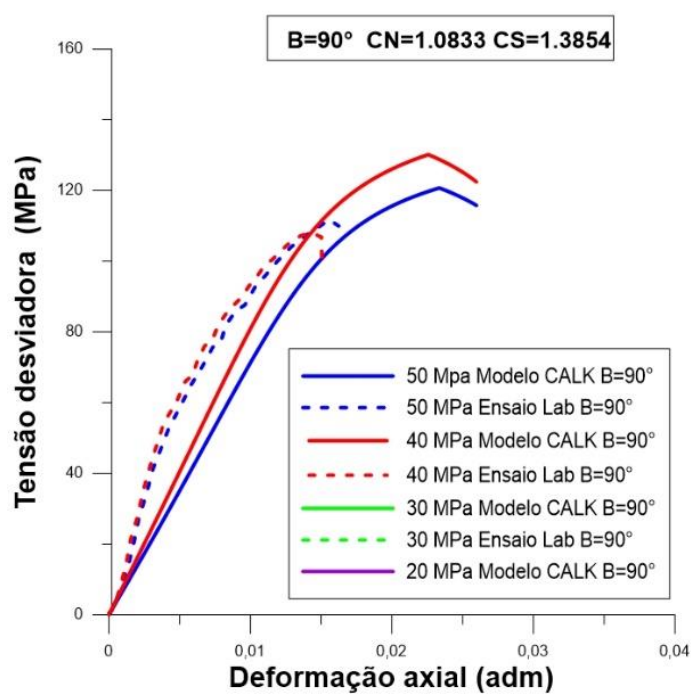

(e)

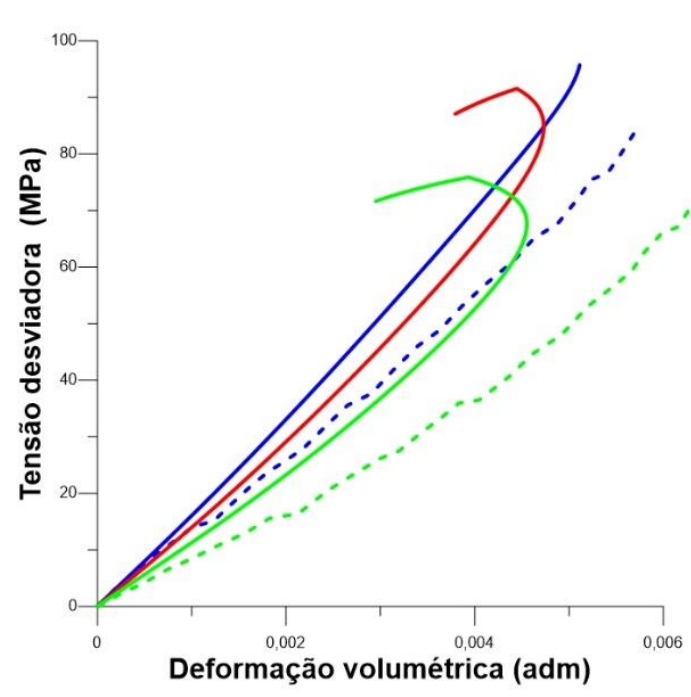

(b)

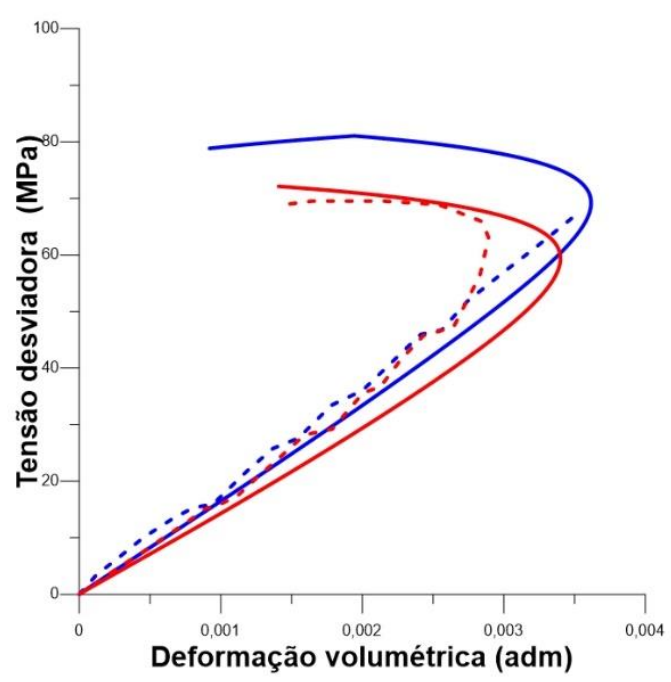

(d)

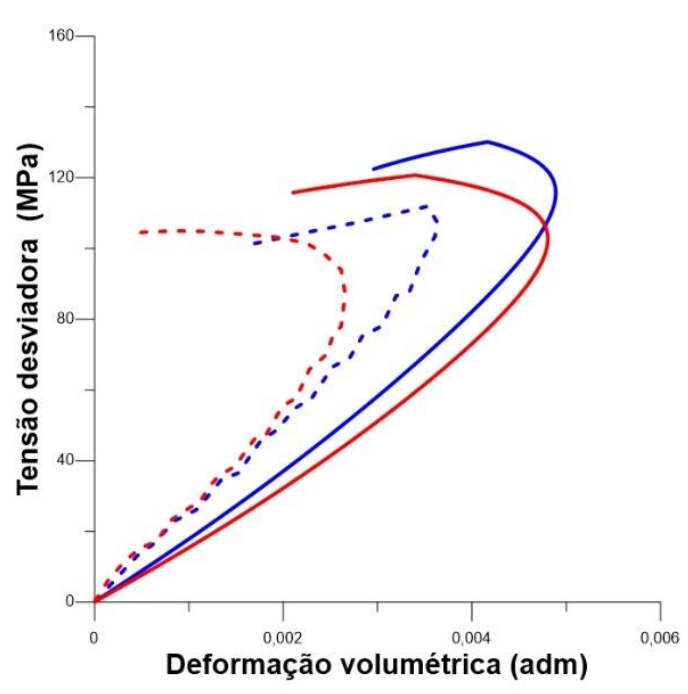

(f)

Figura 89 Comparação entre o modelo anisótropico Lade-Kim e ensaios triaxiais com tensões de confinamento de 30, 40 e 50 MPa para amostras de rocha Tournemire 
shale. (a) Curva tensão desviadora vs deformação axial, (b) curva deformação volumétrica vs deformação axial para $\beta=0^{\circ}$; (c) Curva tensão desviadora vs deformação axial, (d) curva deformação volumétrica vs deformação axial para $\beta=45^{\circ}$; (e) Curva tensão desviadora vs deformação axial, (f) curva deformação volumétrica vs deformação axial para $\beta=90^{\circ}$.

Desta forma, pode-se concluir que o modelo CALK representa razoavelmente bem o complexo comportamento da rocha sedimentar Tournemire shale. 


\section{5 \\ CONCLUSÕES E SUGESTÕES}

\section{1. Conclusões}

A partir do estudo experimental, conclui-se que a resistência da rocha carbonática travertino Romano depende de fatores como orientação das camadas, em relação ao eixo axial, tensão de confinamento e porosidade total, entre outros. Foi observado, em quase todas as amostras da rocha carbonática travertino, que o acamamento poroso coincide com os planos de acamamento depocisional paralelo, inclinado e perpendicular. Segundo os resultados de laboratório feitos na PUC-Rio, no Laboratório de Materiais do Departamento de Engenharia Civil, a rocha carbonática travertino apresentou valores de resistência mais baixas para ângulos $\beta=0^{\circ}$ ( acamamento ortogonal em relação ao eixo axial da amostra) e as maiores para $\beta=90^{\circ}$ (acamamento paralelo em relação ao eixo axial da amostra). Neste caso, se evidenciou que, para ângulos de $\beta=90^{\circ}$, a resistência foi maior devido ao plano de ruptura cisalhante que deve atravessar o acamamento poroso orientado paralelamente ao eixo axial. Além disso, devido ao posicionamento das camadas inclinadas com relação ao eixo axial da amostra, se esperava uma menor resistência nos ensaios triaxiais, mas isto não aconteceu, pelo contrário, os maiores valores apresentados foram para amostras com ângulos de acamamento $\beta=0^{\circ}$. Isto indica que este tipo de material é extremamente heterogêneo e a distribuição dos poros varia em cada amostra, alterando a resistência da rocha.

No processo de calibração analítica, ou direta, realizado com o modelo isotrópico Lade-Kim segundo a metodologia sugerida por Lade (2005), se concluiu que, devido a resultados experimentais e às características heterogêneas da rocha carbonática travertino, os parâmetros obtidos devem ser ajustados até obter o melhor ajuste nas curvas tensão desviadora vs deformação axial e deformação volumétrica vs deformação axial. Além disso, foi observado que pequenas mudanças nos valores dos parâmetros do modelo Lade-Kim alteram os resultados. 
Foram comparados dois modelos constitutivos elastoplásticos com diferentes formulações, Lade-Kim e CCMC, para a representação do comportamento observado em laboratório. Os resultados indicam que o modelo isotrópico Lade-Kim tem a capacidade de representar adequadamente o comportamento mecânico do travertino com orientação das camadas vertical e horizontal, para porosidades entre 4 até $14 \%$, enquanto o modelo isotrópico CCMC não demostrou capacidade suficiente para reproduzir deformações volumétricas da rocha carbonática travertino. Se conclui, então, que o modelo isotrópico Lade-Kim pode representar o comportamento mecânico de uma das fácies encontrada nos reservatórios do Pré-sal brasileiro.

A retroanálise foi utilizada para determinar parâmetros do modelo Lade-Kim da rocha carbonática travertino, usando os algoritmos MINPACK e o DREAM. Além disso, o DREAM foi usado para determinar parâmetros da rocha sedimentar Tournemire shale. Neste trabalho, se comprovou que os algoritmos DREAM e o MINPACK apresentaram resultados mais próximos aos experimentais comparados com os obtidos analiticamente com o modelo isotrópico Lade-Kim nas curvas tensão desviadora vs deformação axial e deformação volumétrica vs deformação axial. Além foi evidenciado que o DREAM apresentou melhores resultados em comparação ao MINPACK. Se conclue que o uso do processo de otimização melhora a calibração dos modelos constitutivos.

O sucesso da otimização depende do número de dados experimentais usados e da metodologia analítica para definir limites prévios dos parâmetros e evitar alto custo computacional e erros de convergência nas simulações com a metodologia inversa.

O modelo CALK foi apresentado é baseado no modelo isotrópico Lade-Kim. O modelo possui 11 parâmetros isotrópicos do modelo Lade-Kim e três parâmetros anisotrópicos, CN, CS e $\eta_{1}$. O tensor anisotrópico foi usado no modelo para mudar os gradientes de escoamento e potencial plástico, como o critério de escoamento. O tensor anisótropico não faz mudanças no critério elástico do modelo, devendo ser incorporado como uma variável independente do tensor de tensões. O modelo CALK difere do modelo transversalmente isotrópico Lade-Kim (anistrópico) apresentado por Abelev et al., 2007. A diferença está no fato que o modelo Lade-Kim anisotrópico requer um escalar para rotacionar o sistema de coordenadas globais, enquanto o modelo CALK escala as tensões que controlam a superfície de escoamento sem rotação do eixo hidrostático. Além 
disso, a complexa metodologia do modelo Lade-Kim anisótropico (Abelev et al., 2007), baseado no endurecimento cinemático, faz que o modelo CALK seja mas simple na implementação e calibração.

O modelo CALK foi validado para amostras das rochas Tournemire shale e travertino. O modelo CALK não apresentou resultados satisfatórios para baixas tensões de confinamento, provavelmente por causa da metodologia explícita usada no algoritmo. O estudo conclui que o modelo CALK conseguiu representar os resultados experimentais das rochas sedimentares aqui testadas, em função da porosidade, tensão de confinamento e orientação das camadas.

\section{2. \\ Sugestões}

A resistência dos carbonatos é afetada pela porosidade, tensão de confinamento e orientação do acamamento com respeito ao eixo axial. Assim, futuros ensaios de laboratório devem usar imagens com microtomógrafos prévios aos ensaios, para determinar e incluir a distribuição da porosidade. Além disso, ensaios com diferentes orientações de acamamento com relação ao eixo axial, como $\beta=30^{\circ}$ e $\beta=60^{\circ}$, deverão ser feitos para determinar a variação da resistência e usar o modelo anisótropico para representá-lo.

Os parâmetros $\psi_{2}$ e $\mu$ da função potencial plástica do modelo Lade-Kim influenciam fortemente as curvas tensão axial vs deformação axial e deformação axial vs deformação volumétrica. No entanto, não garante que sejam os mais relevantes do modelo Lade-Kim. Portanto, é recomendável realizar no futuro, uma análise de sensibilidade para definir limites apropriados na otimização e evitar o alto custo computacional nos algoritmos DREAM e MINPACK.

O modelo elastoplástico CCMC pode ser modificado incorporando uma regra de fluxo não associada e validar posteriormente com os resultados experimentais, e por fim concluir se poderia ser apropriado para representar as rochas sedimentares.

Por fim, quanto ao modelo CALK, fatores como a temperatura e o dano poderiam ser incorporados. Sugere-se que o modelo seja implementado implicitamente e seja testado para altas e baixas tensões de confinamento. 


\section{6 \\ REFERÊNCIAS BIBLIOGRÁFICAS}

ABELEV, A. et al. Modeling Cross Anisotropy in Granular Materials. Journal of Engineering Mechanics. Journal of engineering mechanics, 2007, v. 133, n. 8, p. 919-932.

ABELEV A, V.; LADE P, V. Characterization of Failure in Cross-Anisotropic Soils. Journal of Engineering Mechanics, 2004, v. 130, n. 5, p. 599-606.

ABELEV, A. V.; LADE, P. V. Effects of Cross Anisotropy on Three-Dimensional Behavior of Sand. I: Stress-Strain Behavior and Shear Banding. Journal of Engineering Mechanics, 2003, v. 129, n. 2, p. 160-165.

ALVES, J. L. D et al. Estabilidade de Poços em Rochas Carbonáticas. 4ํㅜㄴ Congresso Brasileiro de Pesquisa e Desenvolvimento em Petróleo e Gás 2007. p. 1-10.

AZEVEDO, I. C. D. D., MARQUES, E. A. G. Introdução à Mecânica das Rochas. Editora UFV, Viçosa, Brasil. 2002.

BARROSO, E. V. Avaliação de um Modelo Elastoplástico para Estudos de Processos de Produção de areia em Rochas Produtoras de Petróleo. Tese de Doutorado. Rio de Janeiro, RJ: Pontifícia Universidade Católica do Rio de Janeiro,PUC-Rio, 2002.

CEKEREVAC, C. et al. Calibration of an elasto-plastic constitutive model by a constrained optimisation procedure. Computers and Geotechnics, 2006, v. 33, n. 8, p. 432-443.

DAVIS, R., \& SELVADURAI, A. Plasticity and Geomechanics. Cambridge: Cambridge University Press, 2002.

FJAR, E. et al. Petroleum related rock mechanics. Elsevier, 2008. ISBN 0-08055709-0. 
FRANKLIN, J. A. (1979). Suggested methods for determining water-content, porosity, density, absorption and related properties and swelling and slakedurability index properties. 1. Suggested methods for determining water-content, porosity, density, absorption and related properties. International Journal of Rock Mechanics and Mining Sciences, 16(2), 143-151

FRANÇOIS, B. et al. An extended Drucker-Prager hardening model for crossanisotropy of soft rocks. In Proceedings of the 15th European Conference on Soil Mechanics and Geotechnical Engineering, 2011a. p. 537-540.

FRANÇOIS, B. et al. Development of an extended Drucker-Prager hardening model for cross-anisotropy of soft rocks. In proceedings of the 2 nd international symposium on computational geomechanics (comgeo II), 2011b. p. 142-152.

GARCÍA-DEL-CURA, M. Á. et al. Sedimentary structures and physical properties of travertine and carbonate tufa building stone. Construction and Building Materials, 2012, vol. 28, no 1, p. 456-467.

GAVIN, H. P. The Levenberg-Marquardt method for nonlinear least squares curvefitting problems. Department of Civil and Environmental Engineering, Duke University, 2011, p. 1-15.

GUIMARÃES A. G. Análise inversa para determinação de parâmetros de deformabilidade de solos. Tese de Doutorado. Minas Gerais, MG. Universidade Federal de Viçosa. 2006

GUIMARÃES, A. G.; DE AZEVEDO, R. F. Análise inversa de ensaios cúbicos triaxiais e hidrostático saturados.2009, p 1-7.

GOODMAN, R. Introduction to Rock Mechanics. New York: John Wiley \& Sons, $1989560 \mathrm{p}$.

HE, Z. et al. A thermo-elastoplastic model for soft rocks considering structure. Comptes Rendus Mécanique, 2017, vol. 345, no 11, p. 752-763.

HELWANY, S. Applied soil mechanics with ABAQUS applications. John Wiley \& Sons, 2007.

HUILLCA, C. A. L. Estudo experimental do comportamento geomecânico do travertino. Tese de Mestrado.Rio de Janeiro, RJ: Pontifícia Universidade Católica do Rio de Janeiro,PUC: 149 p. 2014. 
KARAKUL, H.; ULUSAY, R.; ISIK, N. S. Empirical models and numerical analysis for assessing strength anisotropy based on block punch index and uniaxial compression tests. International Journal of Rock Mechanics and Mining Sciences, 2010, v. 47, n. 4, p. 657-665.

KIEWIET, M. C. D. N. comportamento hidromecânico de zonas de falha em travertino. Tese de Doutorado. Rio de Janeiro, RJ: Universidade Federal do Rio de Janeiro, UFRJ. 2015.

KIM, M. K.; LADE, P. V. Modelling rock strength in three dimensions. International Journal of Rock Mechanics and Mining Sciences \& Geomechanics Abstracts, 1984, v. 21 , n. 1 , p. 21-33.

KIM, M. K.; LADE, P. V. Single hardening constitutive model for frictional materials. Computers and Geotechnics, 1988, v. 5, n. 4, p. 307-324.

LADE POUL, V. Failure Criterion for Cross-Anisotropic Soils. Journal of Geotechnical and Geoenvironmental Engineering, 2008, v. 134, n. 1, p. 117-124.

LADE, P. V. Single hardening model for soils: parameter determination and typical values. Soil constitutive models: Evaluation, selection, and calibration, 2005, p. 290-309.

LADE, P. V. Modeling failure in cross-anisotropic frictional materials. International Journal of Solids and Structures, 2007, v. 44, n. 16, p. 5146-5162.

LADE, P. V.; GUTTA, S. K.; YAMAMURO, J. A. Kinematic hardening predictions of large stress-reversals in 3-D test on loose sand. Computers and Geotechnics, 2009, v. 36, n. 8, p. 1285-1297.

LADE, P. V.; KIM, M. K. Single hardening constitutive model for frictional materials II. Yield critirion and plastic work contours. Computers and Geotechnics, 1988 a , v. 6, n. 1, p. $13-29$.

LADE, P. V.; KIM, M. K. Single hardening constitutive model for frictional materials III. Comparisons with experimental data. Computers and Geotechnics, 1988 b , v. 6, n. 1, p. 31-47.

LADE, P. V.; KIM, M. K. Single hardening constitutive model for soil, rock and concrete. International Journal of Solids and Structures, 1995, v. 32, n. 14, p. 19631978. 
MA, J. An elastoplastic model for partially saturated collapsible rocks. Rock Mechanics and Rock Engineering, 2016, vol. 49, no 2, p. 455-465.

MARQUARDT, D. An Algorithm for Least-Squares Estimation of Nonlinear Parameters. Journal of the Society for Industrial and Applied Mathematics, 1963, v. 11 , n. 2 , p. $431-441$.

MOHAMADI, M.; WAN, R.; SHEN, Z. An elastoplastic description of frictional destructuration in natural clays and shales. Acta Geotechnica, 2018, vol. 13, no 4, p. 911-924.

MORTARA, G. A yield criterion for isotropic and cross-anisotropic cohesivefrictional materials. International Journal for Numerical and Analytical Methods in Geomechanics 2010, vol. 34, no 9, p. 953-977.

MÁNICA, M. et al. A cross-anisotropic formulation for elasto-plastic models. Géotechnique Letters, 2016, vol. 6, no 2, p. 156-162.

NIANDOU, $\mathrm{H}$. et al. Laboratory investigation of the mechanical behaviour of Tournemire shale. International Journal of Rock Mechanics and Mining Sciences, 1997, v. 34, n. 1, p. 3-16.

NIELSEN, Hans Bruun, et al. Damping parameter in Marquardt's method. IMM, 1999.

OKADA, T. Mechanical properties of sedimentary soft rock at high temperatures. Part 1. Evaluation of temperature dependency based on triaxial compression test. Denryoku Chuo Kenkyusho Hokoku, 2005, p. 1-4, 1.

PEI, J. Strength of transversely isotropic rocks. Doctoral dissertation, Massachusetts Institute of Technology, 2008.

PIETRUSZCZAK, S. Fundamentals of plasticity in geomechanics. Boca Raton, FL: Crc Press, 2010.

PIETRUSZCZAK, S.; LYDZBA, D.; SHAO, J. F. Modelling of inherent anisotropy in sedimentary rocks. International Journal of Solids and Structures. International Journal of Solids and Structures, 2002, v. 39, n. 3, p. 637-648.

PIETRUSZCZAK, S.; MROZ, Z. Formulation of anisotropic failure criteria incorporating a microstructure tensor. Computers and Geotechnics, 2000, v. 26, n. 2, p. 105-112. 
RODRÍGUEZ, F. J. A. La porosidad, como componente petrográfico. la porosidad de las rocas carbonatadas. Departamento de Geología da Universidade de Oviedo, 2006.

RONCHI, P.; CRUCIANI, F.; CIRILLI, S. Continental Carbonates as Hydrocarbon Reservoir, an Analogue Case Study from The Travertine of Saturnia, Italy: In 6th International Petroleum Technology Conference. 2013.

ROSCOE, K. H.; BURLAND, J. B. On the Generalized Stress-Strain Behavior of Wet Clays. ResearchGate, 1968.

ROSCOE, K. H.; SCHOFIELD, A.; THURAIRAJAH, A. Yielding of clays in states wetter than critical. Geotechnique, 1963, vol. 13, no 3, p. 211-240.

SCHOFIELD, A.; WROTH, P. Critical state soil mechanics. London: McGraw-Hill, 1968.

SHEN, W. Q. et al. A closed-form three scale model for ductile rocks with a plastically compressible porous matrix. Mechanics of Materials, 2013, v. 59, p. 7386.

SHEN, W. Q.; SHAO, J. F. A micromechanical model of inherently anisotropic rocks. Computers and Geotechnics, 2015, v. 65, p. 73-79.

SHEN, W. Q.; SHAO, J. F. An elastic-plastic model for porous rocks with two populations of voids. Computers and Geotechnics, 2016, v. 76, p. 194-200.

SHEN, W. Q.; SHAO, J. F. Some micromechanical models of elastoplastic behaviors of porous geomaterials. Journal of Rock Mechanics and Geotechnical Engineering, 2017, v. 9, n. 1, p. 1-17.

SHENG, Daichao; SLOAN, Scott W. Load stepping schemes for critical state models. International Journal for Numerical Methods in Engineering, 2001, vol. 50, no 1 , p. 67-93.

SOARES, A. C. Um Estudo Experimental para Definição de Colapso de Poros em Rochas Carbonáticas. Dissertação de Mestrado (Instituto de Geologia) Universidade Federal do Rio de Janeiro, 2000, p 205.

UCHIDA, S.; SOGA, K.; YAMAMOTO, K. Critical state soil constitutive model for methane hydrate soil. Journal of Geophysical Research: Solid Earth, 2012, v. 117, n. B3. 
VELLOSO, R. Q. Estudo numérico da estimativa de parâmetros hidráulicos em solos parcialmente saturados. Tese de Mestrado. Rio de Janeiro, RJ: Pontifícia Universidade Católica do Rio de Janeiro,PUC-Rio, 2000.

VRUGT, J. A. Markov Chain Monte Carlo simulation using the DREAM software package: Theory, concepts, and MATLAB implementation. Environmental Modelling \& Software, 2016, v. 75, p. 273-316.

VRUGT, J. A. et al. Accelerating Markov Chain Monte Carlo simulation by differential evolution with self-adaptive randomized subspace sampling. International Journal of Nonlinear Sciences and Numerical Simulation, 2009, v. 10, n. 3, p. $273-290$.

VRUGT, J. A. et al. Treatment of input uncertainty in hydrologic modeling: Doing hydrology backward with Markov chain Monte Carlo simulation. Water Resources Research, 2008, v. 44, n. 12.

WANG, J. Y. et al. Elastoplastic modeling of mechanical behavior of weak sandstone at different time scales. Journal of Central South University, 2017, v. 24 , n. 3, p. 699-707.

WAN, J. Stabilized finite element methods for coupled geomechanics and multiphase flow. 2003. Tesis Doctoral. stanford university.

WEI, K. M.; ZHU, S. Study of rotational kinematic hardening model: A general plasticity formula and model implement. Scientia Iranica. Transaction A, Civil Engineering, 2013, vol. 20, no 5, p. 1381

WHEELER, S. J. et al. An anisotropic elastoplastic model for soft clays. Canadian Geotechnical Journal, 2003. v. 40, n. 2, p. 403-418.

XIE, S. Y.; SHAO, J. F. An Experimental Study and Constitutive Modeling of Saturated Porous Rocks. Rock Mechanics and Rock Engineering, 2015, v. 48, n. 1, p. 223-234.

YA, K.; FENG, C.; ZEGONG, L. A New Modified Cam-Clay Model Considering Cohesion and the Difference between Yield Strengths of Tension and Compression and Its Numerical Implementation. Electronic Journal of Geotechnical Engineering, 2014, v. 19. 
$\mathrm{YU}, \mathrm{H}$. et al. Rock physics modeling of heterogeneous carbonate reservoirs: porosity estimation and hydrocarbon detection. Applied Geophysics, 2014, v. 11, n. 1 , p. 9-22.

ZHANG, C. et al. Evaluation of the performance of a breakage model for high porosity Haubourdin chalk. Computers and Geotechnics, 2017, vol. 90, p. 113-119.

ZHANG, F.; ZHANG, S. A thermo-elasto-viscoplastic model for soft sedimentary rock. Soils and foundations, 2009, vol. 49, no 4, p. 583-595.

ZHANG, K.; ZHOU, H.; SHAO, J. An Experimental Investigation and an Elastoplastic Constitutive Model for a Porous Rock. Rock Mechanics and Rock Engineering, 2013, v. 46, n. 6, p. 1499-1511.

ZHANG, S. et al. A simple thermo-elastoplastic model for geomaterials. International Journal of Plasticity, 2012, v. 34, p. 93-113.

ZHANG, Y. et al. Experimental and Numerical Investigations on Strength and Deformation Behavior of Cataclastic Sandstone. Rock Mechanics and Rock Engineering, 2015, v. 48, n. 3, p. 1083-1096.

ZHU, Y. A micromechanics-based damage constitutive model of porous rocks. International Journal of Rock Mechanics and Mining Sciences, 2017, v. 91, n. Supplement C, p. 1-6. 


\section{Apêndice I}

Nas tabelas A1, A2 e A3, são apresentados os resultados dos índices físicos obtidos dos corpos de prova horizontais (CPH), inclinados (CPI) e verticais (CPV) da rocha carbonática travertino, respectivamente.

Tabela A1 Porosidade total dos corpos de prova horizontais $\mathrm{CPH}$.

\begin{tabular}{ccccccc}
\hline $\begin{array}{c}\text { Corpo de } \\
\text { prova }\end{array}$ & Vol. Solido & Peso total & Peso seco & $\begin{array}{c}\text { Volume } \\
\text { seco Vs }\end{array}$ & $\begin{array}{c}\text { Volume } \\
\text { vazios Vv }\end{array}$ & $\begin{array}{c}\text { Porosidade } \\
\text { Total }\end{array}$ \\
\cline { 2 - 7 } Horizontal & $\mathrm{V}(\mathrm{cm} 3)$ & $(\mathrm{g})$ & $(\mathrm{g})$ & $(\mathrm{cm} 3)$ & $(\mathrm{cm} 3)$ & $\mathrm{Vv} / \mathrm{V}$ \\
\hline CPH1 & 227,155 & 572,60 & 568,88 & 210,70 & 16,459 & $7,25 \%$ \\
CPH7 & 213,427 & 531,40 & 528,18 & 195,62 & 17,804 & $8,34 \%$ \\
CPH8 & 218,486 & 551,70 & 548,33 & 203,09 & 15,401 & $7,05 \%$ \\
CPH9 & 219,359 & 562,00 & 558,46 & 206,84 & 12,522 & $5,71 \%$ \\
CPH10 & 214,901 & 522,00 & 519,65 & 192,46 & 22,438 & $10,44 \%$ \\
CPH11 & 219,964 & 538,00 & 535,35 & 198,28 & 21,686 & $9,86 \%$ \\
CPH12 & 217,818 & 531,00 & 528,67 & 195,80 & 22,014 & $10,11 \%$ \\
CPH13 & 212,498 & 525,50 & 523,83 & 194,01 & 18,487 & $8,70 \%$ \\
CPH14 & 221,783 & 551,80 & 549,65 & 203,57 & 18,209 & $8,21 \%$ \\
CPH15 & 218,018 & 542,00 & 539,98 & 199,99 & 18,025 & $8,27 \%$ \\
CPH16 & 214,549 & 532,00 & 526,98 & 195,18 & 19,371 & $9,03 \%$ \\
CPH17 & 220,293 & 539,60 & 532,91 & 197,37 & 22,919 & $10,40 \%$ \\
CPH18 & 219,525 & 532,00 & 524,55 & 194,28 & 25,247 & $11,50 \%$ \\
CPH20 & 220,182 & 541,00 & 534,56 & 197,99 & 22,197 & $10,08 \%$ \\
CPH21 & 214,932 & 522,00 & 516,29 & 191,22 & 23,713 & $11,03 \%$ \\
CPH22 & 218,159 & 531,64 & 528,89 & 195,89 & 22,274 & $10,21 \%$ \\
CPH24 & 213,201 & 527,74 & 525,72 & 194,71 & 18,490 & $8,67 \%$ \\
CPH25 & 215,934 & 531,22 & 528,95 & 195,91 & 20,027 & $9,27 \%$ \\
CPH26 & 217,014 & 538,72 & 536,5 & 198,70 & 18,310 & $8,44 \%$ \\
CPH27 & 218,062 & 535,00 & 533,45 & 197,57 & 20,488 & $9,40 \%$ \\
CPH29 & 220,543 & 529,74 & 522,5 & 193,52 & 27,024 & $12,25 \%$ \\
CPH30 & 220,906 & 517,1 & 511,4 & 189,407 & 31,498 & $14,26 \%$ \\
\hline & & & & & & \\
\hline
\end{tabular}

Tabela A2 Porosidade total dos corpos de prova inclinados CPI.

\begin{tabular}{ccccccc}
\hline $\begin{array}{c}\text { Corpo de } \\
\text { prova } \\
\text { Inclinados }\end{array}$ & Vol. Solido & Peso total & Peso seco & $\begin{array}{c}\text { Volume } \\
\text { seco Vs }\end{array}$ & $\begin{array}{c}\text { Volume } \\
\text { vazios Vv }\end{array}$ & $\begin{array}{c}\text { Porosidade } \\
\text { Total }\end{array}$ \\
\cline { 2 - 7 } & $\mathrm{V}(\mathrm{cm} 3)$ & $(\mathrm{g})$ & $(\mathrm{g})$ & $(\mathrm{cm} 3)$ & $(\mathrm{cm} 3)$ & $\mathrm{Vv} / \mathrm{V}$ \\
\hline CP1 01 & 213,251 & 498,76 & 496,98 & 184,067 & 29,184 & $13,69 \%$ \\
CPI 02 & 211,273 & 519,99 & 518,02 & 191,859 & 19,414 & $9,19 \%$
\end{tabular}




\begin{tabular}{lcccccc} 
CPI 03 & 212,894 & 516,31 & 514,72 & 190,637 & 22,257 & $10,45 \%$ \\
CPI 04 & 211,100 & 498,89 & 496,52 & 183,896 & 27,204 & $12,89 \%$ \\
CPI 05 & 210,588 & 509,2 & 506,86 & 187,726 & 22,862 & $10,86 \%$ \\
CPI 06 & 211,065 & 499,47 & 497,9 & 184,407 & 26,657 & $12,63 \%$ \\
CPI 07 & 209,934 & 499,25 & 497,62 & 184,304 & 25,630 & $12,21 \%$ \\
CPI 08 & 210,313 & 520,24 & 518,73 & 192,122 & 18,190 & $8,65 \%$ \\
CPI 09 & 210,217 & 523,78 & 522,29 & 193,441 & 16,776 & $7,98 \%$ \\
CPI 10 & 210,405 & 522,71 & 521,28 & 193,067 & 17,339 & $8,24 \%$ \\
CPI 11 & 211,071 & 515,26 & 513,56 & 190,207 & 20,863 & $9,88 \%$ \\
CPI 12 & 209,289 & 519,61 & 517,93 & 191,826 & 17,463 & $8,34 \%$ \\
CPI 13 & 211,081 & 498,53 & 496,46 & 183,874 & 27,207 & $12,89 \%$ \\
CPI 14 & 212,050 & 508,55 & 507,07 & 187,804 & 24,246 & $11,43 \%$ \\
CPI 15 & 211,107 & 513,45 & 511,7 & 189,519 & 21,589 & $10,23 \%$ \\
\hline
\end{tabular}

Tabela A3 Porosidade total dos corpos de prova verticais CPV.

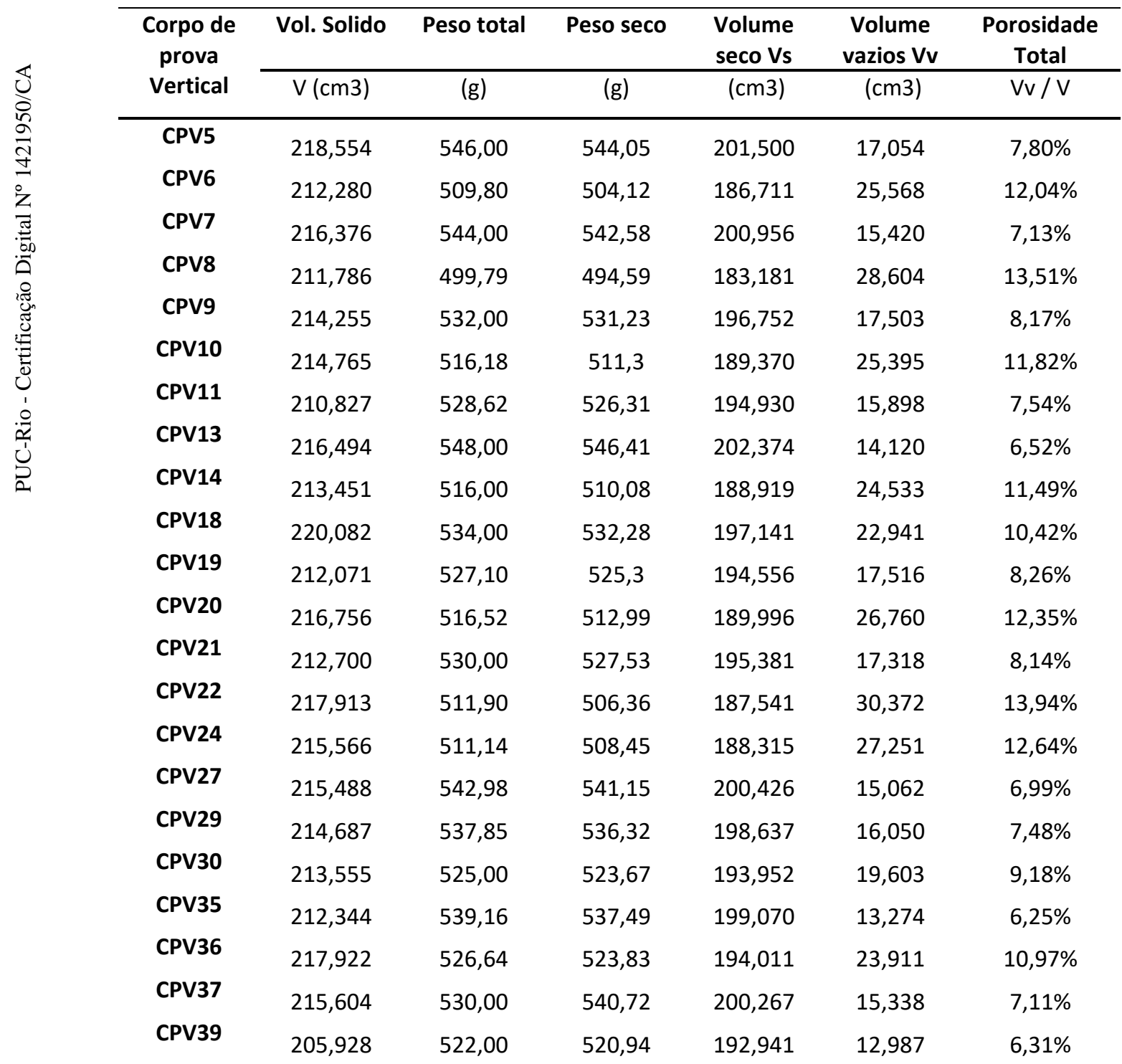




\begin{tabular}{lllllll} 
CPV45 & 216,143 & 537,25 & 533,91 & 197,744 & 18,399 & $8,51 \%$ \\
CPV51 & 235,106 & 591,70 & 590,05 & 218,537 & 16,569 & $7,05 \%$ \\
CPV54 & 212,503 & 509,00 & 506,24 & 187,496 & 25,007 & $11,77 \%$ \\
CPV59 & 241,454 & 600,00 & 598,11 & 221,522 & 19,932 & $8,00 \%$ \\
CPV60 & 226,633 & 564,70 & 562,13 & 208,196 & 18,437 & $8,14 \%$ \\
CPV61 & 231,000 & 580,00 & 578,64 & 214,311 & 16,689 & $7,22 \%$ \\
CPV63 & 224,136 & 553,80 & 551,1 & 204,111 & 20,024 & $8,93 \%$ \\
CPV66 & 229,697 & 569,00 & 566,61 & 209,856 & 19,842 & $8,64 \%$ \\
CPV67 & 232,150 & 583,00 & 581,34 & 215,311 & 16,839 & $7,25 \%$ \\
CPV69 & 210,505 & 575,00 & 527,84 & 195,496 & 15,009 & $7,13 \%$ \\
CPV71 & 224,496 & 537,50 & 530,75 & 196,574 & 27,922 & $12,44 \%$ \\
\hline
\end{tabular}

\section{Apêndice II}

\section{Derivadas do modelo constitutivo Lade-Kim}

Derivada da função de escoamento em termos das tensões

$$
\left\{\frac{\partial f_{s}^{\prime}}{\partial \sigma}\right\}=\frac{\partial f_{s}^{\prime}}{\partial I_{1}}\left\{\frac{\partial I_{1}}{\partial \sigma}\right\}+\frac{\partial f_{s}^{\prime}}{\partial I_{2}}\left\{\frac{\partial I_{2}}{\partial \sigma}\right\}+\frac{\partial f_{s}^{\prime}}{\partial I_{3}}\left\{\frac{\partial I_{3}}{\partial \sigma}\right\}
$$

$$
\frac{\partial f_{s}^{\prime}}{\partial I_{1}}=\left(3 \psi_{1} \frac{I_{1}^{2}}{I_{3}}-\frac{2 I_{1}}{I_{2}}\right)\left(\frac{I_{1}}{P_{a}}\right)^{h} e^{q}+\left(\psi_{1} \frac{I_{1}^{3}}{I_{3}}-\frac{I_{1}^{2}}{I_{2}}\right)\left(\frac{I_{1}}{P_{a}}\right)^{\frac{h}{I_{1}}} h \cdot e^{q}+\left(\psi_{1} \frac{I_{1}^{3}}{I_{3}}-\frac{I_{1}^{2}}{I_{2}}\right)\left(\frac{I_{1}}{P_{a}}\right)^{h} \frac{\partial q}{\partial I_{1}}
$$

$$
\frac{\partial f_{s}^{\prime}}{\partial I_{2}}=\left(\frac{I_{1}^{2}}{I_{2}^{2}}\right)\left(\frac{I_{1}}{P_{a}}\right)^{h} e^{q}
$$

$$
\frac{\partial f_{s}^{\prime}}{\partial I_{3}}=\left(-\psi_{1} \frac{I_{1}^{3}}{I_{3}^{2}}\right)\left(\frac{I_{1}}{P_{a}}\right)^{h} e^{q}+\left(\psi_{1} \frac{I_{1}^{3}}{I_{3}}-\frac{I_{1}^{2}}{I_{2}}\right)\left(\frac{I_{1}}{P_{a}}\right)^{h} e^{q} \frac{\partial q}{\partial I_{3}}
$$

Derivada da variável q respeito os invariantes:

$$
\frac{\partial q}{\partial I_{1}}=\frac{\eta_{1} \alpha\left(\frac{I_{1}}{P_{a}}\right)^{m}\left((m+3) I_{1}^{3}-27 m I_{3}\right) I_{3}}{I_{1}\left((-1+\alpha)\left(I_{1}^{3}-27 I_{3}\right)\left(\frac{I_{1}}{P_{a}}\right)^{m}+\eta_{1} I_{3}\right)^{2}}
$$




$$
\frac{\partial q}{\partial I_{3}}=-\frac{\alpha I_{1}^{3}\left(\frac{I_{1}}{P_{a}}\right)^{m} \eta_{1}}{\left((-1+\alpha)\left(I_{1}^{3}-27 I_{3}\right)\left(\frac{I_{1}}{P_{a}}\right)^{m}+\eta_{1} I_{3}\right)^{2}}
$$

Derivadas dos invariantes das tensões:

$$
\begin{aligned}
& \left\{\frac{\partial I_{1}}{\partial \sigma}\right\}=\{1,1,1,0,0,0\}^{T} \\
& \left\{\frac{\partial I_{2}}{\partial \sigma}\right\}=\left\{\begin{array}{c}
-\left(\sigma_{22}+\sigma_{33}\right) \\
-\left(\sigma_{33}+\sigma_{11}\right) \\
-\left(\sigma_{11}+\sigma_{22}\right) \\
2 \sigma_{23} \\
2 \sigma_{31} \\
2 \sigma_{12}
\end{array}\right\}
\end{aligned}
$$

$$
\left\{\frac{\partial I_{3}}{\partial \sigma}\right\}=\left\{\begin{array}{c}
\sigma_{22} \sigma_{33}+\sigma_{23}{ }^{2} \\
\sigma_{33} \sigma_{11}+\sigma_{31}{ }^{2} \\
\sigma_{11} \sigma_{22}+\sigma_{12}{ }^{2} \\
2\left(\sigma_{12} \sigma_{31}-\sigma_{11} \sigma_{23}\right) \\
2\left(\sigma_{23} \sigma_{12}-\sigma_{11} \sigma_{23}\right) \\
2\left(\sigma_{31} \sigma_{23}-\sigma_{33} \sigma_{12}\right)
\end{array}\right\}
$$

Derivada da função potencial plástica em termos das tensões:

$$
g_{p}=\left[\psi_{1} \frac{I_{1}^{3}}{I_{3}}-\frac{I_{1}^{2}}{I_{2}}+\psi_{2}\right]\left(\frac{I_{1}}{P_{a}}\right)^{\mu}
$$




$$
\begin{aligned}
& \left\{\begin{array}{l}
d \varepsilon_{x}^{p} \\
d \varepsilon_{y}^{p} \\
d \varepsilon_{z}^{p} \\
d \gamma_{y z}^{p} \\
d \gamma_{z x}^{p} \\
d \gamma_{x y}^{p}
\end{array}\right\}=\Lambda\left[\frac{I_{1}}{P_{a}}\right]^{\mu}\left\{\begin{array}{c}
G-\left(\sigma_{y}+\sigma_{z}\right) \frac{I_{1}^{2}}{I_{2}^{1}}-\psi_{1}\left(\sigma_{y} \sigma_{z}-\tau_{y z}^{2}\right) \frac{I_{1}^{3}}{I_{3}^{2}} \\
G-\left(\sigma_{z}+\sigma_{x}\right) \frac{I_{1}^{2}}{I_{2}^{1}}-\psi_{1}\left(\sigma_{z} \sigma_{x}-\tau_{z x}^{2}\right) \frac{I_{1}^{3}}{I_{3}^{2}} \\
2 \frac{I_{1}^{2}}{I_{2}^{1}} \tau_{y z}-2 \psi_{1}\left(\tau_{x y} \tau_{z x}-\sigma_{x} \tau_{y z}\right) \frac{I_{1}^{3}}{I_{3}^{2}} \\
2 \frac{I_{1}^{2}}{I_{2}^{1}} \tau_{z x}-2 \psi_{1}\left(\tau_{x y} \tau_{y z}-\sigma_{y} \tau_{z x}\right) \frac{I_{1}^{3}}{I_{3}^{2}} \\
2 \frac{I_{1}^{2}}{I_{2}^{1}} \tau_{x y}-2 \psi_{1}\left(\tau_{y z} \tau_{z x}-\sigma_{z} \tau_{x y}\right) \frac{I_{1}^{3}}{I_{3}^{2}}
\end{array}\right\} \\
& \left.G=\tau_{1}^{2}\right) \frac{I_{1}^{3}}{I_{3}^{2}} \\
& \mu+3) \frac{I_{1}^{2}}{I_{3}}-(\mu+2) \frac{I_{1}}{I_{2}}+\frac{\mu}{I_{1}} \psi_{2}
\end{aligned}
$$

Matriz constitutiva elástica

$$
\left[D^{e}\right]=\frac{E(1-v)}{(1+v)(1-2 v)}\left[\begin{array}{cccccc}
1 & \frac{v}{1-v} & \frac{v}{1-v} & 0 & 0 & 0 \\
\frac{v}{1-v} & 1 & \frac{v}{1-v} & 0 & 0 & 0 \\
\frac{v}{1-v} & \frac{v}{1-v} & 1 & 0 & 0 & 0 \\
0 & 0 & 0 & \frac{1-2 v}{2(1-v)} & 0 & 0 \\
0 & 0 & 0 & 0 & \frac{1-2 v}{2(1-v)} & 0 \\
0 & 0 & 0 & 0 & 0 & \frac{1-2 v}{2(1-v)}
\end{array}\right]
$$

\section{Derivadas do modelo CALK}

Derivada da função de escoamento:

$\left\{\frac{\partial f_{s}^{\prime}}{\partial \sigma}\right\}=\left[\left(\frac{\partial f_{s}^{\prime}}{\partial A I_{1}}\left\{\frac{\partial A I_{1}}{\partial \sigma^{A n i}}\right\}+\frac{\partial f_{s}^{\prime}}{\partial A I_{2}}\left\{\frac{\partial A I_{2}}{\partial \sigma^{A n i}}\right\}+\frac{\partial f_{s}^{\prime}}{\partial A I_{3}}\left\{\frac{\partial A I_{3}}{\partial \sigma^{A n i}}\right\}\right)^{T} \cdot\left[\frac{\partial \sigma^{A n i}}{\partial \sigma}\right]\right]^{T}$ 
Derivada da função potencial plástico:

$\left\{\frac{\partial g_{p}}{\partial \sigma}\right\}=\left[\left(\frac{\partial g_{p}}{\partial A I_{1}}\left\{\frac{\partial g_{p}}{\partial \sigma^{A n i}}\right\}+\frac{\partial g_{p}}{\partial A I_{2}}\left\{\frac{\partial g_{p}}{\partial \sigma^{A n i}}\right\}+\frac{\partial g_{p}}{\partial A I_{3}}\left\{\frac{\partial g_{p}}{\partial \sigma^{A n i}}\right\}\right)^{T} \cdot \frac{\partial \sigma^{A n i}}{\partial \sigma}\right]^{T}$

Sendo $\left[\frac{\partial \sigma^{A n i}}{\partial \sigma}\right]$ uma matriz jacobiana de $6 \times 6$ :

$\left[\frac{\partial \sigma^{A n i}}{\partial \sigma}\right]=\left[\begin{array}{ccc}\frac{\partial \sigma_{11}^{A n i}}{\partial \sigma_{x x}} & \cdots & \frac{\partial \sigma_{11}^{A n i}}{\partial \sigma_{y x}} \\ \vdots & \ddots & \vdots \\ \frac{\partial \sigma_{23}^{A n i}}{\partial \sigma_{x x}} & \cdots & \frac{\partial \sigma_{23}^{A n i}}{\partial \sigma_{y z}}\end{array}\right]$

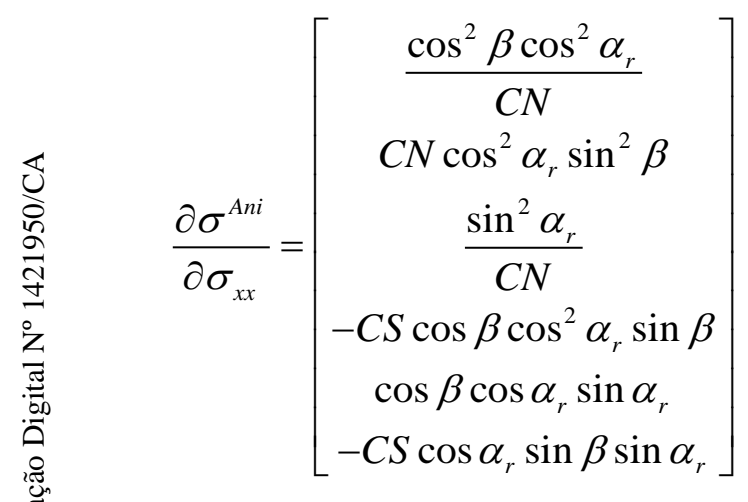

$\frac{\partial \sigma^{A n i}}{\partial \sigma_{y y}}=\left[\begin{array}{c}\frac{\sin ^{2} \beta}{C N} \\ C N \cos ^{2} \beta \\ 0 \\ C S \cos \beta \sin \beta \\ 0 \\ 0\end{array}\right]$

$\frac{\partial \sigma^{A n i}}{\partial \sigma_{z z}}=\left[\begin{array}{c}\frac{\cos ^{2} \beta \sin ^{2} \alpha_{r}}{C N} \\ C N \sin ^{2} \beta \sin ^{2} \alpha_{r} \\ \frac{\cos ^{2} \alpha_{r}}{C N} \\ -C S \cos \beta \sin \beta \sin ^{2} \alpha_{r} \\ -\cos \beta \cos \alpha_{r} \sin \alpha_{r} \\ C S \cos \alpha_{r} \sin \beta \sin \alpha_{r}\end{array}\right]$ 
$\frac{\partial \sigma^{A n i}}{\partial \sigma_{x y}}=\left[\begin{array}{c}\frac{2 \cos \beta \cos \alpha_{r} \sin \beta}{C N} \\ -2 C N \cos \beta \cos \alpha_{r} \sin \beta \\ 0 \\ C S\left(\cos ^{2} \beta \cos \alpha_{r}-\cos \alpha_{r} \sin ^{2} \beta\right) \\ \sin \beta \sin \alpha_{r} \\ C S \cos \beta \sin \alpha_{r}\end{array}\right]$

$$
\frac{\partial \sigma^{A n i}}{\partial \sigma_{x z}}=\left[\begin{array}{c}
-\frac{2 \cos ^{2} \beta \cos \alpha_{r} \sin \alpha_{r}}{C N} \\
-2 C N \cos \alpha_{r} \sin ^{2} \beta \sin \alpha_{r} \\
\frac{2 \cos \alpha_{r} \sin \alpha_{r}}{C N} \\
2 C S \cos \beta \cos \alpha_{r} \sin \beta \sin \alpha_{r} \\
\cos \beta \cos ^{2} \alpha_{r}-\cos \beta \sin ^{2} \alpha_{r} \\
-C S\left(\cos ^{2} \alpha_{r} \sin \beta-\sin \beta \sin ^{2} \alpha_{r}\right)
\end{array}\right]
$$

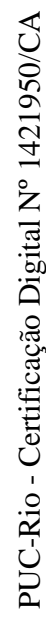

$$
\frac{\partial \sigma^{A n i}}{\partial \sigma_{y z}}=\left[\begin{array}{c}
-\frac{2 \cos \beta \sin \beta \sin \alpha_{r}}{C N} \\
2 C N \cos \beta \sin \beta \sin \alpha_{r} \\
0 \\
-C S\left(\cos ^{2} \beta \sin \alpha_{r}-\sin ^{2} \beta \sin \alpha_{r}\right) \\
\cos \alpha_{r} \sin \beta \\
C S \cos \beta \cos \alpha_{r}
\end{array}\right]
$$




\section{Apêndice III}

Esquema e derivadas do modelo CCMC

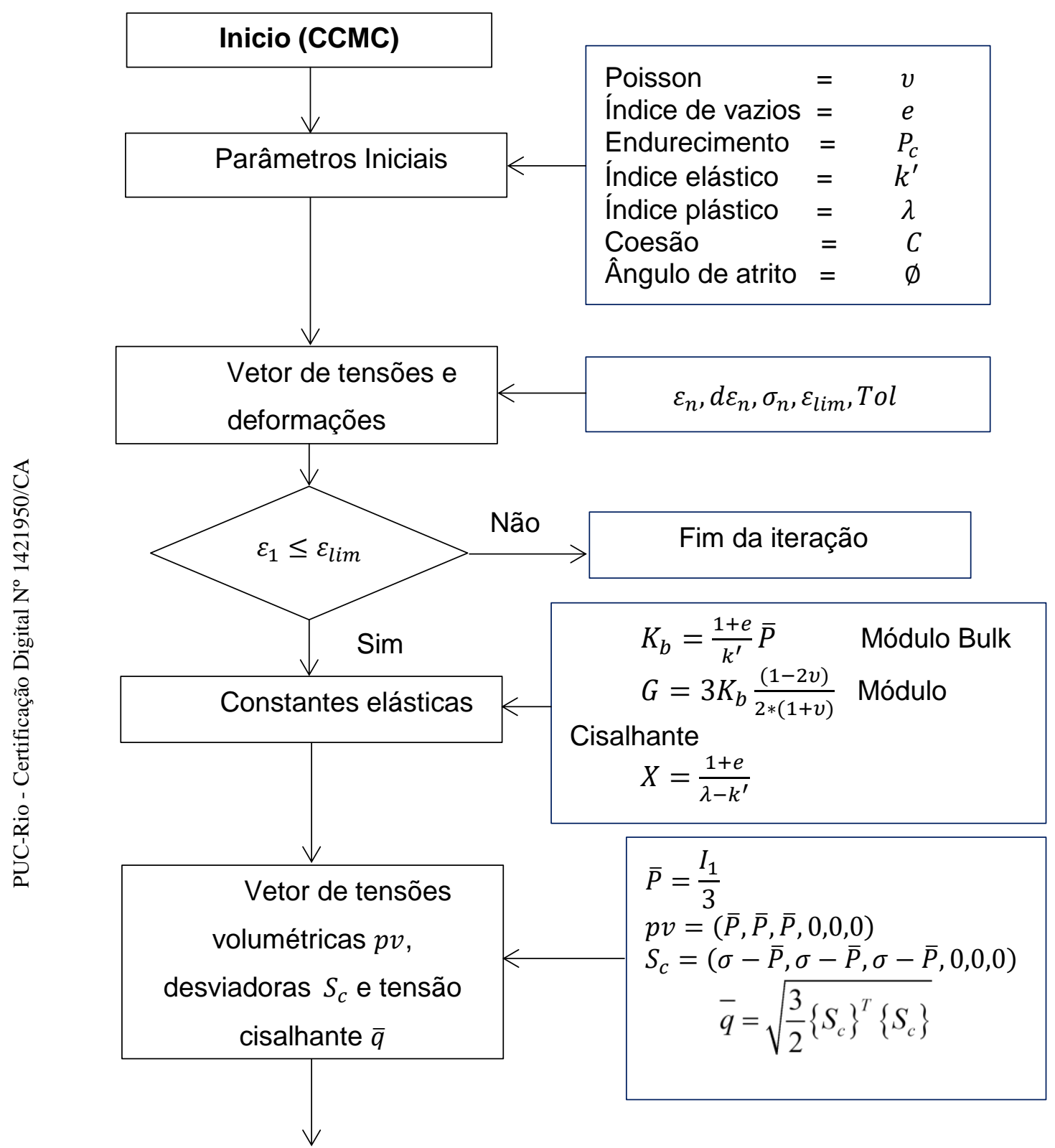




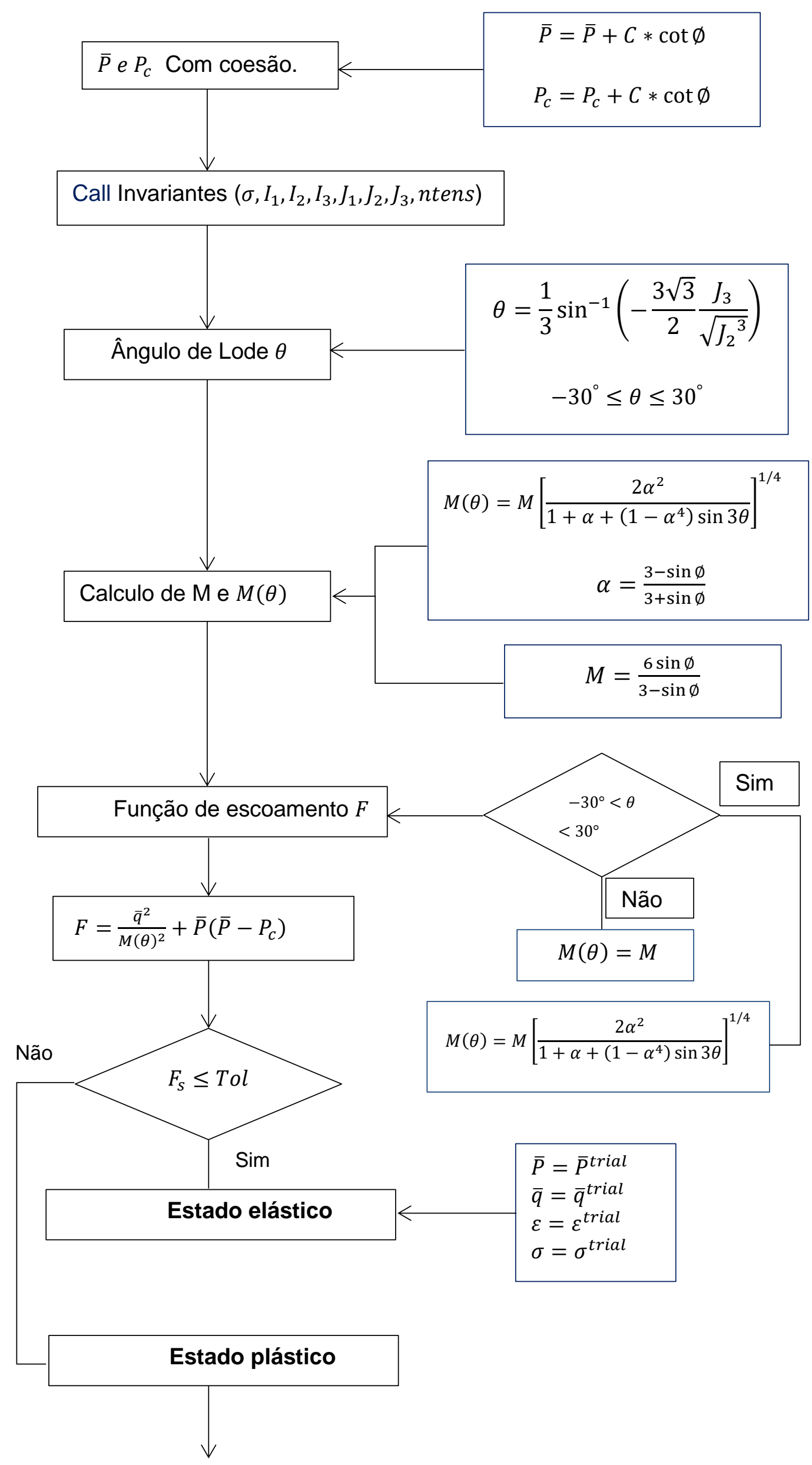




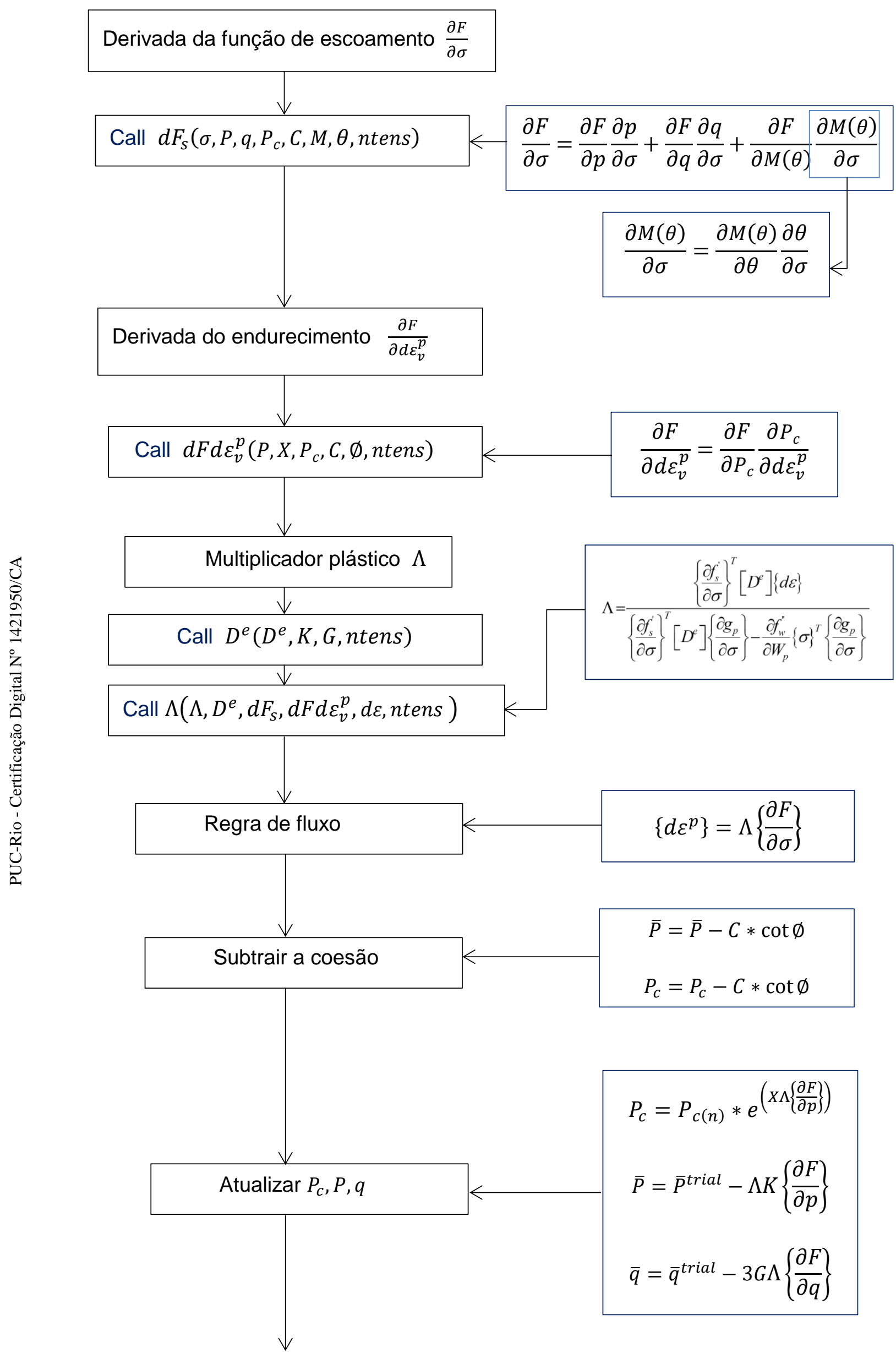




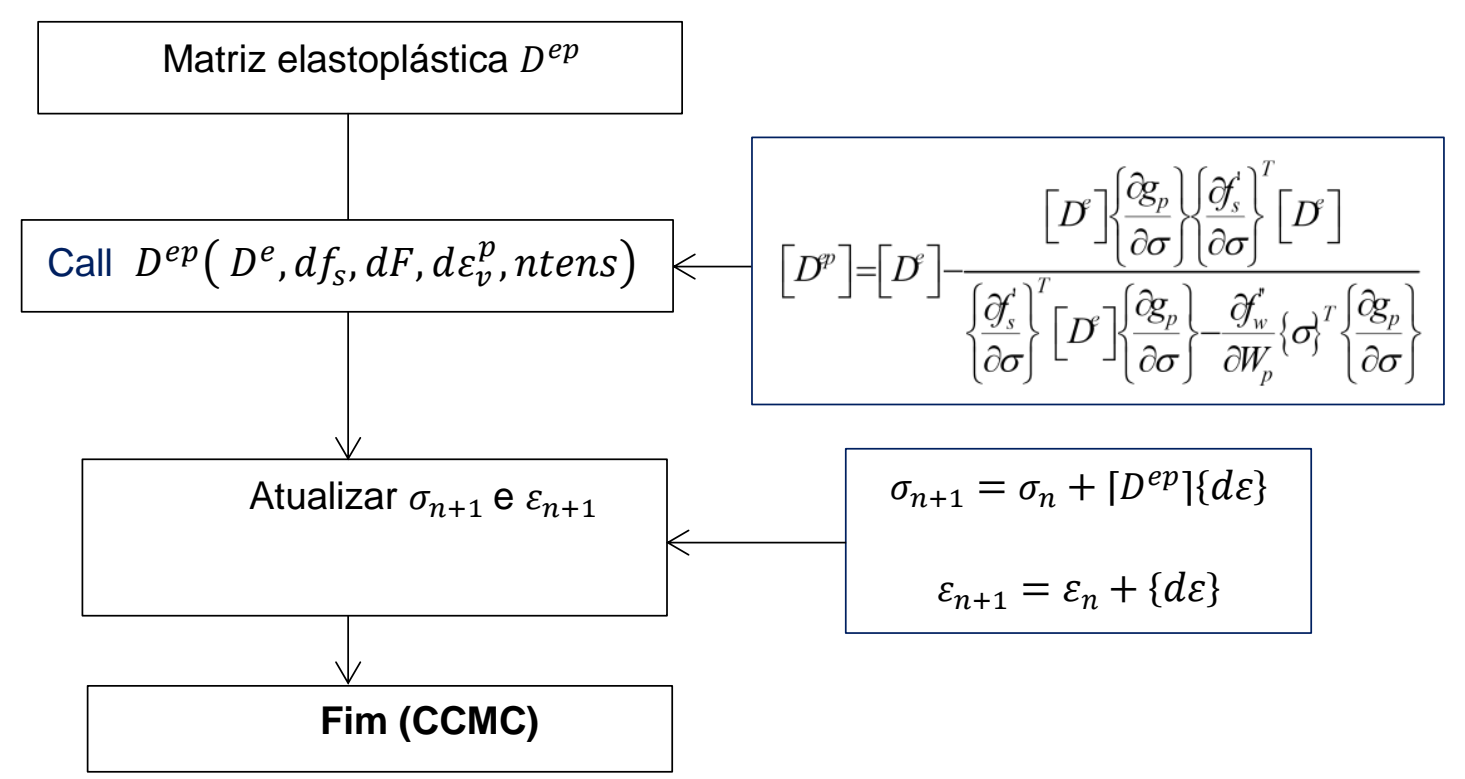

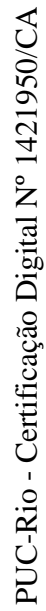

